\title{
INCORPORATING CUMULATIVE ENVIRONMENTAL EFFECTS OF FINFISH MARICULTURE INTO CANADIAN ENVIRONMENTAL ASSESSMENT
}

\section{By}

\section{Sarah Coldwell King}

B.A. McGill University, 2003

\author{
A thesis presented to Ryerson University \\ in partial fulfillment of the \\ requirements for the degree of \\ Master of Applied Science \\ in the Program of \\ Environmental Applied Science and Management
}

Toronto, Ontario, Canada, 2006

C) Sarah C. King, 2006. 
UMI Number: EC53504

\section{INFORMATION TO USERS}

The quality of this reproduction is dependent upon the quality of the copy submitted. Broken or indistinct print, colored or poor quality illustrations and photographs, print bleed-through, substandard margins, and improper alignment can adversely affect reproduction.

In the unlikely event that the author did not send a complete manuscript and there are missing pages, these will be noted. Also, if unauthorized copyright material had to be removed, a note will indicate the deletion.

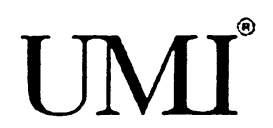

UMI Microform EC53504

Copyright 2009 by ProQuest LLC

All rights reserved. This microform edition is protected against unauthorized copying under Title 17, United States Code.

ProQuest LLC

789 East Eisenhower Parkway

P.O. Box 1346

Ann Arbor, MI 48106-1346 
I hereby declare that I am the sole author of this thesis or dissertation.

I authorize Ryerson University to lend this thesis or dissertation to other institutions or individuals for the purpose of scholarly research.

\section{Sarah C. King}

I further authorize Ryerson University to reproduce this thesis or dissertation by photocopying or by other means, in total or in part, at the request of other institutions or individuals for the purpose of scholarly research.

Sarah C. King 
Incorporating Cumulative Environmental Effects of Finfish Mariculture into Canadian Environmental Assessment

Sarah Coldwell King

Master of Applied Science, 2006.

Environmental Applied Science and Management, Ryerson University.

\begin{abstract}
A Traffic Light Decision Support System (DSS) used in marine finfish federal environmental assessments was expanded to include regional and cumulative environmental impacts. A retrospective review of 23 existing mariculture farms in southwestern New Brunswick indicated whether cumulative interactions would have justified site approvals. Six new criteria were added to the far-field component and other existing criteria were amended. Scores of A, B+, B-, C and pre-emptive C were based on acceptability criteria. Calculations of cumulative ecosystem indices and potential site indices revealed site acceptability, and the index combinations suggested potential site approvals predicted using Hargrave's (2002) three-colour Traffic Light scheme. Before mitigation was considered, 19 of the 23 sites failed the amended set of criteria and after considering mitigation, 8 sites failed. Combining the site and ecosystem indices yielded varying site acceptability scores. The role of mitigation and other factors in hindering sustainable siting was discussed.
\end{abstract}




\section{Acknowledgements}

An immeasurable thank you to Dr. Ron Pushchak for his guidance, support, and mentorship throughout the entire program and thesis process. I couldn't have imagined a better advisor. Thank you to my committee; Dr. Vadim Bostan, Dr. Michal Bardecki, Dr. Tim Sly and Dr. Pushchak for taking the time to be a part of my defense.

A special thanks to my loving family for their encouragement, for providing a frustration outlet and a myriad of supporting roles. Thanks for pushing me along and providing the best possible role-models. Thanks to my sister, Amy, for all her hours of editing throughout the program.

Thanks to Zev Kesler, his family, and all my great friends, for lending an ear, feeding me and making the experience even more enjoyable. An extra thanks to my program comrades, particularly Jelena Vukomanovic and Dennis Maslo, for making early mornings and late nights of work amusing.

Many thanks to the kind people at DFO for all their help, especially Barry Hargrave, for providing me with the information pertinent to my work and paving the way towards a more sustainable approach to aquaculture assessment and management.

Lastly, thanks to Janice Harvey at the Conservation Council of New Brunswick for pointing me in the right direction and to all the people at CCNB for demanding better environmental standards and practice and for striving to preserve New Brunswick's landscapes. 


\section{Table of Contents}

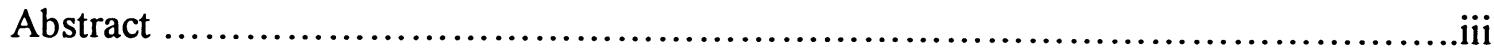

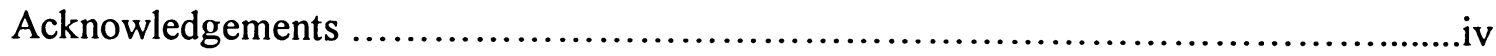

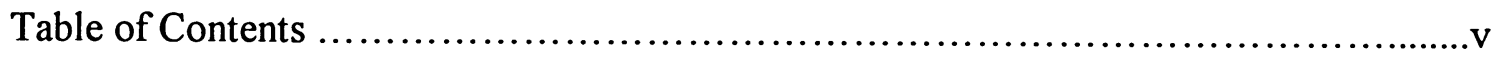

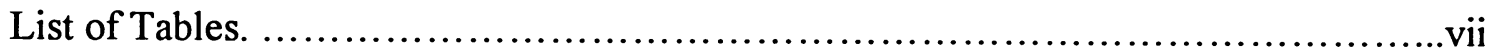

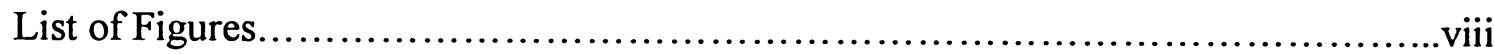

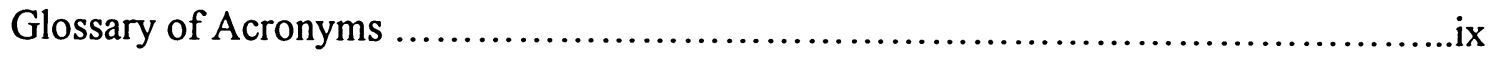

\section{Chapter}

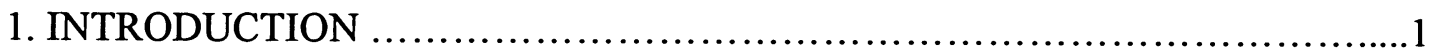

The Southwestern New Brunswick Salmon Aquaculture Industry ...............2 -Industry inception

-Economic setting

-Production and returns

Environmental Setting 6

-Bay of Fundy

-State of the marine environment

Industry Regulation and Management ................................... 9

-Industry re-organization

-Roles and responsibilities

Shortfalls of Current Regulation and Management ............................ 13

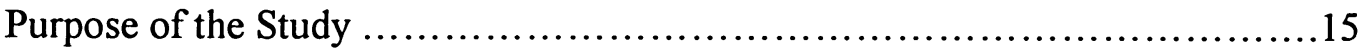

2. ENVIRONMENTAL EFFECTS OF MARICULTURE ..........................16

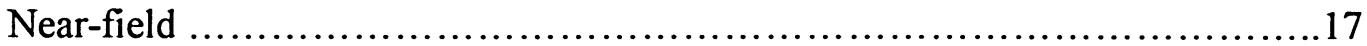

Far-field ............................................................ 21

Cumulative and Regional .............................................25

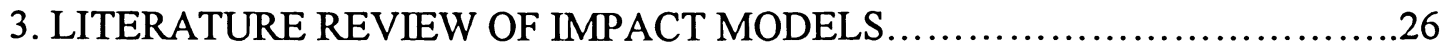




\section{FORMULATION OF THE EXPANDED TRAFFIC LIGHT DECISION}

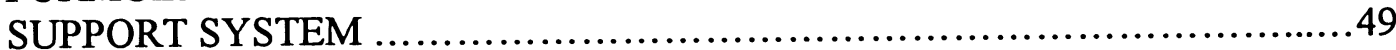

Present Set of Far-field Questions ...........................................49

Proposed Set of Regional Questions ....................................... 50

Justifications for Question Choice and Scoring .............................51

Final Proposed Set of Regional Questions ................................106

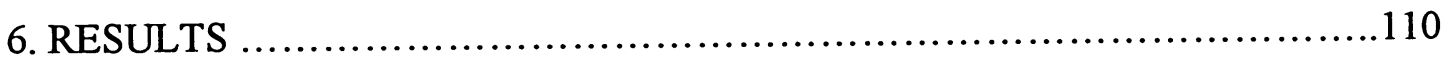

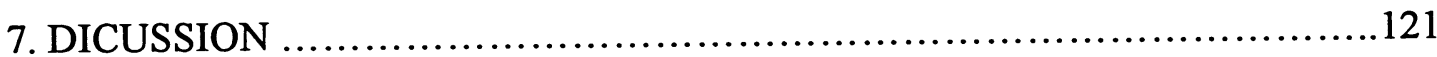

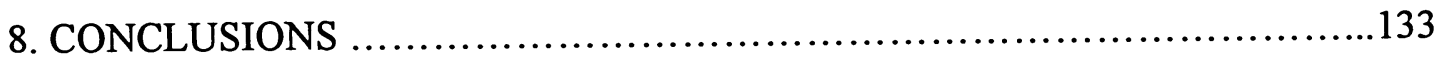

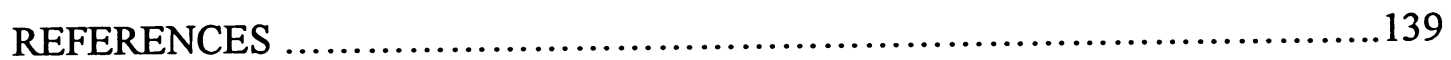

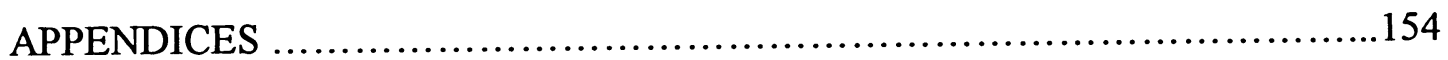

Appendix A........................................................ 154

Appendix B........................................................ 160

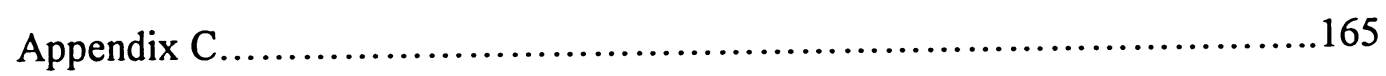

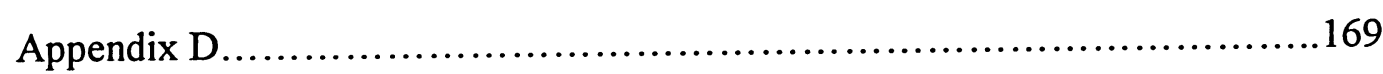




\section{List of Tables}

1. Environmental Quality Matrix for the Quoddy Region, SW Bay of Fundy (Excluding St. Croix Estuary and Cobscook Bay)........................8

2. Environmental effects of chemicals related to aquaculture ......................20

3. Summary of Evaluation of Selected Cumulative Environmental Assessment Methods.

4. Model application in aquaculture regulation around the world.

5. Default Trigger Values- Marine Environment of Australia and New Zealand.

6. Comparison of aquaculture-related nitrogen, carbon and BOD with natural and anthropogenic sources and sinks in the Letang Region.

7. Fluxes of oxygen, nitrogen and carbon as percentages of total fluxes............70

8. Comparison of aquaculture-related $\mathrm{BOD}, \mathrm{C}, \mathrm{N}$ and $\mathrm{P}$ to natural and anthropogenic sources and sinks.

9. CMRs suitable for increased production with respect to $\mathrm{DO} \ldots \ldots \ldots \ldots \ldots \ldots \ldots . . . \ldots 76$

10. Percent of total flux due to salmon aquaculture.

11. CMRs suitable and unsuitable for further production and estimated increased production as number of fish

12. Descriptions of Sediment Conditions in the Bay of Fundy .80

13. Corresponding benthic effect level to sediment condition.

14. CEAA trigger for 23 finfish environmental assessments.

15. Answers to Regional Set of Decision Support System Questions Before Consideration of Mitigation

16. Answers to Regional Set of Decision Support System Questions With Mitigation Considered. 


\section{List of Figures}

1. Salmon Industry Production Value (\$ million) .................................

2. Growth of the salmon aquaculture industry Southwestern New Brunswick, Bay of Fundy from 1979 to 2002 as annual production (thousands of tons) (solid circles) and numbers of sites (approved non- and operating sites) (open circles)........................................

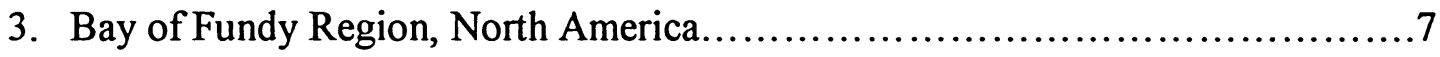

4. Bay Management Areas in 2002 with new subdivision (1B)

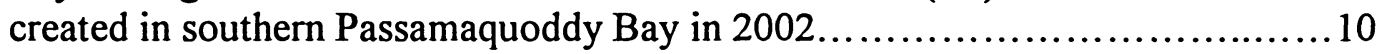

5. Steps of criteria amendment toward application................................49

6. Water mixing zones and coastal management regions of southwestern New Brunswick

7. Coastal Management Regions (CMRs) in SW New Brunswick including salmon farms (2002).

8. Rockweed overgrown with annual algae and epiphytes.

9. Protective top and additional outside netting, Chance Harbour, 2005 .99

10. Spawning areas (current and historical) for major groundfish species, herring, and lobsters in the Bay of Fundy

11. Decision Matrix

12. Mechanical feeder, Chance Harbour, SWNB, 2005 


\section{Glossary of Acronyms}

ACOA $=$ Atlantic Canada Opportunities Agency

$\mathrm{ADD}=$ Acoustic Deterrent Devices

$\mathrm{AHD}=$ Acoustic Harassment Devices

ANZECC $=$ Australian and New Zealand Environment and Conservation Council

APL $=$ Approved Production Limits

$\mathrm{BMA}=$ Bay Management Area

$\mathrm{BOD}=$ Biological oxygen demand

$\mathrm{CCME}=$ Canadian Council of Ministers of the Environment

$\mathrm{CCNB}=$ Conservation Council of New Brunswick

$\mathrm{CDI}=$ Campobello/Deer island $\mathrm{CMR}$

$\mathrm{CEI}=$ Cumulative Ecosystem Index

$\mathrm{CMR}=$ Coastal Management Region

DFO $=$ Department of Fisheries and Oceans Canada

$\mathrm{DO}=$ Dissolved oxygen

DSS $=$ Decision Support System

$\mathrm{EA}=$ Environmental assessment

$\mathrm{EC}=$ Environment Canada

$\mathrm{ESP}=$ Estimated Site Potential

$\mathrm{GM}=$ Grand Manan CMR

$\mathrm{LL}=$ Letang-Letete $\mathrm{CMR}$

NBDELG $=$ New Brunswick Department of Environment and Local Government $\mathrm{NPB}=$ Northern Passamaquoddy Bay CMR

NWPA $=$ Navigable Waters Protection Act

$\mathrm{RA}=$ Responsible authority

SARA $=$ Species at Risk Act

SWNB = Southwestern New Brunswick

TAPL $=$ Total Approved Production Limit

$\mathrm{TC}=$ Transport Canada

TESP $=$ Total Estimated Site Potential 


\section{Chapter 1: INTRODUCTION}

In light of booming global demand for fish and seafood products, we have been forced to abandon natural harvesting techniques and adopt culturing methods as modelled by the agriculture industry. The inability of wild stocks to meet such sonorous demands, diminishing returns in an attempt to do so, and the promise of greater economic development for many resource-dependent coastal communities, has fuelled the blue revolution with marine finfish aquaculture at the forefront. Aquatic species are now reared in net-pens, dotting global coastlines. In Canada, finfish production accounts for about $74 \%$ of total aquaculture production, $86 \%$ being salmon production (Parliament of Canada, 2001). The largest provincial producer of finfish aquaculture is British Columbia, followed by New Brunswick (Parliament of Canada, 2001). The value of finfish production has dramatically increased over time with an astounding rise in total sales described at $642 \%$ between 1986 and 2000 . Overall, the value of all Canadian aquaculture production in 2000 was $\$ 611,572,000$, a significant contribution by a relatively young industry (Parliament of Canada, 2001).

New Brunswick's Southwestern Isles Region of the Bay of Fundy was one of the first areas to successfully employ commercial marine fish farming in North America (Pohle, 2001). With rapid expansion of the industry came the introduction of federal enforcement through the Canadian Environmental Assessment Act, officially as of 2000. Environmental assessment was meant to standardize and improve the site evaluation and decision-making process; however, the inherent subjective nature of judgement-based impact prediction facilitated continued expansion at the consequence of marine ecosystem health. As industry expansion into new coastal areas plateaued in the early $21^{\text {st }}$ century, increased production on-site raised questions by scientists and environmental groups. New decision tools were introduced attempting to curb irresponsible siting; however, site-by-site regulation and management, and legislative loop-holes have left many site owners in violation of environmental standards, unaccountable.

Opinions on the intensive industry are divided, but there exists a general consensus that without a functioning marine environment, mariculture will be unable to continue. Despite the economic and employment opportunities, the repercussions of intensive mariculture in the Bay of Fundy region have become cause for concern, as the 
marine environment experiences increasing stress, and regulation and management remains unable to ensure the environmental sustainability of the industry.

\section{The Southwestern New Brunswick Salmon Aquaculture Industry}

\section{Industry Inception}

In 1978, the southwestern New Brunswick (SWNB) salmon aquaculture industry began with an experimental farm at Lords Cove, Deer Island (DFO, 2003). The second farm in the industry was located at Dark Harbour, Grand Manan; however, during the 1980s, the industry began rapid expansion in the Letang Inlet and then around Deer and Campobello Islands. The industry continued to spread throughout the southwestern region of the Bay of Fundy. Farms moved into Passamaquoddy Bay and Grand Manan in the 1990s (DFO, 2003), and around southern Grand Manan Island and into the bays and coves along the southern coast of N.B. east of the Letang area post-2000. Over the last 3 decades the industry exploded, resulting in a total of 97 marine finfish farms as of May 2006, most of which were sited within $1 \mathrm{~km}$ of the shoreline (Harvey, 2006a; Chang et al., 2005a). While salmon sites were initially largely owned and run by local farmers, currently, large companies are buying out independent farmers and taking over the industry. Three companies presently own approximately $80 \%$ of the farms (Drost, 2005, pers. comm.), with one company owning 60 of the 97 farms (Harvey, 2006a). The total area leased to salmon aquaculture in N.B. as of 2004 has been estimated at 1,206 hectares (AFA, 2004) and most of this area is shared with fishing grounds, other industry, tourism and other activities in a small area of $40 \times 50 \mathrm{~km}$ in the Bay of Fundy (Harvey, 2004). The Letang Inlet holds the highest concentration of salmon farms of any area in Canada, and no fishing currently takes place in this area (Harvey, 2004).

\section{Economic setting}

The SWNB salmon aquaculture industry is based out of Charlotte County. Although some sites have spread east into another county, the employees and spin-off industries predominantly reside in Charlotte County. The population of Charlotte County is approximately 27,366 and this population occupies 12,426 private dwellings (StatsCan, 2002). This region is also known as the Charlotte Community Economic Development 
Agency (CEDA), or Enterprise Charlotte. Enterprise Charlotte is one of N.B.'s 15 CEDAs created in 2002 to 'work with regional business communities in various areas of strategic importance, including export readiness, electronic commerce and business, improved competitiveness and diversification of N.B.'s economy' (NBDTED, 2002).

The 1996 Census indicated that the unemployment rate for Enterprise Charlotte was $22.8 \%$, the second highest rate for all CEDAs and above the provincial rate of $15.5 \%$. However, the participation rate of the working age population in the labour force was slightly higher than the provincial average; $62.7 \%$ compared to $62.2 \%$ (NBDTED, 2002). The largest areas of labour force involvement by industry included Manufacturing (24\%), Retail Industries (9\%), Fishing and Trapping Industries (9\%) and Accommodation, Food and Beverage Industries (7\%) (NBDTED, 2002). At the 2000 Census, the average family income in Charlotte County was $\$ 58,167$, almost $\$ 15,000$ lower than the national average $(\$ 72,524)$ (StatsCan, 2004).

Although the salmon aquaculture industry is relatively new, it has developed into a key agri-food industry for both New Brunswick and the Charlotte County region (AFA, 2004; DFO, 2005). The N.B. salmon aquaculture industry generated a farm gate value of $\sim \$ 175$ million and 1,849 jobs $(\sim 1,600$ direct) in 2004 , representing $96.7 \%$ of the total farm gate value of cultured species and providing the backbone of the Charlotte County economy (DFO, 2005; AFA, 2004). The value of production increased steadily from 1979 to about 2002 when production value appeared to have peaked, dropped slightly and levelled off between $\$ 175-\$ 185$ million as depicted in Figure 1 below.

Figure 1: Salmon Industry Production Value (\$ million).

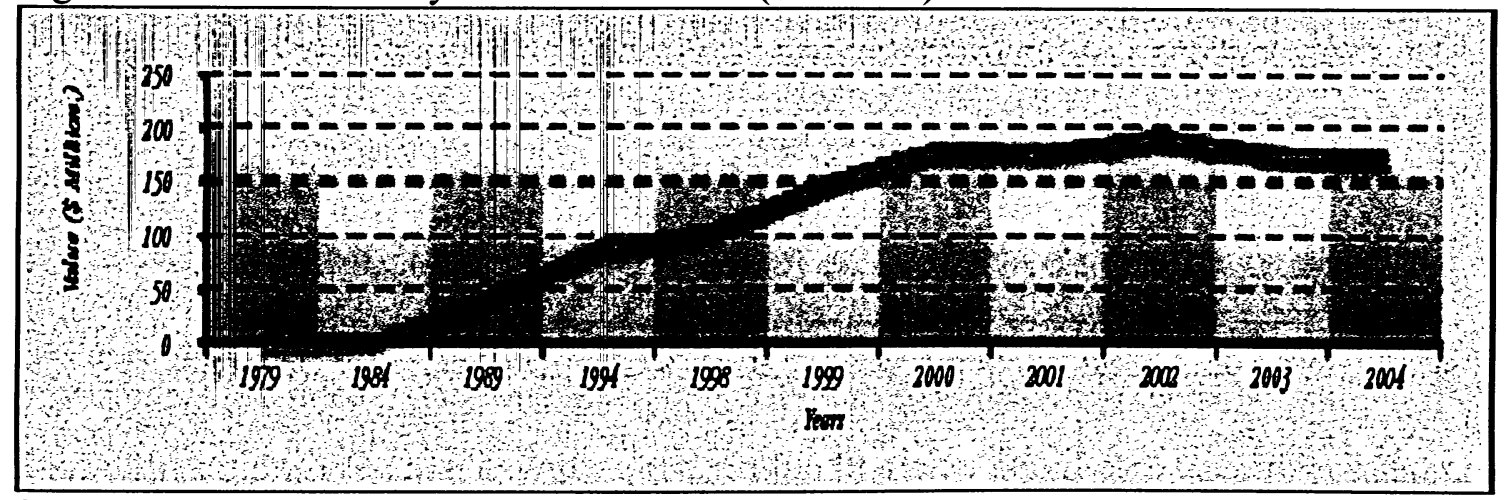

Source: AFA, 2004. 
The production of farmed Atlantic salmon is a two-phase process. The first phase involves the production of juveniles (smolt) from eggs in land-based freshwater hatchery facilities, and the second phase involves the transfer of the smolts to net-pens in the open marine water (Milewski, 2001). After the average grow-out period of 21.25 months (Strain, 2003), fish are marketable and removed from the net-pens for sale.

In 2004, production was estimated at 35,000 MT, up 2,000 MT from 2003 (Chang et al., 2005a; AFA, 2004). Salmon industry production has shown a general increasing trend since the first yield was produced in 1979. As shown in Figure 2 below, production per site has not been continuous, while the number of sites has been continuous. This can be attributed to the fact that smolts added to a new site are harvested the following year or that some sites may be fallowed for a year. In some cases, however, sites have fish of various life stages so each year will produce a yield (Middleton, 2005, pers. comm.). There have been four periods of increasing productivity based on year-toyear changes in site-specific production. These periods include: 1982-83, 1985-89, $1993-$ 94, and 1997-98 (DFO, 2003). These periods were followed by three or four years of diminished yield/site; the most significant decline taking place in 1997-1998 as a result of a disease outbreak. Stocking levels were consequently reduced at farms to help lower the likelihood of infections (DFO, 2003). The maximum stocking density recommended by the New Brunswick Department of Agriculture, Fisheries and Aquaculture (DAFA) for a salmon site is $18 \mathrm{~kg} / \mathrm{m}^{3}$. The total number of fish on-site depends on the number of cages, size of the cages, Estimated Site Potential and Approved Production Limit. 
Figure 2: Growth of the salmon aquaculture industry Southwestern New Brunswick, Bay of Fundy from 1979 to 2002 as annual production (thousands of tons) (solid circles) and numbers of sites (approved non- and operating sites) (open circles).

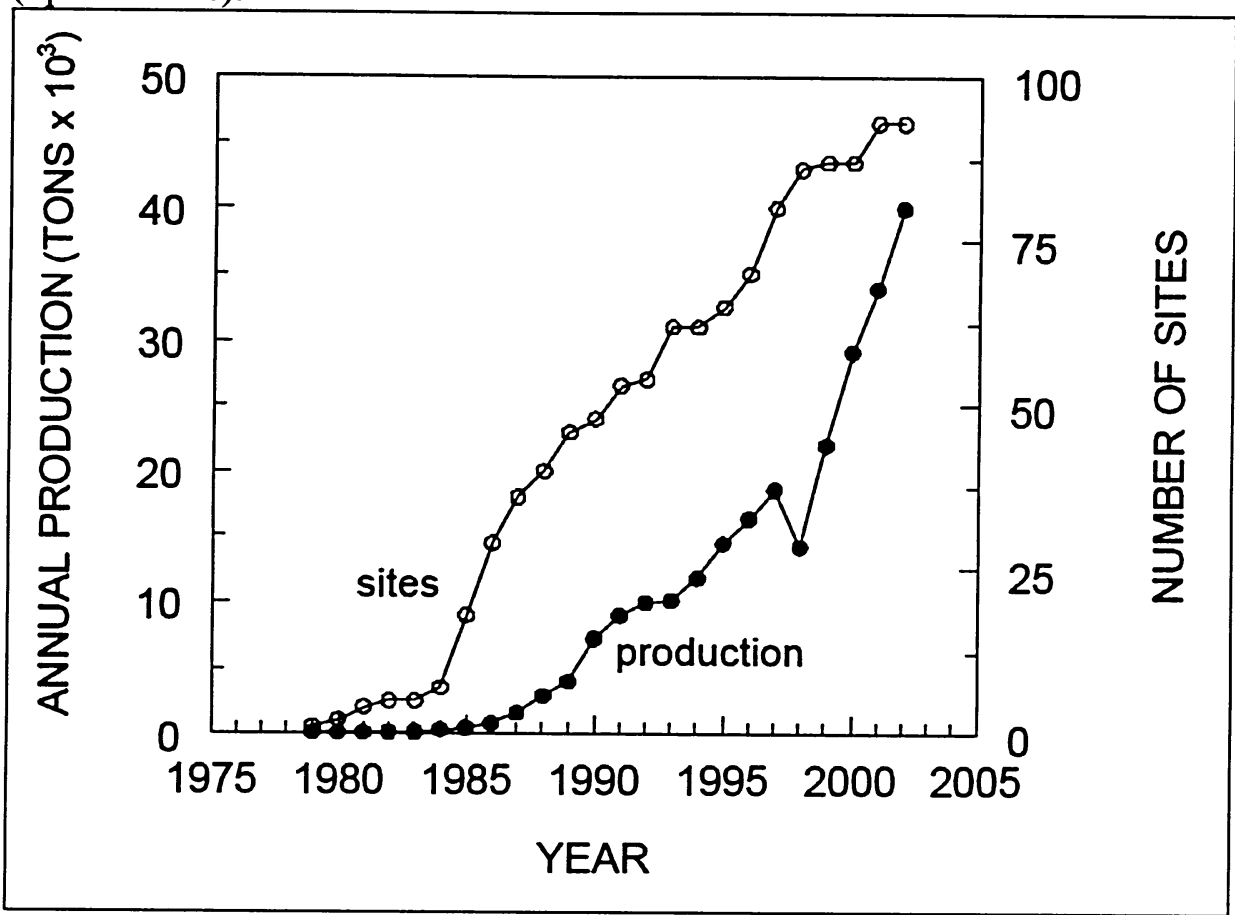

Source: DFO, 2003.

Although over the last 3 decades the industry expanded throughout SWNB at a significant pace, in recent years expansion has been limited by decreased accessibility to new sites. This has resulted in about 10 leases being granted since 1998 (DFO, 2003). While siting new farms has not occurred at the rapid pace of years past, production has increased on-site. Between 1998 and 2002 annual production increased from $14 \times 10^{3}$ tons to $40 \times 10^{3}$ tons. If stocking density on-site was in compliance with the provincial guidelines, increased production can be attributed to increasing the number and/or sizes of net-pens/site to accommodate more fish per farm (DFO, 2003). Often smaller sites are fallowed or abandoned and production is transferred to another existing site (DFO, 2003). While disease has been more carefully managed in recent years, more fish onsite create the potential for a greater loss if fish become infected. In July 2005, the federal government provided a one-time investment of up to $\$ 20$ million to the N.B. salmon aquaculture industry to assist with short-term funding after significant uncompensated losses were incurred due to eradication orders aimed at disease control (DFO, 2005). The 
funds were to help salmon growers refinance and secure working capital to enable placement of juvenile salmon in pens that season, while consideration of long term solutions takes place (DFO, 2005).

\section{Environmental setting}

The SWNB aquaculture industry is situated in the outer Bay of Fundy (Refer to Figure 3). The Bay of Fundy is a large macro-tidal embayment that forms the northeastern arm of the Gulf of Maine. It is closely linked oceanographically to the greater Gulf of Maine, the Scotian Shelf and North-western Atlantic, and receives the inputs of 44 major rivers and many smaller ones (Wells, 2003). The tides of the Bay of Fundy range from $\sim 4 \mathrm{~m}$ at the mouth of the Bay to an average of $12 \mathrm{~m}$ in Minas Basin (Percy et al., 1997). Because the tidal movements are so strong, water mixing, exchange, and currents create a dynamic environment, characteristic of high productivity due to nutrient upwelling (Percy et al., 1997). Absolute temperatures in the Bay of Fundy range from $\sim 0.5-15.2^{\circ} \mathrm{C}$, with seasonal lows occurring in February and March and seasonal highs occurring in August and September (Peterson et al., 2001). The shallower coastal waters of New Brunswick's coastlands are extremely ecologically important, providing productive and protective habitat for many native species. The shorelines support numerous nesting and feeding sites for seabird and shorebirds such as the endangered Harlequin Duck; provide habitat for raptors such as osprey and the endangered Bald Eagle and Peregrine Falcon; border important feeding and rearing grounds for seals, porpoises and whales including endangered species such as the Right Whale; and provide shelter and food for predators and prey (NTNB, 2006).

While expanses of Fundy coastline remain untouched, most coastal and offshore areas have come under increasing development and use. The waters and shorelines of the Bay of Fundy are 'part of a working landscape' (NTNB, 2006) both through selfsustaining ecosystem processes and various resource-reliant activities. Many activities have reaped the benefits of the Bay's wealth; however, over the years, increasing pressure, overexploitation and disruption have compromised the state of health of the Bay of Fundy. 
Figure 3: Bay of Fundy Region, North America.

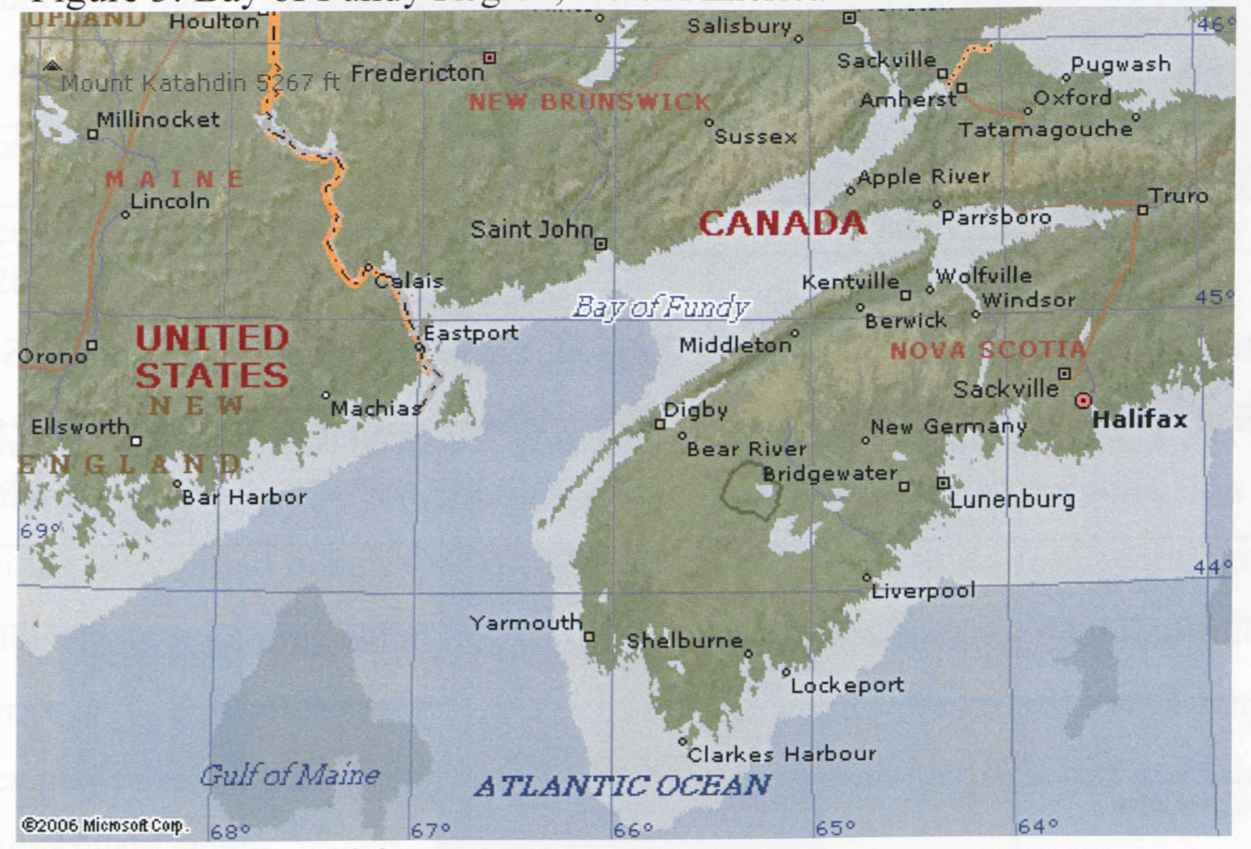

Source: Encarta, 2006.

The term marine ecosystem health is often used to categorize a marine environment's sustainability, ability to maintain its metabolic activity level, internal structure and organization, and ability to be resilient to stress over a wide range of temporal and spatial scales (Epstein, 1999 in Wells, 2003). Ill-health is often characterized by major changes in mortality, disease, and chronic disturbances across various taxonomic groups (Sherman, 2000a in Wells, 2003). Other more general health indices have been suggested to indicate changing ecosystem states including biodiversity, productivity, yield, resilience and stability (Wells, 2003). In other cases, indicator species such as benthic invertebrates and fish can be used in various forms of measure such as contaminant monitoring and effects, routes of bioaccumulation and trophic transfer, impaired growth or reproductive capacity, etc.. (Wells, 2003). The use of any of these indicator types would depict a stressed and disturbed marine environment, suffering from a compromised state of marine ecosystem health in the SWNB Bay of Fundy.

A study conducted by the Conservation Council of New Brunswick (CCNB) presented an environmental quality matrix for the southwestern Bay of Fundy using comparative rating for 6 regions in terms of various environmental indicators. Each region received a rating of serious (red), moderate (yellow), or good (green) for each 
indicator. This revealed the general trend of environmental quality in each area and the entire Quoddy Region. A condensed version of the matrix is presented below and explanations of the indicators are presented in Appendix A.

Table 1: Environmental Quality Matrix for the Quoddy Region, SW Bay of Fundy (Excluding St. Croix Estuary and Cobscook Bay)

\begin{tabular}{|c|c|c|c|c|c|c|c|c|}
\hline & Indicator & $\begin{array}{l}\text { Entire } \\
\text { Quoddy } \\
\text { Region }\end{array}$ & $\begin{array}{l}\text { Pass. } \\
\text { Bay } \\
\text { Subregion }\end{array}$ & $\begin{array}{l}\text { Letang } \\
\text { Subregion }\end{array}$ & $\begin{array}{l}\text { West Isles } \\
\text { Subregion }\end{array}$ & $\begin{array}{l}\text { Maces } \\
\text { Bay } \\
\text { Subregion }\end{array}$ & $\begin{array}{l}\text { Grand } \\
\text { Manan }\end{array}$ & $\begin{array}{l}\text { Open/ } \\
\text { Wolves }\end{array}$ \\
\hline \multirow{5}{*}{ 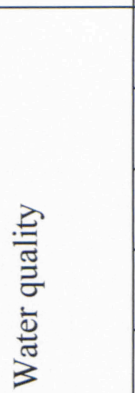 } & Bacteria & & & & & & & \\
\hline & \begin{tabular}{|l|l} 
Nutrients \\
\end{tabular} & & & & & & & \\
\hline & \begin{tabular}{|l} 
Sediments \\
\end{tabular} & & & & & & & \\
\hline & \begin{tabular}{|l} 
Toxic contaminants \\
\end{tabular} & & & & & & & \\
\hline & \begin{tabular}{|l} 
Dissolved oxygen \\
\end{tabular} & & & & & & & \\
\hline \multirow{7}{*}{ 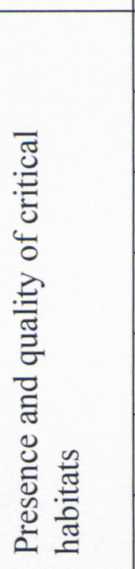 } & Benthic habitat & & & & & & & \\
\hline & \begin{tabular}{|l|} 
Wetlands \\
\end{tabular} & & & & & & & NA \\
\hline & \begin{tabular}{|l} 
Seagrass beds \\
\end{tabular} & & & & & & & \\
\hline & $\begin{array}{l}\begin{array}{l}\text { Nesting and foraging } \\
\text { areas }\end{array} \\
\end{array}$ & & & & & & & \\
\hline & $\begin{array}{l}\text { Spawning and nursery } \\
\text { areas }\end{array}$ & & & & & & & \\
\hline & $\begin{array}{l}\text { Legally protected areas } \\
\text { protected }\end{array}$ & & & & & & & \\
\hline & Marine mammals habitat & & & & & & & \\
\hline \multirow{4}{*}{ 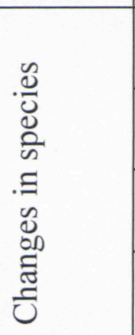 } & Populations & & & & & & & \\
\hline & Diversity & & & & & & & \\
\hline & Dominance & & & & & & & \\
\hline & \begin{tabular}{|l|} 
Invaders \\
\end{tabular} & & & & & & & \\
\hline \multirow{4}{*}{ 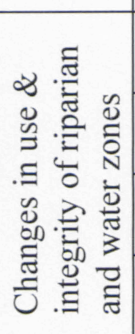 } & $\begin{array}{l}\text { Clearing, dev.natural } \\
\text { areas }\end{array}$ & & & & & & & \\
\hline & $\begin{array}{l}\text { Replacement of } \\
\text { traditional uses }\end{array}$ & & & & & & & \\
\hline & $\begin{array}{l}\begin{array}{l}\text { Erosion \& deposition } \\
\text { changes }\end{array} \\
\end{array}$ & & & & & & & \\
\hline & \begin{tabular}{|l} 
Tidal barriers on streams \\
\end{tabular} & & & & & & & NA \\
\hline
\end{tabular}




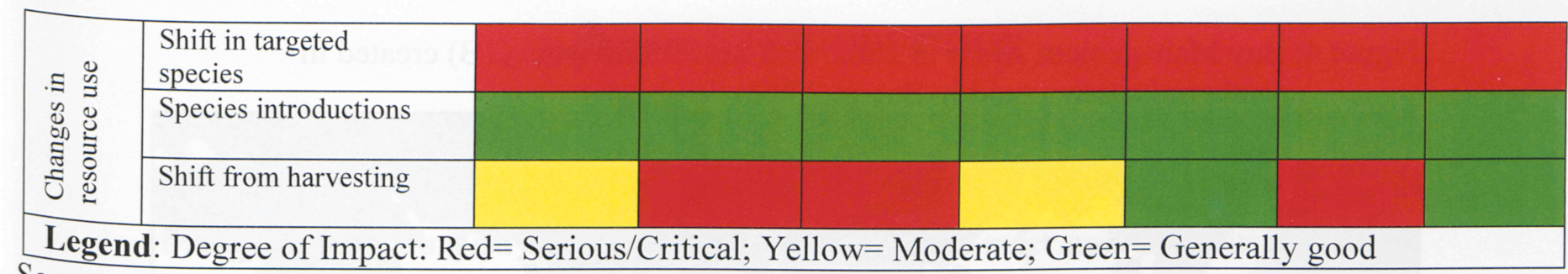

Source: CCNB, 2003.

The environmental quality matrix indicates that two areas of the Quoddy region in particular are seriously stressed; the Letang and Passamaquoddy subregions. The other 4 subregions were found to be experiencing moderate changes in environmental quality with indicators suggesting some aspects of good ecosystem health. Overall, development and human disturbance have resulted in the Quoddy region experiencing moderate changes in environmental quality, with some indicators seriously affected and others remaining fairly stable.

\section{Industry Regulation and Management}

A growing concern by environmental groups that the salmon industry was exacerbating the stressed state of the Bay of Fundy (particularly coastal) environment played a small role in the initial reconfiguration of the industry. Spatial re-organization of farms aimed to address disease management, increase production efficiencies and reduce negative interactions with traditional fisheries in 1998 (DFO, 2003). Multi-year class rearing moved to single-year (either odd or even designation) classes in specific areas to control disease and ensure a period of fallowing. In the late 1990s, Bay Management Areas (BMA) were introduced to allow expansion of the industry and improve economic efficiency but reduce the likelihood of disease transmission. In 2000, 21 BMAs created by the DAFA became part of the Bay of Fundy Marine Aquaculture Site Allocation Policy, and after 2 years, expansion caused the number of BMAs to increase to 22 (Please refer to Figure 4 below). At the time of creation it was thought that BMAs were sufficiently large and separated to ensure disease management (AFA, 2000; DFO, 2003). 
Figure 4: Bay Management Areas in 2002 with new subdivision (1B) created in southern Passamaquoddy Bay in 2002.

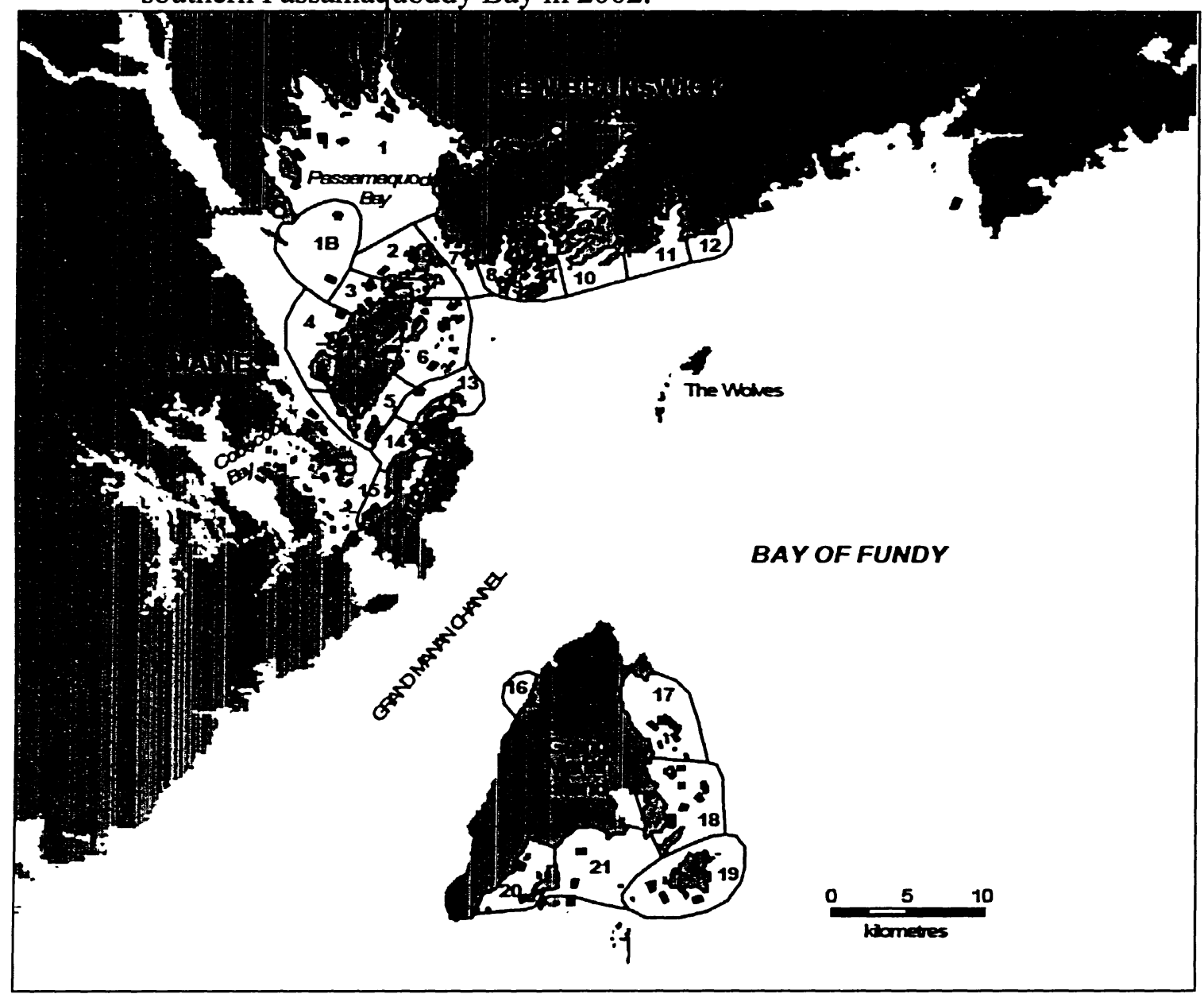

Source: DFO, 2003.

There are five agencies that govern the regulation and management of the salmon aquaculture industry in New Brunswick. Provincially, there is the DAFA and the Department of Environment and Local Government (DELG) and federally there is the Department of Fisheries and Oceans (DFO), Environment Canada (EC), and Transport Canada (TC) (AECC, 2004).

The Department of Agriculture, Fisheries and Aquaculture is the primary agency responsible for aquaculture. It is in charge of development and infrastructure, issuing licences, occupation permits and leases, and conducting monitoring inspections (Parliament of Canada, 2001). The General Regulation pursuant to the Aquaculture Act sets out detailed requirements related to siting and operations. A lease, occupation permit and licence are all required in order to carry out aquaculture in N.B. and other permits or 
approvals may be required through other agencies. Under the Aquaculture Act and General Regulation, limitations are placed on site area and level of production. The Department of Natural Resources and Energy is responsible for Crown lands but has delegated the authority for leasing to DAFA for marine aquaculture sites (AECC, 2004).

The provincial Department of the Environment and Local Government (DELG) is responsible for the Clean Environment Act, the Clean Water Act, and the Pesticides Control Act. Under the authority of the Clean Environment Act, DELG issues Certificates of Approval ( $\mathrm{C}$ of $\mathrm{A}$ ) to each site. Standard industry environmental management guidelines are attached to each $\mathrm{C}$ of $\mathrm{A}$ and together, they stipulate operating conditions for the site including the annual monitoring and reporting requirements (AECC, 2004). DELG was first given this authority in 2002, so all sites since 2002 follow the $\mathrm{C}$ of $\mathrm{A}$ system. It is the intent of DELG, through the development of the Environmental Management Guidelines to address environmental issues pertaining to marine finfish aquaculture. DELG also develops and implements sediment remediation plans if necessary; reviewed and approved in collaboration with the Aquaculture Site Remediation Committee (ASRC) comprised of representatives from DELG, DAFA, DFO, and Environment Canada (AECC, 2004). DELG is also responsible for the Environmental Impact Assessment Regulation 87-83 under the Clean Environment Act, under which some marine-based aquaculture facilities may require registration. Registration for these projects is typically triggered by water withdrawal, wastewater treatment, introduction of a non-native species, or by the presence of rare, unique or endangered environmental features that may be affected by the project (DELG, 2005).

In 1984, the federal government designated the Department of Fisheries and Oceans (DFO) as the lead agency for aquaculture. An aquaculture coordinator appointed by DFO coordinates among federal agencies the review of aquaculture applications and the assessment of proposed sites for aquaculture licences and leases, in addition to various other tasks (Standing Senate Committee on Fisheries, 2001). The applications are forwarded to DFO from the province. DFO also exerts power through the Fisheries Act. Pursuant to the Fisheries Act, DFO is responsible for the management of fish habitat, the protection of marine mammals, fish health, and the movement of stock between water bodies; introductions and transfers (AECC, 2004). Additionally, DFO is responsible for 
the Oceans Act. The Oceans Act does not directly apply to the salmon aquaculture industry; however, in recent times principles have been taken from it relating to the development of marine environmental quality guidelines and integrated management initiatives (AECC, 2004). DFO and the province of N.B. signed a memorandum of understanding in 1989 directed at a coordinated system of licensing and leasing of commercial aquaculture activities. This enabled the establishment of coordinating committees and interagency cooperation.

Under the Navigable Waters Protection Act, Transport Canada is also a responsible agency when a work may impact navigability. If a proposed site is in violation of either the NWPA or the Fisheries Act or if an approval or permit must be issued, the Canadian Environmental Assessment Act (CEAA) will be triggered and a federal environmental assessment may be conducted pursuant to the Law List regulations. CEAA is also triggered if the federal government is a proponent, provides financial assistance, or gives up interest in land. Federal EAs are now required for all proposed salmon mariculture sites in N.B.

Environment Canada does not issue any permits or licenses to salmon farms related to the protection of the marine environment; however, it provides technical and scientific advice to DAFA, DELG and DFO relating to their areas of responsibility (AECC, 2004) and on conducting federal environmental assessments (EC, 2001).

The Bay of Fundy Marine Aquaculture Site Allocation Policy specifies the process for applying for a lease and license, and sets out the information requirements for the application of a new or expanding aquaculture lease (AECC, 2004). The policy states that each approved marine aquaculture operation is monitored in accordance with the Provincial Environmental Monitoring Program (EMP). The EMP monitors and rates sites in relation to their marine sediment impacts in the vicinity of the aquaculture operation (DAFA, 2005). Both DAFA and DELG have an active role in implementing the Environmental Monitoring Program. The license holder retains a contractor approved by DELG to carry out the protocols identified in the EMP, reports monitoring results, and maintains monitoring results for a period of 20 years (NBDELG, 2001). If a site is fallowed but still licensed monitoring must still be carried out. 
There are two other related activities aimed at ensuring the sustainability of the industry: the Fish Health Management Program and the Waste Management Plan. The Fish Health Management (Surveillance) Program monitors fish health, increases knowledge relating to fish protection, and prevents and controls fish health concerns (NBDELG, 2001). This Program only relates to cultured fish. The Waste Management Plan considers issues related to harvesting protocols, handling and disposal of blood water and stunwater, the use of disinfectants in operations, and waste disposal (NBDELG, 2001). A comprehensive, industry-wide waste management plan to be incorporated into Bay Management Area Agreements, regulation, development of sitespecific plans, and Approvals to Operate is ultimately the goal (NBDELG, 2001).

\section{Shortfalls of Current Regulation and Management}

Although the management and regulation of the mariculture industry in SWNB has evolved to become more diligent and stringent, there remain various shortfalls that hinder sustainability and contribute to significant environmental degradation. Although environmental sustainability is a growing objective, focus continues to be directed at industry sustainability and the ability to compete in the global market.

There are a number of inadequacies in regulation and management of the mariculture industry in SWNB. Some of the major shortfalls found in aquaculture policy, regulation and management include:

- There exist no environmental criteria outlined in the Site Allocation Policy

- Environmental considerations play a small role in determining the Estimated Site Potential and Approved Production Limits

- Regulatory siting distance between farms is $300 \mathrm{~m}$, much shorter than B.C. requirement of $1 \mathrm{~km}-3 \mathrm{~km}$

- Industry managed on a site-by-site basis

- Industry management mainly focused on limiting escapes, preventing spread of disease and economic prosperity.

- EMP only considers sediment impacts

- Farms are required to maintain an oxic state but are not penalized for having hypoxic or anoxic conditions

- Federal EA process is inconsistent

- Fisheries Act responsibility of DFO not being upheld-HADD violations not issued

- Policy predominantly focuses on the financial aptitude of farmers proposing sites, and the importance of lease and permit obtainment. 
In addition to the above criticisms, DAFA states that 'if, at any time, unacceptable environmental impacts are found, site management practices and physical parameters will be evaluated with the salmon farmer in an effort to correct practices that may be contributing to the site degradation' (Harvey, 2004). However, despite monitoring and alleged enforcement to meet industry standards, a study conducted in 2004 found that $36 \%$ of the 96 salmon farms operating in SWNB failed to meet provincial environmental standards, based on monitoring of sediments underneath the cages (Harvey, 2004). This is of particular concern because the study revealed that many of the polluting sites are clustered within a few areas, resulting in a larger impact than just the site footprint. All of them are in close proximity to shore, fishing grounds and boating areas (Harvey, 2004).

The two main areas where industry regulators are failing to address potential environmental interactions are during establishment of production levels and siting. Production levels have been rising despite the fact that fewer leases have been granted in recent years. During establishment of production levels by DAFA, regional and cumulative interactions between all farms within a region are not consider, nor are the ratios of aquaculture-related fluxes of dissolved oxygen and nutrients to natural fluxes. As a result, the production levels of some areas such as the Letang, have exceeded the environment's assimilative capacity (DFO, 2003). Evidence suggests that production levels are reaching dangerous levels and continued expansion will result in further shifts in ecosystem structure and function.

Many models have attempted to simulate farm-environment interactions; however, few have been used in siting. Until very recently siting has been largely judgement-based, consideration of environmental components has been inconsistent, and cumulative effects improperly addressed. As part of the federal environmental assessment process, site evaluations are conducted by DFO using a decision support system. Decision support systems are successful at removing much of the subjectivity inherent in environmental assessment and decision making, and evaluating proposals based on scientific evidence. Despite the grand improvement in site evaluations presented through application of the DSS, cumulative environmental effects remain inadequately addressed in the evaluation process, and rising evidence suggests that regional and cumulative effects are plaguing the Bay. 


\section{Purpose of the study}

It might be expected that a lack of consideration of regional and cumulative environmental effects in site evaluations has led to both expansion of the industry to inappropriate areas and increased levels of production beyond the marine environment's ability to assimilate farm-related wastes. The purpose of this study was to determine whether consideration of regional and cumulative environmental effects in site evaluations would alter the approval outcomes of salmon mariculture sites currently in operation in SWNB. This was achieved through the amendment of Hargrave's (2002) decision support system to address mariculture siting on a regional basis as opposed to solely on a site by site basis. This approach is expected to better address the growing knowledge of fish farm-environment interactions and consider the ecosystems stresses attributable to mariculture in combination with other existing and future stresses placed on the marine environment. 


\section{Chapter 2: ENVIRONMENTAL EFFECTS OF MARICULTURE}

There are many negative environmental effects of salmon aquaculture on the marine environment. These effects can be localized or near-field, far-field, regional and cumulative in nature. Salmon aquaculture acts independently, and in combination with, other coastal development to both cause stress on, and significantly alter, the delicate but complex Bay of Fundy coastal landscape. Much of the productive habitat (benthic and pelagic) found within the aquatic system has been damaged or destroyed, as salmon farming has expanded and intensified in the last two decades. Production of 40000 tonnes of fish results in $\sim 80000$ tonnes of solid waste discharged into the marine environment (Harvey, 2006a). The solid waste released from finfish aquaculture sites is waste feed and faeces which is released into the water column and either deposited immediately below the cage or transported to the area surrounding the cage footprint. It is not only the physical development and presence of the net-pens that cause impacts, but the biogeochemical composition of the ecosystem is also altered by the main constituents of waste feed and faeces which inlcude organic matter, carbon, nitrogen, phosphorous, and by additives such as medications, metals and other chemicals. The release of these constituents contribute to changes in the pelagic and benthic environment that result in habitat reconfiguration, altered habitat function, degraded water and sediment quality, and changes in food-web dynamics through disruption of natural succession and predator-prey relationships. Overall, the demands placed on the marine environment of the Bay of Fundy by the intensive level of production are beginning to exceed the ecosystem's ability to meet them. As a result, the ecosystem has and continues to exhibit various stress-related responses, many of which may indicate the presence of long-term and irreversible damage.

The following chapter presents a general overview of the range and extent of environmental impacts incurred by the aquatic environment and native species in the Bay of Fundy. This is not an exhaustive or specific recount, as more specific information is presented in Chapter 5 which discusses amendments made to the current Traffic Light DSS. This chapter focuses on near-field and far-field effects, as the bulk of the literature addresses these interactions. Regional and cumulative effects are introduced but discussed in greater detail in Chapter 5, as few studies directly address these interactions. 


\section{Near-field effects}

The localized or near-field effects account for aquaculture-environmental interactions in the immediate vicinity of fish farms. These effects are fairly well understood and have been increasingly studied and documented in the past decade. The most widely discussed near-field effects relate to the presence of the cage structure, sedimentation of organic matter, organic enrichment and the impacts on aquatic species, and the presence and impacts of trace metals and chemicals in the environment.

\section{Presence of physical structure}

The physical structure of the fish cage can have negative effects on both the environment beneath the cage and species that inhabit the lease area. The net-pens are anchored to the sea bottom with large nets suspended in the water column to contain the fish. Netting often also covers the structure above the water surface to ward-off avian predators. The farm sites usually have lights to deter birds from feeding on the fish and to enable fishermen to work at night. The existence of the cages within the lease area, often many hectares in size, excludes pelagic, bird and mammalian species from their habitat, causes behavioural modifications and has been known to lead to mortality through entanglement in the nets (Milewski, 2001). The presence of lights at night in the marine environment have also been found to induce behavioural changes in marine species, especially birds, and has caused shifts in plankton communities due to altered photoperiods (Milewski, 2001; EC, 2001). On site, if predators of the cultured fish become too much of a nuisance, under appropriate authorization, farm owners may use fire arms to kill species in the vicinity of the cages (EC, 2001; Milewski, 2001).

\section{Sedimentation}

Sedimentation of salmon waste feed and faeces in the net-pen footprint has been measured at rates ranging from 1 to $181 \mathrm{~g} \mathrm{C} / \mathrm{m}^{2}$ day (Wildish et al., 2004). Hargrave (1994) suggested that flux rates of fish feed and faeces greater than $1.0 \mathrm{~g} \mathrm{C} / \mathrm{m}^{2}$ day lead to organic enrichment on the benthic environment in net depositional sediments. When fluxes exceed this rate, the increased presence of organic matter leads to raised metabolic activity of aerobic bacteria causing rapid utilization of pore water dissolved oxygen 
(Wildish \& Pohle, 2005). When prolonged or permanent low oxygen result from respiratory oxygen uptake exceeding oxygen supply by natural processes, sulfate reducing and methanogen bacteria promote sulfide $\left(\mathrm{H}_{2} \mathrm{~S}, \mathrm{~S}^{-}\right)$accumulation, methane production, low redox potentials (negative $\mathrm{Eh}$ ) and FeS formation (Holmer et al., 2005). The sediment surface then develops a black, top-down sulphide layer (Wildish et al., 2004).

Various types of bacteria are involved in mineralization of sulfur in sediments. One well-known bacteria is Beggiatoa, an anaerobic chemoautotrophic filamentous white sulfur bacteria that use oxygen to oxidize $\mathrm{H}_{2} \mathrm{~S}$ to elemental sulfur (So) (Hargrave, 2006). This bacteria requires both oxygen and $\mathrm{H}_{2} \mathrm{~S}$ for metabolism and thus Beggiatoa occurs within the sediment at the oxic/anoxic interface (Hargrave, 2006). White filamentous Beggiatoa mats are an indication of reduced conditions that have reached the sediment/water boundary (Hargrave, 2006). These conditions are indicative of the total replacement of aerobic species by anaerobic microorganisms (Wildish \& Pohle, 2005).

\section{Organic enrichment and benthic species}

Under normal environmental conditions, the aerobic sediment-water interface houses abundant and diverse macrofauna and meiofauna (Wildish et al., 2004). However, hypoxic and HS- conditions are the major causes of death to these species. The death of burrowing macrofauna leads to a rapid decline of aerated water within the upper sediment layer which perpetuates hypoxia and anoxia (Wildish et al., 2004). The general effects of organic enrichment on macrobenthic infauna are well documented. Decreased oxygen and accumulated free $\mathrm{S}$ at the sediment-water interface lead to changes in species abundance and composition. Generally, small-bodied species replace larger sized species and suspension feeders are replaced with deposit feeders that occupy the sediment surface layer (Edgar et al., 2005; Hargrave, 2006). The entire benthic community is transformed; dominated by opportunistic and low oxygen/free $S$ tolerant species. Macrobenthic species may differ in their tolerance to the toxic effects of free $S$; however, there is no apparent effects threshold in the number of taxa with increasing free $\mathrm{S}$ concentrations, and biodiversity is drastically reduced (Hargrave, 2006). Hypoxia could cause endocrine disruption in fish and eliminate populations of sensitive species. Although some 
information exists about the tolerance of aquatic life to hypoxia, information does not exist regarding hypoxia-induced fish mortality because wild fish can swim around it (Karim et al., 2003).

\section{Metals}

Aquaculture operations play a role in releasing metals into the marine environment through treatment of nets with copper-based antifouling paints, leaching by metal cage structures (cadmium, lead, copper and zinc) and feed $(\mathrm{Cu}, \mathrm{Zn}, \mathrm{Fe}, \mathrm{Mg}$ ) (Burridge, 2003; Mendiguchia et al., 2006). Due to its toxicity and ability to bioaccumulate, the concentrations and impacts of copper have been widely studied. In sediments near active net-pens in SWNB, elevated levels of $\mathrm{Cu}$ and $\mathrm{Zn}$ were measured, and most samples exceeded the Interim Sediment Quality Guideline $(18.7 \mathrm{mg} / \mathrm{kg})$ (CCME, 2002; Burridge et al., 1999; Chou et al., 2002). Chou et al. (2002) determined the level of copper, zinc, iron and manganese in fish feed, fish feed constituents and sediments collected near aquaculture sites in SWNB. They found that at hypoxic or anoxic sites the concentration of copper in sediment was over two times greater than the concentration in feed, and zinc was one to two times greater (Chou et al., 2002).

These authors suggested that the elevated copper concentrations may have played a role in observed lethality in amphipod and echinoid fertilization bioassays as well as Microtox® tests (Burridge, 2003). Debruyn et al. (2006) found elevated levels of mercury in demersal rockfishes near salmon farms in coastal B.C. The authors attributed the elevated concentrations to a combination of higher rockfish trophic position and higher mercury levels in prey near farms. They also suggested that 'mercury concentrations in long-lived species such as rockfishes change over a longer time scale than cycles of production and fallowing', thus effects of metals associated with aquaculture may be long-term (Debruyn et al., 2006).

\section{Chemicals}

The information regarding the potential effects of chemicals used in aquaculture is incomplete and full of debate (Burridge, 2004). However, various chemicals used in aquaculture and the resulting effects on the marine environment and its species have been 
identified. A compilation of the literature addressing chemical compounds used in the Canadian aquaculture industry was performed by Burridge (2004) and has been modified and presented in Table 2 . The table only reflects those chemicals which have evidence of potential effects.

Table 2: Environmental effects of chemicals related to aquaculture

\begin{tabular}{|c|c|c|}
\hline Chemical & $\begin{array}{l}\text { Persistence in } \\
\text { Sediment }\end{array}$ & Potential Effects \\
\hline $\begin{array}{l}\text { Oxytetracycline } \\
\text {-Antibiotic }\end{array}$ & $\begin{array}{l}\text { Long periods especially } \\
\text { under anoxic conditions }\end{array}$ & $\begin{array}{l}\text { Uptake by oysters and crabs either in the laboratory or in close } \\
\text { proximity to salmon cage sites (DFO 1997); } \\
\text { Concentration in tissues of rock crabs over US FDA limit } \\
\text { (Capone et al. 1996) } \\
\text { Resistance to oxytetracycline may occur in fish, } \\
\text { non-target organisms and bacterial community } \\
\text { near aquaculture sites (Björklund et al 1991; } \\
\text { Hansen et al. 1993; Hirvelä-Koski et al. 1994) }\end{array}$ \\
\hline $\begin{array}{l}\text { Romet } 30 \\
\text {-Antibiotic }\end{array}$ & - & $\begin{array}{l}\text { Uptake by oysters (Jones 1990; LeBris et al. 1995; Capone et al. } \\
\text { 1996; Cross unpublished data) }\end{array}$ \\
\hline $\begin{array}{l}\text { Teflubenzuron } \\
\text {-Drug; In-feed sea lice } \\
\text { control }\end{array}$ & $\begin{array}{l}\text { High persistence }>6 \text { months } \\
\text { in areas }<100 \mathrm{~m} \text { from } \\
\text { treated cage (SEPA 1999b) }\end{array}$ & $\begin{array}{l}\text { Chitin formation inhibitor; Juvenile lobster mortalities reported } \\
\text { (SEPA 1999b); Mitigation possible by depuration prior to } \\
\text { molting (McHenery 1997; SEPA 1999b) }\end{array}$ \\
\hline $\begin{array}{l}\text { Emamectin benzoate } \\
\text {-Drug; in-feed sea lice } \\
\text { control }\end{array}$ & $\begin{array}{l}\text { Potential to persist (SEPA } \\
\text { 1999b) }\end{array}$ & $\begin{array}{l}\text { Withdrawal period of } 25 \text { days prior to marketing salmon } \\
\text { Chloride ion movement disruptor (Roy et al. 2000); Lethal to } \\
\text { lobsters at } 735 \mu \mathrm{g} / \mathrm{kg} \text { of food (Burridge et al. 2002); Induces } \\
\text { molting in lobsters (Waddy et al. 2000c) }\end{array}$ \\
\hline $\begin{array}{l}\text { Ivermectin } \\
\text {-Drug; In-feed 'offlabel' } \\
\text { treatment for sea lice } \\
\text { control }\end{array}$ & $\begin{array}{l}\text { Could persist for } 28 \text { days } \\
\text { (Wislocki et al. } \\
\text { 1989; Roth et al. 1993) }\end{array}$ & $\begin{array}{l}\text { Withdrawal period of } 180 \text { days prior to marketing; Accumulated } \\
\text { in lobster tissue over } 10 \text { days (Burridge, Haya } \\
\text { and Zitko unpublished data); Chloride ion movement disruptor } \\
\text { (Roy et al. 2000); Cumulative } 80 \% \text { Atlantic salmon } \\
\text { mortality to } 0.2 \mathrm{mg} / \mathrm{kg} \text { for } 27 \text { days (Johnson et al. } 1993 \text { ); } 96-\mathrm{h} \\
\text { LC50 at } 8.5 \mathrm{mg} / \mathrm{kg} \text { food for shrimp; NOECb was } 2.6 \mathrm{mg} / \mathrm{kg} \\
\text { food (Burridge and Haya 1993) }\end{array}$ \\
\hline $\begin{array}{l}\text { Azamethiphos } \\
\text {-Pesticide; bath } \\
\text { treatment for sea lice } \\
\text { control }\end{array}$ & $\begin{array}{l}\text { Not expected to persist } \\
\text { (Tomlin 1997) }\end{array}$ & $\begin{array}{l}\text { Does not accumulate but a neurotoxin, acetylcholinesterase } \\
\text { (AChE) inhibitor, but not cumulative (Roth et al. 1993, } \\
\text { 1996); Mutagenic in vitro (Committee for Veterinary Medicinal } \\
\text { Products 1999; Zitko 2001); } 1 \text {-h bath at } 1 \mathrm{mg} / \mathrm{L} \text { : lethal to } 15 \% \\
\text { salmon after } 24 \mathrm{~h} \text { (Sievers et al. 1995); Larval/adult lobster } 48 \text {-h } \\
\text { LC50 at } 3.57-1.39 \mathrm{ig} / \mathrm{L} / \mathrm{NOEC} 120 \mathrm{~min} \text { at } 1 \mathrm{ig} / \mathrm{L} \text { (Burridge et } \\
\text { al. 1999a, 2000a); Behavioral responses at }>10 \mathrm{ig} / \mathrm{L} \text { (Burridge et } \\
\text { al. 2000a,b) }\end{array}$ \\
\hline $\begin{array}{l}\text { Iodophors } \\
\text {-Disinfects equipment }\end{array}$ & No & $\begin{array}{l}\text { Formulations may contain compounds harmful or toxic to } \\
\text { aquatic biota (Zitko 1994; Madsen et al. 1997; Ashfield et al. } \\
\text { 1998) }\end{array}$ \\
\hline $\begin{array}{l}\text { Chlorine/Hypochlorite } \\
\text {-Disinfectant; net } \\
\text { cleaning }\end{array}$ & - & Toxic to aquatic organisms (Zitko 1994) \\
\hline $\begin{array}{l}\text { Polystyrene beads } \\
\text {-Styrofoam floats }\end{array}$ & $\begin{array}{l}\text { Source of low molecular } \\
\text { weight contaminants (Zitko } \\
\text { 1994) }\end{array}$ & $\begin{array}{l}\text { Benthic fauna altered by altering pore water gas exchange, by } \\
\text { ingestion or by providing habitat for opportunistic organisms } \\
\text { (Goldberg 1997) }\end{array}$ \\
\hline
\end{tabular}

Table modified and taken from Burridge, 2004. All sources found within that document. 
The relevance of chemicals to the N.B. aquaculture industry is presented and discussed further in Chapter 7.

\section{Far-field effects}

The far-field effects of aquaculture are less well understood than the near-field effects and, to date, relatively few studies have addressed these considerations. Studies have, however, pointed to three main effects of mariculture that extend beyond the cage footprint: sedimentation, eutrophication and food-wed changes (Hargrave, 2003). The three main effects are interrelated and are discussed below with that in mind.

\section{Sedimentation and inlet-wide effects of organic enrichment}

Excess feed and faecal matter mainly settles rapidly and accumulates near the netpen; however, there is the potential for horizontal transport and widespread dispersion, particularly in areas with high currents (Hargrave, 2003). Organic material related to finfish aquaculture has been reported at distances of 200-300m (Pohle et al., 2001) and up to $1.2 \mathrm{~km}$ away from farm operations (Hargrave, 2003). Many impacts have been associated with enrichment occurring away from the vicinity of the cage. Examples include: increased growth of Ulva and Enteromorpha (green algae) on intertidal clam flats distant from salmon farms in the Bay of Fundy (Wildish et al., 2004); changes in sediment chemistry; and changes in benthic macrofaunal community structure, abundance and diversity.

Changes in pelagic and benthic metabolism due to finfish farming have the potential to occur on an inlet-wide scale. While most far-field samples show lower benthic fluxes characteristic of other coastal areas in the Bay of Fundy, in SWNB, benthic metabolism modifications have been observed at distances of $>500 \mathrm{~m}$ from netpens where respiration changed from predominantly aerobic to anaerobic respiration at a threshold sulfide concentration between 200 and $300 \mu \mathrm{M} \mathrm{S}^{-}$(Hargrave, 2003). Highest levels of $\mathrm{S}^{-}$, gas exchange and $\mathrm{NH}_{4}{ }^{+}$release occurred at farm sites that had experienced high rates of organic loading, however, elevated respiration and ammonium flux showed 
response did occur away from sites (Hargrave, 2003). These impacts and the changes of community structure are discussed in greater detail in Chapter 5 .

\section{Eutrophication}

In SWNB, areas of intensive aquaculture output waste streams that can alter the natural oxygen and nutrient fluxes of the ecosystem. Environmental impacts that result from these changes include: decreased water transparency due to addition of suspended particulate matter from organic wastes; stimulation of phytoplankton and/or macroalgae growth by increased nutrients; and stress to cultured and native species due to reduced dissolved oxygen levels (Strain \& Hargrave, 2005).

Nutrient concentrations in the Quoddy Region are naturally relatively high due to upwelling of deep, nutrient-rich water. High background levels in conjunction with high mixing and flushing characteristics of the Bay enable much of the nutrient additions to be processed (CCNB, 2004). However, measurements in 1994 and again in 1999/2000 in the Letang Inlet showed high values of several nutrients (CCNB, 2004), and mariculturerelated nutrient fluxes relative to background levels have been found to be extremely elevated in the entire Letang area. Fluxes have also been rising in other areas such as the Deer-Campobello Island region (Strain \& Hargrave, 2005). These fluxes are discussed in greater detail in Chapter 5 .

Although the effects of nutrient loading can be delayed, prevented or even countered by increases in grazer activity, consumption of annual algae by herbivores under normal population conditions, and phytoplankton blooms which have a positive effect on filter feeders, nutrient enrichment can have widespread negative effects. One of the major consequences of nutrient enrichment includes oxygen depletion.

In SWNB, Hargrave (2003) reported that observations had been made of reduced DO levels up to $>500 \mathrm{~m}$ away from operating finfish sites. The values at approximately $500 \mathrm{~m}$ were $60 \%$ saturation; below levels known to be stressful to fish ( $80 \%$ saturation; approximately $7 \mathrm{mg} / \mathrm{l}$ ) (Hargrave, 2003). The extent and implications of reduced DO are discussed in greater detail in Chapter 5.

Nutrient enrichment also has implications on primary productivity. A study relating to the growth of different phytoplankton species under experimental conditions 
in the presence of excretion products from various fish and shellfish showed that 'growth inhibition with exposure to finfish excretory products was thought to be due to dissolved organic components or altered nitrogen:phosphorus ratios' (Hargrave, 2003). In the natural environment, nutrient loadings most frequently result in increased numbers of fast-growing annual algae, resultant changes in community structure, green tides or algal mats in intertidal zones (Robinson et al., 2004), and brief blooming periods of filamentous brown algae (CCNB, 2004). Excess nutrient concentrations can alter foodweb dynamics by shortening the number of trophic levels and reducing species diversity (CCNB, 2004). Proliferation of algae can also be harmful and even toxic to cultured and native species. Harmful algal blooms such as redtide caused by the organism Mesodinium rubrum occurred in Passamaquoddy Bay in late summer of 1998 (Fundy Forum, 2006). In 2000 a study was initiated aimed at investigating the potential far-field impacts of increased eutrophication on soft-shell clams possibly attributed to salmon aquaculture. The study found that between 1984 and 2001 a dramatic increase in algal cover occurred in one of the study areas and generally there were more clams away from algal mats than underneath. Circumstantial evidence suggested that a likely contributor to eutrophication and resulting algal mats were salmon farms (Robinson et al., 2004). In 2003, salmon mortalities occurred during a redtide event in salmon cages off Grand Manan where PSP toxins were detected in the guts of salmon (Martin et al., 2004). Toxic algal blooms have resulted in many shellfish bed closures in the Bay of Fundy region in the past decade or so. The extent of the role that aquaculture played in this bloom is not known; however, increased nutrient inputs from human activities including fish farming is suspected to exacerbate these phenomena. Results from a 20-year monitoring program in the Bay of Fundy indicate an increase in the number of algal species over time (Martin et al., 2004).

\section{Trace metals}

In addition to trace metals being detected immediately below the net-pens, copper and zinc have been detected away from farm sites. Using $\mathrm{Zn}$ and $\mathrm{Cu}$ as tracers for farm waste deposition, Yeats et al. (2004) found elevated levels of $\mathrm{Cu}$ and $\mathrm{Zn}$ in sediment remote from salmon cages in depositional areas in SWNB and in the Broughton Archipelago. The authors found that deposition occurred in intertidal sediments 
associated with farms in the Letang area and near a site in Maces Bay that had only been in operation for a few months. Suspended particulate matter in Lime Kiln Bay also showed elevated concentrations of $\mathrm{Zn}$ and $\mathrm{Cu}$ (Yeats et al., 2004). It was determined that changes in $\mathrm{Zn}$ and $\mathrm{Cu}$ levels co-vary with changes in sediment flocculation characteristics associated with farm waste, and suspended particulate matter is a vector for transport of farm wastes to depositional sites (Yeats et al., 2004; Milligan \& Law, 2004).

\section{Antibiotic resistance}

As discussed above, antibiotics such as oxytetracycline are used in the mariculture industry to control parasitic infestations. These antibiotics have the potential for far-field impacts by inducing drug resistance in natural microbial populations on an inlet-wide scale (Hargrave, 2003). Oxytetracycline, added to marine sediments, was found to be traceable up to 18 months and the percentage of resistant bacteria ${ }^{1}$ after an initial 10-day treatment was $>100 \%$ for all sediments tested (Hargarve, 2003). Oxytetracycline was also found to be detectable for periods of $>1$ year in fish farm sediments in Finland and Norway, with high levels of bacterial resistance in sediments and wild fish intestines (Hargrave, 2003). Observations of OTC resistance with minimum inhibitory concentrations up to $160 \mu \mathrm{g}$ OTC/ml have been found up to $100 \mathrm{~m}$ away from net-pens in SWNB (Friars \& Armstrong, 2002 in Hargrave, 2003). Further research is required to determine the likelihood, extent and effects of antibiotic resistance in the intensive mariculture area of SWNB.

\section{Displacement of other activities}

Although the salmon aquaculture industry introduced new opportunity for fishermen of exhausted fisheries, it displaced other activities found in SWNB. Fishermen of other traditional fisheries such as lobster, scallops and herring are forced to compete for harvesting areas and although siting considers traditional fisheries in the area, many fishermen feel that their harvests have been negatively impacted by expansion of the aquaculture industry (DFO, 2003). Areas densely populated with farms also pose an obstacle for navigation, which is why siting of new farms requires approval under the

\footnotetext{
${ }^{1}$ Percentage of resistant bacteria $=$ ratio of numbers growing on substrate $+/$ - OTC (Hargrave, 2003).
} 
Navigable Waters Protection Act. Aesthetics have also been an issue for tourism-related activities, home owners and other users of the marine environment, as farm-related debris is washed into shore.

\section{Cumulative and Regional Effects}

Although there have been few studies conducted on the cumulative and regional impacts of finfish aquaculture, and in particular, in SWNB, evidence does exist to support the presence of these types of environmental effects. These effects include: benthic habitat fragmentation, skewed fluxes of dissolved oxygen, nitrogen, phosphorous and carbon due to aquaculture, impacts on marine species by acoustic deterrent devices, the spread of disease, impacts of escaped cultured fish on wild stocks, and disruption of critical fish habitat and endangered species habitat. Evidence supporting potential and existing cumulative and regional effects is presented and discussed in Chapter 5 to justify the need for consideration in siting decisions. Some information on environmental recovery is also given concerning the impacts of organic enrichment. 


\section{Chapter 3: LITERATURE REVIEW OF IMPACT MODELS}

In an attempt to predict and quantify the environmental effects of marine finfish aquaculture on the aquatic environment, various models have been developed over the last 20 years. Models can provide a detailed understanding of the physical environment and predict environmental changes that may otherwise not be observed (Sturley \& Bowen, 1996). In general terms, they are simplifications of the natural systems they are meant to describe (Nordvarg \& Håkanson, 2002), and offer a relatively fast glimpse into natural processes that would otherwise be observed over extremely lengthy time frames.

In light of the shortfalls of judgement-based impact prediction, it became evident that practical management required the use of predictive mathematical models if adverse impacts were going to be lowered and sustainable farming operations were going to be achieved (Nardvarg \& Håkanson, 2002; Dudley et al., 2002). Thus, to support policy and integrated coastal planning/management, regulatory agencies have been moving toward incorporating simulation and predictive models into the decision process of environmental impact assessment (EIA) and other environmental management tools (Sturley \& Bowen, 1996; Stigebrandt et al., 2004; Henderson et al., 2001; Perez et al., 2002; Hargrave et al., nd). Aquaculture-related models have predominantly been developed by experts in more wealthy fish farming regions such as Northern Europe, United States and Canada (Henderson et al., 2001); however, other countries producing for the global market have also began to develop and adopt modelling techniques (Karim et al., 2003; Chau, 2005; Islam, 2005). Models have been developed for general marine or aquatic application and for specific geographic regions such as the marine environment of Southwestern New Brunswick's Bay of Fundy. The substantial body of literature outlining modelling techniques developed for mariculture is presented below along with its current application in regulation, focusing on finfish aquaculture in the region of SWNB.

Due to the complex nature of the marine environment, models take on many forms and address or incorporate a variety of environmental components. Some models are very simple and one-dimensional, focussing on one environmental component (eg. patterns of organic sediment enrichment), and others are more complex, comprehensive and attempt to predict many outcomes, outputs or impacts (eg. organic transport, 
deposition, enrichment, and benthic community distributional impacts). Whether complex or simple, models relating to aquaculture attempt to address one or more nearfield (site-specific) or far-field (inlet or bay-wide) effect(s) that alter ambient conditions. The inherent weakness of simulation modelling is that in order for a model to be applicable it must be simple enough to be operable and time and cost effective while not so simple that it does not adequately represent the environment it intends to simulate. Oversimplification creates an underestimation of contributing factors; however, models that attempt to incorporate all relevant components are generally cumbersome, highly complex and difficult to employ. As a result, most models attempt to address one environmental component as diligently as possible but all environmental components are not considered within any one model. This paradox has prompted the introduction and development of more blanket approaches to considering and incorporating all relevant environmental components into one system.

Many generalized models aid in both development and application of fish farm predictive models. These include, but are not limited to:

- ocean circulation models or geophysical fluid dynamic models (eg. CANDIE) which provide predictions of temporal and spatial evolution of three-dimensional currents and water property variables, provide the basis for linking physical models with marine ecological processes, and provide the far-field information required for near-field models (Sheng et al., 1998; Wildish et al., 2004);

- hydrodynamic models which provide predictions of the effect of fixed structures on flow fields through the consideration of the system's geometry of the system, and provide velocity and turbulence fields necessary to predict sediment movement (Wildish et al., 2004);

- biogeochemical models which provide information regarding pelagic and benthic geochemistry, interaction and trophic status (Fasham, 1993;Soetaert et al., 2000); and,

- sediment transport models which predict the time period for the spatial distribution of suspended sediment and particulate matter and the exchanges of this matter between the water column and benthos (van Rijn et al., 2001; Wildish et al., 2004). Sediment transport models, in particular, have achieved a high level of sophistication and are able to incorporate key factors such as water mixing, mechanistic descriptions of deposition and resuspension and varying particle sizes and cohesiveness, etc. (Wildish et al., 2004) affecting settling and transport of particulate matter. 
As a primary consequence of finfish aquaculture, the discharge of waste and its resultant dispersion, benthic enrichment and trophic alterations have been widely modelled. As previously discussed, there are many components to waste discharge including organic matter (from faecal matter and uneaten feed), nutrients (nitrogen and phosphorous) and chemicals associated with in-feed treatments. There is a substantial body of literature outlining models that address one or more of these components in a site-specific or near-field context.

\section{Organic dispersion, deposition and enrichment}

Silvert (1992) reviewed many of the early attempts to model dispersion and deposition of waste material on the benthic environment. Most of the models discussed are numerical simulation models based on factors affecting particle settlement such as water depth, time to reach the bottom, current speed, consideration of tidally-varying currents. An overview of earlier modelling works addressing benthic impacts was presented by Silvert and Sowles (1996) who pointed out that further research is required to address degradation and recovery of areas under cages. Findlay and Watling (1997) proposed a model based on the balance between benthic oxygen supply and oxygen demand given the rate of organic deposition (Hargrave, 2003). Stucchi et al. (2002) presented an analytical near-field depositional model designed to quantitatively determine the effects on the waste footprint (of a single net-pen farm configuration) resulting from changing the depth under the net-pens taking into account the standard deviations of the depth-averaged velocity (currents). This diagnostic model has also been used to examine the changes to the farm footprint that result from orienting a two by four linear grouping of net-pens perpendicular to and parallel to the principal current direction.

Dudley et al. (2000) advanced the field through inclusion of an improved resuspension component in their Aquaculture Waste Transport Simulator (AWATS) package. While both hydrodynamic and transport models are included in AWATS, through improvements in estimates for the critical resuspension velocity of net-pen wastes, the particle-tracking waste transport model simulates the transport of finfish aquaculture wastes through first-order estimates of the physical dispersion. Application 
of this package of models to sites in coastal Maine proved its applicability to the regulatory process; however, the model requires field data for flow calibration, in some cases modelled data did not match field data, and some failure in model output left room for package improvement. Cromey et al. (2002) also incorporated resuspension into their computer particle tracking model, DEPOMOD, which predicts the solids accumulation on the seabed and consequential changes in the benthic community associated with the fish farm. The model integrates five modules to produce relationships between benthic descriptors and solids accumulation that enables prediction of the potential level of benthic community impact of a farm throughout the growing cycle, after an increase in fish capacity, and during a site suitability assessment. DEPOMOD is one of the few models to have undergone rigorous validation (Perez et al., 2002). Carroll et al. (2003) adapted the DEPOMOD model for use in the Mediterranean, calling it MERAMOD. The model incorporates detailed bathymetric, hydrographic and benthic data sets to enable quantification of benthic effects associated with predicted deposition of waste from seabream and seabass farms. In addition, MERAMOD includes distinctive Mediterranean characteristics through a wild fish module, which considers waste food and faeces from the farmed fish removed by wild fish, and a particle tracking component specific to seabass and seabream.

\section{Nutrient additions}

Silvert (1994) greatly contributed to the modelling field with his fish growth model developed for salmon aquaculture in SWNB. The model was used to estimate nutrient release and oxygen demand from farms in the Letang Inlet for 1992. The model is based on a temperature-corrected allometric expression for growth where Silvert estimated the growth rate of a $50 \mathrm{~g}$ smolt at $6^{\circ} \mathrm{C}$. Strain and Hargrave (2005) built on the growth parameters of Silvert's model and updated it using the SWNB seasonal temperatures, smolt size and grow-out period, in addition to a doubling time for smolt that matched the harvest weight reported for farms in SWNB. They named the model the Q10. Strain and Hargrave (2005) also delineated a more widely-used model that predicts salmonid growth in the SWNB salmon industry called the thermal-unit growth coefficient (TGC model). The authors tuned this model using SWNB temperature data, smolt size 
and grow-out period and adjusted the TGC to a value of $0.00265 \mathrm{~g} 1 / 3{ }^{\circ} \mathrm{C}-1 / \mathrm{d}$ to correctly predict the harvest weight of salmon in SWNB (Strain \& Hargrave, 2005). After the daily growth rates predicted by the two models were compared for the full grow-out period in SWNB, Strain and Hargrave (2005) subtracted C, N and P content stored in the fish, estimated using the fish growth model derived from the nutrient content in feed, to predict $\mathrm{C}, \mathrm{N}$ and $\mathrm{P}$ waste discharges. Mass balance equations were employed and related to the feed conversion ratio (FCR). The authors included the carbon consumed by fish respiration in addition to the organic carbon in faeces and uneaten feed in the waste $C$ discharge component. Dissolved waste feed and faeces and $\mathrm{N}$ and $\mathrm{P}$ in uneaten feed are considered in $\mathrm{N}$ and $\mathrm{P}$ excretions. The respiration demand of oxygen from the respiration component of $\mathrm{C}$ was then determined.

Nordvarg and Håkanson (2002) constructed various mass balance models for phosphorous aimed to predict the increase in surface water total concentrations. These comprehensive models incorporated resuspension and other contributing variables and provided an output to be used in two new regression models geared to predict the: a) chlorophyll- $\alpha$ concentrations; and b) Secchi depth caused by fish emissions in order to identify emission-sensitive coastal areas in the Åland archipelago, Baltic Sea. The modelling task was focussed on phosphorous because it is the limiting nutrient in this coastal area. This work, aimed at making models practically useful in licensing, demonstrated the importance of estimating the environmental response to case-specific loads and locations; however, the data used for the critical model test originated from this location and thus restricts widespread applicability

Islam (2005) proposed a model for estimating the nutrient $(\mathrm{N}$ and $\mathrm{P}$ ) budget in a hypothetical cage aquaculture farm with values for feed loss, feed conversion ratio (FCR) and nutrient content in feed and fish. The model predicted the amount of nutrient produced and released to the environment per ton of fish (kg/ton fish). An FCR-based regression model for predicting nutrient loadings for a given diet was also proposed. Papatryphon et al. (2005) presented a nutrient-balance model that based N, P and total solids emissions on the difference between the amount of nutrient ingested through feed and that laid down as gain. Nutrient digestibility and whole-body composition coefficients were used to distinguish between solid and dissolved emissions. The model 
undertook a validation-type process utilizing data and measurements of variable quality obtained from commercial fish farms and plots of observed or model-predicted values and residual plots were used to analyze the data (Papatryphon et al., 2005). Specific criteria relating to measurement uncertainty were used to test model adequacy with regards to its purpose. Although it was not a classic validation, because nutrient-balance principles have been previously validated in controlled experiments, the validation was deemed suitable (Papatryphon et al., 2005).

\section{Water quality}

Gilligrand and Turrell (1997) reviewed three models used to provide a first order estimate of the relative impact on water quality. The first model, an equilibrium concentration enhancement model (ECE), estimated dissolved amoniacal nitrogen; the second model calculated the amount of dichlorvos that could be used over $1 \mathrm{yr}$ such that the annual mean Environmental Quality Standards are not exceeded; and the third model was an advection-diffusion model that simulated a typical treatment of the fish farms within a sea loch and estimates resulting dichlorvos concentrations. Advection was simulated using a particle tracking approach and diffusion was simulated using a twodimensional Gaussian equation describing the concentration field from each of the tracked releases. The model tracked the treatment chemical from each site as it spread and progressed seawards.

Wu et al. (1999) delineated two deterministic models that simulated hydrographic and ambient water quality conditions within a sub-tropical fish culture site in Hong Kong, China, where trash-fish were used as feed. Tidal flows and salt transport were considered in the hydrodynamic model and results from this model were input into the water quality model, run to accommodate specified waste loadings. The model applied mass balance equations for each substance associated with aquaculture operation wastes (BOD, organic

$\mathrm{N}$, ammonical nitrogen, nitrate nitrogen, DO, suspecded solids, salinity and temperature). The simulation predicted the extent of pollution and area affected under various fish stocking and waste loading conditions. Historical and field data were used in model calibration and validation. 


\section{Spread of disease and chemicals}

The DEPOMOD model (Cromey et al., 2000) was modified to consider in-feed lice treatments, accounting for the varying half-lives of the medicines, their persistence in sediments, resuspension along the sea bed and the differences in digestive loss through the fish itself. Greenberg et al (2005) provided a means to effectively model the nearshore hydrodynamics of intertidal drying areas, an important embayment attribute often omitted from circulation models. Models without the capacity to simulate dry areas may have errors in the area of the wet domain and/or volume of water within the domain (Greenberg et al., 2005). Through the inclusion of an algorithm in a comprehensive, 3D finite element model, QUODDY_dry was developed and used in particle tracking to examine the potential spread of disease (ISA), estimate tidal excursions around farms, and determine minimum currents for adequate oxygen supply to farms, relating currents to sedimentation regimes. This model, developed for the Quoddy region of SWNB, has extremely important implications for high density aquaculture areas such as Lime Kiln Bay and Back Bay, two areas separated by a shallow area that dries at low tide. The authors suggest that models without the capability to simulate the drying effects of intertidal areas may produce errors relating to the wet domain or the volume of water within the domain.

\section{Geographic Information Systems}

The use of Geographic Information Systems (GIS) as a modelling tool has become increasingly popular in recent years. GIS technology has been used in aquaculture for 15 years (Cromey et al., 2002; Nath et al., 2000; Perez et al., 2003). Due to the spatial component of aquaculture data, Wright and Bartlett (2000) suggested that GIS have the potential to contribute to coastal management in a number of ways. In the case of aquaculture, the use of GIS not only provides a visual inventory of the physical, biological and economic characteristics of the environment, it also allows rational management without complex and time-consuming manipulations. Despite these benefits, the use of GIS in aquaculture has been modest and reported in literature by few authors (Perez et al., 2005). 
Perez et al. (2002) improved upon an existing predictive particulate waste distribution model for farmed Atlantic salmon. The improved model incorporated a GIS and a spreadsheet using existing distribution algorithms and it was functioned to calculate feed loading for all the cages within an area. The model then spread the input load over the whole cage area and simulated post-depositional distribution of the carbon. The model used approximate estimates of feed and faecal waste derived from dietary considerations (mass balance model) and separate, unique settling velocities for waste feed and faecal particles. The model incorporated values of current speed and direction recorded over spring and neap tides. Perez et al. (2003a) took three submodels (distance to beaches, nautical sports, and viewshed) and combined them to determine cage culture sites in areas that can coexist with the tourism industry in Tenerife, Canary Islands.

Perez et al. (2003b) used a GIS to create a spatial water quality database consisting of variables that were found to affect seabream and seabass mariculture development in Tenerife. These variables were grouped in a logical model and combined to generate outputs showing suitable siting areas. The model proved especially sensitive to sea temperature and suspended solids. Site suitability studies using GIS-based models, remote sensing, and GPS were also conducted for offshore (exposed, floating cages) marine culture of seabream and seabass (Perez et al., 2005), and brackish water aquaculture development in southwestern Bangladesh (Salam et al., 2003).

\section{Holding capacity (stocking density) and carrying capacity models}

With a growing knowledge and understanding of the dynamics of fish farm waste in the vicinity of the site, and consequential environmental impacts, models have also been developed to approximate the holding capacity of each individual aquaculture site. Holding capacity and carrying capacity are often used interchangeably; however, for the purpose of this paper, holding capacity will refer to the stocking density or capacity of a farm site and carrying capacity refers to the maximum production level of an area or water body. Lee et al. (2003) emphasized the relationship between sustainable management of mariculture, proper siting of fish farms, and stocking density control. The authors suggested that these factors are all related to the carrying capacity of the water body concerned, which is predominantly regulated by its flushing characteristics. 
Telfour and Robinson (2003) presented four questions that must be asked in all capacity models. These include:

- What determines the productivity of the environment

- What do the farmed organisms consume/produce in terms of food/waste

- How does the environment respond to waste loadings

- How much change is permissible (Telfour \& Robinson, 2003)

DFO (2003) suggested an optimum holding capacity may be defined as 'one that leads to fluxes of oxygen, nitrogen and carbon through salmon that are within the natural ranges of variability and do not add significantly (for example $<10 \%$ ) to natural fluxes'. The optimum was determined through the comparison of fluxes from salmon in various Coastal Management Regions with fluxes due to natural and anthropogenic sources and sinks for these elements.

Lee et al. (2003) developed a 3D hydrodynamic model and coupled it with a water quality model. The tidal flushing time was determined from robust $3 \mathrm{D}$ hydrodynamic and mass transport models. Due to the complexity of the water movement between the embayment and open water environment, the authors defined both 'local' and 'system-wide' flushing times to represent the effectiveness of the mass exchange with the surrounding water body and the open sea respectively. In an attempt to address the response of the water column and benthic layer to pollutant releases, the water quality model was used to simulate the sediment-water-pollutant interaction. The holding capacity was predicted in terms of key water quality parameters (chlorophyll-a, DO, organic $\mathrm{N}$, and potential lowest DO on a day of negligible photosynthetic production) with values supported by field data (Lee et al., 2003).

Stigebrandt et al. (2004) developed a mathematical model system as part of the Modelling-Ongrowing fish farms-Monitoring (MOM) management system introduced by Ervik et al. (1997). The model was designed to estimate the holding capacity of sites for fish farming, expressed in terms of maximum fish production per month, and considered three environmental requirements including: no disappearance of benthic fauna due to organic build up; maintenance of high water quality at the farm; and maintenance of high water quality surrounding the farm. The holding capacity is determined by the lowest of all three fulfilled requirements. The model is comprised of four sub-models (fish (adapted for Atlantic salmon), dispersion, benthic and water quality in fish cages) that are linked 
through a process of output parameters of one sub-model becoming input parameters of another. The model was also developed in order to accommodate the use of chemicals and medical treatments and their consequential effects. The complete system estimates environmental effects on both site and regional scales, which will be discussed in a following section. This work recognized the importance of both model simulations and monitoring in prevention and regulation of environmental impacts of aquaculture.

Silvert and Sowles (1996) provided a compilation of various modelling approaches used to assess the holding capacity of a fish-farm with consideration given to its application to full inlets. The paper presented the holding capacities of 20 inlets in SWNB derived from: a) a model looking only at the tidal exchange assuming complete mixing inside and outside the inlet; b) a model incorporating freshwater flushing into the flushing rate; and c) a different form of the tidal flushing model but assuming total mixing.

Earlier works (Silvert \& Sowles, 1996) prompted modelling aimed specifically at estimating the holding capacity of farmed-fish in a body of water or a coastal area; a modelling method that has become increasingly prevalent in the literature. Nordvarg and Håkanson (2002) developed load diagrams along with their models to roughly estimate an acceptable amount of fish production in a specific coastal area. Telfour and Robinson (2003) used two methods of determining the carrying capacity for aquaculture in Mulroy Bay Co. Donegal, Ireland. The first model used food availability to estimate the sustainability of mussel and shellfish farming within the bay, and the second estimated oxygen demand of the system from physico-chemical processes related to both natural and anthropogenic nutrient inputs.

Sumagaysay-Chavoso et al. (2004) estimated the environmental capacity in terms of the maximum amount of dissolved inorganic nitrogen (DIN) or dissolved inorganic phosphate (DIP) input to the system, largely from milkfish culture, using regression analysis and nutrient criteria (nitrite, nitrate, and phosphate). The nutrient and salt budgets for the entire estuary were determined using the one-box model by LOICZ-IGBP (Sumagaysay-Chavoso et al. 2004).

The work of Page (2003) described a simple model for estimating the impact of the existing Approved Production Limit (APL) and Estimated Site Potential (ESP) on DO 
levels in Seal Cove, Grand Manan Island, SWNB. The rate of DO utilization was determined and compared to the cove's flushing time to yield a ratio that shows whether DO is being utilized faster than the water body can replenish it. This ratio provided insight into a site's maximum carrying capacity by considering the system's ability to maintain DO at non-critical levels.

Overall, with exception of a few, most models presented above are generally casespecific, address one or few environmental aspects of aquaculture outputs and address impacts in close proximity to the aquaculture operation. These models aid in predicting potential near-field impacts of proposed farms, determining areas suitable for finfish rearing based on features of the proposed lease area and determining holding capacities for sites and coves.

\section{Modelling far-field and regional environmental effects}

Most predictive modelling relating to aquaculture focuses on near-field effects. With acknowledgment of the potential regional effects of intensive aquaculture waste, in conjunction with the rising stress on the marine environment associated with natural and other anthropogenic sources of nutrient loadings, endeavours have begun to shift towards development of far-field or regionally-oriented models.

Strain et al. (1995) developed a model suited to predict impacts solely on a regional scale as opposed to on an individual fish farm basis. The simple pragmatic model was designed to evaluate initial inputs of waste from traditional fishing, salmonid mariculture, industrial operations and municipal sewage disposal within the Letang inlet (Bay of Fundy) and compared estimated annual BOD from salmon aquaculture with the other natural (background) and industrial sources. The concentrations of C, N, P and BOD due to anthropogenic inputs for each box were calculated for both low and high tide assuming total input equalled total output over the tidal cycle and the water was completely mixed. The predictive tool was used to show that inputs of carbon, N, P and BOD from finfish aquaculture mirrored or exceeded estimated phytoplankton production.

Strain (2003) updated the fish growth model of Silvert (1994) to assess more broad-scale impacts of nutrient discharges and oxygen demand from the salmon aquaculture industry in SWNB (reflecting total licensed capacity of the industry in 2002). 
This was carried out by examining the total waste outputs for entire CMRs based on APLs. These estimates were set against natural levels found in CMRs of the SWNB region in order to determine the likelihood for far-field effects. Islam (2005) used a similar type of model to calculate the annual global loading and release of $\mathrm{N}$ and $\mathrm{P}$ from cage aquaculture to the coastal and marine environment. These outputs were used to suggest areas of potential impacts of nutrient loading on the ecosystem and critical points for nutrient output minimization.

\section{Regional water quality and eutrophication}

The impacts of nutrient additions to the aquatic environment have been modelled relating to regional water quality and eutrophication. Gillibrand and Turrell (1997) used a simple water quality model to highlight lochs most at risk of over-development by simulating eutrophic impacts of nutrient and chemical releases in whole sea lochs in Scotland. Aure and Stigebrandt (1990) also presented a regional water quality model in association with the previously discussed MOM model which estimates the potential effects on the surrounding inshore areas such as bays, archipelagos and fjords (Stigebrandt et al., 2004). Doglioli et al. (2004) developed a 3D numerical model by coupling a three-dimensional Lagrangian model, Lagrangian Assessment for Marine Pollution 3 Dimensional model (LAMP3D), into the hydrodynamical model, the Princeton Ocean Model (POM) to pragmatically describe both the 3D hydrodynamic flows and the 3D dispersion phenomena of pollutants (dissolved nutrients, faecal matter and feed wastes) coming from a marine fish cage in the Mediterranean Sea. The model estimates regional dispersion patterns of $\mathrm{N}, \mathrm{P}$ and organic $\mathrm{C}$ using a 3D mesoscale grid and compares them to in situ experimental data. Although this model predicts regional dispersion, it only considers releases from a single farm site and is likely case-specific due to the wind-driven and exposed system found of the Mediterranean site which is not characteristic of more sheltered bay characteristics.

Eutrophication can lead to hypoxic conditions that can, among other things, create stress for reared fish (Karim et al., 2003). Karim et al. (2003) developed the first fish preference and mortality model relating to hypoxia. The model was developed for and applied to Hakata Bay where hypoxic water occurs every summer. A fish preference and 
mortality sub-module was integrated within a hydrothermal and eutrophication model (CHEM) to predict behavioural characteristics and fatalities of certain species under hypoxic conditions.

Chau (2005) also developed a multi-dimensional (an unsteady three-dimensional finite difference numerical) model for eutrophication dynamics in the coastal waters of Tolo harbour, Hong Kong. The authors employed a numerically-generated, boundaryfitted, orthogonal curvilinear grid system and grid technique aimed at modelling the transport and interaction of nine water quality constituents (carbonaceous BOD, dissolved and particulate $\mathrm{N}$ and $\mathrm{P}, \mathrm{DO}, \mathrm{NH}_{4}, \mathrm{NO}_{2}$ and $\mathrm{NO}_{3}, \mathrm{PO}_{4}$, phytoplankton and zooplankton). The model is able to simulate the interactions amongst all the constituents, the eutrophication process and the featured bottom water anoxic condition in the harbour during summer months. This was successfully completed by means of the coupled aspect of the model that has common computational grid and time steps for both the hydrodynamic and water quality processes. This and other regional models are generally more complex and incorporate more variables than the models simulating impacts in the near-field; however, many of these models are still very specialized.

\section{Modelling cumulative environmental effects of aquaculture}

Although it was recognized in the early 1990s that simulation modelling proves to be the only CEA method that adequately addresses all CEA evaluation criteria (Smit \& Spaling, 1995)(See Table 3 below), studies that present or expound a modelling tool designed to predict the cumulative environmental impacts of aquaculture are scarce. The work of Strain et al. (1995) and Strain (2003) presented above addressed some cumulative effects; however, the models were not specified to do so. One attempt was made by Chou et al. (2004) who quantified the cumulative impact from aquaculture in SWNB using sediment metals, organic $\mathrm{C}$ and $<63 \mu \mathrm{m}$ particles. After selecting factors to normalize sediment chemistry in and around the cage, a statistical model to predict the environmental monitoring program conditions of anoxic, hypoxic, or normal in relation to culture activities was employed. This model enables simplified predictions of site conditions and aquaculture waste-related degradation using chemical constituent measurements. The trends predicted by the model are useful for detecting and assessing 
the cumulative effects of aquaculture wastes discharged to the marine environment. The authors suggest that use of the EMP alone for assessing the aquaculture site could result in misclassifications in differentiating hypoxia and anoxia at some sites.

Table 3: Summary of Evaluation of Selected Cumulative Environmental Assessment Methods

\begin{tabular}{|l|l|l|l|l|l|l|}
\hline \multicolumn{7}{|c|}{ Evaluation Criteria } \\
\hline Method & $\begin{array}{l}\text { Temporal } \\
\text { accumulation }\end{array}$ & $\begin{array}{l}\text { Spatial } \\
\text { accumulation }\end{array}$ & $\begin{array}{l}\text { Type of } \\
\text { perturbation }\end{array}$ & $\begin{array}{l}\text { Process of } \\
\text { accumulation }\end{array}$ & $\begin{array}{l}\text { Functional } \\
\text { change }\end{array}$ & $\begin{array}{l}\text { Structural } \\
\text { change }\end{array}$ \\
\hline GIS & S & S & S & X & P & S \\
\hline Loop analysis & $\mathbf{X}$ & $\mathbf{X}$ & $\mathbf{S}$ & $\mathbf{S}$ & $\mathbf{X}$ & $\mathbf{X}$ \\
\hline $\begin{array}{l}\text { Landscape } \\
\text { analysis }\end{array}$ & $\mathbf{S}$ & $\mathbf{S}$ & $\mathbf{S}$ & $\mathbf{S}$ & $\mathbf{P}$ & $\mathbf{S}$ \\
\hline $\begin{array}{l}\text { Argonne } \\
\text { multiple matrix }\end{array}$ & $\mathbf{X}$ & $\mathbf{P}$ & $\mathbf{S}$ & $\mathbf{S}$ & $\mathbf{X}$ & $\mathbf{X}$ \\
\hline $\begin{array}{l}\text { Simulation } \\
\text { modelling }\end{array}$ & $\mathbf{S}$ & $\mathbf{S}$ & $\mathbf{S}$ & $\mathbf{S}$ & $\mathbf{S}$ & $\mathbf{S}$ \\
\hline $\begin{array}{l}\text { Cause-effect } \\
\text { diagramming }\end{array}$ & $\mathbf{X}$ & $\mathbf{X}$ & $\mathbf{S}$ & $\mathbf{S}$ & $\mathbf{X}$ & $\mathbf{X}$ \\
\hline $\begin{array}{l}\text { Multi-attribute } \\
\text { tradeoff analysis }\end{array}$ & $\mathbf{X}$ & $\mathbf{P}$ & $\mathbf{S}$ & $\mathbf{X}$ & $\mathbf{X}$ & $\mathbf{X}$ \\
\hline $\begin{array}{l}\text { Linear } \\
\text { programming }\end{array}$ & $\mathbf{P}$ & $\mathbf{S}$ & $\mathbf{S}$ & $\mathbf{P}$ & $\mathbf{P}$ & $\mathbf{S}$ \\
\hline $\begin{array}{l}\text { Land } \\
\text { disturbance } \\
\text { target }\end{array}$ & $\mathbf{S}$ & $\mathbf{S}$ & $\mathbf{P}$ & $\mathbf{P}$ & $\mathbf{S}$ & $\mathbf{S}$ \\
\hline $\begin{array}{l}\text { CEA Reference } \\
\text { Guide }\end{array}$ & $\mathbf{S}$ & $\mathbf{S}$ & $\mathbf{S}$ & $\mathbf{P}$ & $\mathbf{S}$ & $\mathbf{S}$ \\
\hline S, satisfactorily mets criterion; X, does not meet criterion; P, partially meets criterion \\
\hline
\end{tabular}

Source: Smit \& Spaling, 1995

\section{Practical applications in EIA, siting and management of mariculture}

While many models were developed with the intent of being used in site decisions, regulation and management, few models are used directly for these tasks in the global aquaculture industry (Henderson et al., 2001). Modelling has been incorporated into regulation, licensing and EIA through setting holding capacity (biomass/production levels), licensing of medicines, EIAs of site applications through prediction of waste outputs and impacts, site management (growth model predictions) and environmental monitoring (setting model outputs against EQSs (Henderson et al., 2001).

Henderson et al. (2001) presents an overview of modelling being used in aquaculture regulation. The results of his study are compiled below and represent work until and including the year 2001. 
Table 4: Model application in aquaculture regulation around the world

\begin{tabular}{|c|c|c|c|}
\hline & \multicolumn{3}{|c|}{ Impact modelled } \\
\hline Country & Nutrients & Organic & Medicines \\
\hline Norway & $\begin{array}{l}\text {-possible use of simple water quality } \\
\text { classification based on DO levels as part of } \\
\text { a box model } \\
\text {-for reg of salmon farms }\end{array}$ & $\begin{array}{l}\text {-MOM impact models predicting spreading of } \\
\text { faeces and particulates under marine cage } \\
\text { farms, nutrient release, and oxygen } \\
\text { consumption; not in routine use }\end{array}$ & - \\
\hline Sweden & $\begin{array}{l}\text {-models for potential use by regulators are } \\
\text { under development but not employed }\end{array}$ & - & - \\
\hline $\begin{array}{l}\text { The } \\
\text { Netherlands }\end{array}$ & $\begin{array}{l}\text {-an ecosystem model developed for the } \\
\text { Oosterschelde ecosystem has been used to } \\
\text { simulate the impact of nutrient input } \\
\text { reduction by shellfish, to the Oosterschelde } \\
\text { estuary. }\end{array}$ & - & - \\
\hline Scotland & $\begin{array}{l}\text {-use of simple box models to predict cage } \\
\text { farm impacts on nutrient levels } \\
\text {-used by regulators and consultants during } \\
\text { EIA and licensing process. }\end{array}$ & $\begin{array}{l}\text {-OPENSED, a particle tracking model, is in } \\
\text { use by the Scottish Executive } \\
\text { Rural Affairs Department for EIA assessment. } \\
\text {-DEPOMOD, predicts deposition of organic } \\
\text { and medicinal waste and benthic biological } \\
\text { impacts, in terms of an 'infaunal trophic index' } \\
\text { will be adopted by the Scottish Environment } \\
\text { Protection Agency (SEPA) to aid in } \\
\text { establishing appropriate biomass limits and } \\
\text { impact zones at fish farm sites. } \\
\text {-Alongside the use of DEPOMOD, } \\
\text { hydrographic data (mean current speed and } \\
\text { direction, current residuals plus period of still } \\
\text { water) and benthic infaunal data are used in a } \\
\text { simple relationship 'decision guidance model' } \\
\text { by SEPA }\end{array}$ & $\begin{array}{l}\text { - Models of medicines } \\
\text { dispersion are already } \\
\text { available for semi- } \\
\text { enclosed Scottish sea } \\
\text { lochs in order to } \\
\text { regulate the use of sea- } \\
\text { lice treatment } \\
\text { chemicals } \\
\text {-DEPOMOD is used } \\
\text { in the regulation of in- } \\
\text { feed medicines and } \\
\text { considers differing } \\
\text { half lives of the } \\
\text { medicines, persistence } \\
\text { in sediments, } \\
\text { resuspension along the } \\
\text { sea bed and the } \\
\text { digestive loss through } \\
\text { the fish itself. }\end{array}$ \\
\hline Ireland & $\begin{array}{l}-2 \text { and 3-D hydrodynamic models (DIVAST } \\
\text { and TRIVAST) used to study plumes of } \\
\text { nutrients from cages and nutrient } \\
\text { enhancement } \\
\text {-used by industry consultants for EISs as } \\
\text { part of the application process. }\end{array}$ & $\begin{array}{l}\text {-DIVAST predicts sediment deposition below } \\
\text { cages, although the model has limitations in } \\
\text { terms of settlement rates of faeces and feed. } \\
\text {-benthic quality criteria are being developed }\end{array}$ & $\begin{array}{l}\text {-DIVAST predicts } \\
\text { soluble and particulate } \\
\text { medicine transport } \\
\text { from cages. }\end{array}$ \\
\hline France & $\begin{array}{l}\text {-models recommended as a regulatory tool } \\
\text { within the EIS to obtain an exploitation } \\
\text { permit. } \\
\text {-mathematical models used describing the } \\
\text { hydrodynamics in a tidal environment (i.e. } \\
\text { areas of the European continental shelf) and } \\
\text { are used to estimate soluble and settleable } \\
\text { loadings, their concentration and deposition } \\
\text {-models run by applicants. } \\
\text {-linear model predicting dissolved organic } \\
\text { nitrogen from a recirculating system by sea } \\
\text { bass is in use and for open systems } \\
\text {-carrying capacity models predicting } \\
\text { optimal standing shellfish biomass in a } \\
\text { given basin or bay used to provide reg } \\
\text { authorities with advice }\end{array}$ & - & - \\
\hline Portugal & $\begin{array}{l}\text {-a trophic capacity modelling approach is } \\
\text { being used to simulate bivalve growth, and } \\
\text { determine carrying capacity of cultured }\end{array}$ & - & - \\
\hline
\end{tabular}




\begin{tabular}{|l|l|l|l|}
\hline & $\begin{array}{l}\text { areas as a function of sediment quality, } \\
\text { water circulation, bathymetry and human } \\
\text { impact. }\end{array}$ & & \\
\hline Spain & - & $\begin{array}{l}\text {-an ecosystem modelling approach including } \\
\text { the impact on benthic fauna has been applied } \\
\text { in calculating mass balances and estimating } \\
\text { carrying capacity of suspended mussel culture } \\
\text { in the Spanish rias. } \\
\text {-currently working with the industry and } \\
\text { Spanish government on benthic impact } \\
\text { assessment and modelling of fish farm debris }\end{array}$ & - \\
\hline
\end{tabular}

Source: Adapted from Henderson et al., 2001.

Based on the overview presented above, it is evident that Norway, Ireland and Scotland are the leaders in model application in regulation, and overall, northern Europe has led development in this field. Since publication of this overview, Canada has progressed in the incorporation of modelling into aquaculture regulation. In British Columbia, DEPOMOD has been adopted and is currently used during habitat assessments by DFO. The B.C. DEPOMOD incorporates such things as the exact position of the cage, planned feed use, potential stocking levels, settling rates of the waste material, current readings, and various other considerations (Special Committee on Sustainable Aquaculture, 2006).

While some of the models presented above are very comprehensive and incorporate a number of variables and potential aquaculture-related impacts, few address the potential of regional and cumulative interactions attributable from various marine activities. Models were presented that address more than one environmental component; however, most models tend to address one farm at a time and do not approach production from a cumulative perspective. Other than B.C., model application to site evaluations in Canada lags behind other countries, and implementation in B.C. is very recent. Modelling has been extensively used in N.B. aquaculture but not directly to provide a site decision. The models presented by Greenberg et al. (2005), Page (2003), Strain (2003) and Strain \& Hargrave (2005) are of particular interest for industry management and would be extremely useful in the site evaluation process.

\section{New Brunswick}

In the last few years, the salmon aquaculture industry and regulating bodies in SWNB have recognized the need for improved management of intensive operations. 
Various models have been used to asses the environmental interactions of the industry with the marine environment and the interaction of farm outputs/impacts with certain species. Particle tracking models have also been used to determine impact areas of disease transmission in highly concentrated farm zones with the intention of determining safer siting areas. Oceanographic circulation models and GIS-based information on resource and activity distribution have been used for siting decisions; however, until very recently, predictive impact models were not used in the siting process. This is largely attributable to the uncertainties noted above, the difficulty of obtaining relevant data from the industry such as stock size, feeding rates, FCRs, rates and quantities of medical treatments (DFO, 2003), in addition to a lack of ambient data, biological community structure, other industry information, and environmental quality standards or thresholds. All of this information is necessary to predict pollutant loadings and assess resultant impacts or changing baseline conditions. The perceived or true complexity of models also often hinders application in a policy or decision-making setting, and thus if models are to be utilized, they must be easy to use, interactive, and highly functional (Westmacott, 2001).

In recognition of the various challenges associated with incorporating modelling into decision-making, decision support systems (DSS) were introduced as a viable decision-making alternative (Silvert, 1994a; Hargrave, 2002). During a DFO symposium held at the end of a three-year (2000-2003) study called the Environmental Studies for Sustainable Aquaculture (ESSA), participants (industry stakeholders and interested parties) recognized a DSS as an efficient tool for management of finfish aquaculture. The term 'decision support system' (DSS) takes on many definitions and the support tool has had widespread application in many fields. In the ESSA context, the DSS was described as "a computer-based, integrated method for supporting management decisions within a structured frame in problem situations" (Hargrave, 2002; Silvert, 1994a; Ferreira, 2000).

Decision support systems can be developed as a screening tool to assess the environmental impacts of individual projects or as a planning tool for developing and analyzing alternative management strategies (Westmacott, 2001). The purpose of the DSS determines the contents, design, and scoring and weighting scheme. A DSS typically consists of a user interface, a knowledge base or database and a series of models 
(Westmacott, 2001). Estuarine water and sediment quality models for nutrification, sedimentation and oxygen consumption/demand, in addition to a particle tracking model (with re-suspension and benthic response sub-models) fitted to the hydrodynamics of various areas have been proposed to allow model output to be evaluated within a DSS framework and aid in determination of site suitability and carrying capacity (Hargrave, 2002; Ferreira, 2000). However, in N.B., model outputs do not provide straightforward classification schemes for scoring to be used within the DSS and limited availability of environmental information has largely hindered model-based DSS application to aquaculture (Hargrave, 2002).

With these challenges in mind, Hargrave (2002) proposed an alternative to a solely model-based DSS. Hargrave (2002) developed a Traffic Light DSS to assess nearfield and far-field parameters interacting with or affected by marine finfish aquaculture. The decision outcome produced by the Traffic Light method is presented through proportions of the conventional traffic light colour scheme, where green=pass, yellow= caution or conditional, and red=fail. The DSS is based on data and answers to 22 questions organized in one or more worksheets of an Excel® spreadsheet. General site information is obtained from the license application and used both to initiate the DSS and to evaluate site-related questions. Two sets of questions are then applied to each application, the first set pertaining to ecosystem variables (far-field information) to derive a cumulative ecosystem index, and the second set are site variables (near-field information) to derive a cumulative site index. The questions are answered by yes, no or a numerical value. Answers correspond to one of four possible numerical scores (A, B-, $\mathrm{B}+, \mathrm{C}$ equal to $3,1.5,-1.5,-3)$. The far- and near-field variables are based on predetermined or proposed qualitative criteria and existing or proposed threshold values for these variables. The Traffic Light Method indicates scores above (A; dark green), intermediate to (B+; light green or B-; orange) or below $(\mathrm{C}$; red) criteria for acceptability (Hargrave, 2002). A more conventional three-colour Traffic Light scale is used to represent all possible combinations of the Ecosystem Index and Site Index. Decisions are then reached based on the proportion of green, yellow and red. Included in the far-field set of questions are three pre-emptive questions where a score of $\mathrm{C}$ is an automatic disapproval of the site application. A full description and organization of the DSS may be 
found in Hargrave (2002). The work of Hargrave (2002) was the first of its kind to both present a comprehensive description for practical DSS application and test its effectiveness for evaluating site applications and decisions for finfish aquaculture farms. The prototype DSS presented in the paper was applied to 8 proposed finfish farms and proved beneficial at applying a consistent and standardized method to decision making (Hargrave, 2002).

This DSS was adopted by the Habitat Management division of DFO and has been used in siting since 2003 (Rose, pers. com., 2006). The tool has been well received by habitat biologists and serves as an effective means of removing much subjectivity and inconsistency from the site evaluation process. The DSS also attempts to incorporate ecosystem variables and cumulative impacts indirectly into the siting process, as opposed to simply site-specific variables as was standard practice for the majority of approved projects before DSS inception. The DSS was updated in 2004 to include estimates of waste feed and fecal matter deposition at various distances from a proposed farm site using site-specific variables (farm size, numbers of fish to be stocked, water depth and current velocity)(Hargrave, pers. comm., 2006a). To date, the DSS has not been used by consultants or practitioners; however, the industry has complete knowledge of DSS application and there has been interest expressed by the consulting sector for adoption (Rose, pers. comm., 2006).

While acceptance and application of the DSS has been a major advance in the N.B. finfish aquaculture industry, there are some areas of improvement. During presentation of the DSS prototype and since adoption by Habitat Management, the author (Hargrave, 2002, 2006a) has expressed the need to consider broad spatial scale, sitespecific (local, near-field), and cumulative effects in siting decisions in order to properly protect and manage the interactions of fish-farms and the marine environment. However, while broad-scale effects are considered through the far-field component of the DSS, cumulative effects are addressed indirectly but not from a regional perspective.

Another weakness is that although the DSS is partly aimed at removing subjectivity from the decision process, subjectivity still lies in the far-field component of the decision tool. The question pertaining to the presence of critical fish habitat at or within $1 \mathrm{~km}$ of the site has room for much interpretation. The habitat in question could be 
critical to fisheries or critical to ecosystem function (Rose, pers. comm., 2006), and whether the habitat is deemed critical or how critical may all be viewed differently depending on the habitat manager. As such, critical habitat criteria should be clearly identified and defined in order to remove some of the subjectivity.

The DSS also does not consider the assimilative capacity of the environment to process mariculture wastes. The holding capacity of a site (in practice expressed as the stocking density, estimated site potential, and/or approved production limit) considers environmental characteristics of the site area and immediate vicinity, rather than the characteristics of the inlet, bay or marine region in which the site will be placed. Finfish aquaculture sites are divided into 22 Bay Management Areas (BMA); however, neither the ambient environmental conditions of these areas nor their assimilation potential are considered in siting except for the percent saturation level for dissolved oxygen. Other cumulative effects related to aquaculture and aquaculture in combination with other activities are not considered in the DSS such as habitat fragmentation.

Overall, due to the site-specific nature of finfish aquaculture management in the Bay of Fundy, the DSS currently in use predominantly considers variables directly relating to the proposed farm site. In mariculture management worldwide, modelling has seldom been used for the multi-farm or multi-user scenario (Henderson et al., 2001). Ireland is possibly the only jurisdiction that has begun to adopt a multi-farm approach used in EIA through two models, DIVAST and TRIVAST; however, no environmental quality targets have been developed by the regulator against which one could compare results (Henderson et al., 2002). It has become evident that sustainable management of the aquaculture industry in the SWNB region of the Bay of Fundy must take a more regional approach, focussing on the environmental carrying capacity of entire regions, siting farms in consideration of avoiding exceedance of the total assimilative capacity determined by and set against both baseline conditions and environmental quality targets, and considering the total affected area due to aquaculture and other activities. This can only be achieved through consideration and incorporation of cumulative effects assessment into the decision process by way of the Traffic Light Decision Support System. 


\section{Chapter 4: METHOD}

The following procedure was used to incorporate regional and cumulative environmental considerations into the decision process of marine finfish aquaculture, and to determine whether adaptation of the current Traffic Light Decision Support System (DSS) used in the federal EA process would have enabled siting of past approved sites in light of these considerations.

1. The Traffic Light Decision Support System for marine finfish aquaculture siting in the Bay of Fundy proposed by Hargrave (2002) and employed by DFO assessors in the federal environmental assessment process since 2003 was chosen for expansion based on its flexibility and ability to address many environmental components at a time. The DSS was analyzed for areas of improvement and possible expansion.

2. Data relating to finfish sites (Approved Production Limits, Estimated Site Potentials, Environmental Monitoring data) and Coastal Management Regions (CMRs) (volume, area, residence time, ambient dissolved oxygen) was obtained from various sources.

3. The existing DSS was adapted based on existing research to incorporate regional and cumulative environmental considerations into the far-field set of questions that incorporate ecosystem variables. Refer to Chapter 5 for adaptation justification, procedures, calculations and scoring.

4. Thirty-two finfish (mainly salmon) aquaculture federal EAs were formally requested through the Access to Information Act from the Dept. of Fisheries and Oceans, the Atlantic Canada Opportunities Agency, and Transport Canada. The requested EAs were all finfish projects proposed in the Bay of Fundy, southweatern New Brunswick, listed in the CEAA public registry.

5. A total of $25 \mathrm{EAs}$ were acquired both from this request and from personal contacts at Transport Canada, 23 (22 salmon and 1 cod) of which pertained to the study.

6. The adapted set of far-field questions was applied to the EAs to determine whether DSS approval would have been granted with regional factors being 
considered. The site-specific (near-field information) set of questions was not directly applied and it was assumed that the proposed site passed the site specific set of questions.

7. For each assessed site, EAs within the same CMR that had not been approved at the time of site application were not considered in the decision process. As such, many calculations presented in Chapter 5 were redone to reflect values of the time period in which the proposed site would have been assessed. Total Approved Production Limits (TAPL) and Total Estimated Site Potential (TESP) for each CMR reflected the time of proposal.

8. In cases where data or information was missing from the EA document and the information or data could not be estimated or obtained from other sources, the question was left blank in the DSS and no score was assigned. ${ }^{2}$

9. The Cumulative Ecosystem Index was determined for each EA based on the aggregation of all regional questions.

10. Legitimacy of prior approval was then evaluated based on the findings of the adapted set of regional questions and potential cumulative site indices.

\section{Assumptions made while performing retrospective review}

Because Environmental Monitoring Program (EMP) results are not available for sites prior to 2002, some assumptions had to be made about the state of the benthic environment beneath cages for sites proposed between 1998-2002 and for the number of sites experiencing low EMP ratings. This was necessary in order to estimate the area affected within each CMR. Based on historical data, many salmon farms in operation prior to the regulatory environmental monitoring program were not meeting sediment quality objectives. In order to answer questions (i) and (ii), it was assumed that approximately half of the sites in operation within a CMR before that time were likely operating with oxic 2 or lower lease sites. This assumption is based on both post-2002 EMP results and general trends of sites approved before the EMP. Therefore, for site 404,

\footnotetext{
${ }^{2}$ If the computer-based DSS is run, all answers must have a score otherwise a blank space is recognized as a score of C (Hargrave, 2002). Because scores were calculated by hand, and due to lacking information enabling estimates, some questions did not receive an answer.
} 
it was assumed that approximately half the existing sites at the time of proposal were considered oxic 2 or hypoxic.

The same logic was used for site 186 , however, monitoring information indicates that this area had 16 sites with oxic 2 or hypoxic conditions during the 2002 monitoring year. Many of these 16 sites continued to have these sediment rating or the rating worsened, thus instead of assumig half of 26 sites were oxic 2 or lower, for site 186 we assume sites that were hypoxic during 2002 monitoring likely had oxic 2 or lower ratings prior to the EMP. Thus, 14 sites were hypoxic 2 or lower within the CMR at the time of proposal. The NPB site 370 was assumed to have 6 sites oxic 2 or lower prior to site application. Based on the 2002-2005 monitoring, 6 out of 7 sites were hypoxic and anoxic and this region was sited in early years and has long flushing and residence times relative to the other CMRs.

The 2002-2005 monitoring information for GM CMR indicates that no sites were experiencing hypoxic conditions and few were experiencing oxic 2 conditions in 2002 and thus it can be assumed that for GM site 324 only 4 farms in operation at the time of site proposal were oxic 2 or less.

It is also assumed that all farms had an operation lifetime of 20 years unless monitoring data or EAs indicate otherwise. 


\section{Chapter 5: FORMULATION OF THE EXPANDED TRAFFIC LIGHT DECISION SUPPORT SYSTEM}

The following chapter describes the methods used to amend the far-field set of criteria (questions) found in the Traffic Light Decision Support System described by Hargrave (2002) and used today by DFO assessors in finfish aquaculture site evaluation. The decision support system (DSS) used by DFO employs a question-answer technique. The proposed additions and alterations to the DSS follow the same format. The following figure outlines the method used to arrive at the expanded set of far-field questions before application to the 23 approved salmon aquaculture environmental assessments.

Figure 5: Steps of criteria amendment toward application

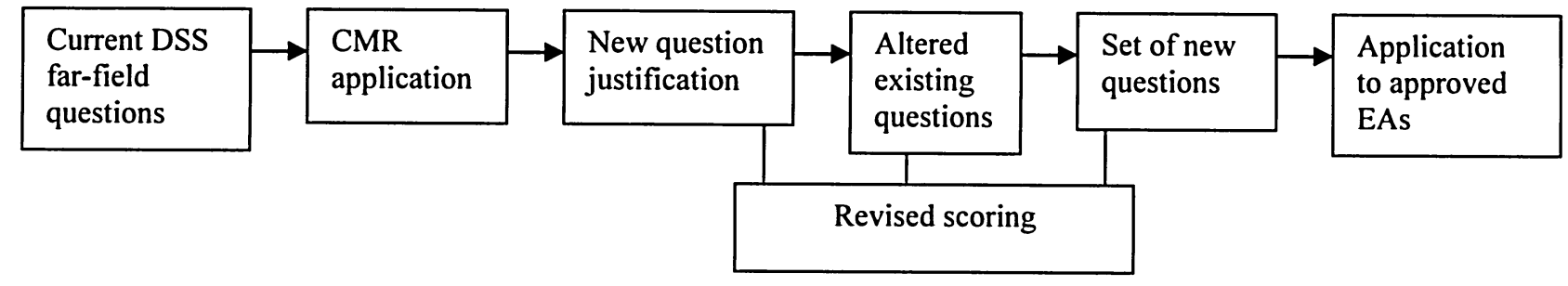

\section{Present Set of Far-field Questions: Ecosystem variables (far-field information) to derive a cumulative ecosystem index}

The following set of questions in the Traffic Light Decision Support System (DSS) is aimed at determining the potential for negative ecosystem-level impacts and conflicts of ecosystem use (Hargrave, 2002). Each question and scoring scheme is presented below. These questions and the subsequent paragraph discussing the cumulative ecosystem index is taken from, and found in, Hargrave (2002).

(i) If there are shellfish closures in the area, what is the distance $(\mathrm{km})$ from the proposed lease site? No closures $=$ " 0 "; no shellfish closure at or near the site, score A; closures occur $<3 \mathrm{~km}, \mathrm{C}$; $<5 \mathrm{~km}, \mathrm{~B}-;<10 \mathrm{~km}, \mathrm{~B}+; \geq 10 \mathrm{~km}, \mathrm{~A}$.

(ii) Are any species (fish or invertebrates) harvested for food or are there macroalgal beds within $300 \mathrm{~m}$ ? If the distance of the site is $<300 \mathrm{~m}$ from an existing fishery or macroalgal bed, score $\mathrm{B}+$, otherwise $\mathrm{A}$.

(iii) Is there a finfish aquaculture lease site within $3 \mathrm{~km}$ ? If the proposed location is within $3 \mathrm{~km}$ of an existing site, score $\mathrm{C}$, otherwise $\mathrm{A}$. $\mathrm{C}$ is a pre-emptive condition for the cumulative EI. 
(iv) Is there a Marine Protected Area, Marine Park or other protected area within $5 \mathrm{~km}$ ? These areas should be avoided; however, if a protected area exists within 5 $\mathrm{km}$ of the proposed site, score B-, otherwise A.

(v) Are there any endangered fish, mammal or bird species at the site or within $5 \mathrm{~km}$ for which mitigation measures to minimize harmful effects cannot be applied? If the distance is $<5 \mathrm{~km}$, score $\mathrm{C}$, otherwise $\mathrm{A}$. C is a preemptive condition for the cumulative EI.

(vi) Is there river discharge into the inlet/bay system or other factors to create stratification at any time in the year? If stratification occurs at any time of the year, score B-, otherwise A.

(vii) Is there a sill at any location within the inlet/embayment system? If a sill exists at any location within the inlet system to potentially restrict tidal exchange and mixing of the water column, score B-, otherwise A.

(viii) Is there any industry (e.g. pulp and paper, logging, fish processing, marina) within $5 \mathrm{~km}$ of the site? If the potential for other sources of industrial waste discharge exists within $5 \mathrm{~km}$ of the proposed site, score B-, otherwise A.

(ix) How many people live within $1 \mathrm{~km}$ of the site? As population are a source of sewage and other urban discharge, human populations close $(<1 \mathrm{~km})$ to the proposed site must be considered. If numbers (general estimations) are small $(<10)$ score A, $(<50)$ score B+, $(<500)$ score B-, otherwise score C.

(x) Is there a critical fish habitat (e.g. spawning or nursery area, migration route) at or within $1 \mathrm{~km}$ of the site? If a critical habitat is known to be present for which mitigative measures cannot be applied, score $\mathrm{C}$, otherwise $\mathrm{A}$. $\mathrm{C}$ is a pre-emptive condition for the cumulative EI.

\section{Cumulative ecosystem index (EI)}

The EI is the sum of the numeric scores for the ecosystem variable questions presented above. If a $\mathrm{C}$ is assigned to any of the questions containing pre-emptive $\mathrm{C}$ values (iii, $v, x)$, the $E I$ is equal to $C(E I=C)$. However, if a $C$ is not assigned for any of the pre-emptive questions, the maximum value for EI equals 30 and the minimum score is -25.5. If $\mathrm{EI}>20$ a score of $\mathrm{A}$ is given; $\mathrm{EI}=10-19$, a score of $\mathrm{B}+$ is given; $\mathrm{EI}=5-9$, $\mathrm{B}$ - is given; and $\mathrm{EI}<4, \mathrm{C}$ is given.

\section{Proposed set of Regional Questions: Cumulative environmental effects variables} (regional and ecosystem information) to derive a Cumulative Effects Index.

The following is a proposed list of questions to be added to the current DSS. These questions attempt to take a more regional approach to site evaluation and decision making, through the incorporation of potential cumulative environmental effects, ecosystem components, and regional data, information and management into the siting 
process of environmental assessment. Each new question is placed into context, justified, and formulated. Methods to answer the question are given where necessary along with a scoring scheme based on the one used in the current DSS. The numbers corresponding to the questions below represent their number in the final merged set of questions presented at the end of this chapter.

(I) What Coastal Management Region (CMR) does the proposed site belong to?

(II) How many farms exist and are in operation in this CMR? What is the CMR Approved Production Limit?

(III) Does the proposed farm fall within a CMR that has been deemed unsuitable for siting based on insufficient environmental assimilative capacity for $\mathrm{N}$ or $\mathrm{C}$ and sufficient $\mathrm{DO}$ ? If not, does the proposed production level coincide with the Total Approved Production Limit of the respective CMR?

(i) Based on the number of sites in the CMR that were oxic 2, hypoxic or anoxic during the last 3 monitoring periods, what is the percent habitat loss?

(ii) How long have the oxic 2 or below sites in the CMR been operating or what is the estimated operation lifetime?

(iii) Will predator acoustic deterrent or harassment devices be used at the proposed site?

\section{Justifications for Question Choice and Scoring}

\section{Coastal Management Regions (CMRs) as alternatives to Bay Management Areas}

The Coastal Management Regions (CMRs) are oceanographic and hydrographic sub-regions that incorporate the Bay Management Areas (BMAs) presently used in site management by NBDAFA (DFO, 2003). The CMRs are much larger in area and contain many salmon aquaculture sites because they encompass the 21 BMAs. The concept of a CMR was initially introduced by DFO in the late 1990s (DFO, 2003), and has since been increasingly used in Bay of Fundy salmon aquaculture-related discourse and literature addressing better management of the industry, far-field impacts of operation byproducts, and suggested approaches to determination of waste outputs and approved production limits (APLs) (eg. Strain \& Hargrave, 2005; DFO, 2003; Strain, 2005).

The Coastal Management Regions (CMRs) were initially based on and determined from water mixing and residence time characteristics, where a tidal current 
model was used in conjunction with estimates of mean water mass residence time to determine areas where mixing in regions supersedes mixing between regions (DFO, 2003). The outcome of this analysis was a set of 8 CMRs presented as a map (Figure 6). These CMRs include: Grand Manan divided into two subregions (1-south, 2-north); Campobello and Deer Islands divided into 3 subregions (3-Campobello Island, 4-Deer island north, 5-Deer Island south); Northern Passamaquoddy Bay (6); Letang/Letete Passage (7) with subdivisions by inlet; and Other Areas (8) that may not all belong to a condensed area but many areas such as Beaver Harbour, Foleys Cove and Maces Bay to Seeleys Cove (DFO, 2003). Figure 6 shows three groupings of water mixing zones. Working from the outside in, the light dotted lines outline the overall mixing area, the dark solid lines encompass areas with a water mass that is fairly isolated, and the dark dotted lines indicate areas where there is a potential for limited exchange.

Figure 6: Water mixing zones and coastal management regions of southwestern New Brunswick.

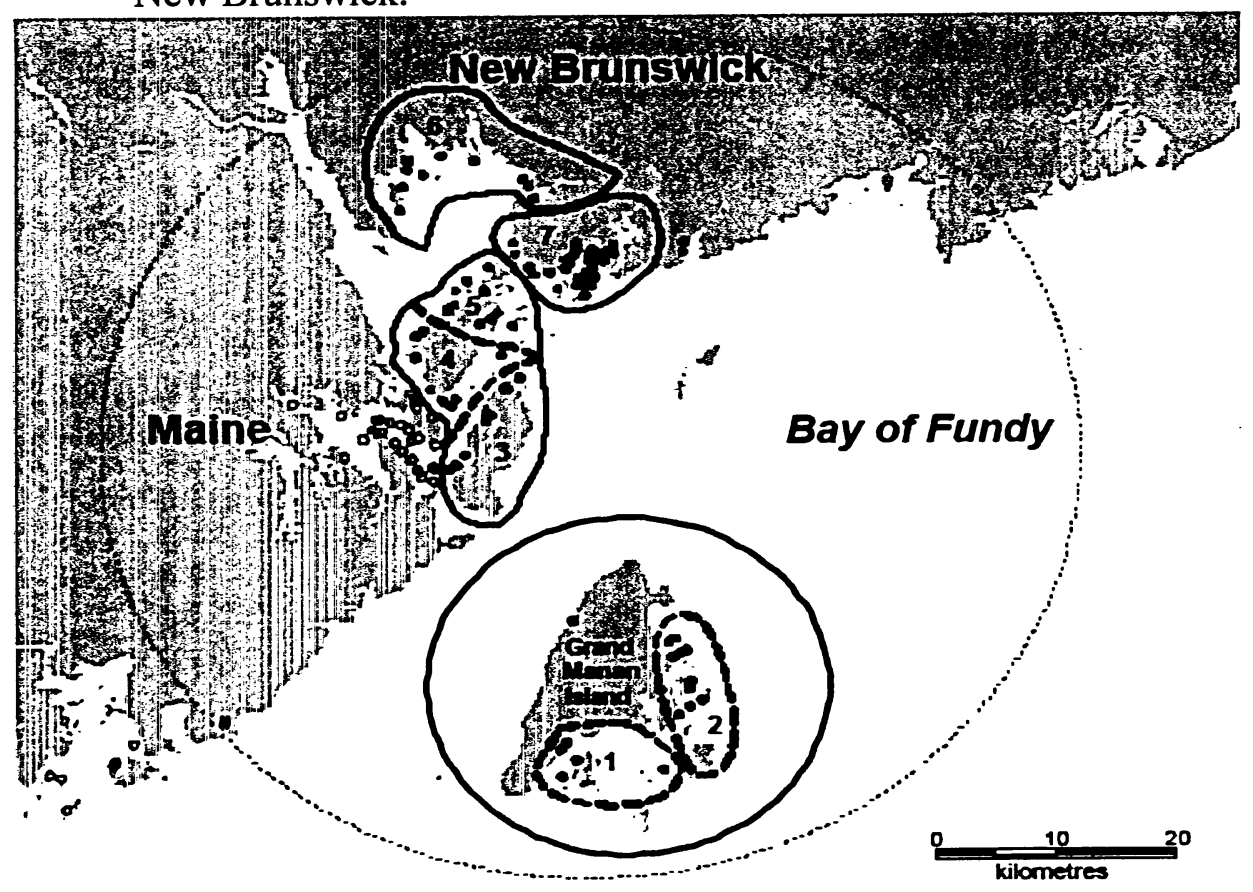

Source: DFO, 2003.

As depicted above, the CMRs and sub-regions are based on water mass exchange characteristics. More recent work (Strain \& Hargrave, 2005) seems to mainly focus on the 4 main CMRs outlined by the dark solid lines in Figure 6 and written in italics in the 
previous paragraph. It is acknowledged that some division into smaller regions than those identified above with overall mixing outlined by light dotted lines is necessary for effective industry management. However, considering a more precautionary approach, as advised under the 1997 Canada Oceans Act, for the purposes of this paper the 4 main CMRs and the 'other' designation will be used as management divisions (Figure 7). In addition to purely oceanographic and hydrographic characteristics suggesting these regions are useful management divisions, model-derived water circulation patterns, buffer zones and management of disease also support the use of these CMRs.

Fig. 7: Coastal Management Regions (CMRs) in SW New Brunswick including salmon farms (2002).

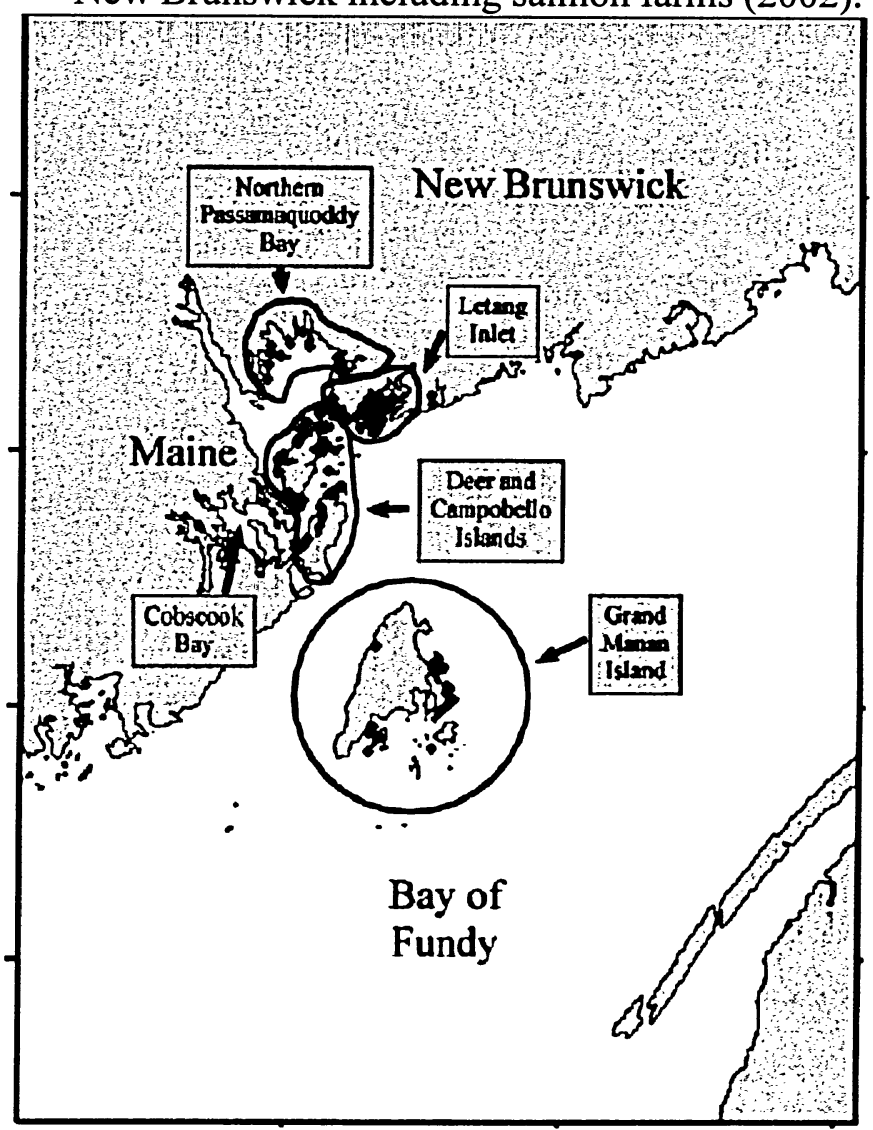

Source: Strain \& Hargrave, 2005.

(i) Evidence supporting CMR-based analysis

Bay Management Areas were initially designed to allow economic expansion of the finfish farming industry while minimizing potential for disease transmission between sites (DFO, 2003). This management strategy has become part of New Brunswick's Bay 
of Fundy Marine Aquaculture Site Allocation Policy, in which the BMAs are separated into single year classes in order to reduce disease transmission potential when multi-year classes are found within the same hydrographic mixing unit (DFO, 2003).

There are two shortfalls of this management strategy: in many cases mixed year classes are side-by-side in the same hydrographic area due to the BMAs' small size; and BMA boundaries may not be consistent with water exchange patterns (Page et al., 2004). While it has been suggested by DFO (2003) that all farms within a hydrographic area have the same year class or that BMAs be large enough to reduce risk of year class interaction, there is evidence that these BMAs are far too small and management by means of CMRs is more appropriate for minimizing risk of interaction.

During a series of fish health management studies to understand the spread of disease (mainly the ISA virus assumed viable in seawater for 1 tidal cycle) between sites and BMAs, water circulation patterns were determined using the QUODDY_DRY 3D finite element circulation model $^{3}$ (Page et al., 2004). These studies also employed $5 \mathrm{~km}$ radius buffer zones around each site, as recommended in the Norwegian ISA Management Plan as an appropriate distance of influence from an infected farm (Page et al., 2004). Overlaps between the $5 \mathrm{~km}$ buffer zones of sites and between the BMAs were determined. The overlaps of the model-derived current influence zones (tidal excursions) of the sites and between BMAs were also determined. While the $5 \mathrm{~km}$ buffer zones are circular in shape, the model-derived zones are often elongated and take various shapes.

To date, results have been presented for Grand Manan Island and the Letang area (Page et al., 2005; Chang et al., 2005). For Grand Manan Island, the $5 \mathrm{~km}$ buffer zone was found to be a fairly suitable choice; however, it underestimated the maximum distance traveled by particles in BMA 19 and overestimated distance traveled by most particles in BMAs 20 and 21. Use of the $5 \mathrm{~km}$ buffer zone showed overlap both between farms and the BMAs, suggesting the need for a single buffer zone for all farms in southern Grand Manan (Page et al., 2005). Page's model-derived results (particle trajectories) indicated that there is water exchange between the southern and eastern sides of Grand Manan Island. In order to avoid extensive overlap of tidal excursions, two

\footnotetext{
${ }^{3}$ It should be noted that the model only considers the $\mathrm{M}_{2}$ tide; however, this tide is a major component of the tides in the Grand Manan and Letang areas. In areas where other factors such as the spring and neap tide and/or wind play a major role, they will also be considered (Chang et al., 2005).
} 
management areas were suggested with 3 sites $(413,292$, and 202) in one area and the remainder in the other (Page et al., 2005). However, because this division would divide the existing BMA 20, and there remains a likelihood of exchange between sites in the current BMA 20 even if they are assigned a different management area, taking a more conservative approach with the results of the $5 \mathrm{~km}$ buffer zone in mind, suggests the use of a single management area (CMR).

Similar results were found by Chang et al. (2005) for the Letang area (Letete passage, Back Bay, Bliss Harbour, and Lime Kiln Bay) including northern Deer Island. The study included BMAs 2, 3-east, $6,7,8,9$, and 10 . The use of the $5 \mathrm{~km}$ buffer zone suggested that due to significant water exchange between the BMAs and sites there should be one management zone (Chang et al., 2005). Use of the model-derived tidal excursions zones suggested an overestimation of water exchange by the $5 \mathrm{~km}$ buffer zones. It also showed that sites in the northern Deer Island area were isolated from the other sites in the study based on overlaps between excursion zones and site areas; however, overlaps among tidal excursion areas indicate some interaction with farms in the N. Deer Island area (Chang et al., 2005). Results from both approaches suggest significant water exchange and overlap of tidal areas in the Letang area (particularly BMAs 9 and 10 and some overlap between BMAs 7, 8, 9 and 10), strengthening the argument towards a single management area (Chang et al., 2005). Overall, due to the potential spread of ISA and other diseases transmitted through water, the overlap of water exchange indicates that in order to minimize the risk of disease, each area studied (Grand Manan Island and Letang area) should be considered as one management region or CMR. To date, the remaining BMAs have not been modeled. However, taking the more conservative approach using $5 \mathrm{~km}$ buffer zones, all BMAs follow a similar pattern as the two regions studied and thus N. Passamaquoddy Bay and Campobello/Deer Island should also be two complete CMRs.

Also relating to the use of buffer zones is a lease's physical interaction or interference with existing harvested fisheries (Hargrave, 2002). The extent of this buffer zone will change depending on various regulatory, geographic, hydrographic and harvesting factors and conditions. If a buffer of $300 \mathrm{~m}$ is utilized, as in British Columbia (Hargrave, 2002), and hydrographic conditions are considered, each lease's buffer would 
be smaller than the buffer to prevent disease transmission and therefore, in order to consider disease transmission and other particle-related impacts from aquaculture, the larger CMRs are more suitable.

Lastly, condensing the 22 BMAs into larger CMRs allows regional management and analysis as opposed to a predominantly site-specific basis. Question (iii) of the current far-field set states that 'the cumulative number of farms already approved within an inlet system must be considered in making a decision to increase the number' (Hargarve, 2002). Based on the reasoning presented above for CMR utilization in licensing and siting, Hargrave's logic can be applied on an entire CMR basis instead of a single inlet. A CMR approach enables better management of potential far-field, cumulative and site-specific effects of current and future salmon farm production. ${ }^{4}$

The following 2 proposed Regional Questions pertain to coastal management regions:

(I) What Coastal Management Region (CMR) does the proposed site belong to?

(II) How many farms are in operation in this CMR (includes leases fallowing but not abandoned) and what is the total CMR Approved Production Limit?

These preliminary questions place the site application in a regional management context. The first question (I) situates the proposed site in a CMR in order to determine whether the application will be rejected based on previously determined CMR characteristics. This question does not have a scoring scheme; however, depending on the results of subsequent questions the application could be rejected based on the CMR designation.

The second question (II) also provides information for subsequent questions. The information required for this question can be acquired from the most recent monitoring results or the NB Department of Agriculture Fisheries and Aquaculture. This question also does not have a scoring scheme.

\footnotetext{
${ }^{4}$ The province of New Brunswick is currently in the process of converting the 22 BMAs into 5 larger BMAs (Coombs, 2006, pers. comm..). It is not presently known whether the new BMAs will resemble the CMRs; however, it is likely that CMR designation will be considered in BMA choice.
} 
Aquaculture-related Dissolved Oxygen and Fluxes of Nitrogen and Carbon

Provincial monitoring of the health of salmon farms relates solely to the benthic environment. Typically, the water quality of the lease area is not formally considered. In general, there are two agencies that have responsibilities for ensuring that habitat and water quality are maintained in the province of New Brunswick. The New Brunswick Department of the Environment and Local Government (NBDELG) has responsibility under the Water Quality Regulations - Clean Environment Act and the Clean Water Act to ensure the health of the marine environment and DFO has responsibility under the Fisheries Act to protect fish and fish habitat (NBDELG, 2001). The N. B. Water Quality Regulations define water pollution as 'alterations and additions to the waters of the Province of New Brunswick "which renders or is likely to render harmful---or less useful for domestic, municipal, industrial, agricultural, recreational or other lawful uses or harmful or less useful to animals, birds or aquatic life"'(NBDELG, 2001). Pursuant to Section 3 of the Regulation, approvals are required where direct or indirect water pollution is caused to waters of the Province. Under the Clean Environment Act, waters of the Province includes coastal water within the jurisdiction of N.B.

Under the Fisheries Act, Section 35.1 relates to habitat provisions and states that, "No person shall carry on any work or undertaking that results in the harmful alteration, disruption or destruction of fish habitat". Section 36.3 relates to inputs of pollution and states that, "no person shall deposit or permit the deposit of a deleterious substance of any type in water frequented by fish or in any place under any conditions where the deleterious substance or any other deleterious substance that results from the deposit of the deleterious substance may enter any such water". Definitions for deleterious substances can be found in Appendix A. DFO is responsible for ensuring compliance with these provisions. While the release of waste from finfish farms can fit the definition of deleterious substances in the quantities produced by intensive production, and these releases may result in the harmful alteration, disruption or/and destruction of fish habitat, HADD authorization is not mandatory when siting. In other words, in order to have the Fisheries Act enforced and HADD authorized, someone must declare that a site is in violation of s. 35.1; however, if this does not take place, which is the norm, the provincial guidelines remain the only environmental standard (Harvey, 2005, pers. comm.). 
Despite provincial and federal responsibilities, and in the absence of Fisheries Act enforcement, other than DO surface levels on site, ambient marine water quality parameters are not considered in siting or environmental monitoring in N.B.. Site production levels are based primarily on physical attributes such as depth, cage type, mooring configurations, and the like (Sweeney International, 2004). The Estimated Site Potential (ESP) is defined as the 'maximum number of fish that may be permitted on an aquaculture site at any one time' (Sweeney Intl., 2004). The formula used to derive the ESP was first developed and incorporated into the Guidelines for Determining the Size and Production Levels for Marine Aquaculture Sites in the Bay of Fundy in May 1993; however, it was recently amended in 2004.

The original ESP formula was developed assuming that ideal conditions exist at a proposed site and thus only physical conditions need to be considered. It has become evident over time that other environmental factors must be considered in determining production levels; however, although researchers have attempted to derive a formula incorporating environmental effects, they concluded that investigations were limited by insufficient data from the aquaculture industry (Sweeney International, 2004). Incorporation of environmental variables would thus require further research on variables such as dissolved oxygen (DO) and its role as a limiting factor in sustainable aquaculture (Sweeney International, 2004). Therefore, the amended formula only addresses physical and technological changes in the industry since the formula was created, including net depth, percent usable area, percent usable area lost per meter depth and the method for calculating depth at the center of the site at mean low tide. The 1993 and amended formulas are presented below. An explanation for the 1993 formula is presented in Appendix A.

1993: $\mathrm{ESP}=[($ Area $\times \mathrm{D} \%) \times 6.0] \times 18 \mathrm{~kg} / \mathrm{m}^{3} / 4 \mathrm{~kg}$

Amended: $\mathrm{ESP}=[($ Lease Area $\times \mathrm{SA} \%) \times \mathrm{Dn}] \times 18 \mathrm{~kg} / \mathrm{m}^{3} / 4.5 \mathrm{~kg}$

Where,

- ESP= "Estimated Site Potential" or maximum number of fish permitted on site at any one time;

- Lease Area = the total approved area $\left(\mathrm{km}^{2}\right)$ of the site below mean low tide;

- $\mathrm{Dn}=$ depth of the nets; 
- $\mathrm{SA} \%=15.79 \%-[.27 \% \times(\mathrm{Da}-8.0)]$;

- $\mathrm{Da}=$ the average depth at the site at mean low tide;

- $18=$ the maximum stocking density allowed on a marine finfish aquaculture site expressed in $\mathrm{kg} / \mathrm{m}^{3}$;

- $4.5=$ the average market weight in kg of cultured Atlantic salmon in the Bay of Fundy (Sweeney International, 2004).

The Allowable or Approved Production Limit (APL) is the production limit that is determined as a percentage of the ESP. It takes into account some environmental considerations such as sediment grain size criteria for erosional and depositional site conditions and recommendations provided by the Aquaculture Site Evaluation Committee. Erosional sites generally have an APL of 70\% of the ESP and marginally depositional sites have an APL of $50 \%$ of the ESP. If degradation becomes evident, the APL may be reduced; however, if erosional sites meet minimum environmental site requirements after two production cycles, a production increase may be allowed (Sweeney International, 2004).

Overall, water quality variables are not a mandatory part of siting or monitoring by means of the environmental monitoring program, or setting of production levels. To better address the potential for salmon aquaculture-related water quality impacts, siting decisions must address important parameters such as DO, nutrients and C. Environmental criteria, salmon farm outputs, measures of ambient condition degradation, and comparative studies on aquaculture fluxes versus natural fluxes provide a foundation for estimating environmental carrying capacity based on water quality in the absence of widely accepted methods.

\section{(i) Thresholds and criteria for marine water quality and species health}

Various water quality and species health criteria have been devised in an attempt to protect and ensure marine environmental health. These criteria enable an assessor to set observed environmental variables against environmental objectives or thresholds in order to determine whether finfish aquaculture is adversely affecting ambient conditions. Criteria exist in some capacity for each of the variables in question (DO, N, P, and C).

Dissolved oxygen is a necessary component for all aerobic marine species. Interim water quality guidelines have been developed for DO in marine and estuarine 
waters for the protection of aquatic life (CCME, 2003). The guideline for the recommended minimum concentration of DO in marine and estuarine waters is $8.0 \mathrm{mg} / \mathrm{l}$ (CCME, 2003); however, in areas where the natural DO level is less than the recommended interim guideline, the natural concentration should become the interim guideline at that site (Demers, 2006, pers.comm.). The depression of DO below this value should only occur as a result of natural processes and when ambient DO concentrations are $>8.0 \mathrm{mg} / \mathrm{l}$, human activities should only decrease DO levels below $10 \%$ of the natural concentration expected in the receiving environment at that time (Demers, 2006, pers.comm.). The Australian and New Zealand Guidelines for Fresh and Marine Water Quality (2000) state that the percent saturation should not drop below a lower limit of $90 \%$ saturation and an upper limit of $110 \%$ saturation. These values were taken during the day and it is acknowledged that levels will vary diurnally and monitoring should track changes in DO levels. The water quality guidelines relating to aquaculture and the protection of cultured species state that DO should not fall below $5 \mathrm{mg} / \mathrm{l}$ (ANZECC, 2000). This value is much less than the values presented above and does not relate to wild species' protection.

It has been determined that at lowered DO levels, salmon become stressed and begin exhibiting behavioural changes. Studies have found these threshold levels to be $\leq$ $\sim 6.75 \mathrm{mg} / \mathrm{l}$ and $\leq 6 \mathrm{mg} / \mathrm{l}$ (Page, 2003), and $7 \mathrm{mg} / \mathrm{l}$ (Hargrave, 2003). Different species will exhibit different levels of impact at various lowered DO levels. Furthermore, the impact of the localized reductions of DO on the ecosystem partially depends on the degree of spatial and temporal persistence of reduced levels, and partially on the degree of reduction (Page, 2003).

In areas naturally prone to low DO levels or where oxygen depleting stresses such as aquaculture create a low DO environment, the rate of water exchange and DO replenishment become important factors in determining cultured and wild species productivity. Although oxygen depletion is often high in the immediate vicinity of the cage, conditions of low water exchange can lead to significant oxygen deficit gradients away from the cages (Silvert \& Sowles, 1996). Informal calculations have suggested that reductions in DO decrease with increasing distance from a lease site but, can extend from 100-1000 $\mathrm{m}$ in uneven but narrow plumes (Page, 2003). In these oxygen-deprived areas, 
if the DO is being used up faster than it can be replenished, there will be stresses on aquatic species.

Two terms used to describe water exchange and mixing are residence time and flushing rate. The residence time measures the time spent by a water parcel or a pollutant in a given water body (Delhez, 2006; Sheldon \& Alber, 2001). Other authors refer to this as the flushing time (Choi \& Lee, 2004), determined traditionally using tidal prism or salt-balance concepts, and in recent times using 3D numerical hydrodynamic and mass transport models (Choi \& Lee, 2004). The residence time, using the tidal prism method, is generally accepted as the number of tidal cycles or time needed to exchange about $63 \%$ of a waterbody (Page, 2003). The USEPA (2006) defines the flushing time as the "time required for a waterbody to exchange its water with water from the parent waterbody. However, other authors suggest that flushing time is considered a single value systemlevel measure for the entire water body, while the residence time is a spatially-varying local measure (Choi \& Lee, 2004).

Using the tidal prism method, Page (2003) states that the time for $95 \%$ flushing is equal to 3 times the residence time and this logic assumes full mixing of the water entering and present in the waterbody, where all water entering is 'new' water and all water leaving will not return (Page, 2003). Because many of these assumptions are not entirely tenable, RT is often underestimated by a factor of at least 2 and thus the flushing rate is underestimated by a factor of 5 . More accurate determinations of residence time and flushing rate can be estimated by circulation models; however, in the absence of such data the tidal prism method can produce fairly reasonable approximations.

Some studies suggest that the use of flushing rates should be limited to fresh water (and the materials dissolved within) and is the time required for the freshwater inflow to equal the amount originally present in the estuary. This represents the transit time through the entire system (from head of tide to the mouth) (Sheldon \& Alber, 2001). Residence time, on the other hand, can be calculated for any type of material (including fresh water), and will vary depending on the starting location of the material (Sheldon \& Alber, 2001). Due to conflicting definitions, for the purpose of this paper, residence time and flushing time will follow the description presented by Page (2003) using the tidal prism model. 
Due to the importance of nutrient additions and/or limitations in the aquatic environment, and the associated potential adverse impacts, environmental quality criteria have been established addressing various forms of $\mathrm{N}$ and $\mathrm{P}$.

The form of nitrogen present in surface waters depends on several factors, including $\mathrm{pH}$, the amount of available oxygen, and the types of biological communities that are present. Nitrate $\left(\mathrm{NO}_{3}{ }^{-}\right)$tends to be the dominant form of nitrogen in waters with normal levels of dissolved oxygen (EC, 2005). If, however, nitrate is present in waters with very low $\mathrm{DO}$, bacteria will convert it to nitrite $\left(\mathrm{NO}_{2}{ }^{-}\right)$, and then $\mathrm{N}_{2}$ gas. This is because all other forms of nitrogen can be converted naturally to nitrate in soils and water by bacteria. Alternatively, nitrate can enter the surface water through deposition, runoff, streams and rivers from groundwater seepage, and other non-point anthropogenic sources such as industry, agriculture and residential outputs and runoff (EC, 2005). Nitrate is easily taken up by plants and algae for growth, highly mobile in the environment, and does not bind to soils or particles and is thus easily transported in water. Because nitrate is an essential nutrient, high levels in the marine environments can lead to overproduction of plants and algae which can consequently result in indirect toxic effects on other aquatic species through DO reduction or the excretion of toxins (EC, 2005). Direct effects such as stunted growth and maturity, and lowered reproductive success may also occur, especially with exposure at early life stages (EC, 2005). In extreme cases some aquatic invertebrates and fish may die at high levels of exposure to nitrate (EC, 2005)

The other essential nutrient, phosphorus exhibits many of the same characteristics as nitrogen. In the environment, phosphorus is often expressed as total phosphorus because its nutrient form can be taken up very quickly and is therefore very difficult to measure (EC, 2005a). Like nitrogen, phosphorus in the marine environment occurs in many forms. The inorganic phosphate organophosphate components of total phosphorus are typically derived from soil, plant, and animal material (Australian Government, 2005). In the natural environment, partially reduced forms of phosphorus such as phosphonates are produced and metabolised, and nucleic acids, an important form of phosphates, store genetic information (Australian Government, 2005).

While phosphorus is a key nutrient in plant growth, not all forms are bioavailable for growth. Oxidation-reduction potential of the environment, largely dependent on 
microbial activity and organic matter, plays a major role in the forms, and therefore availability, of phosphorus (Australian Government, 2005). Various processes can breakdown organic and complex forms into the bioavailable inorganic form. Free orthophosphate ions, small molecular weight organic forms on short time scales, and higher molecular weight organic and inorganic forms on longer time scales are readily available for plant and algae growth (Australian Government, 2005).

The major transport mechanism of phosphorus is through water. Most total phosphorus is transported through runoff, streamflow, and groundwater flow, however, some total phosphorus is also transported by wind, dust and deposition (EC, 2005a). Phosphorus can also enter the marine environment from anthropogenic point sources such as sewage treatment plants, industrial effluents, and aquaculture operations, and nonpoint sources such stormwater, agricultural, and runoff (EC, 2005a). The impacts of high levels of $\mathrm{P}$ inputs vary in aquatic systems. Phosphorus can be toxic, but toxicity rarely occurs in nature and is generally not a concern. Of more concern are the indirect effects of phosphorus. These impacts are similar to those caused by high levels of nitrogen and include: increased productivity, algal mats, increased sedimentation of organic matter, and decreased DO.

\section{(ii) Environmental criteria}

The presence of excess nutrients, the reduction of DO levels and the stimulation of algal growth in the marine environment are all aspects of eutrophication (Strain, 2005). However, few environmental quality criteria for the protection of aquatic life were developed with eutrophication in mind. It is recognized that various factors, such as flow, light, turbidity, temperature, zooplankton grazing, in addition to nutrient levels can limit plant and algae growth. It is also acknowledged that the prevention of algal blooms based purely on nutrient reductions may not be possible. However, these considerations should not and have not deterred attempts to create suitable total recommended $\mathrm{P}$ and $\mathrm{N}$ guidelines (ANZECC, 1992). The Canadian government identified the need to address the growing eutrophication problems occurring in estuaries, inlets and coastal ecosystems on the Atlantic and Pacific coasts through a scoping assessment initiated in 2003 by the 
NGSO. The goal was to understand causes of marine eutrophication and identify possible nutrient management strategies. ${ }^{5}$

The CCME is working on Canadian Water Quality Guidelines for the Protection of Aquatic Life for $\mathrm{P}$ and $\mathrm{N}$ but does not currently set values for marine waters (Demers, 2006, pers.comm.). There exists an interim guideline for nitrate ions $(<16 \mathrm{mg} / \mathrm{l})$; however, this does not relate directly to eutrophication or other indirect threats to marine environmental health, and relates only to direct toxic impacts (CCME, 2003).

Sumagaysay-Chavoso et al. (2004) reviewed environmental quality criteria from various regulatory bodies for $\mathrm{P}$ and $\mathrm{N}$ in several forms. They found that total $\mathrm{P}$ should not exceed $0.17 \mathrm{mg} / \mathrm{l}$ (USEPA- Effluent standards), 0.06 (CCME-Canadian water quality guidelines, 1994) to $0.83 \mathrm{mg} / \mathrm{l}$ (USEPA) for $\mathrm{NO}_{2}-\mathrm{N}$, and 10.0 (Department of Environment and Natural Resources (DENR),1995) to $16.9 \mathrm{mg} / \mathrm{l}$ (USEPA) for $\mathrm{NO}_{3}-\mathrm{N}$. The maximum allowable TAN levels were found to range from $0.66 \mathrm{mg} / \mathrm{l}$ at $25^{\circ} \mathrm{C}$ and $\mathrm{pH}$ 8 (CCME) to $1.77 \mathrm{mg} / \mathrm{l}$ (USEPA). Other criteria found were the proposed ASEAN water quality criteria for parameters with varying units. These include: $0.055 \mathrm{mg} \mathrm{NO} \mathrm{N}_{2} \mathrm{~N} / \mathrm{l}$, $0.045 \mathrm{mg} \mathrm{PO}_{4}-\mathrm{P} / \mathrm{l}, 0.17 \mathrm{mg}$ total $\mathrm{P} / \mathrm{l}$, and a concentration of $10 \mathrm{mg} \mathrm{Chl} a / \mathrm{m}^{3}$ for estuaries and open coastal waters (Sumagaysay-Chavoso et al., 2004).

The Australian and New Zealand governments set joint water quality guidelines for influent (water entering an aquaculture operation), source water, and the safety of aquatic foods for human consumers including foods produced by aquaculture, commercial, recreational or indigenous fishing, but not recreational and commercial fisheries, based on wild populations of aquatic organisms (ANZECC, 2000). These guidelines were developed to assist water resource managers to maintain an appropriate level of water quality for existing and future aquaculture activities, and to provide the basis for various aquaculture-related management decisions such as EIA, monitoring, zoning, site selection, site capacity, stocking densities, feeding regimes, production schedules, etc.(ANZECC, 2000). The physico-chemical stressor guidelines relating to

\footnotetext{
${ }^{5}$ To date, concentrations of nutrients (N, P, silicate) and other parameters (chlorophyll a, residence time, loading, etc.) in Canadian nearshore environments and any information relating to algal blooms and other eutrophic effects (fish kills, changes in biodiversity, etc.) have been gathered. A draft guidance framework is expected at the end of 2006 (EC, 2005). The guidance document will hopefully help fill in current knowledge gaps and provide a basis for more appropriate marine environmental criteria.
} 
nutrients in saltwater environments include: nitrate $=<100000 \mu \mathrm{g} / \mathrm{l}$; nitrite $=<100 \mu \mathrm{g} / \mathrm{l}$; and phosphates $=<50 \mu \mathrm{g} / \mathrm{l}($ ANZECC, 2000).

As previously stated, the shortfall of these guidelines is that they are meant only to protect cultured species and not wild populations. As such, the Australian government also set water quality guidelines for managing aquatic ecosystems with the aim to protect wild fish species. Various key indicators were selected as significant water quality characteristics for the protection of aquatic ecosystems (ANZECC, 2000). Relevant parameters for the purpose of this paper include: frequency of algal blooms expressed as changes from natural conditions, total $\mathrm{N}(\mathrm{TN})$, total $\mathrm{P}(\mathrm{TP}), \mathrm{NOx}, \mathrm{NH}_{4}$, filterable reactive phosphate (FRP), Chl $a$ and DO. The water quality guidelines vary depending on the level of disturbance of a particular area and the type of aquatic ecosystem due to the diversity of aquatic environments in Australia. For slightly disturbed ecosystems, similar to areas where aquaculture may be present, the ranges of trigger values for the parameters described above are compiled and presented below (Table 5) in ascending numerical order. These values are taken from 3 of the 4 most environmentally relevant geographic areas for which values have been derived.

Table 5: Default Trigger Values- Marine Environment of Australia and New Zealand

\begin{tabular}{|l|l|l|}
\hline & \multicolumn{2}{|c|}{ Marine Environment } \\
\hline Parameter & Inshore & Offshore \\
\hline $\mathrm{TN}(\mu \mathrm{gN} / \mathrm{l})=<$ & $100,120^{*}, 230$ & $100,120,230$ \\
\hline $\mathrm{TP}(\mu \mathrm{gP} / \mathrm{l})=<$ & $15,20,25$ & $10,20,25$ \\
\hline $\mathrm{NOx}(\mu \mathrm{gN} / \mathrm{l})=<$ & $\mathbf{5 , 5 , 2 - 8 ,}$ & $1-4,5,5$ \\
\hline $\mathrm{NH} 4(\mu \mathrm{gN} / \mathrm{l})=<$ & $1-10,5,15$ & $1-6,5,15$ \\
\hline $\mathrm{FRP}(\mu \mathrm{gP} / \mathrm{l})=<$ & $5,5,10$ & $2-5,5,10$ \\
\hline $\mathrm{Chl} a(\mu \mathrm{g} / \mathrm{l})=<$ & $0.7,1,0.7-1.4$ & $0.3,0.5-0.9,1$ \\
\hline $\begin{array}{l}* \\
\text { *bold }=\text { values not specific to inshore or offshore environments (cited as 'marine') and could be applied to } \\
\text { both environments; duplicate values between areas were left to show trends within inshore or offshore }\end{array}$ \\
\hline
\end{tabular}
Data taken from ANZECC, 2000.

Trigger values for inshore and offshore are generally similar; however in some cases offshore values tend to be more stringent depending on the geographic location. There is substantial variability between some locations for both inshore and offshore values. This demonstrates that species sensitivity will vary between cases and ecosystem type.

Overall, because many of the environmental criteria presented above for DO, $\mathrm{N}$ and $\mathrm{P}$ have different units, it is difficult to compare guidelines between regulating bodies. Furthermore, not all of the guidelines are intended to protect aquatic species; some 
criteria are water quality guidelines, and others relate to effluents. Therefore, some may be more or less stringent than necessary to protect indigenous species and ecosystem health. Comparable values are fairly similar but the context of the specific environment is important to consider and accounts for varying values. Lastly, while regulating bodies address the need to consider eutrophication in guideline determination, to date few have actually been adopted concerning this aquatic problem. Increasing work dealing with aquaculture-related nutrient additions and resultant eutrophication has begun to fill this information gap and will provide currently lacking data for future guideline development.

(iii) Aquaculture-related water quality degradation in the Bay of Fundy

Growing information on the role aquaculture plays in rising nutrient and organic matter levels and decreasing dissolved oxygen levels suggests that cumulative impacts due to intensive culture in the Bay of Fundy are degrading ambient conditions and exceeding natural assimilative capacities in many areas. Salmon consume oxygen both through respiration and by metabolic activities that release $\mathrm{N}$ and $\mathrm{P}$ into the water column at the farm site (Strain \& Hargrave, 2005). Oxygen is further consumed as waste feed in the form of large particles is deposited in the benthic environment. This feed also releases nutrients on time-scales of days to months. Smaller feed particles and faecal matter are degraded in the water column, again creating oxygen demand and nutrient releases 'distributed over broad areas, on a time-scale of several days' (Strain \& Hargrave, 2005).

As salmon production increases, oxygen demand and nutrient inputs also increase. Crossing the line of intensity and carrying capacity can lead to wide-spread eutrophication impacts that can alter extensive ecosystem function and configuration (Strain, 2005). Factors such as decreased DO, increased dissolved nutrients and suspended particulate organic matter, increased organic sedimentation, and associated changes in benthic habitat and communities are the most commonly observed environmental changes (Hargrave, 2003). However, all these factors are related to eutrophication, water quality and regional assimilative capacity which are not considered in farm siting or environmental monitoring in SWNB.

While the physico-chemical and biological water quality parameters serve as satisfactory indicators of aquatic environmental quality in many geographic regions, 
unique regional characteristics of SWNB make some of these parameters less suitable as environmental criteria relating to eutrophication (Strain, 2005). For example, the high turbidity of inshore waters suggests plant and algae production is light-limited as opposed to nutrient-limited. As such, increases in water column $\mathrm{Chl} a$ or the underlying benthic epiphytes are unlikely (Strain, 2005). The intertidal zone has been found to have high levels of macroalgal growth (Robinson et al., 2005; Strain \& Hargrave, 2005) and thus macroalgal growth is a potentially useful indicator of water quality in SWNB. However, in practice, the lack of historical data and clear cause-effect relationships makes these criteria less applicable (Strain, 2005). Some areas are also naturally prone to lowered DO levels and thus site-specific and ambient conditions must be obtained before being compared against any suggested trigger value. Lastly, while water quality guidelines for the protection of aquatic life have been proposed, few relate directly to eutrophicationcausing variables such as $\mathrm{N}$ or $\mathrm{P}$ in Canada. Considering water quality indicators on an ecosystem-wide basis is also important for maintaining overall benthic and pelagic species protection. The most substantive guidelines to date are those of Australia; however, due to the various geographic locations and lack of comparative studies of environmental characteristics between Canada and Australia, use of these variables for SWNB may not be suitable.

\section{(iv) Relating environmental criteria to environmental concentrations}

In light of these difficulties, some experts are skeptical as to whether any single eutrophication indicator will adequately relate to and meet the needs of salmon culture management in Canada (EC, 2005; Strain, 2005). In consideration of these concerns and in the absence of eutrophication-related criteria, researchers in the field have taken a comparative approach to impact quantification by setting aquaculture inputs against natural and other anthropogenic sources of N, P, C and oxygen demand, and have considered influences on ambient conditions and ecosystem metabolism (Strain \& Hargrave, 2005).

Strain (2003) used a fish growth model to estimate the total SWNB salmon industry-related oxygen demand and nutrient discharges and then assessed the potential for these discharges to influence natural conditions in the CMRs. The results show that 
aquaculture discharges into the Letang/letete CMR have the potential to decrease oxygen by $17 \%$ of saturation $(275 \mathrm{mM})$ and to increase nutrient concentrations (dissolved inorganic $\mathrm{N} 6.2 \mathrm{mM} \geq$ background levels of $9.7 \mathrm{mM}$ in Back Bay, 1999) in the whole inlet. He also found that farming activity in this area may have already exceeded the environmental carrying capacity (Strain, 2003). Phosphorus levels, due to their higher natural levels, were similar to background concentrations. Changes in the other CMRs were found to be minor and much lower than offshore nutrient concentrations. However, variations in local environments (for example, in areas of low currents or flushing) could create more impacts close to the farm site since scale was a major factor in impact analysis (Strain, 2003). Strain's study also found that the salmon aquaculture industry was the largest anthropogenic contributor of oxygen demand and nutrients to the Letang/letete CMR, exceeding two fish processing plants, a pulp mill and a sewage treatment plant, in 1992. A decade later, aquaculture exceeded these sources by a factor of 1.6 to 3.4 (Strain, 2003).

Hargrave (2003a) took this information a step further and compared the relative magnitude of salmon aquaculture-related oxygen, $\mathrm{N}$ and carbon fluxes in the Letang/letete CMR with natural and anthropogenic sources and sinks for these elements. The results are shown in Table 6. Inputs are expressed as MT/d. Data for other anthropogenic sources from 1991-1992 are taken from Strain et al. (1995) and increased by $25 \%$ to reflect industrial and population growth since 1992 . Inputs from salmon aquaculture were derived from total annual discharges for 2002 for odd and even years. 
Table 6: Comparison of aquaculture-related nitrogen, carbon and BOD with natural and anthropogenic sources and sinks in the Letang Region.

\begin{tabular}{|lccc|}
\hline Source & BOD & Nitrogen & Carbon \\
\hline runoff & 0.35 & 0.03 & 0.82 \\
precipitation & - & 0.05 & - \\
sewage treatment & 0.24 & 0.013 & 0.14 \\
pulp mill & 0.65 & 0.011 & 0.38 \\
fish plant production & 7.2 & 0.75 & 4.18 \\
salmon aquaculture & & & \\
(1991-1992) & 12.0 & 0.79 & 2.33 \\
(2002 odd) & 9.9 & 0.79 & 2.82 \\
(2002 even) & 24.7 & 1.97 & 6.85 \\
\hline
\end{tabular}

Source: Hargrave, 2003a.

The author suggested that when all sources were considered, CMRs where the BOD loadings and nutrient discharges were within natural variability may have an assimilative capacity for these inputs. Conversely, large fractions of total inputs associated with aquaculture would imply or could predict potential changes (Hargrave, 2003a). The results of this part of the study are presented in Table 7. Values in bold represent CMRs and years where fluxes of elements through salmon are $>20 \%$ of the total. In Table 6, oxygen consumption includes respiration of fish plus faeces and waste food; total $\mathrm{N}$ loss includes soluble excretion and burial in sediments; and carbon release includes respiration and burial in sediment (Hargrave, 2003a). 
Table 7: Fluxes of oxygen, nitrogen and carbon (percent of total flux)

\begin{tabular}{|lcccccc|}
\hline Area (CMR) & \multicolumn{2}{c}{ Oxygen } & \multicolumn{2}{c}{ Nitrogen } & \multicolumn{2}{c|}{ Carbon } \\
Year & odd & even & odd & even & odd & even \\
\hline Grand Manan(1.2) & 0.3 & 0.3 & 11.9 & 12.7 & 5.2 & 5.6 \\
$\begin{array}{l}\text { Campobello/Deer } \\
\text { Islands (3,4,5) }\end{array}$ & 0.4 & 0.2 & 17.2 & 8.7 & 7.8 & 3.8 \\
$\begin{array}{l}\text { N. Passamaquoddy } \\
\text { Bay (6) }\end{array}$ & $<0.1$ & 0.1 & 2.2 & 4.0 & 0.9 & 1.7 \\
Letang/Letete (7) & 1.1 & 2.8 & 21.9 & 41.2 & 10.3 & 22.3 \\
$\quad$ Lime Kiln Bay & 8.6 & 21.4 & 54.4 & 78.5 & 32.6 & 58.8 \\
Bliss Harbour & 3.7 & 10.0 & 41.8 & 68.7 & 22.8 & 47.3 \\
Back Bay & 5.6 & 14.7 & 38.3 & 63.8 & 19.7 & 42.0 \\
Letete Passage & 0.3 & 0.2 & 8.1 & 6.3 & 3.3 & 2.9 \\
Other Areas (8) & 1.1 & 0.5 & 19.8 & 11.2 & 9.2 & 4.9 \\
\hline
\end{tabular}

Source: Hargrave, 2003a

Based on the data, oxygen depletion due to salmon in even year production exceeds the threshold in Lime Kiln Bay (Letang/letete CMR), and similar but more drastic patterns are shown for $\mathrm{N}$ and $\mathrm{C}$ in the entire Letang area. Other CMRs exhibit lower values for all variables; however, percent values for $\mathrm{N}$ are generally more elevated than oxygen and $\mathrm{C}$.

Strain and Hargrave (2005) updated the work of Strain (2003) and Hargrave (2003a) to include phosphorus inputs of some natural and anthropogenic sources to the Letang Inlet. (Table 8) All units and data specifications are similar to Table 6.

Table 8: Comparison of aquaculture-related BOD, C, N and P to natural and anthropogenic sources and sinks.

\begin{tabular}{|lllll|}
\hline Source & BOD & Carbon & Nitrogen & Phosphorus \\
\hline runoff & 0.35 & 0.82 & 0.03 & 0.0018 \\
precipitation & - & - & 0.05 & 0 \\
sewage treatment & 0.24 & 0.14 & 0.013 & 0.0024 \\
pulp mill & 0.65 & 0.38 & 0.011 & \\
fish plant & 7.2 & 4.18 & 0.75 & 0.10 \\
Salmon aquaculture & & & & \\
1991-1992 & 12.0 & 2.3 & 0.79 & 0.12 \\
2002 odd years & 10 & 2.6 & 0.71 & 0.12 \\
2002 even years & 25 & 6.5 & 1.8 & 0.31 \\
\hline \hline
\end{tabular}

Source: Strain and Hargrave, 2005. 
Strain and Hargrave (2005) also updated the comparative values of the relative magnitude of oxygen, $\mathrm{C}$ and $\mathrm{N}$ fluxes due to salmon aquaculture in the CMRs of SWNB with the fluxes reflecting the primary natural sources or sinks. The results follow a similar pattern as the previous study; however, conditions in the Letang/letete CMR worsened and the other CMRs remain under, but approaching, the threshold. These results are presented in Table 10 in a subsequent section. Overall, the values were used to examine the significance of aquaculture wastes on an inlet-wide basis from distances of 2 to $25 \mathrm{~km}$, determine the extent to which the salmon industry is transforming natural processes, and provide indicators of environmental carrying capacity within CMRs.

\section{(v) Environmental carrying capacity for oxygen utilization}

Based on the information presented above relating to DO, there exists an opportunity for improved management decisions through an estimation of environmental carrying capacity with respect to oxygen utilization.

In order to practically relate and apply the information above to siting farms, Page (2003) developed a simple model for estimating the impact of Approved Production Limits and Estimated Site Potentials on dissolved oxygen levels of Seal Cove, Grand Manan Island. The model was based on knowledge of ambient DO concentrations, a suitable DO lower limit threshold, the rate of oxygen utilization by caged salmon, and the flushing rate of the Cove. The author suggested that the calculations could be used to estimate the number of salmon required to meet a 'target' DO (Page, 2003). Page (2003) used the tidal prism method to determine the residence time and flushing rate of the Cove. In order to determine the rate of DO utilization by the salmon, the author used the most current APLs and ESPs (2002-2003) to create the combined APL and ESP for all farms within the Cove. The oxygen consumption rate for salmon with an average water temperature of $\sim 12^{\circ} \mathrm{C}$ and fish swimming at $\sim 1$ body length $/ \mathrm{s}$ is $\sim 100 \mathrm{mg} \mathrm{DO} / \mathrm{kg} / \mathrm{h}$, and thus for a fish wet weight of $4 \mathrm{~kg}$, the consumption rate is $400 \mathrm{mg} \mathrm{DO} / \mathrm{fish} / \mathrm{h}$. To acquire the DO consumption rate for all the fish in the Cove, the author multiplied $400 \mathrm{mg}$ $\mathrm{DO} / \mathrm{fish} / \mathrm{h}$ by the total APL and then by the total ESP yielding a value in units of $\mathrm{mg}$ DO/h. Page (2003) states that these rates are most suitable to the 'later summer and earlyfall of a pre-market salmon production cycle'. The amount of time for the salmon to use 
all of one of three DO buffers ( $1 \mathrm{mg} / \mathrm{l}, 2 \mathrm{mg} / \mathrm{l}$, and $3 \mathrm{mg} / \mathrm{l})$ was then determined and used in a ratio of time for fish to utilize the DO buffer (Tbuf) to flushing time (Tfl) (Page, 2003). Using the ratio evaluation scheme presented below, the result provided an indication of the likelihood for cultured salmon to influence ambient DO concentrations, and the ability to increase APL production toward the ESP.

Tbuf/Tfl >>1: salmon require a long time to use the DO buffer relative to the time needed to flush the bay and thus the risk of using up the buffer is small. NOT at maximum carrying capacity

Tbuf/Tfl $<<1$ : DO being utilized faster than replenishment and thus there is a high risk of using up the buffer and DO levels below the threshold.

AT or EXCEEDING maximum carrying capacity

Tbuf/Tfl $\approx 1$ : the utilization rate is similar to the flushing rate and localized depletions of DO below the threshold may occur, especially if DO utilization is increased.

APPROACHING or AT maximum carrying capacity (Page, 2003)

The author states that if APL or number of fish is increased, the ratio is reduced by $\sim 0.1$ for every 100,000 fish. If the water temperature or the weight of the fish is increased, a similar reduction is observed (Page, 2003).

For the above calculations, the author makes some assumptions that may lead to uncertainties. These include: homogeneous mixing throughout the Cove; DO concentrations being consistently as high as $9 \mathrm{mg} / \mathrm{l}$; the threshold value is appropriate; other sources of oxygen utilization are unimportant relative to salmon respiration in Seal Cove; and all scenarios are based on worst-case conditions (Page, 2003).

\section{(vi) Applicability of DO utilization model to CMRs}

The model used by Page (2003) was employed for a semi-enclosed embayment with more than one operating salmon farm. The cove contained certain hydrographic characteristics that enabled estimation of flushing time and residence time. For the purposes of the calculations, Page (2003) assumed total mixing and used certain averaged values such as fish wet weight, ambient DO, salmon oxygen consumption rates, and the threshold value of $6 \mathrm{mg} / \mathrm{l}$. Due to the applicability of this model to both siting farms and setting production limits, it is proposed that the skeleton of this model be used to estimate 
the rate of DO utilization by salmon farms within CMRs. The model is applicable to CMRs based on the fact that they are functional hydrographic entities with minimal cross boundary water exchange, and thus residence times and flushing rates can be estimated.

The residence times for each CMR were obtained and flushing times were calculated from these values (Refer to Appendix B). It should be noted that freshwater and wind mixing were not included in flushing rates. Silvert and Sowles (1996) estimated the holding capacities of 20 inlets using three models; a purely tidal flushing model, tidal flushing model including freshwater runoff, and another form of a tidal flushing model. Wind mixing and consequential wave-induced flushing was found to be very difficult to model due to variability. The authors found that there were no notable differences in model outputs and thus inclusion of freshwater and wind mixing in flushing rates did not significantly alter estimates of holding capacities (Silvert \& Sowles, 1996). Furthermore, it has been observed that the peak growing season coincides with periods of minimum stream discharge and therefore runoff does not substantially alter nutrient loadings (Silvert \& Sowles, 1996).

The following equation components have been retained from the original model for the purpose of the analysis presented below.

- Salmon oxygen consumption rate $=\sim 100 \mathrm{mg} \mathrm{DO} / \mathrm{kg} / \mathrm{h}$

- Average salinity $=32$

- Average temperature $=12^{\circ} \mathrm{C}$ : annual range of temp at various farms throughout SWNB found to be $10-15^{\circ} \mathrm{C}$ with variations over the tidal cycle $\sim 1^{\circ} \mathrm{C}$ (Peterson et al., 2001)

- $\quad$ Fish swimming speed $=\sim 1$ body length/s (Peterson et al., 2001)

The remaining components have been changed to reflect the most current industry information. Variables changed for application of the model to each CMR are as follows.

- Total APLs (TAPL) and total ESPs (TESP) to date for each entire CMR were obtained from NBDELG. Sites where ESPs were not available from NBDELG were either obtained from their EA or an average ESP value derived from the other ESP values in the respective CMR was allocated to that site in order to be able to calculate the cumulative or total ESP for each CMR. Refer to Appendix B.

- Average fish wet weight $=4.5 \mathrm{~kg}$ : values of $4.9 \mathrm{~kg}$ (Hargrave, 2003; Peterson et al., 2001), $4.0 \mathrm{~kg}$ (Page, 2003), and $4.5 \mathrm{~kg}$ have been recommended; however, the amended ESP equation uses a value of $4.5 \mathrm{~kg}$ to represent the average market 
weight of salmon (Sweeny International, 2004), and in light of precaution without overestimation, $4.5 \mathrm{~kg}$ has been chosen as a suitable value.

- Threshold DO level $=7 \mathrm{mg} / \mathrm{l}$ :CCME (2003) recommends a value of $8 \mathrm{mg} / \mathrm{l}$ but states that in areas where natural levels are lower than the interim guideline the value should be used as the threshold. DO levels in many areas of SWNB have been found to be as low as $7 \mathrm{mg} / 1$ ( $~ 80 \%$ saturation) during late summer early fall (Hargrave, 2003; Page, 2003). Aquatic species have been found to exhibit behavioural changes at concentrations $<7 \mathrm{mg} / \mathrm{l}$.

- DO buffer $=1.0 \mathrm{mg} / \mathrm{l}: \mathrm{CCME}$ (2003) states that when ambient DO concentrations are $>8.0 \mathrm{mg} / \mathrm{l}$, human activities should not cause DO levels to decrease by more than $10 \%$ of the natural concentration expected in the receiving environment at that time $(0.8 \mathrm{mg} / \mathrm{l}$, thus $\sim 1.0 \mathrm{mg} / \mathrm{l})$. Although in extreme cases DO levels have been measured at $50 \%$ saturation (Peterson et al., 2001) and $80 \%$ saturation in some areas in late summer/early fall, these values are not representative of DO levels in all areas. Therefore, taking the median DO value of $8.0 \mathrm{mg} / \mathrm{l}$ between the average range of values $(7-9 \mathrm{mg} / \mathrm{l})$ in the Bay of Fundy during peak growing season (day 250-350), and $10 \%$ of this value, there is a $1 \mathrm{mg} / \mathrm{l}$ buffer between the median ambient value and the threshold.

- DO consumption rate for $4.5 \mathrm{~kg}$ fish $=450 \mathrm{mg} \mathrm{DO} / \mathrm{fish} / \mathrm{h}$

CMR volumes were also obtained in order to perform calculations. Similar assumptions were made for the amended equation as those made for the original. These assumptions include: mixing within the CMR; fairly consistent DO levels across CMRs; an appropriate threshold value was chosen; and scenarios are based on worst case conditions such as those found in late summer/early fall.

\section{(vii) Estimating the rate of $D O$ utilization}

Given the components of the equation presented above, the following procedure was used to determine the amount of time required for the salmon to use up the DO buffer in a CMR, and to determine the ratio between this rate and the flushing time.

\section{1: Residence time (RT) and flushing time (FT)- From the RT, the FT for each CMR} has been determined based on the tidal prism method suggested by Page (2003). $\mathrm{RT}$ is equal to the time to exchange $63 \%$ of the water within the CMR, and time for $95 \%$ flushing to take place is 3RT. However, as noted by Page (2003), the flushing rate is generally underestimated by a factor of at least 2 and thus when used in the ratio, $\mathrm{FT}=5 \mathrm{RT}$. 
2: Consumption rate for TAPL and TESP-The DO consumption rate for salmon, 450

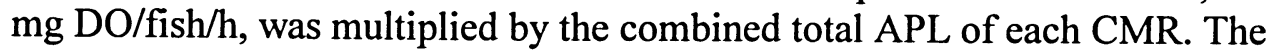
same procedure was used for the total ESP.

3: Time for DO buffer utilization- The following procedure was conducted twice to determine the Tbuf. The first Tbuf used the consumption rate based on the combined total APL and the second used total ESP.

CMR volume (litres) $x$ Average ambient DO in the CMR $(8 \mathrm{mg} / \mathrm{l})=\mathbf{X ~ m g}$

$\mathbf{X} \mathrm{mg} /$ Consumption rate for CMR TAPL or TESP $(\mathrm{mg} \mathrm{DO} / \mathrm{h})=\mathbf{Y} \mathrm{hrs}$

$\mathbf{Y}$ hrs $/ 24$ hrs $=\mathbf{Z}$ days

4: Ratio of DO utilization of buffer to flushing time- As noted in Page (2003), if other factors are incorporated into the DO buffer utilization rate such as increased respiration due to feeding ( $2 \times$ respiration rate), post feeding $(4 \mathrm{x}$ basal metabolism), increased biomass in the CMR aside from the APL, increased BOD due to other industries, sediments, salmon feed and faeces ( $\sim 60 \%$ of oxygen used by salmon respiration), the time required for DO buffer utilization can be cut in half. Other factors affecting increased metabolic activity and respiration include: rising seasonal temperatures; storm events or higher currents in more offshore locations leading to higher swimming speeds; and smaller fish with faster swimming speeds (have been measured up to $2 \mathrm{bl} / \mathrm{s}$ (Peterson et al., 2001)). Therefore, in consideration of the possibility of these factors influencing DO utilization, the ratio equation is:

Tbuf $/ \mathrm{Tfl}=(\mathrm{Z} / 2$ days $) /(\mathrm{FT})$

5: Environmental carrying capacity and allowed increased production- based on the evaluation scheme presented by Page (2003), each CMR Tbuf/Tfl ratio for TAPL and TESP was found to be greater than, less than or equal to 1 . From these results it was determined whether each CMR was exceeding, at, or below the environmental carrying capacity with respect to maintaining DO at non-critical levels. In cases where the ratio was found to be $>>1$, the ratio of the TAPL was then compared to the ratio of the TESP to determine whether the TAPL could be increased within the CMR, and if so by how much assuming each additional 100,000 fish reduces the ratio by $\sim 0.1$. The findings of these calculations are presented below. 
Table 9: CMRs suitable for increased production with respect to DO

\begin{tabular}{|c|c|c|c|c|c|}
\hline \multirow{2}{*}{ CMR } & $|c|$ Tbuf/Tf & $\begin{array}{c}\text { Environmental } \\
\text { Carrying Capacity } \\
\text { for DO }\end{array}$ & $\begin{array}{c}\text { Increase } \\
\text { TAPL? }\end{array}$ & $\begin{array}{c}\text { Allowed } \\
\text { Increase of Fish }\end{array}$ \\
\cline { 2 - 5 } & TESP & TAPL & YES & 7500000 \\
\hline GM & 8.0 & 15.5 & Not exceeded & YES & 5400000 \\
\hline CDI & 9.1 & 14.5 & Not exceeded & YES & 7100000 \\
\hline NPB & 6.5 & 13.6 & Not exceeded & NO & NA \\
\hline LL & 0.4 & 0.7 & Exceeded & NO & 900000 \\
\hline OTHER & 1.1 & 2.9 & Almost reached & YES & \\
\hline
\end{tabular}

It should be noted that these values are based on current production levels and research conducted to date. If significant changes in production levels in the industry take place, or if new research on ambient DO concentrations presents different results, values will need to be adjusted. Also, the OTHER category presently considers the coastline extending east from the Letang CMR designation and includes areas such as Beaver Harbour, Foley's Cove, Seeley's Cove and Macey's Bay. Areas beyond this point such as Duck Cove, Little Dipper Harbour, Chance Harbour and Haley's Cove have had leases sited since most recent research was conducted; however, due to their small areas and the coastal proximity to other sites, it is expected that significant increases in production will likely contribute to exceedances of carrying capacity for this coastal management region (Refer to Appendix B for 2005 site map).

(viii) CMR environmental assimilative capacities for nitrogen \& carbon

In the absence of substantial available data on nutrients to enable model prediction of net exchanges, rates of ecosystem fluxes can be used as indicators of overall ecosystem metabolism, and can be weighed against additional fluxes due to salmon aquaculture (Strain \& Hargrave, 2005). By comparing the relative magnitude of oxygen, carbon and nitrogen fluxes due to salmon operations with natural sources of sinks, Strain and Hargrave (2005) determined CMRs which are at risk of altering natural ecosystem structure and function because contributions of salmon fluxes represent considerable percentages of natural processes. It has been suggested that salmon wastes should not contribute more than $20 \%$ of total fluxes. Strain and Hargrave (2005) present CMRs and sub-regions that are exceeding this threshold (Hargrave, 2003; Strain \& Hargrave, 2005). 
Given the suggested conservative threshold of $<20 \%$ of aquaculture-related contributions to natural fluxes of oxygen, $\mathrm{C}$ and $\mathrm{N}$, the values highlighted red in Table 10 illustrate CMRs where the environmental carrying capacity for additional fluxes due to salmon operations is being exceeded. Considering the CCME (2003) recommendation that anthropogenic activities should not reduce oxygen levels below $10 \%$ of natural concentrations, and other researchers have suggested the same threshold to maintain natural variability in nutrient fluxes (Hargrave, 2003), this value should be used in order to suggest areas where anthropogenic inputs may have the potential to overwhelm ecosystem function. As such, in Table 10, values in yellow represent areas which may be at risk of surpassing the threshold. Although measurements were taken for oxygen, oxygen-related environmental carrying capacity was addressed in the previous section and thus was not included in this table.

Table 10: Percent of total flux due to salmon aquaculture

\begin{tabular}{|l|cccc|}
\hline & \multicolumn{2}{c}{ Nitrogen } & \multicolumn{2}{c|}{ Carbon } \\
CMR & odd & even & odd & even \\
\hline Grand Manan & 10 & 11 & 6.5 & 7.1 \\
Campobello/Deer Islands & 16 & 7.3 & 10 & 4.6 \\
N. Passamaquoddy Bay & 1.7 & 3.2 & 1.1 & 2.1 \\
Letang/Letete & 22 & 70 & 14 & 34 \\
$\quad$ Lime Kiln Bay & 93 & 330 & 58 & 160 \\
Bliss Harbour & 58 & 210 & 37 & 100 \\
Back Bay & 47 & 170 & 29 & 84 \\
$\quad$ Letete Passage & 6.2 & 11 & 3.9 & 5.2 \\
Other Areas* & 19.8 & 11.2 & 9.2 & 4.9 \\
\hline RED= exceedance of $<20 \%$ of total fluxes & & & \\
YELLOW = exceedance of $<10-20 \%$ of total fluxes & & & \\
\hline
\end{tabular}

Source: Strain \& Hargrave, 2005: *Hargrave, 2003.

While phosphorus is also a component of aquaculture waste that leads to risks of increased algae production, lower DO levels, and degradation of ecosystem-wide water quality, there exists significant uncertainty $(67 \%)$ in the estimates of $\mathrm{P}$ discharge. This is said to be attributable to the variability of $\mathrm{P}$ in feed and fish tissue and limited FCR data (Strain \& Hargrave, 2005). The calculations performed for $\mathrm{N}$ and $\mathrm{C}$ can be performed for $\mathrm{P}$; however, with high uncertainty the results would be less relevant and potentially misleading, thus $\mathrm{N}$ represents nutrient contributions.

Table 9 and 10 presented CMRs that are approaching or exceeding environmental carrying capacity relating to DO utilization, and are exceeding or at risk of exceeding the 
threshold of salmon-related fractions of natural fluxes, respectively. Based on these findings, CMRs presented in Table 11 are deemed unable to further support aquaculture operations based on a loss of ecosystem function, assimilative capacity, and water quality. The CMRs have been graded based on their suitability for increased or continued production. Suitability was determined based on DO utilization, potential to increase TAPL, and percent of total flux of $\mathrm{C}$ and $\mathrm{N}$ due to salmon relative to natural processes.

- If Tbuf/Tfl $<$ or $=1$, the CMR was deemed unsuitable.

- If the $<20 \%$ threshold for $\mathrm{N}$ and $\mathrm{C}$ was exceeded, the $\mathrm{CMR}$ was deemed unsuitable.

- If the $<10-20 \%$ threshold was exceeded, the CMR was deemed conditionally suitable.

- Any instance where a CMR is deemed unsuitable means that the CMR is unsuitable; however, if a CMR is deemed conditionally suitable for $\mathrm{N}$ and $\mathrm{C}$ and substantially suitable in terms of DO, the CMR may be deemed suitable.

Findings regarding environmental carrying capacity are supported by previous studies (Strain et al., 1995; DFO, 2003; Strain \& Hargrave, 2005; Strain, 2003, 2005; CCNB, 2003; Wildish, 2006, pers. comm..).

Table 11: CMRs suitable and unsuitable for further production and estimated increased production as number of fish

\begin{tabular}{|c|c|c|c|c|c|}
\hline \multirow[t]{2}{*}{ CMR } & \multicolumn{3}{|c|}{ Suitability } & \multirow{2}{*}{$\begin{array}{c}\text { Number } \\
\text { of fish }\end{array}$} & \multirow[t]{2}{*}{ *Terms of increased production } \\
\hline & Unsuitable & $\begin{array}{c}\text { Conditionally } \\
\text { Suitable * }\end{array}$ & Suitable & & \\
\hline GM & & $\checkmark$ & & 7500000 & $\begin{array}{l}\text { Suitable as long as } \mathrm{N} \text { levels remain } \\
\text { constant and TESP is not exceeded. }\end{array}$ \\
\hline CDI & & $\checkmark$ & & 5400000 & $\begin{array}{l}\text { Suitable if current ODD year production } \\
\text { is decreased, TAPL does not reach } \\
\text { TESP, no additional nutrient-releasing } \\
\text { industry is introduced to the area, and } \\
\text { percent } N \text { does not increase to } 20 \% \text {. }\end{array}$ \\
\hline NPB & & $\checkmark$ & & 7100000 & $\begin{array}{l}\text { Suitable if TESP is not reached or is } \\
\text { decreased, and if TAPL is not increased. }\end{array}$ \\
\hline LL & $\checkmark$ & & & & \\
\hline OTHER & & $\checkmark$ & & 900000 & $\begin{array}{l}\text { Increased production not recommended } \\
\text { in areas currently designated as OTHER } \\
\text { due ratio of almost } 1 \text {. However, siting is } \\
\text { suitable if current APL at each site is not } \\
\text { increased towards the ESP, if TAPL is } \\
\text { only raised to a ratio of TESP Tbuf/Tfl= } \\
2 \text { in order to maintain ratio above } 1 \text {, if } \\
\text { the TAPL is decreased, ambient } \\
\text { temperatures do not increase and no } \\
\text { nutrient releasing industry is introduced } \\
\text { to the area. }\end{array}$ \\
\hline
\end{tabular}


Based on the findings above, the following question was formulated relating DO, $\mathrm{N}$ and $\mathrm{C}$ to $\mathrm{CMR}$ waste assimilative potential and environmental carrying capacity.

(III) Does the proposed farm fall within a CMR that has been deemed unsuitable for siting based on insufficient environmental assimilative capacity for $\mathrm{N}$ or $\mathrm{C}$ and sufficient DO? If not, does the proposed production level coincide with the TAPL limit of the respective CMR?

Question (III) is meant to address potential cumulative and ecosystem-wide water quality degradation in the absence of clear and defined environmental criteria developed with eutrophication and species protection in mind. The most suitable available environmental criteria and thresholds were chosen and available ambient data were compiled in order to weigh the significance of aquaculture-related waste inputs and consequential oxygen demand against natural processes. From this, in the absence of a formal procedure, a conservative conclusion was made regarding CMRs that are exceeding or are at risk of exceeding their environmental assimilative capacity for salmon wastes. Although two different methods were used for $\mathrm{DO}$ and, $\mathrm{N}$ and $\mathrm{C}$, the results of both methods provide insight about unsuitable and suitable CMRs for siting farms and potential for increased production based on key water quality parameters and natural processes.

Question (III) is answered in two parts. First, the assessor will refer to Table 11 to determine whether the CMR is suitable for siting. If so, the assessor will then refer to the number of fish that may be added to total approved production limit and determine whether the quantity is suitable for siting of a new farm or increasing production of an existing farm.

Scoring: Question (III): To consider water quality parameters and the ability of the CMRs of SWNB to assimilate additional aquaculture wastes from a new lease or increased production, the following scoring scheme will be applied in EA review. If the first part of the question is answered with a YES, then $C$ is assigned. If the answer is NO, then $\mathrm{A}$ is assigned; however, if total approved production limits do not allow for addition of the proposed production levels, $\mathrm{B}+$ is assigned and the proponent must either lower proposed production or reapply. 
Overall it is expected that this question will prevent further damage in CMRs where water quality is poor, and allow recovery in CMRs where water quality is at risk.

Hypoxia within CMRs and benthic habitat impacts

Build up of organic matter from excess feed and faeces under the salmon cages in SWNB has led to benthic environmental degradation and the need for environmental monitoring of sediment chemistry. Since 2002, sites have been monitored relating to both redox (oxidation-reduction) potential and sulfide content to determine the state of oxygen levels beneath each net-pen through the Environmental Monitoring Program (EMP). These EMP indicators, relating to the immediate vicinity of the cages, were chosen based on data relating to organic enrichment, scientific and methodological confidence, feasibility and cost effectiveness (NBDELG, 2001). Monitoring takes place in the fall (peak growth and feeding period of mid-Aug.- mid. Oct.) with spring follow up if the site shows a high level of organic enrichment, pursuant to the appropriate methods and specifications of the EMGs (NBDELG, 2001).

\section{(i) Sediment quality objectives}

As described above, pursuant to Section 35.1 of the Fisheries Act, a HADD is not permitted in the Bay of Fundy. According to Wildish et al. (1999), DFO and the EMGs, a contravention of the Section 35.1 occurs when sediments become anoxic. There are 4 levels of oxygen content as described in Table 12.

Table 12: Descriptions of Sediment Conditions in the Bay of Fundy

\begin{tabular}{|l|l|}
\hline Sediment Condition & \multicolumn{1}{|c|}{ Observed and measured condition } \\
\hline Oxic 1 & $\begin{array}{l}\text {-Redox Potential (Eh) }=>+100 \mathrm{mVNHE} \\
\text {-Sulfide }=<300 \mu \mathrm{M}\end{array}$ \\
\hline Oxic 2 & $\begin{array}{l}\text {-Redox Potential }(\mathrm{Eh})=0 \text { to } 100 \mathrm{mVNHE} \\
\text {-Sulfide }=300-1300 \mu \mathrm{M}\end{array}$ \\
\hline Hypoxic & $\begin{array}{l}\text {-Redox Potential }(\mathrm{Eh})=0 \text { to }-100 \mathrm{mVNHE} \\
\text {-Sulfide }=1300-6000 \mu \mathrm{M}\end{array}$ \\
\hline Anoxic & $\begin{array}{l}\text {-Redox Potential }(\mathrm{Eh})=<-100 \mathrm{mVNHE} \\
\text {-Sulfide }=>6000 \mu \mathrm{M}\end{array}$ \\
\hline
\end{tabular}

Source: NBDELG, 2001. 
The Aquaculture Environmental Coordinating Committee (AECC) concurred with the determination of Wildish et al. (1999) that the sediment conditions correspond to the following rating scale of sediment condition relating to effect level (NBDELG, 2001).

Table 13: Corresponding benthic effect level to sediment condition

\begin{tabular}{|l|l|}
\hline Sediment condition & Effect level related to conditions \\
\hline Oxic 1 & Low effect \\
\hline Oxic 2 & Moderate effects \\
\hline Hypoxic & Higher level of effect \\
\hline Anoxic & High level of effect \\
\hline
\end{tabular}

Source: NBDELG, 2001.

Leases must therefore be in the oxic category, otherwise 'non-compliance will trigger a response under the Remediation Guide, Section 4 of the EMGs' (NBDELG, 2001). During monitoring, the diver will observe the percentage of bacterial matting at each segment of the transect, the presence and relative abundance of macroinvertebrates, the presence of gas bubbles, depth of organic build-up, estimated current speed and direction, depth, etc. (NBDELG, 2001). Although the presence of benthos is considered, species diversity and abundance are not determining factors of site compliance.

\section{(ii) Benthic impacts of low oxygen conditions}

A severe consequence of sedimentation on the benthic environment is a reduction in oxygen levels that alter both species configuration and diversity. While various environmental conditions such as sediment type, current velocity, and resident flora species, among others may determine the type of benthic communities present, the onset of hypoxic or anoxic conditions has proven to alter the existing habitat beneath and immediately adjacent to the cage, creating conditions favourable to new populations. The EMGs define anoxic conditions by 'the absence of macrofauna, the change from aerobic to anaerobic microflora, or by measurements of sulfide in excess of $6000 \mu \mathrm{M}$ and an oxidation-reduction (redox) potential of $-100 \mathrm{mV}$ '(NBDELG, 2001).

Observations in SWNB have shown that with sedimentation rates $>1 \mathrm{~g} \mathrm{C} / \mathrm{m}^{2} \cdot \mathrm{d}$ aerobic respiration is insufficient to prevent organic matter accumulation leading to the formation of hypoxic or anoxic sediments (Hargrave, 1994). Generally, when increased metabolic activity of aerobic bacteria in the sediment surface layer cause oxygen uptake 
to exceed oxygen supply, hypoxic conditions and sulphide producing anaerobic microorganisms take over (Pohle, 2006, pers. comm.; Wildish \& Pohle, 2005). Low oxygen inhibits, and free $\mathrm{S}$ interferes with, aerobic and benthos respiration and thus reducing conditions at the sediment interface enable few macrofauna species to survive (Pohle, 2006, pers. comm.; Hargrave, 2006). Only macrobenthos with low sensitivity and high tolerance will persist. These are generally small body-sized species, deposit feeders, and species with short life-cycles, found at the upper layer of the sediment (Hargrave, 2006). One study found that non-opportunistic macrobenthic infauna taxa were reduced by $50 \%$ of the mean at reference stations at free $\mathrm{S}$ concentrations $\sim 1000 \mu \mathrm{M}$ and by $\sim 70 \%$ at $\mathrm{S}$ concentrations $\sim 3000 \mu \mathrm{M}$ (Hargrave, 2006). Low oxygen and free S-sensitive species such as molluscs (most sensitive) and crustaceans (moderately sensitive) disappear and organic enrichment-tolerant opportunistic infauna species such as polychaete worms (eg. Capitella capitata) appear and dominate (Pohle, 206, pers. comm.; Wildish \& Pohle, 2005; Hargrave, 2006). While meiofauna exhibit varying degrees of sensitivity, Capitella capitata and some nematodes are often the only taxa remaining when surface sediments contain relatively high ( $>5000$ to $10000 \mu \mathrm{M}$ ) concentrations of free S (Hargrave, 2006). However, these opportunistic infauna species are not usually preferred prey species of bottom feeding fish and invertebrate epifauna, and therefore, food supply is decreased and food-web dynamics altered at the sediment surface (Hargrave, 2006). Furthermore, it has been determined that even S-tolerant and opportunistic species display limits of tolerance. For example, in the Broughton Archipelago, Capitella disappeared at S concentrations $>7200 \mu \mathrm{M}$ (Hargrave, 2006). Therefore, while initially increased organic deposition may stimulate macrofauna growth, the impacts associated with high levels of organic deposition characteristic of finfish farming areas results in overall diminished benthic community functions and productivity.

Numerous studies have addressed the benthic impacts associated with organic enrichment, including the progression from aerobically-dominated species to anaerobically-dominated species with increasing sulfide readings and decreasing Eh readings (Wildish et al., 2001, 2005; Pohle et al., 2001; Wildish \& Pohle, 2005; Holmer et al., 2005; Hargrave 1994, 2003, 2006). For example, Wildish et al. (2005) compared 
pre-operational community structures to post-operational configurations. The preoperational macrofaunal community surveyed at a site in Passamaquoddy Bay (1998) was mixed containing both deposit feeders (63\%) and suspension feeders, consistent with the sediment and deposit type. In contrast, small-bodied deposit feeders which largely feed on organic matter at the sediment surface were the most abundant macrofauna found at the post-operational locations (Wildish et al., 2005). Biomass dominants were 2 large echinoderms ( 2 species of sea cucumber) and nematodes that are tolerant of anaerobic conditions.

In the operating farm's footprint, macrofaunal species diversity may be zero or contain only tolerant opportunists, and dominance levels are generally high (Wildish \& Pohle, 2005). Fallowing studies, such as one conducted by the Conservation Council of New Brunswick (CCNB), provide evidence of such trends. The CCNB conducted a 3 year monitoring study at a site in Crow Harbour that had recently ceased operation after 2 years of production (Harvey, 2006, pers. comm.). The study began in mid-August of 2002, days following the last harvest, and a month after the last major feeding. Sampling was then completed at the same location in 2003 and 2004. Redox and sulphide readings were taken pursuant to the methods and protocols of the EMGs and benthic infauna was sampled in order to determine the effects on benthic communities (Harvey, 2006, pers. comm.). A reference site was also used to compare results. The results, presenting 4 measures of species diversity for the macrobenthic community, showed significantly larger proportions of total taxa at the reference site compared to the recently fallowed site, with an increasing number of taxa with each year post-fallowing at the abandoned farm. Species richness followed the same pattern while species diversity was greater at the reference site but a pattern at the farm site was less defined and species eveness showed no identifiable relationship (Harvey, 2006, pers. comm.). These results were congruent with rising Eh values and falling sulphide readings with each year, and showed how organic enrichment drastically changes species composition through a process of elimination and recolonization as oxygen levels diminish and then rise.

Although natural dynamics promote species decline and recolonization, the unnatural excess deposition of organic matter on the sea floor inhibits natural succession, alters food-web dynamics characteristic of the region and causes local extinction of 
macrofauna communities beneath and immediately beside the cage footprint. These consequences are not currently considered in the Environmental Monitoring Program and the focus remains on sulfide and redox readings.

\section{(iii) Regional and cumulative benthic impacts: Habitat loss and fragmentation} While the EMGs address geochemical benthic impacts in the immediate vicinity of the cage, they fail to address more regional and ecosystem impacts. Organic deposition and enrichment not only affect the environment beneath the cage but affect overall foodweb dynamics and available habitat which consequentially alters the overall structure, function and health of the benthic environment.

Environmental regulation and monitoring in the Bay of Fundy is directed at single lease operations, typical of EA processes and regulations that ignore cumulative effects. Each lease is responsible for maintaining oxic conditions, otherwise remediation of hypoxic conditions is necessary. A shortfall of this approach is the lack of consideration for the consequences of many potential hypoxic or anoxic sites in one region. The regional or far-field impacts of hypoxic conditions on a region's benthic configuration are not fully understood; however, it can be deduced that the existence of many hypoxic sites, and thus areas of unsuitable macrofaunal habitat, in one geographic or hydrographic region, create discontinuous habitat, areas of extirpation and a strain on ecosystem health. This discontinuity of habitat is widely known as habitat fragmentation.

Habitat fragmentation is a process in which large continuous areas of habitat are reduced or significantly altered to smaller areas, creating an isolation of original habitat into patches (Hovel, 2003). One of the major potential impacts of the deposition of organic matter in intensive salmon farming areas such as the Bay of Fundy is benthic habitat fragmentation (Milewski, 2001). Habitat fragmentation has been found to dramatically influence species persistence, abundance, diversity and survival both directly and indirectly in terrestrial and marine environments (Frost et al., 1999; Irlandi 1995, 1999; Hovel, 2003; Roberts \& Poore, 2005). In the marine environment, various factors may contribute to habitat fragmentation; many of which are natural (currents, waves, bottom feeding animals) (Hovel, 2003). Not all of these factors will promote adverse benthic community responses because in naturally formed habitats, species are 
adapted to the conditions. However, in disturbed environments where habitat is segregated into patches, species biodiversity can be affected due to the lack of ability to perform natural functions. Species such as barnacles are able to scatter their larvae broadly by currents and tides, maintaining connectivity among patches of habitat. Shortdispersed species such as dogwhelks, on the other hand, have limited dispersal capabilities, hindering movement among patches of habitat (Pannacciulli, nd). As such, species diversity can be decreased at patches of habitat where fragmentation is prevalent.

The influence of habitat cover and configuration on fauna is quite difficult to determine because of the various factors that affect benthic health (Hovel, 2003). Some of the factors that could affect benthic health in the Bay of Fundy include trawling, scallop dragging (Robinson et al., 2001; Kenchington, 1999), eutrophication which leads to smothering algal blooms (CCNB, 2004) (See Figure 8 below), chemical additions to the aquatic environment, rockweed harvesting (CCNB, 2004), and various other oxygendepleting or habitat-destroying activities. In recent years, finfish aquaculture has singlehandedly contributed to many of these negative impacts, and habitats in areas other than immediately beneath cage sites have been altered in SWNB (Hargrave, 2003; Wildish et al., 2004; Milewski, 2001). As such, aquaculture in the Bay of Fundy is both directly, indirectly, and synergistically contributing to benthic habitat fragmentation.

Figure 8: Rockweed overgrown with annual algae and epiphytes.

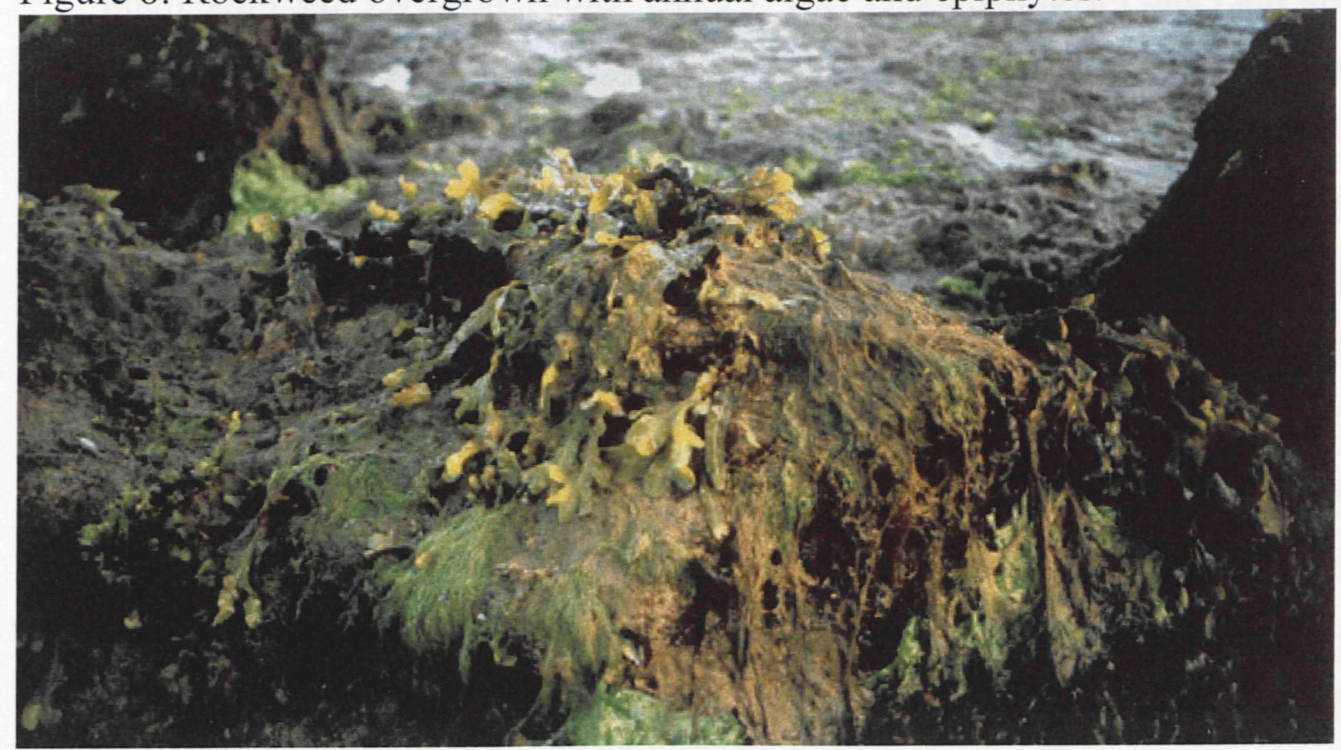

Source: CCNB, 2004. 
Rockweed (Ascophyllum nodosum) is a proliferate seaweed (algae) species in the Bay of Fundy region and an important habitat for at least 22 species of fish (7 of commercial importance), invertebrate species and the prey of some waterfowl (Rangeley \& Kramer, 1998; Fundy Forum, 2001). One way that this productive habitat has been adversely affected is by heavy nutrient additions associated with the aquaculture industry (CCNB, 2004). In areas of the Quoddy region surveyed by CCNB (2004) rockweed beds were found to be highly fragmented. Increased annual green and brown algal blooms in the vicinity of nutrient point sources such as fish farms in the Quoddy region has led to shading of rockweed and creation of low-oxygen conditions in these stands (CCNB, 2004). Rockweed beds are prominent in intertidal areas. Because intertidal areas represent 15 to $40 \%$ of the total area in various CMRs (Strain \& Hargrave, 2005), and an important benthic habitat, high levels of fragmentation in these areas causes a significant decline in available macrophyte and macrofauna habitat.

In addition to impacts on rockweed associated with eutrophication, rockweed is harvested at various locations in the SWNB region (Ugarte \& Sharp, 2001). Leased harvesting areas are broken down into 3 harvesting regions (DFO, 1999): region A is equivalent to the Other CMR, however, extending all the way east along the south coast; region $\mathrm{B}$ consists of CMRs NPB, LL and CDI; and region C consists of the region surrounding the GM CMR. It has been noted that most rockweed harvesting takes place in the Letang Inlet and Passamaquoddy Bay (CCNB, 2004); however, the three main regions comprise 64 management sectors where harvesting may have active lease areas (DFO, 1999). The pilot program that took place between 1995 and 1998 set a harvesting quota at 10,000t, pursuant to the Southwest New Brunswick Rockweed Fishery Management Plan. This represents about 7\% of the total standing stock (Ugarte \& Sharp, 2001). In 1998, harvesting occurred in 39 of the 64 management sectors in SWNB with rockweed harvested within beds with patches varying from 1 to $300 \mathrm{~m}^{2}$ (DFO, 1999). An average of $8 \mathrm{~kg} / \mathrm{m}^{2}$ of rockweed is removed from these patches (Sharp, 2006, pers. comm..), and from $3 \%$ to $100 \%$ of the clumps are impacted by the cutter rake (DFO, 1999). The harvesting season typically starts June $1^{\text {st }}$ following algal reproduction, and extends until October (Blinn, 2005). The rockweed harvest has continued since 1998 under the stipulations of the original Plan and the Rockweed Management Committee 
recommended one company, Acadian Seaplants Limited, be awarded an exclusive license to all three rockweed harvesting areas (Ugarte \& Sharp, 2001).

There is concern that the ecological function of rockweed and the species that utilize the habitat will be compromised by commercial harvest (Fundy Forum, 2001). This practice adds additional stress to already heavily impacted areas. The resultant impacts on species diversity associated with this stressor in combination with other stressors has been the focus of a new unifying ecological theory (CCNB, 2004). The theory combines three separate ecological theories on the role of productivity (nutrient loading), disturbance (harvesting and habitat loss) and consumption (grazers and predation) on diversity (CCNB, 2004). Worm et al. (2002) suggested that interactions among the most common human impacts on the ecosystem (nutrient supply, productivity and resource harvesting) are likely synergistic. Using empirical (field) data across large spatial scales and theoretical modelling, the authors showed that aquatic communities exhibit the same striking pattern. This pattern is as follows: 'the effects of nutrient enrichment depend on grazer pressure and vice versa; these human alterations to the ecosystem have strong and opposing effects on diversity (community structure) and these effects can shift or change effects depending on the degree of consumer removal (harvesting) and resource (nutrient) enrichment' (Worm et al., 2002). It could be said that this theory addresses the role of aquaculture which causes nutrient loadings and habitat loss, in conjunction with harvesting and other natural and anthropogenic habitat manipulation, plays on diversity. This finding emphasizes the need to consider multiple stressors and manage habitat loss and fragmentation not on an individual basis but rather based on all other impacts.

Although the relationship between spatial arrangement of habitat and marine fauna response is not clearly defined (Roberts \& Poore, 2005), studies have been conducted attempting to identify ecological patterns relating to scale and type of habitat. Eggleston et al. (1999) conducted a study on the 'habitat patchiness' component of scale and provided evidence that estuarine macrofauna responses to habitat patchiness in seagrass and oyster shell habitat are dependent on species, taxa, functional group, and body size and are also related to habitat type. The results of the study raised a number of concerns including: responses by mobile organisms to complex benthic habitats; the 
disproportionate reduction in faunal density and diversity in small versus large patches of oyster shell habitat; and the negative impacts on biodiversity through large-scale fragmentation of subtidal oyster reefs in certain regions (Eggleston et al., 1999). While this study did not clearly define a single relationship between macrofauna response and habitat fragmentation, it did show that benthic species are affected by habitat patchiness. Furthermore, although the Bay of Fundy may not have a habitat identical to that studied by Eggleston et al. (1999), rockweed provides the same structured habitat and provides similar benefits to benthic species as seagrass habitats (Lipcius et al., 2005). As a result, it can be assumed that habitat fragmentation both beneath sea cages and in the surrounding region will have a negative impact on benthic community health.

On the whole there is little experimental evidence to enable model formulation relating organismal response to habitat fragmentation; however, the use of a threshold in the form of percent area disturbed can be a useful way to avoid excessive destruction of habitat in one region. In terrestrial environments (forest ecosystems), it has been predicted and validated by empirical studies that faunal abundance is not influenced by changes in habitat configuration until a threshold level of $30-50 \%$ habitat loss is reached (Hovel, 2003). Generally marine ecosystems have been found to be less sensitive to habitat fragmentation than terrestrial systems, however, marine habitat connectivity has been found to be more important than in terrestrial systems (Carr et al., 2003). As such, although fauna in marine environments do not respond identically or posses identical thresholds of response as terrestrial species to habitat fragmentation, marine species do exhibit biological responses worthy of consideration. Therefore, in light of a lack of empirical data regarding thresholds of response for marine species, and in consideration of the potential habitat loss associated with salmon aquaculture and habitat lost to other stresses within CMRs, it is proposed that a conservative approach be taken and greater than $30 \%$ habitat loss be avoided within each CMR of the Bay of Fundy region to ensure adequate conservation of functional benthic habitat.

\section{(iv) Spatial and temporal cumulative impacts}

Another benthic impact that is not considered in regulation and monitoring is the overlapping of organic deposition footprints that through additive contributions from 
many salmon farms in close proximity and high density areas cause cumulative benthic impacts. Although far-field impacts of organic deposition have been less well studied, it has been reported that in SWNB after farm operation for $\sim 5$ years, organic enrichment effects were measurable over $>200 \mathrm{~m}$, and after 12 years macrofaunal community diversity declined throughout the inlet system (Hargrave, 2003). Infaunal diversity was found to be significantly higher at distances of $>500 \mathrm{~m}$ from finfish sites, as was benthic respiration and ammonium flux (Hargrave, 2003), thus indicating that organic enrichment impacts extend beyond the area beneath and immediately adjacent to the lease site. Macroalgal growth in the intertidal zone has been observed, and tracers show that waste discharges from fish farms are reaching the intertidal zones more than a kilometer away from the farms (Robinson et al., 2005). Strain and Hargrave (2005) also noted that oxygen consumption rates in intertidal sediments of SWNB farming areas were higher than those measured on the seabed adjacent to cages or in intertidal sediments far removed from aquaculture areas. The results suggested that in Lime Kiln Bay, SWNB, only $\sim 1 \%$ of the total solids discharged from salmon cages $(\sim 2 \%$ of the refractory solids) were found in sediments close to farm sites, even in a highly depositional environment. Although the results were not well constrained, the implications counter previous thoughts that the majority of waste solids accumulate near the cages and suggest that even at depositional sites, wastes were likely contributing to benthic impacts in the intertidal zones (Strain \& Hargrave, 2005).

Another study relating far-field effects associated with mariculture, carried out in 2 embayments in the Letang inlet and at a reference site, showed a transition of the benthos of Lime Kiln Bay to a biologically-stressed community correlated with increased levels of organic matter from multiple salmon farms 200-300m away (Wildish \& Pohle, 2005). Factors such as seasonal geochemical differences could not account for these changes, and similar trends were not seen at the reference site (Wildish \& Pohle, 2005). Overall, because the mandatory distance between sites in SWNB is $300 \mathrm{~m}$ and leases placed before this requirement may be $<300 \mathrm{~m}$ apart, impact footprints extending $>500 \mathrm{~m}$ from farms in an area where sites are concentrated provides the opportunity for impact footprints that overlap. Furthermore, if the organic matter from multiple operations is depositing in the intertidal zones close to culture areas, the cumulative impacts from all 
farms create the possibility for a substantial part of each CMR (15-40\%) to be subject to benthic disturbance. Therefore, there is evidence alluding to the need for regional and cumulative benthic consideration to accompany site-specific management.

Temporal cumulative benthic impacts must also be considered as it has been found that with increased years of operation, benthos become more altered (Hargrave, 2003). Results from the study presented above, described significant temporal changes of the benthic macrofaunal community related to mariculture between 1994 and 1999 at the experimental locations (Wildish \& Pohle, 2005). Wildish and Pohle (2005) tested the null hypothesis that benthic macrofaunal communities in the Letang distant from farm sites were not significantly different between 1975 and 1997 or 2000, thus no far-field effects were attributable to mariculture. A comparison of early (1975) and later $(1997,2000)$ samples at the same locations show a clear temporal change in community structure for all stations (Wildish \& Pohle, 2005), thus rejecting the null hypothesis.

Based on the information above, it can be concluded that it is not adequate to consider the benthic impacts of a site independently of the other sites in a particular region. Due to the threat of potential spatial and temporal cumulative benthic impacts, particularly in high density, close proximity, net depositional areas, all sites within a CMR must be considered in order to properly protect benthic species habitat and health.

\section{(v) Benthic species recovery time}

In an attempt to rectify benthic degradation but more often in reaction to disease outbreaks, salmon farms have been fallowed in SWNB. Many studies have been conducted relating to fallowing and sediment chemistry recovery rates, and in recent times, attention has been directed toward benthic species' recovery after periods of hypoxia or anoxia (Wildish \& Pohle, 2005). The studies reviewed in Wildish and Pohle (2005) found the recovery time for benthic macrofauna to range from 6 months to $>2$ years. However, noticeably improved conditions have been measured at times as short as 2 months at salmon farms in Australia (Macleod et al., 2004). Variations in recovery time could be associated with a lack of a recovery endpoint to suggest when benthic conditions had resumed pre-disturbance status, differences from initial benthic communities, whether the location was net depositional (took longer to recover) or erosional (Wildish 
\& Pohle, 2005), or a lack of establishment of local baseline standards (Macleod et al., 2004). While it had been generally accepted that benthic recovery followed a similar process as sediment chemistry, and ceased finfish-related sedimentation led to improved conditions under net-pens, recent studies found that benthic species do not recover at the same rate as sediment (Harvey, 2006, pers. comm.; Macleod et al., 2004). In one case, benthic faunal community recovery was greater than 18 times the sediment recovery time (Macleod et al., 2004). The concern is thus raised that if it is determined that fallowing or decreased production is required at a degraded lease site in SWNB, under current monitoring requirements, improvements will be based only on redox and sulfide readings and not benthic species' abundance and diversity. Therefore, species will not be given adequate recovery time before sedimentation recommences, and this could result in a permanent reduction of biodiversity and biomass at this location (Harvey, 2006, pers. comm.). Based on this information, in addition to the consideration of cumulative temporal impacts, an adequate recovery time for benthic species after fallowing practices of a particular site in a CMR must be incorporated into the decision process in order to properly estimate viable versus altered benthic habitat.

The EMGs state that "as information becomes available, other indicators of environmental impact may be incorporated into the Guidelines." It is recommended that in light of lacking information, the studies presented above provide a basis for adjustments to monitoring reflecting far-field, cumulative and regional impacts on benthic habitat.

The following two proposed Regional Questions pertain to benthic impacts:

(i) Based on the number of sites in the CMR that were oxic 2, hypoxic or anoxic during the last 3 monitoring periods, what is the percent habitat loss?

(ii) How long have the oxic 2 or below sites in the CMR been operating and what is the estimated operation lifetime?

Questions (i) and (ii) reflect important benthic health factors that must be considered in siting of salmon farm through incorporation of the information presented above. Question (i) incorporates the spatial component and the recovery time component, while question (ii) incorporates the temporal component. 
In order to respond to question (i), the assessor requires two things: the most recent EMP information including the present year and previous three years' results; and the equation used to calculate percent area of habitat loss in the CMR of the proposed site. ${ }^{6}$ The most recent monitoring results are presented in Appendix C. The information has been reorganized and placed into groups according to their designate CMR, whereas current monitoring results obtained from NBDELG are organized according to site \# and BMA. For the purpose of this paper the CMRs are colour-coded so as to better distinguish between regions. Question (i) is a two part question with three steps. The steps are as follows:

STEP 1: Determine the number of sites in the CMR that are now or were in the last three years oxic 2, hypoxic or anoxic. Oxic 2 is chosen instead of hypoxic as the threshold because research has shown that significant benthic community reconfiguration (40-60\% loss of infaunal taxa) occurs at $S$ levels found in the Oxic 2 range of the EMGs (Hargrave, 2006). Therefore, hypoxic and anoxic conditions should not be the determination of a level of diminished habitat function as by the time hypoxia or anoxia is reached reductions in taxa may have reached $90 \%$ (Hargrave, 2006). The time period of three years was chosen based on the most conservative recovery time suggested to date ( $>2$ years) with an addition of a year to account for the differences in sediment versus benthic community recovery. Thus, if a site in the CMR is currently or has had conditions that have facilitated the potential for macrofauna species extirpation or reconfiguration of benthic habitat, then in order to cautiously account for habitat lost and species affected, these sites are considered to be a loss of habitat.

STEP 2: Once the number of sites has been determined, the percent habitat loss must be calculated. Because the majority of the studies state that the most heavily impacted area is the cage footprint, the following equation has been developed for the area affected of circular cages:

Area affected $=\pi r^{2}$,

\footnotetext{
${ }^{6}$ The EMP results are available at the N.B. Dept. of Environment and Local Government (NBDELG).
} 
where $\mathrm{r}=11 \mathrm{~m}$, the area affected $=380 \mathrm{~m}^{2}$, and thus for a lease containing a total of 14 cages (in 2001) the total area affected $=0.5 \mathrm{~km}^{2}$ (Wildish \& Pohle, 2005). As presented above, studies relating to far-field impacts on benthic species indicate that the area of influence extends beyond the area immediately below the cage $(200-500 \mathrm{~m})$. As such, it is suggested that the entire lease area of the hypoxic site be considered in the area affected.

Based on 18 approved salmon farms in the Bay of Fundy, the average area of a lease is 22.84 hectares or $0.23 \mathrm{~km}^{2}$. This value is smaller than that suggested by Wildish and Pohle (2005) because it takes into account that all leases will not be as large or contain as many cages as the one described above. However, the possibility of overlapping impact footprints and cumulative impact areas of intertidal zones within CMRs must also be considered. If the average affected area is equal to $0.23 \mathrm{~km}^{2}$, impacts have been found to extend up to $\sim 500 \mathrm{~m}(0.5$ $\mathrm{km}$ ), and the regulation has traditionally called for a $300 \mathrm{~m}$ separation, this $300 \mathrm{~m}$ distance must be considered as a potential overlapping or cumulative impact zone. Although siting in recent years has discouraged siting a farm within $3 \mathrm{~km}$ of another, some sites in the study area may be within $300 \mathrm{~m}$ due to past approval. Therefore, in CMRs where 2 or more sites are <oxic 2, a safety factor of $300 \mathrm{~m} \mathrm{x}$ $300 \mathrm{~m}=90,000 \mathrm{~m}^{2}$ or $\sim 0.10 \mathrm{~km}^{2}$ must be added to the affected area of the CMR for each additional two <oxic 2 sites. Thus, two sites <oxic 2 in a CMR would have a safety factor of $0.10 \mathrm{~km}^{2}, 4$ sites <oxic 2 would have a safety factor of 0.20 $\mathrm{km}^{2}, 0.3 \mathrm{~km}^{2}$ would be added if there were 6 sites, and so on.

To account for cumulative depositional impacts within intertidal zones, an additional area of $0.25 \mathrm{~km}^{2}$ is added to the initial affected area. This value was arbitrarily selected due to the lack of evidence relating to the extent of intertidal areas impacted within each CMR and the degree of disturbance associated with these impacts. However, due to the importance of the intertidal zone as productive habitat and because intertidal areas constitute $15-40 \%$ of CMRs, decreased habitat function within these areas must be accounted for. 
Based on uncertainty regarding the extent of habitat destruction from other activities in the Bay of Fundy such as trawling, dragging, dredging and the potential for tidal power, it is suggested that an additional $0.50 \mathrm{~km}^{2}$ be added to the affected area within each CMR.

Rockweed harvesting must also be considered in the total habitat affected due to its significant role in removing productive benthic habitat and the potential for synergistic impacts on the benthic environment and species that inhabit it. Back of the envelope calculations suggest that if an average of $8 \mathrm{~kg} / \mathrm{m}^{2}$ is removed from rockweed lease areas, and $10,000 t$ is the maximum allowable harvest per annum, then at any particular year approximately $1.25 \mathrm{~km}^{2}$ of rockweed can be removed by the harvest. It has been said that biomass removal is more appropriately expressed as tonnes or percent removal (Sharp, 2006, pers. comm..); however, for the purposes of this study a conversion to an approximate area affected is necessary. Therefore, this value should be taken as a loose habitat loss estimate simply to consider the potential role that rockweed harvest plays in total area affected by aquaculture in combination with other destructive activities. Because this value represents the total area within all three harvested regions, dividing this value by 5 gives a loose estimation of affected areas within each CMR. Again, harvesting is not uniform across all CMRs and some CMRs are harvested more than others but for the purposes of this study and until more conclusive information is available for the tonnage within each area for each year, an area of $0.25 \mathrm{~km}^{2}$ is added to the affected area within each CMR.

The resulting approximate total affected area of benthic habitat after considering $<$ oxic 2 finfish sites in combination with other habitat disturbances within a CMR is determined by the following equation:

Total affected area $=(\#$ of sites $<$ oxic 2 in the CMR $) \times\left[\left(0.23 \mathrm{~km}^{2}+0.25 \mathrm{~km}^{2}\right)+\right.$ the safety factor of $0.10 \mathrm{~km}^{2}$ if necessary] + the additional potential area affected of $0.75 \mathrm{~km}^{2}$. 
STEP 3: Once the total area affected has been determined for the CMR, this value is divided by the total area of the CMR. The CMR areas are presented below.

$$
\begin{aligned}
& \mathrm{LL}=37.2 \mathrm{~km}^{2} \\
& \mathrm{CDI}=172 \mathrm{~km}^{2} \\
& \mathrm{GMI}=172 \mathrm{~km}^{2} \\
& \mathrm{NPB}=172.3 \mathrm{~km}^{2} \\
& { }^{7} \text { Other }=50.5 \mathrm{~km}^{2}
\end{aligned}
$$

(Hargrave, 2006a, pers. comm. Data taken from Gregory et al., 2003).

In order to demonstrate the procedure, an example is provided in Appendix C.

Question (ii) takes into account the temporal cumulative impacts of salmon farms in operation for many years. Because sites become more degraded with time, sites that have been in production for greater than 2 years with lowered oxygen conditions will likely have continual adverse benthic impacts until production is significantly lowered or ceased. Furthermore, in areas where consistent production has taken place for many years ( $>5$ years), the risk becomes higher that impacts will not be localized but move far-field and regional. As such, siting a salmon farm in a CMR with long-term cases of lowered oxygen conditions is less preferred than a CMR with younger lease sites or sites that have not had low oxygen levels. If a site is in its first year of operation and it has oxic 2 or lower monitoring results, the estimated time of operation is important as it has already degraded the environment and will likely continue to do so.

It is expected that by forcing consideration of the overall state of the benthic habitat in siting decisions, benthic community studies will be encouraged to aid in understanding the effects of long term disturbance and disturbance leading to habitat fragmentation. The goal should be to not simply attempt to avoid anoxic conditions but maintain a healthy environment at each lease site if salmon operations are to continue.

Scoring: Question (i): Given current research and taking a conservative approach, the following scoring scheme has been designed for percent habitat loss. If a CMR has 0-

\footnotetext{
${ }^{7}$ Although the Other CMR is not a continuous or confined region, because, for example, the entire shoreline from Beaver Harbour east has been characterized as important lobster habitat and many areas are recruitment areas (DFO, 2001), a loss of habitat along this coast results in an overall loss of productive habitat in the Other CMR.
} 
$10 \%$ habitat loss a score of A will be given; $11-20 \%=$ a score of $\mathrm{B}+; 20-30 \%=\mathrm{B}-;$ and $>$ $30 \%$ is assigned a score of $C$.

Question (ii): If oxic 2, hypoxic or anoxic sites within a CMR have been or will be (if it is the first year of production) in operation for 1-2 years a score of $\mathrm{B}+$ is given; for 3-4 years, B- is given; and > 5 years $\mathrm{C}$ is assigned.

\section{Predator deterrent devices and endangered species ${ }^{8}$}

Question (v) of the present Far-field set of questions addresses endangered species. This question states that,

'aquaculture sites should not be located within $5 \mathrm{~km}$ of habitat utilized by any protected or endangered species unless effective mitigation measures can be applied to reduce potential harmful effects. For example, if acoustic deterrent devices are used to protect cultured fish against predators (e.g. seal and birds), they can emit noise to interfere with predator behavior over distances $>5 \mathrm{~km}$. Use of alternative predator avoidance methods could reduce the potential harmful effect on an endangered species' (Hargrave, 2002).

There has been growing evidence that noise plays a major role in species' behavioural modification, displacement and decline in the marine environments. Negative effects have been observed in bird populations and marine mammals. Environment Canada (2001) states that noise deterrents should be used when predation becomes a significant problem. These acoustic deterrents include devices such as whistles, sirens, firecrackers, recorded distress or predator calls, electronic sound systems, and automatic exploders that produce random sound patterns at various frequencies and intensities. With provision of a "scare permit" under the Regulations of the Migratory Birds Convention Act from the Canadian Wildlife Service, firearms or aircraft are considered in extreme cases.

Two basic types of underwater noise devices employed to ward off predators are low-powered devices called acoustic deterrent devices (ADDs) used to temporarily displace marine mammals, and high-powered acoustic harassment devices (AHDs) designed to cause pain and used to prevent predation on fish (Milewski, 2001). ADDs and AHDs emit different noise levels and have different ranges of audibility depending

\footnotetext{
${ }^{8}$ For the purposes of this paper, unless specifically stated otherwise, the term 'endangered species' is used to represent all species designations under SARA and COSEWIC.
} 
on ambient noise (Taylor et al., 1997). It is assumed that the fundamental frequency determines the radius of the zone of audibility, the higher the frequency the more absorption and the smaller the range (Taylor et al., 1997). The zone of severe disturbance and discomfort is an area within which the sound level is highly likely to reach a level where significant disturbance in terms of habitat exclusion or discomfort to the animal occurs.

Taylor et al. (1997) used 3 different types of AHDs used at net-pens to determine the zone of audibility for porpoises. They found that in low ambient noise conditions, the range of audibility was between a minimum radius of $2.8 \mathrm{~km}$ to a maximum radius of $12.2 \mathrm{~km}$ (Taylor et al., 1997). The authors determined that these zones of audibility are likely to represent a significant proportion of coastal habitat in high density fish farm areas such as the Quoddy Region of the Bay of Fundy, and that several commercial AHDs produce sounds loud enough to adversely affect harbour porpoises, and potentially other marine mammal species such as the endangered right whale (Taylor et al., 1997). The impacts of ADDs are thus regional and potentially cumulative concerns, as opposed to simply a concern immediately around a site.

Because seals are a major predator of cultured salmon, the ADDs and AHDs are generally designed to either scare the seals by emitting loud noises (Goldburg \& Triplett, 1997) or to cause physical pain. Most acoustic models are designed to produce sound with fundamental frequencies that match the greatest hearing sensitivities of phocid seals ( 5 and $35 \mathrm{kHz}$ ) (Johnston, 2002). However, often the seals become habituated to the noise emitted by the ADDs, limiting their effectiveness (Jacobs \& Terhune, 2002). Furthermore, marine mammals may be affected in many different ways by AHD sounds, such as behavioural modifications, disruption to activities, displacement from habitat, physiological changes, and physical and auditory damage (Taylor et al., 1997). In areas such as the Quoddy region, harbour porpoises, a threatened species, may perceive ADD or AHD noises as a threat and avoid them. In such instances their habitat becomes reduced and movements between important areas may be limited or hindered (Taylor et al., 1997). Empirical evidence has shown total exclusion of porpoises within $400 \mathrm{~m}$ of an active AHD and significant reductions in porpoise abundance within $3.5 \mathrm{~km}$ (Taylor et al., 1997). Johnston (2002) also found porpoise density to be reduced in the vicinity of an 
active AHD in the Bay of Fundy. Although AHDs are often intended to cause pain to the predator, at very close distances physical damage can occur to both target and non-target species (Morton \& Symonds, 2002). Taylor et al. (1997) report that theoretically, harbour porpoises could incur immediate hearing damage and injury within 7 meters of an AHD.

Other species, such as the killer-whale, are particularly vulnerable to the AHDs because of the nature and sensitivity of their hearing (Morton \& Symonds, 2002). A study conducted in B.C. found that the installment of 4 high-amplitude AHDs at a salmon farm in the Broughton Archipelago caused a decline in killer-whales. The study observed that once AHD deactivation took place, whale occurrence re-established to baseline levels, concluding that displacement resulted from the deliberate introduction of noise into the marine environment (Morton \& Symonds, 2002).

There are also suggested to be various potential negative impacts on migratory bird populations. Birds are also predators and devices are intended to deter them from diving and attacking farmed fish. However, like marine porpoises and whales, these birds are at risk of harm. Some potential impacts include: alteration of normal bird movement patterns; avoidance of otherwise accessible habitat; interference with animals' communication signals and passive listening abilities due to "acoustic masking"; and hearing damage (EC, 2001). Fish species have varying sensitivities to noise, some affected by noise and others affected by the vibrations associated with noise production (Milewski, 2001). There have been few studies conducted on the effects of underwater noise associated with ADDs and AHDs used at salmon farms on fishes or invertebrates.

Overall, wildlife that is not deterred by the AHDs is more frequently exposed to them and thus is at a greater risk of incurring physical harm. However, those species that are deterred by them must avoid areas of habitat and migration routes.

Certain types of deterrent devices do not employ noise and have proven effective at deterring predators. This method of deterrence has been called exclusion and often involves physical barriers (Wursig \& Gailey, 2002). For example, certain cage structural modifications do not enable water predators (seals) to attack the netcage directly due to extra protective netting or wiring extending away from the top of the cage. Netting is also often applied on the top of the cages (Figure 9) inhibiting birds from attacking smolts (Drost, 2005, pers. comm.). 
Figure 9: Protective top and additional outside netting, Chance Harbour, 2005.

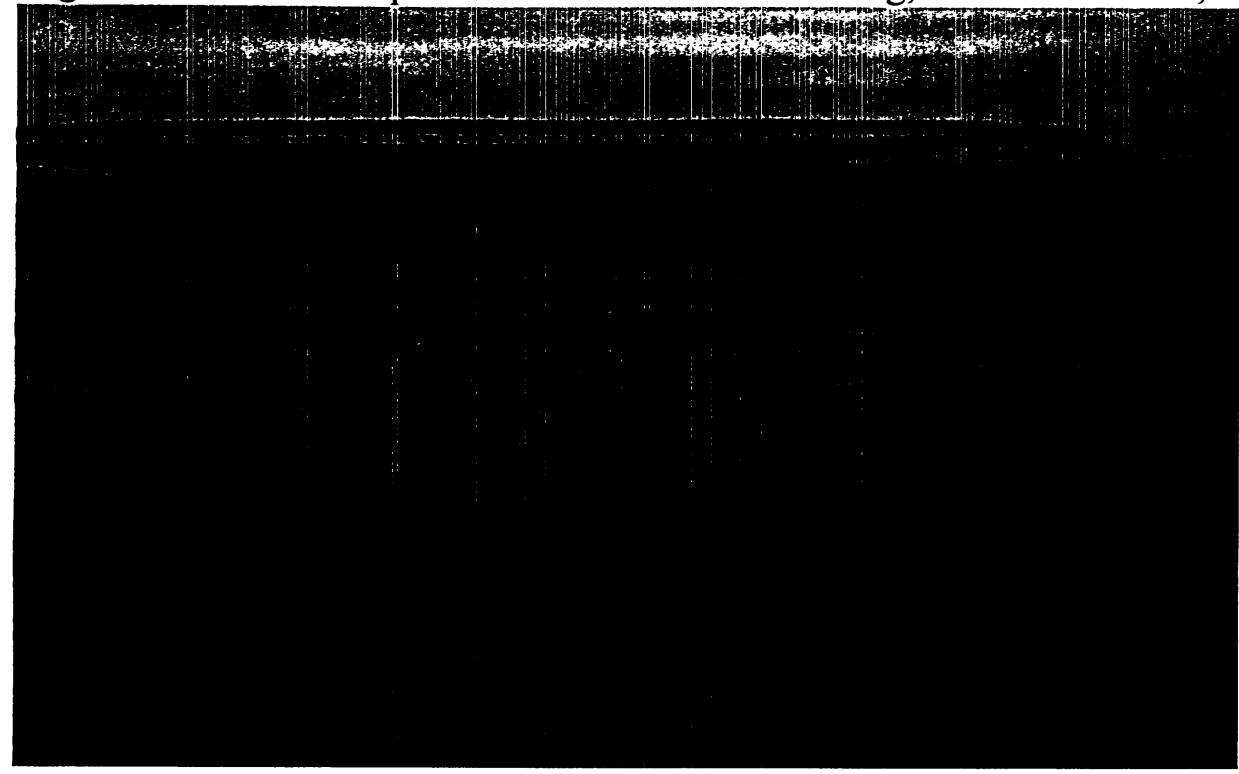

Negative impacts to marine species associated with netting deterrents have been quite infrequent but have included entanglements of marine mammals in the nets and enclosures (Wursig \& Gailey, 2002). These methods have proven effective at excluding predators from fish pens; however, these barriers must be heavy and strong enough to withstand attacks from large predators (Wursig \& Gailey, 2002). Overall, these types of deterrent devices have been found to have sporadic impacts but generally do not pose many of the major threats to physical health of aquatic species.

A survey of the number of AHDs being used to deter seals from approaching salmon cages was conducted in the Quoddy Region and Grand Manan Island, in 1996. The results found that in the Quoddy Region and in the Grand Manan area, $46 \%$ and 22\% respectively of aquaculture sites were using some form of AHD during daylight hours (Johnston \& Woodley, 1998). AHDs were also found to be operating during evening hours only, thus underestimating the total percent of AHD use. The study identified that three different intensities of AHDs were being used, all of which had the potential to negatively impact marine mammal populations, including the threatened harbour porpoise (Johnston \& Woodley, 1998).

Based on the lack of experimental evidence that AHDs and ADDs significantly reduce predation in salmon farming regions, and in light of evidence suggesting that that 
some AHDs may pose a threat to migratory birds and marine mammals, particularly in the form of habitat exclusion (Taylor et al., 1997), the use of these devices must be reconsidered. Authorities are no longer advising the use of ADDs in Canada (Wursig \& Gailey, 2002). In B.C. the use of AHDs and ADDs has been banned. In N.B. use of ADDs has diminished; however, some ADDs and AHDs are still in use, although the exact number is not known (Coombs, 2006, pers. comm..).

Based on the growing concern for endangered species, and the impacts associated with deterrent devices, the following question will be added to the DSS.

(ii) Will predator acoustic deterrent or harassment devices be used at the proposed site?

Scoring: Deterrent devices that do not employ sound or reverberations are less harmful to wild populations. Physical barriers provide the safest option for both deterring predators for industry benefit and eliminating the harm associated with acoustic devices (Wursig \& Gailey, 2002). As such, to accompany Question (v) in the existing DSS, proposed leases that intend to use deterrent devices that do not emit noise or reverberations or use no deterrent devices at all will score $\mathrm{A}$, otherwise $\mathrm{C}$ will be assigned.

\section{Amendments to existing far-field questions}

\section{Critical fish habitat}

Within the current DSS, critical habitat is defined as 'essential areas for feeding and reproduction that are required to sustain identifiable stocks or populations in specific areas. Migration routes are also to be protected from interference' (Hargrave, 2002). Although the DSS attempts to remove subjectivity from the decision process, the question pertaining to critical habitat continues to leave room for interpretation. Habitat biologists may differ in their definitions or evaluations of habitat and whether it is in fact critical (Rose, 2006, pers.comm.). The Fisheries Act defines fish habitat as 'spawning grounds and nursery, rearing, food supply and migration areas on which fish depend directly or indirectly in order to carry out their life processes'. Thus, if the definition of 
habitat is taken from the Fisheries Act, the subjectivity remains in the word critical, and where this habitat is found.

Wild salmon stocks have suffered a devastating decline and hatchery-reared salmon have been unable to initiate adequate self-sustaining populations in the Bay of Fundy regions. Atlantic salmon migration routes have been identified from two rivers in the Passamaquoddy Bay region. Postsmolt migration routes through Passamaquoddy Bay were influenced by a combination of hydrographic conditions, tidal flow, and residual surface currents, and found to be closely related to the counterclockwise residual surface current in the bay (Lacroix et al., 2004). Salmon followed various routes; however, the majority of postsmolts from the St. Croix and Magaguadavic River exited along the western arm of the bay and through Western Passage, or followed an eastern eddy characteristic of summer and exited through the Letete Passage (Lacroix et al., 2004).

Lacroix et al. (2004) found that the migration success of hatchery-reared and wild smolts out of the estuaries was high (range, 90-97\%), and the overall success of postsmolts moving out of Passamaquoddy Bay and into the several passages leading to the Bay of Fundy was reasonable (range, 71-88\%). They also concluded that the presence of salmon farms along the migration route from the Magaguadavic River did not delay eventual migration from the bay and the speed of migration through different habitats was generally similar for both rivers (Lacroix et al., 2004). However, most losses of smolts and postsmolts from the Magaguadavic River occurred in areas near the salmon farms where potential predators were abundant (Lacroix et al., 2004).

Migration routes of other species such as American shad also involve the Bay of Fundy. Similar to salmon, shad have an acute sense of homing and return to the river where they were born (DFO, 2006). The American shad migrating in the Bay of Fundy are generally enroute to the Annapolis, Shubenacadie and Saint John Rivers (DFO, 2006). The river most relevant to the SWNB salmon aquaculture industry and related area of interest is the Saint John. This river outputs into an area east of the current 'Other' CMR designation, towards which industry has been expanding (DFO, 2006). The shad begin to enter the Bay of Fundy in late April, and by early June large numbers begin to migrate around the Bay of Fundy. Migration follows a counterclockwise direction, 
occurring off Nova Scotia in spring, at the head of the bay during summer, and off New Brunswick in the fall (DFO, 2006).

\section{Spawning}

Diadromous species migrate to and from the rivers of the Bay of Fundy region to spawn and grow. However, spawning grounds of local stocks have been identified in the Bay of Fundy for cod, haddock, pollock and herring. Historically, spawning grounds for one or more of these species occurred in all of the discussed Coastal Management Regions providing productive inshore fisheries (Graham et al., 2002). Overfishing, technological advancements, market demand, and government policy all put pressure on the fisheries. Dredging, dumping, pollution (pulp and paper, industry), development, increased water temperatures, agriculture runoff, the decline of key prey species (herring and gaspereau) and associated feeding grounds, and aquaculture have acted cumulatively to create a generally unfavourable environment for inshore and coastal spawning over the last 50 years (Graham et al., 2002).

Although active spawning areas have dramatically declined in the Bay of Fundy, local fishermen and scientific information have identified areas of continued active spawning. These areas are presented in Figure 10 below. It is believed that active spawning areas also exist in areas that are not fished. Fish may be found in former fishing and spawning grounds, however, because these areas are not fished, reproductive populations are not confirmed (Graham et al., 2002). 
Figure 10: Spawning areas (current and historical) for major groundfish species, herring, and lobsters in the Bay of Fundy.

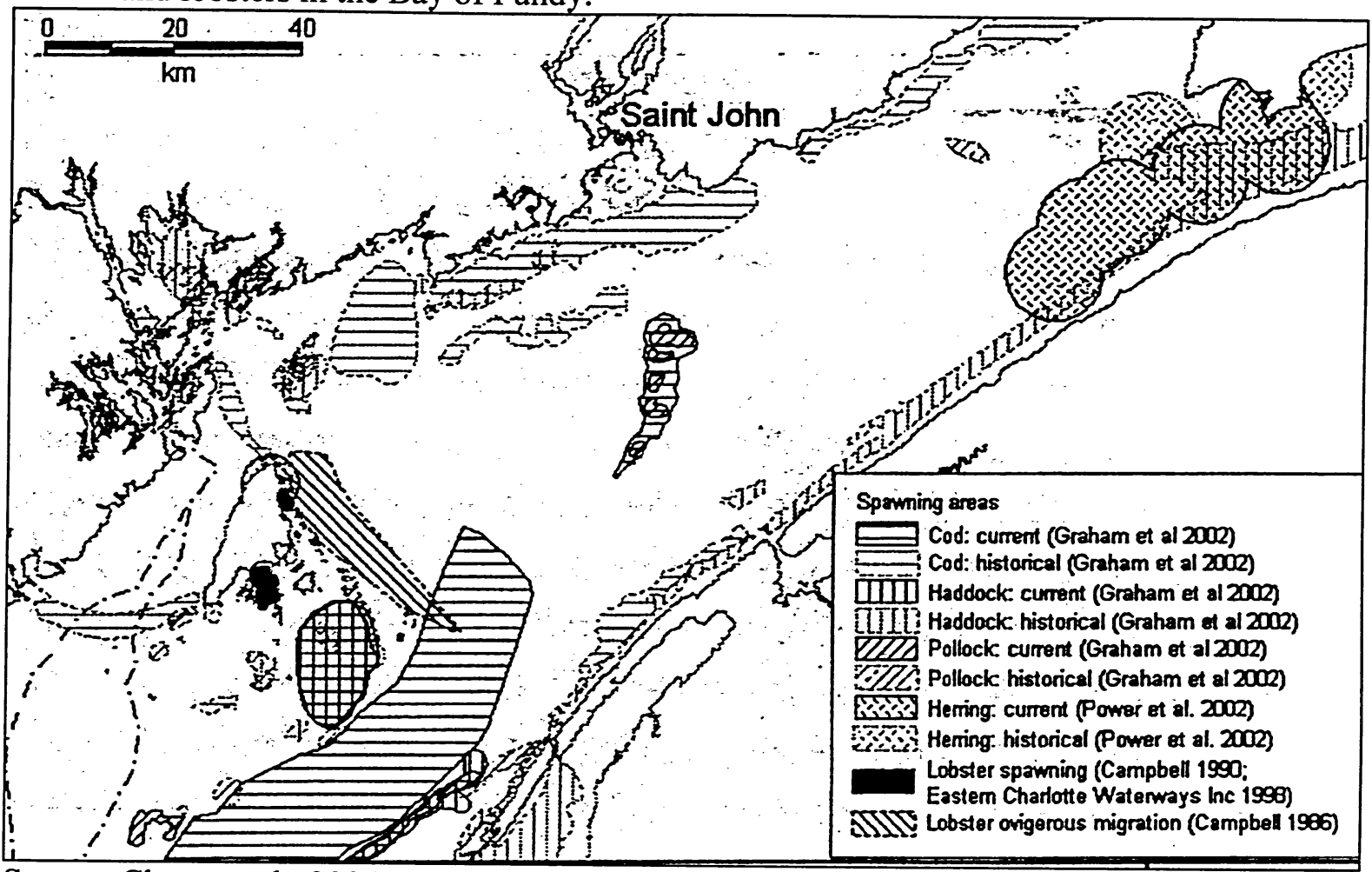

Source: Chang et al., 2005.

The map above outlines lobster spawning areas in the Bay of Fundy. Additionally, the entire shoreline from Beaver Harbour east has been characterized as important lobster habitat, with many recruitment areas (DFO, 2001). Grand Manan island is also host to two critical habitat areas, Flagg Cove and Whale Cove; however, siting is no longer allowed close to these areas. Although the overall lobster stocks in the Bay of Fundy have not diminished due to salmon aquaculture (Robichaud, 2006, pers. comm..), siting of cages does displace lobster. In the early 1990s, a cage was sited in an area with the largest concentration of females with eggs in the Bay of Fundy and all the lobster were displaced out of their bottom habitat that had been preferred for thousands of years (Robichaud, 2006, pers. comm..). Once the site had been removed, the lobster eventually returned, confirming the causal relationship between mariculture siting and species displacement, and raising concern about the presence of aquaculture in areas critical to reproduction and productivity. Therefore, areas deemed important lobster habitat such as 
those stated above should be considered as critical for maintaining productivity and abundant stock levels.

As stated previously, these life processes are essential in maintaining productive and abundant fish populations. Currently, however, important indigenous species are struggling to self-sustain and survive due to past over-fishing, present coastal development, lack of prey groundfish species, degraded marine and fresh-water quality and overall habitat destruction. Because much of the benthic and sheltered coastal habitat has been destroyed, other vital life components and processes must be preserved. In the presence of multiple environmental stresses and vast expanses of altered, disrupted and unsuitable fish habitat, logically it would appear that all remaining fish habitat is in fact critical if species diversity is to be maintained and diminished populations recovered. However, socio-economic fervour drives marine resource use and thus the best possible cohabitation between fish and development must be enforced.

The current DSS question pertaining to fish habitat is an appropriate means of fish habitat protection relating to aquaculture if the criteria deeming an area critical are more clearly outlined. Properly mitigating against impacts for some fish habitat components is less possible. For example, migration is a crucial element of diadromous species' survival and mitigative measures relating to migration are not really possible in the marine environment. As such, in areas of relatively confined migration routes such as the Letete passage, southwestern and eastern Deer Island, and northwestern Campobello Island, proposed or existing sites do not leave ample space for fish species if siting must be $1 \mathrm{~km}$ away from a known migration route. Therefore, the presence of aquaculture farms has a strong potential to significantly impact fish migration. The nearshore and periphery of Passamaquoddy Bay and the coastal area east of Musquash is also a significant migration zone; however, in consideration of the larger area for fish to navigate away from infrastructure, this area is not as critical as those previously stated.

Due to the importance of scarce spawning grounds for cod, pollock, haddock, herring, and lobster in the Bay of Fundy, and the many factors that have destroyed suitable coastal habitat and feeding grounds, protection of the remaining active spawning grounds is vital to maintain scarce stocks. Lobster is one of the last remaining productive 
fisheries and in order to keep populations high, the important habitat along the coast east of Beavour harbour should be protected.

The criteria for determining critical fish habitat has been outlined for some of the major established fisheries in the Bay of Fundy including lobster, salmon, American shad, herring, cod, pollock, and haddock (Fundy Forum, 2001). There remain questions about spawning grounds, feeding grounds, and nursery areas for native species not discussed above. Therefore, subjectivity may still be present for sites proposed where unconfirmed spawning, migration, feeding, or nursery areas may exist. In an area where coastal development and resource exploitation has both diminished local prey and predator stocks and removed vast expanses of vital fish habitat, it is difficult to determine areas of the Bay of Fundy that are not critical fish habitat, especially in inshore regions. However, with abandoned inshore fishing areas, appropriate fisheries management and integration of scientific and local knowledge, areas critical to sustaining and regenerating local stocks can be identified and preserved.

The question pertaining to critical fish habitat has been altered to reflect the criteria presented above. The new question will read as follows:

(xii) Is there a critical fish habitat (e.g. spawning or nursery area, migration route) at or within $1 \mathrm{~km}$ of the site?

Scoring: The scoring for the altered question is as follows. If a critical habitat is known to be present relating to migration, spawning or important lobster habitat as outlined above, or as deemed by the habitat biologist relating to any critical habitat component for which mitigative measures cannot be applied, a score of $\mathrm{C}$ is assigned. If a site is proposed in a migration route less confined like those found in Passamaquoddy Bay and along the coast east of Musquash, a score of B- will be assigned. All sites not proposed at or within $1 \mathrm{~km}$ of a known critical fish habitat will be denoted a score of $\mathrm{A}$. $\mathrm{C}$ is a pre-emptive condition for the cumulative EI. 


\section{Ecologically Significant Areas and preserves}

Question (vi) of the existing far-field set of questions states that Marine Protected Areas, Marine Parks and other protected areas should be avoided by a distance of at least $5 \mathrm{~km}$. Ecologically Significant Areas (ESA) identified in the coastal Charlotte County region by the Nature Trust of NB in cooperation with the provincial Dept. of Environment and Dept. of Natural resources and Energy, should also be included in the list of areas to avoid by $>5 \mathrm{~km}$. These ESAs were determined based on their important habitat, their rich diversity of species or special features such as rare plants, animals, geology or wetlands (NTNB, 2006). ESA information is compiled in a database that is managed by the Dept. of Environment and used in many development and management decisions (NTNB, 2006).

The Nature Trust has worked with private landowners to conserve coastlines. These areas are comprised of preserves and conservation easements including 15 saltwater islands and 6 stretches of undeveloped coastline. These protected areas include: the Letang Islands archipelago, New River Island, The Bishop and Ashburton Head on Grand Manan Island, Chocolate Cove on Deer Island and the Nature Trust is currently working with owners of coastland on Grand Manan Island and Navy Island (near St. Andrews) to ensure protection (NTNB, 2006). These areas should be included in the list of important areas to avoid in siting of aquaculture farms.

All questions that have remained the same as those found in the original DSS have been justified by Hargrave (2002) and this work supports all principles and evidence backing those variables considered. It is not evident that current research exists to expand or improve the existing questions or the scoring schemes.

\section{Final Proposed Set of Regional Questions}

This set of questions includes the newly proposed questions in addition to questions that were kept from the existing DSS. Some existing questions may have been only slightly altered, whereas, others may have been completely removed and new added. 
Initial questions:

I. What Coastal Management Region (CMR) does the proposed site belong to?

II. How many farms are in operation in this CMR (includes leases fallowing but not abandoned) and what is the total CMR Approved Production Limit?

III. Does the proposed farm fall within a CMR that has been deemed unsuitable for siting based on insufficient environmental assimilative capacity for $\mathrm{N}$ or $\mathrm{C}$ and sufficient DO? If not, does the proposed production level coincide with the TAPL limit of the respective CMR? If the first part of the question is answered YES, then $\mathrm{C}$ is assigned. If the answer is NO, then $\mathrm{A}$ is assigned; however, if total approved production limits do not allow for addition of the proposed production levels, $\mathrm{B}+$ is assigned and the proponent must either lower proposed production or reapply. $\mathbf{C}$ is a preemptive condition for the cumulative $\mathbf{E I}$.

If the proposed site does not fall within a CMR already determined to be at its environmental carrying capacity based on levels of DO, $\mathrm{N}$ and $\mathrm{C}$ and/or has not been deemed incapable of increasing its production, the proposal will undergo the series of questions below.

(i) Based on the number of sites in the CMR that were oxic 2, hypoxic or anoxic during the last 3 monitoring periods, what is the percent habitat loss? If a CMR has $0-10 \%$ habitat loss a score of $\mathrm{A}$ will be given; $11-20 \%=$ a score of $\mathrm{B}+; 21-29 \%=\mathrm{B}-;$ and $>30 \%$ is assigned a score of C.

(ii) How long have the oxic 2 or below sites in the CMR been operating and what is the estimated operation lifetime? If oxic 2 , hypoxic or anoxic sites within a CMR have been or will be (if it is the first year of production) in operation for $1-2$ years a score of $\mathrm{B}+$ is given; for 3-4 years, $\mathrm{B}$ - is given; and $>5$ years $\mathrm{C}$ is assigned.

(iii) Will predator acoustic deterrent or harassment devices be used at the proposed site? Proposed leases that intend to use deterrent devices that do not emit noise or reverberations or no deterrent devices at all will score $\mathrm{A}$, otherwise $\mathrm{C}$ will be assigned.

(iv) If there are shellfish closures in the area, what is the distance $(\mathrm{km})$ from the proposed lease site? No closures $=$ " 0 "; no shellfish closure at or near the site, score A; closures occur $<3 \mathrm{~km}, \mathrm{C}$; $<5 \mathrm{~km}, \mathrm{~B}-;<10 \mathrm{~km}, \mathrm{~B}+; \geq 10 \mathrm{~km}, \mathrm{~A}$.

(v) Are any species (fish or invertebrates) harvested for food or are there macroalgal beds within $300 \mathrm{~m}$ ? If the distance of the site is $<300 \mathrm{~m}$ from an existing fishery or macroalgal bed, score $\mathrm{B}+$, otherwise $\mathrm{A}$.

(vi) Is there a Marine Protected Area, Marine Park, Ecologically Significant Areas, preserves or other protected area within $5 \mathrm{~km}$ ? These areas should be avoided; however, if a protected area exists within $5 \mathrm{~km}$ of the proposed site, score B-, otherwise A.

(vii) Are there any endangered fish, mammal or bird species at the site or within 5 $\mathrm{km}$ for which mitigation measures to minimize harmful effects cannot be 
applied? If the distance is $<5 \mathrm{~km}$, score $\mathrm{C}$, otherwise $\mathrm{A}$. $\mathrm{C}$ is a preemptive condition for the cumulative EI.

(viii) Is there river discharge into the inlet/bay system or other factors to create stratification at any time in the year? If stratification occurs at any time of the year, score B-, otherwise A.

(ix) Is there a sill at any location within the inlet/embayment system? If a sill exists at any location within the inlet system to potentially restrict tidal exchange and mixing of the water column, score B-, otherwise A.

(x) Is there any industry (e.g. pulp and paper, logging, fish processing, marina) within $5 \mathrm{~km}$ of the site? If the potential for other sources of industrial waste discharge exists within $5 \mathrm{~km}$ of the proposed site, score B-, otherwise A.

(xi) How many people live within $1 \mathrm{~km}$ of the site? As population are a source of sewage and other urban discharge, human populations close $(<1 \mathrm{~km})$ to the proposed site must be considered. If numbers (general estimations) are small $(<10)$ score A, $(<50)$ score B+, $(<500)$ score B-, otherwise score C.

(xii) Is there a critical fish habitat (e.g. spawning or nursery area, migration route) at or within $1 \mathrm{~km}$ of the site? If a critical habitat is known to be present as deemed by the habitat biologist relating to any critical habitat component for which mitigative measures cannot be applied, a score of $\mathrm{C}$ is assigned. If a site is proposed along the coast east of Beavour Harbour, in confined migration routes of Letete passage, southwestern and eastern Deer Island, and northwestern Campobello Island, or in a spawning area as discussed above, a score of $\mathrm{C}$ is assigned. If a site is proposed in a migration route not deemed a $\mathrm{C}$ (nearshore and periphery of Passamaquoddy Bay and the coastal area east of Musquash) a score of B- is assigned. All sites not proposed within $1 \mathrm{~km}$ of a known critical fish habitat will be denoted a score of $\mathrm{A}$. C is a pre-emptive condition for the cumulative $E I$.

\section{Cumulative ecosystem index (EI)}

The EI is the sum of the numeric scores for the ecosystem variable questions presented above. If a $\mathrm{C}$ is assigned to any of the questions containing pre-emptive $\mathrm{C}$ values (III, vii, xii), the $E I$ is equal to $C$ and thus the application is rejected. If a $C$ is not assigned for any of the pre-emptive questions, the maximum value for $\mathrm{EI}$ is equal to 36 . Following the same scoring scheme for the EI as presented in the current DSS but accounting for additional questions, if $\mathrm{EI}>29$ a score of $\mathrm{A}$ is given; $\mathrm{EI}=20-28$, a score of $\mathrm{B}+$ is given; $\mathrm{EI}=11-19, \mathrm{~B}-$ is given; and $\mathrm{EI}<10, \mathrm{C}$ is given.

Overall, as information for these important issues and critical variables becomes available, 'more accurate quantitative assessments of environmental interactions and sustainable stocking levels' can be determined (DFO, 2003). It is expected that it will become evident that siting or increased site production in SWNB without substantially 
lowered overall production will soon no longer be permitted. Presently, the SWNB portion of the Bay of Fundy has been designated a controlled production area in the NPB CMR and the Deer Island portion of CDI, and an exclusion area in the LL, GM and Campobello Island portion of CDI. This leaves the OTHER CMR for siting and parts of NPB and Deer Island under certain provisions. There has also been work completed to determine areas where offshore farming is suitable in an attempt to avoid inshore areas. However, until absolutely no siting is permitted in SWNB, it is recommended that the modified DSS be used in siting of new leases in an attempt to minimize or avoid irreversible ecosystem damage.

Amending the DSS may limit comparison between new and old sites; however, because the DSS is in its early stages of implementation and amendments have already been made to the original DSS, comparative capabilities are not really an option. Additionally, site specific variables may still be compared as they will not be altered. 


\section{Chapter 6: RESULTS}

The following chapter presents the results of the retrospective review conducted on 23 finfish aquaculture environmental assessments (EAs). As previously discussed, the far-field/newly amended regional questions of the decision support system were applied in the context of a site evaluation for 23 proposed farms (Refer to Appendix D for a list of environmental assessments). The sample included EAs for new sites, sites that were relocating and existing sites wishing to increase production. Before the retrospective review could take place, the EAs were separated by CMR and organized into order of approval date from earliest to most recent. The majority of EAs fell within the Grand Manan CMR (11 salmon and 1 cod site), the second most represented CMR was Campobello/Deer Island (5), 4 sites were found in the Other CMR (plus one farm to be sited in 2005), and 1 site from the Northern Passamaquoddy Bay CMR. The number of EAs per CMR relative to the total number of existing and operating finfish farms yields the following proportional representation: $\mathrm{GM}=46 \%$; $\mathrm{CDI}=17 \%$; Other $=40 \%$; and $\mathrm{NPB}=13 \% .{ }^{9}$ The sample did not include any EAs for sites proposed in the Letang/Letete CMR and only one EA was examined for a site in the NPB CMR. This coincides with the pattern of industry expansion; these regions were populated in the 1980s and early 1990s with farms before federal environmental assessment was mandatory.

Approval dates ranged from March 1998 to November 2005, with the later approval dates found for EAs in the Other CMR and earlier approval dates for EAs in the NPB, CDI and GM CMRs. This also coincides with industry expansion. With recognition of intensive and overpopulation of farms in much of the Quoddy region came a movement into coastal regions east of the densely populated areas.

The lead $\mathrm{RA}^{10}$ for the EAs was either ACOA, DFO, or TC. The triggers for the EAs are presented in Table 14 below as the total number of EAs for each trigger. The two law list ${ }^{11}$ triggers were NWPA 5(1)(A) and Fisheries Act 35(2); however the few EAs

\footnotetext{
9 'Operating farms' are those that have been in operation for 2 or more of the last 4 years or farms sited in 2005.

${ }^{10}$ As defined under CEAA, a responsible authority (RA) is "the federal authority that is required to ensure that an environmental assessment of the project is conducted.

${ }^{11}$ Law List Regulations-Regulations prescribing provisions of Acts of Parliament and regulations made pursuant to any such Act that confer powers, duties or functions on federal authorities or on the Governor
} 
triggered by the Fisheries Act were also triggered by NWPA. EAs that did not have a law list trigger had three triggers. This group of triggers included: funding by a federal authority; the project not being found on the exclusion list; and the activity relating to a physical work.

Table 14: CEAA trigger for 23 finfish environmental assessments

\begin{tabular}{|l|l|}
\hline CEAA trigger & Number of EAs \\
\hline Law list & 111111111111 \\
\hline $\begin{array}{l}\text { Funding, Not on exclusion } \\
\text { list, Physical work }\end{array}$ & 1111111111 \\
\hline
\end{tabular}

The distribution of the sample between the law list and the group of the other three triggers was fairly even. This finding mirrors the division of approval dates into groups of EAs before and after the requirement for NWPA. The EA for Site 381 approved in April 1999 claimed that it was the first salmon farm required to conduct a CEAA screening pursuant to NWPA in SWNB. However, some sites proposed after this time were not triggered pursuant to NWPA. Site 303, formally approved in September 2000 , required a CEAA screening triggered by NWPA that was initiated 1.5 years after the site had been put in the water.

\section{Addressing Regional and Cumulative Environmental Effects}

Cumulative effects were addressed in all of the EAs pursuant to the provisions of the Canadian Environmental Assessment Act. Some EAs addressed cumulative impacts more diligently than others; however, on the whole with exception of the most recent EA conducted (Site 494), discussions of the interactions between the proposed site, existing sites and other industry were minimal. Scores of significance in the environmental effects matrices and interaction table often went from significant in the potential impacts table to insignificant after consideration of mitigation with limited to no reasoning. As such, little transparency was given to the process. Regional impacts were generally not discussed

in Council, the exercise of which requires an environmental assessment (Law List Regulations SOR 94/636) 
except in the context of high density areas such as the Letang region. Assessment of cumulative effects was judgement-based and no mention of modelling approaches or other scientific means was found in any EA except that of Site 402. For that individual site, the results of the DSS conducted by DFO yielded an unacceptable score; however, the site was still approved due to mitigation and monitoring. Site applications submitted post-2002 were meant to be evaluated by DFO using the DSS; however, the other sites assessed post-2002 did not mention the DSS in the EA.

When regional and cumulative impacts were assessed before mitigation and monitoring was considered, the application of the amended regional set of DSS questions to the EAs yielded the results presented in Table 15 below. 


\section{Acceptable Sites Before Mitigation Considered}

Four of the twenty-three proposed sites received an acceptable Cumulative Ecosystem Index (CEI) score for the amended set of regional questions based on the information found in the sample EAs. Site 282 received a score of A and sites 377, 168 and 256 all received a grade of B+. Sites 377, 168 and 256 were not allocated a score of A for the regional set of questions because they received a failing grade of $\mathrm{C}$ for the new questions ii and iii. Question ii represents the potential for temporal cumulative environmental impacts on the benthic environment and a failing grade of $\mathrm{C}$ suggests that the presence of a number of farms within the CMR under oxic 2 conditions still creates the potential for altered habitat despite the fact that the percent habitat loss within the CMR may be relatively low. The scores for question $\mathrm{i}$ were within the $\mathrm{A}$ and $\mathrm{B}+$ range; however, for sites found within the CDI CMR the percentages were approaching concerning levels and were $1 \%$ away from the B- category. Question iii, relating to the use of ADDs, is important because the impacts of one or more ADDs by a single site or

the impacts of ADDs by various farms within a CMR can create the opportunity for both one time and cumulative effects on marine species in an entire region.

\section{DSS Unapproved}

The application of the amended set of regional DSS questions yielded an unacceptable CEI score for the remaining 19 out of 23 sites. The main reason for a failing score was the presence of endangered species within $5 \mathrm{~km}$ of the proposed site (question vii) yielding a pre-emptive score of $\mathrm{C}$. Only four sites $(377,168,256,282)$ were proposed in areas where endangered species were not known to frequent. However, 8 EAs did not even discuss the interaction of the project with endangered species and 7 simply gave the issue an insignificant rating in the 'potential environmental effects table' without explanation. For some of these sites, other literature suggested that endangered species were known to frequent the area. The EA for GM site 270 stated that wildlife and marine mammals were not even subject to analysis of significance and there was no mention of endangered species other than the acknowledgement that the region was an important migratory bird area. 
Another pre-emptive question, xi, was also a reason for unacceptability. Eleven sites were found to be proposed within $1 \mathrm{~km}$ of critical fish habitat. Site 404 was the only one to have a pre-emptive $\mathrm{C}$ score for critical habitat without also having a pre-emptive $\mathrm{C}$ score for endangered species. The critical habitat was either discussed in the EA or found in the areas discussed in the amendments made to the original question.

The new question III did not yield pre-emptive $C$ scores. As such, all sites were able to proceed with the remaining regional questions. If there had been an EA for a site proposed in the LL CMR, a pre-emptive score of $\mathrm{C}$ would have been assigned and the proposal would have not been able to proceed. The other CMRs, however, had not reached their environmental assimilative capacity at the time of assessment for the sample sites. Because the other new questions were not given a pre-emptive $\mathrm{C}$ option, they did not play a primary role in allocating a failing score for the regional set of questions. As previously discussed, in instances where a pre-emptive $\mathrm{C}$ score does not render the site unacceptable, the newly added questions were the main reason for the sites receiving a grade lower than $\mathrm{A}$.

\section{Acceptable Sites After Mitigation Considered}

The DSS does not take into account possible mitigation efforts for the majority of the questions, and therefore is largely used as a screening tool to indicate preliminary (pre-mitigation) effects (Hargrave, 2002). However, both question vii and xii stipulate that a YES to the question should only be answered if mitigation measures cannot be employed or are not substantive at minimizing the potential negative impacts of the project. The results presented in the table above reflect only the presence of endangered species and critical fish habitat with respect to the proposed site and not the potential to mitigate against threats to species. Assuming mitigation will be effective, considering these measures in the application of questions vii and xii to the sample EAs drastically changed the DSS CEI.

According to Hargrave (2002), if mitigation measures are presented in the information accompanying the site application, this information is used in the application of the DSS, otherwise, possible mitigation is not relevant to the DSS application or decision. Therefore, EAs that did not specify mitigation measures for endangered species 
or critical fish habitat retained the pre-emptive $\mathrm{C}$ score for these questions. These sites include: $282 \mathrm{~b}, 270,381,495,186,402$, and 370 . Lacking mitigation for endangered species was the reason for retaining the $\mathrm{C}$ score; mitigation was suggested for impacts to fish habitat for all sites. The amended results are presented in Table 16 along with the newly calculated CEI score and related colour code. Because vii and xii are the only questions that consider mitigation, no other answers were altered. 


\begin{tabular}{|c|c|c|c|c|c|c|c|c|c|c|c|c|c|c|c|c|}
\hline & & & 獄 & & z & & 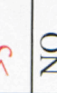 & & 留 & 说 & $z$ & & & $\frac{O}{v}$ & z & \\
\hline$\stackrel{+}{q}$ & 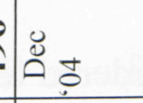 & & है & $\cong$ & z & ב & 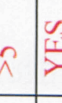 & & 留 & \& & $\stackrel{q}{z}$ & $\bar{z}$ & ิิ) & $\frac{O}{v}$ & z & \\
\hline in & 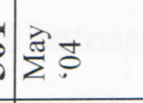 & & है & $\sigma$ & z & & م. & & 崖 & $\begin{array}{l}\underbrace{\circ} \\
\end{array}$ & そz & & ลิ) & & z & \\
\hline$\dddot{q}$ & 鄫 & & 产 & $\infty$ & z & $\stackrel{\circ}{\circ}$ & 凡 & & 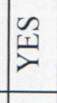 & 饮 & 隽 & \& & ลิ) & $\frac{O}{v}$ & z & \\
\hline F & & & 离 & I & \& & $\dot{\leftrightarrow}+$ & $z$ & & 夋 & 迸 & z & 管 & Оิ & & $\dot{z}$ & \\
\hline : & 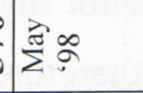 & & $\frac{\infty}{\hat{z}}$ & r & $\bar{z}$ & है & 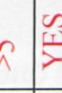 & & 象 & ڤิ & $\bar{\nabla}$ & 至 & ฉిڤ & & 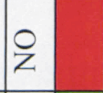 & \\
\hline $\bar{F}$ & 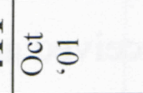 & & $\overline{\hat{\theta}}$ & m & $\bar{z}$ & 气े & 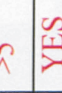 & & z & 䆃 & $\stackrel{\text { }}{Z}$ & 8 & 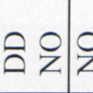 & & $z$ & \\
\hline 命 & $\equiv$ & & है & i & z & $\stackrel{\circ}{\circ}$ & . & & 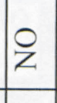 & \& & z & \& & â: & 20 & z & \\
\hline . & $\equiv$ & & $\overline{\hat{\theta}}$ & iे & z & 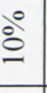 & 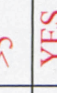 & & 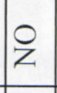 & \& & z & z & â: & 28 & z & \\
\hline 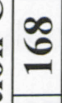 & $\frac{3}{2}$ & & $\overline{\hat{z}}$ & $\infty$ & $\stackrel{0}{z}$ & 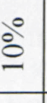 & n & & z & 兑 & z & \& & aิ) & 8 & z & \\
\hline$\stackrel{\circ}{\bullet}$ & 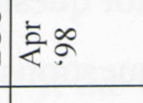 & & ठิ & 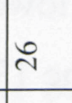 & z & @. & 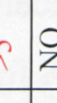 & & 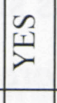 & $\frac{8}{z}$ & 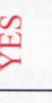 & \& & ầ & 8 & z & II \\
\hline 0 & 운? & & $\Sigma_{0}$ & $\pi$ & $\stackrel{8}{z}$ & के & 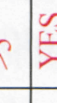 & & 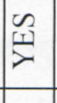 & 兑 & z & \& & â & 8 & z & . \\
\hline$\frac{f}{f}$ & 总可 & & ह & ส & z & 잉 & 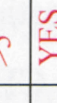 & & 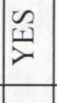 & aิ & 8 & \& & aิ & 8 & z & 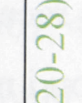 \\
\hline$\frac{7}{7}$ & 然 & & E. & $\bar{\lambda}$ & $\stackrel{\imath}{z}$ & हैं & 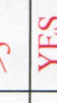 & & 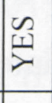 & ิิ & z & 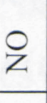 & â & 18 & 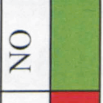 & $\frac{\|}{x}$ \\
\hline & $\frac{2}{2} \sigma \bar{z}$ & & ड & $\overline{\mathrm{u}}$ & $\stackrel{z}{z}$ & $\stackrel{\circ}{\circ}$ & 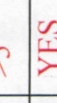 & & 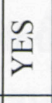 & ฉิ & 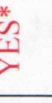 & \& & â & 8 & \& & $\begin{array}{l}+ \\
\| \\
\|\end{array}$ \\
\hline$\tilde{q}$ & 呟o & & ड & i & そ & $\stackrel{\check{\circ}}{\circ}$ & 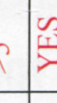 & & 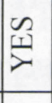 & ิิ & 8 & \& & & & z & $\ddot{\bar{\sigma}}$ \\
\hline$n$ & 莺8 & & ટ્ & i & $\stackrel{̊}{z}$ & 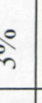 & $\begin{array}{ll}4 \\
\end{array}$ & & 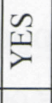 & 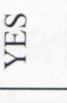 & 8 & $\bar{z}$ & â? & & \& & $\frac{\lambda}{y}$ \\
\hline & 8 & & 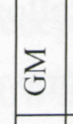 & i & $\mathrm{z}$ & हैं & そ & & $\hat{\text { a }}$ & ิิ & 管 & $\stackrel{8}{z}$ & â) & $\frac{\mathrm{O}}{\mathrm{v}}$ & & 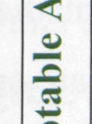 \\
\hline & 送。 & & ह & $=$ & $\bar{z}$ & ìं & $\begin{array}{l}0 \\
\vdots\end{array}$ & & 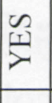 & ิิ & 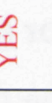 & z & â: & & \& & 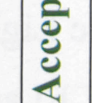 \\
\hline & 8 & & हू & 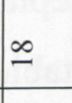 & $\bar{z}$ & ì & 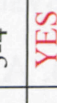 & & z & ฉิ & $\hat{x}$ & $\stackrel{8}{z}$ & : & & $\stackrel{\imath}{z}$ & 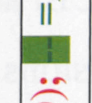 \\
\hline & 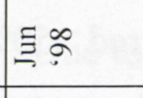 & & है & $\simeq$ & $z$ & î. & $z$ & & $\stackrel{x}{>}$ & ฉิః & 8 & $\bar{z}$ & â: & & \& & $\frac{v}{I T}$ \\
\hline & 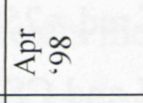 & & ह5 & $\simeq$ & $\stackrel{2}{z}$ & is. & $\frac{8}{z}$ & & 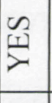 & $\hat{a}$ & $\frac{8}{z}$ & 8 & âßz & $\frac{8}{\mathrm{v}}$ & $\stackrel{8}{z}$ & 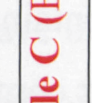 \\
\hline & 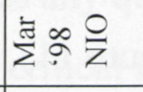 & & ह & 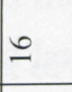 & z & îl & $q$ & & 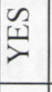 & z & z & z & â 28 & $\widehat{\circ}$ & \& & है \\
\hline & 递 & 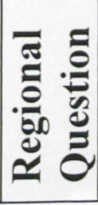 & & & & & 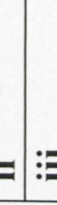 & & 2 & $=$ & $\bar{z}$ & & $\therefore$ & $\pi$ & $:=0$ : & 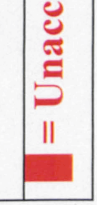 \\
\hline
\end{tabular}


The calculation of CEI scores for each site after mitigation was considered for question vii and xii revealed significantly different outcomes from those presented in the previous table. Whereas the majority of CEIs in Table 15 presented a grade of $\mathrm{C}$, removal of the pre-emptive $\mathrm{C}$ option through the incorporation of mitigation measures (assumed to be effective) led to only 8 sites (381, 270, 282b, 402, 186, 370, 6 and 495) receiving a failing grade. Sites $381,270,282 \mathrm{~b}, 186,370$ and 495 failed because they did not suggest any means to mitigate against the potential harm to endangered species and therefore received a pre-emptive $C$ score for question vii. Site 402 failed because it received an unacceptable DSS rating by DFO at the time of proposal due to an inability to properly mitigate against potential impacts to endangered species. The result of the EA stated that the proponent was not allowed to move forward with the project and thus the project was never initiated. Site 6, the only cod farm, received an unacceptable CEI score due to the combination of a number of low scores. This site received the lowest score for questions ii, iii, iv, v, vi, and $x$, and only received a score of $A$ for 5 of the 13 scored questions. A CEI score of B- (orange) was calculated for 4 sites (403, 404, 501, and 496). Most of these sites received a low score for one or all of questions ii, iii, $v$ and $x$. A lower score for question i may have also played a role in the B-CEIs for sites found within the Other CMR. A score of B+(light green) was calculated for 8 sites (303, 413, 416, 168, 256, 377, 411 and 494). These scores fell short of an A score due to low grades for the newly added questions. Intermediate scores of B+ and B- represent conditional acceptance.

When combining the cumulative ecosystem and site index scores, the four-colour scoring system was converted to a three-colour Traffic Light system (red, green, yellow). The intermediate light green $(\mathrm{B}+)$ is scored $50 \%$ green and $50 \%$ yellow, and the lower intermediate orange (B-) is scored 50\% yellow and 50\% red (Hargrave, 2002). Following the Traffic Light Decision Matrix for marine finfish farm suitability representing all possible CEI and CSI scores with the three-colour system, acceptable and unacceptable DSS decisions can be determined (Hargrave, 2002). An acceptable decision is indicated if the color matrix is $>50 \%$ green and an unacceptable decision is indicated if red $>50 \%$. Scores containing B + and B- can permit a provisional level of acceptance if red $=25 \%$. Any other combination is a decision of unacceptable such as if both the CEI and CSI have scores of B-. A diagram of the decision matrix is presented below (Figure 11). 
Figure 11: Decision Matrix

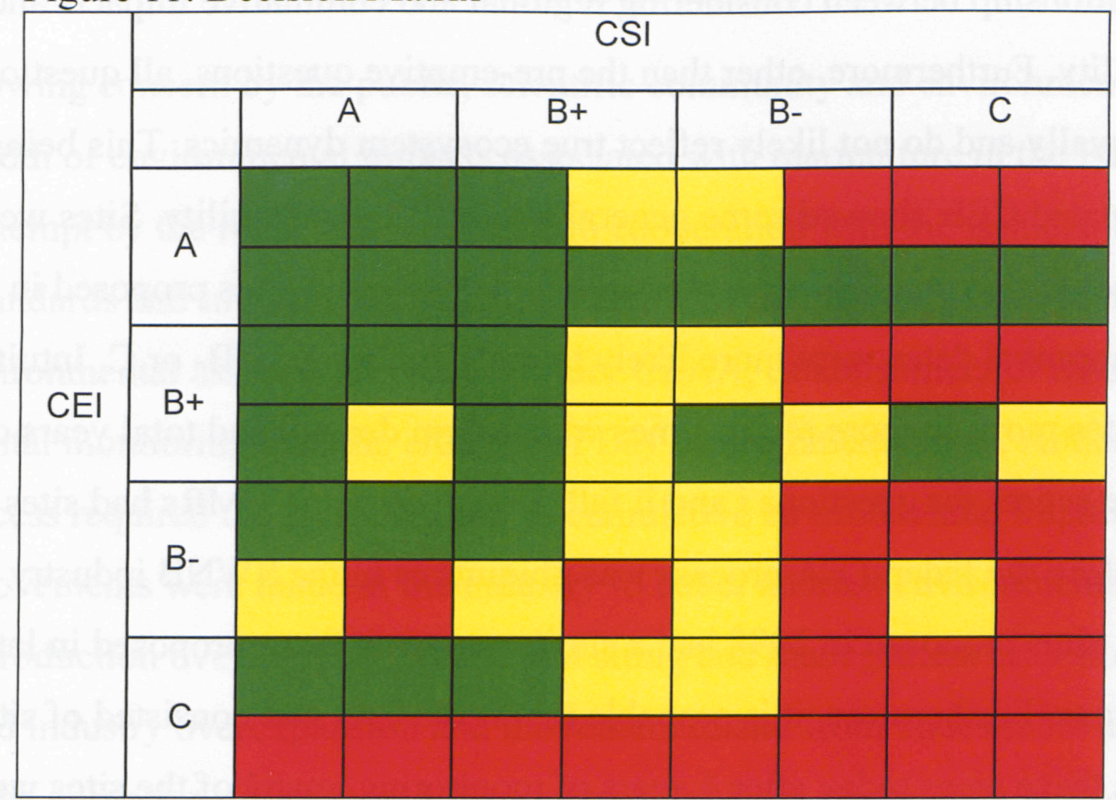

Source: Hargrave, 2002.

If the Cumulative Site Index (CSI) was found to have a score of A the following sites would receive an overall acceptable DSS score based on the CEI scores presented above: 324, 303, 282, 303(2000), 403, 413, 416, 168, 256, 377, 411, 404, 501, 496, and 494. If the CSI was B+ for sites $403,404,501$, and 496 , the overall score would have not been acceptable based on the B- CEI score. If CSI scores of B- had been assigned, only those sites that received a CEI score of A would have been acceptable. Although for this study it was assumed that all sites received a passing grade of $\mathrm{A}$ or $\mathrm{B}+$, in reality this is highly unlikely. One site reported that the benthic conditions in the proposed lease area were already degraded meaning variables such as sulphide and redox readings would have been beyond acceptable levels and would have received low scores. Other sites reported relatively low mean peak velocities or higher percent sediment organic matter, all which would affect the site-specific scoring.

\section{General Trends}

Due to the nature of the questions and the scoring system, significant trends in the parameters measured overtime are not highly likely. Because a site could have failed to address any question and more recent EAs conducted did not seem to be anymore apt to avoid critical fish habitat or areas frequented by endangered species, it is difficult to show 
a causal relationship between considering regional and cumulative impacts and site unacceptability. Furthermore, other than the pre-emptive questions, all questions are weighted equally and do not likely reflect true ecosystem dynamics. This being said, the newly calculated CEIs showed some general trends in site suitability. Sites were more likely to receive a score of $\mathrm{B}+$ or $\mathrm{A}$ if proposed in 1998, and sites proposed in the later half of the approval dates were more likely to receive a score of B- or C. Intuitively, as approval dates move to more recent times where farm density and total years of operation increase, the scores for questions $i$ and ii fall. However, some CMRs had sites for almost a decade before the federal EA process was ubiquitous in the SWNB industry and thus in some cases, sites proposed in 1998 had a similar score as those proposed in later years for these questions. Furthermore, it is probable that if the EAs had consisted of sites being proposed in these areas today after 4 years of monitoring, many of the sites would have much lower scores pertaining to question $i$. At the time of study initiation, site 494 represented a siting process that would take place at current production levels. Although the site was deemed acceptable, within the CMR, the percent habitat loss was approaching the higher limits and the estimated DO buffer utilization to flushing time ratio was found to be approaching 1 . Thus, if additional sites are proposed in this CMR, they may be deemed unacceptable according to the DSS. Also, the Other CMR occupies the southeastern coast of $\mathrm{NB}$, areas frequented by endangered species and known important lobster habitat. Because the other three CMRs that have not exceeded assimilative capacity (NPB, CDI and GM) have a relatively large area, the percent habitat loss is not expected to reach $30 \%$ or even $20 \%$; however, with increased rockweed harvesting, scallop dragging and other benthic habitat-destroying activities, siting new farms will become less likely if cumulative and regional impacts are considered in the event that exclusion and controlled production areas are opened. 


\section{Chapter 7: DISCUSSION}

Growing concern by the public, scientific community and environmental groups on the breadth of environmental impacts associated with mariculture in the Bay of Fundy led to an attempt by the regulatory agencies, in cooperation with the farmers, to raise industry standards and improve the siting process. This involved application of the federal environmental assessment process under CEAA, establishment of mandatory environmental monitoring, and the creation of Bay Management Areas. Although the CEAA process required the consideration of cumulative environmental impacts, and many improvements were made in the industry to better address environmental problems, increased production over the past decade and siting and management on a site-by-site basis caused industry overexpansion and movement to and from undesirable areas. Traditionally, characteristic of most EA processes, far-field, cumulative and regional impacts were not adequately addressed when evaluating proposed mariculture sites in N.B.. The spatial scope was generally too small and the temporal scope often not properly considered. Cumulative effect sections of EAs were brief, generic and scores of significance often went from significant to insignificant with little to no explanation other than, 'The project is not likely to result in significant cumulative environmental effects'. Until recently, site evaluation and effects assessment was judgment-based, highly subjective and variable between sites. Over time it became evident that in order to ensure a more sustainable industry and remove the subjective nature of decision-making, siting had to take a more standardized, science-based approach.

The commitment to increasing objectivity in the decision-making process was introduced and demonstrated by Hargrave (2002) through his Traffic Light Decision Support System. Decision support systems have long been recognized as an appropriate and effective decision-making aid; however, widespread application in aquaculture industries has not occurred. Modelling is used in various jurisdictions worldwide; however, until very recently no science-based modelling tool was used in the decision process in N.B. Hargrave's (2002) consideration of far-field impacts along with sitespecific impacts revolutionized the site evaluation process by standardizing the variables considered across all proposed finfish farms. 
Considering environmental interactions other than those found in the immediate vicinity of the cage paints a significantly different picture of the breadth of changes incurred by the marine environment, and the threats to ecosystem health. Although the DSS is non-dynamic and conservative, it still reveals short-falls and inconsistencies in the mariculture EA process.

Preliminary analysis conducted for the purposes of amending the far-field questions confirmed past suspicions that the industry was causing some areas to reach or exceed both their carrying capacity and production potential. The determination of control and exclusion zones, and the spreading of sites east along the coast, demonstrated that regulating authorities recognized the need to control Bay of Fundy production. Unfortunately, these measures did not solve the density problem and contributed to further disruption of already stressed, sensitive and ecologically important coastal areas. Because few sites in the more densely populated areas have been removed or fallowed due to environmental concerns, constant or increased production has begun to alter natural fluxes of DO, N,P and C. Although the LL CMR is the only area where production has decreased in the past decade or so, this area has exceeded its environmental carrying capacity. Interestingly enough, the move of the industry east along the coast was intended to relieve the stress imposed by high rates of production in the areas first populated; however, according to the Tbuf/Tfl ratio and percent $\mathrm{N}$ of total fluxes, the Other CMR is already approaching its carrying capacity. The NPB, CDI and GM CMRs have a higher current production potential; however, these findings only represent CMR site suitability before the consideration of other cumulative and regional impacts addressed in the regional questions.

Application of the amended regional questions to the 23 EAs both provides strength for Hargrave's (2002) argument that far-field considerations are necessary in site selection and supports the hypothesis that considering regional and cumulative environmental impacts in the site evaluation process through the use of a DSS yields different results than those found using traditional environmental assessment methods. Siting on a regional basis may have prohibited farms proposed from 1998-2005 from being sited in regions that have degraded ecosystem characteristics. Due to the sitespecific nature of previous assessment (save those conducted post-2002 using the DSS), 
far-field, regional and cumulative effects were not given much attention. Until the current DSS was introduced to DFO for use in site evaluations, siting was conducted primarily on a site-by-site basis with little consideration given to the surrounding area, or the region.

The results of the retrospective review demonstrated that before mitigation was considered for the two pre-emptive $\mathrm{C}$ score questions (vii \& xii), the majority of sites would have been found unacceptable based on far-field, regional and cumulative environmental effects. This shows that both endangered species and critical fish habitat are known to be present at most of the finfish leases sited between 1998 and 2005. The sites that were found to be acceptable did not receive a score of A because they were assigned a failing grade of $\mathrm{C}$ for the new questions ii (relates to potential temporal impacts) and iii (relates to ADD use). This suggests that regional and cumulative impacts played a major role in conditional acceptance in the results of EAs for which pre-emptive questions did not trigger automatic unacceptability.

This trend was supported after mitigation measures were considered for the preemptive questions. Removal of the concerns pertaining to endangered species and critical fish habitat from the equation yield significantly different results. As opposed to 19 sites receiving an unacceptable score, only 8 sites failed the regional set of questions. Six of these sites failed because they did not suggest any means to mitigate against the potential harm to endangered species and therefore received a pre-emptive $\mathrm{C}$ score for question vii. Site 402 failed because it received an unacceptable DSS rating by DFO prior to this analysis due to an inability to properly mitigate against endangered species. One site received an unacceptable score due to the combination of many low scores, and 4 sites received a conditional B- due to the combination of lower scores for one or all of questions $\mathrm{i}$, ii, iii, $\mathrm{v}$ and $\mathrm{x}$. The remaining sites received a score of B+ or A. Sites that fell short of an A received low grades for the newly added questions, accompanying the results found prior to the consideration of mitigation. This suggests that while there are varying reasons for why sites did not receive a $\mathrm{CEI}=\mathrm{A}$ and although all sites may not have failed the regional set of questions, the majority of sites received poor scores for at least 2 of the new questions, especially sites proposed in more recent years. This demonstrates that in consideration of far-field, regional and cumulative effects, many sites should have been sited elsewhere in order to receive a CEI score of A. The CDI and 
Other CMR have percentages of habitat loss higher than the remaining CMRs. Although they are within the $\mathrm{A} / \mathrm{B}+$ scoring levels, benthic habitat has been compromised and if the affected area is underestimated these regions may be within the B-/C scoring bracket.

Overall, after incorporating possible Cumulative Site Index scores with the CEI scores, mitigation enabled 15 sites to be approved if the site $\mathrm{CSI}=\mathrm{A}$, and 4 sites to be approved if the site $\mathrm{CSI}=\mathrm{B}+$. Sites receiving a score of $\mathrm{B}+$ would have also been approved with a score of $A$, thus the maximum number of sites approved would have been dependent on the proportion of $B+$ scores. As stated before, it is not likely that all sites would have received a score of $\mathrm{B}+$ or $\mathrm{A}$. In his analysis of 8 sites using the current DSS, Hargrave (2002) found that all 8 sites were deemed unacceptable, 5 failed the farfield component and 3 failed the site-specific component. Each site had either a failing CEI or CSI score and no site had a failing score for both. It is not certain whether there is a relationship between sites passing site-specific questions and failing far-field questions, and visa-versa; however, his results demonstrate that a passing score for one set of questions does not ensure a passing score for the other set of questions. Therefore, assuming that all sites receive a passing grade likely over-estimates the total number of sites that would have passed the DSS.

Because the amended questions incorporate calculations that apply to the industry as it currently stands and is thus more appropriately suited for new farms, proposals today would likely result in lower scores. If production increases or remains constant, cumulative and regional effects will persist and grow with compounding pressures from other development. As a result, using the amended questions as part of the DSS would result in fewer sites accepted and possibly a decrease in overall production. Lastly, although the amended DSS can only be applied to the SWNB Bay of Fundy region due to the use of industry and regional data, ensuring a standardized method within an intensified region is more important than a generalized tool applicable across regions. However, the concepts found within the DSS can be applied to other industries and the DSS itself can be further amended to incorporate other industry and regional information. 


\section{Challenges, Sources of Error and Inconsistency}

During the completion of the retrospective review, there were various challenges that created the potential for error. Before the retrospective review could begin, all CMR calculations had to be redone because values presented in Chapter 5 represent current production levels and industry information. Therefore, sites proposed from 1998-2004 would have been sited at a time with a lower TAPL and TESP. Furthermore, the N and C flux information reflects 2002 industry production levels and thus is not fully representative of levels for CMR conditions at the time of earlier siting.

Another potential source for error was the estimation of the date that farms were established. Because an EA for every site was not available, it was difficult to determine when other farms had been sited. For the purpose of the analysis, if an EA was not provided but the site was found to have 2002 monitoring information, it was assumed that it was in the water pre-1998, otherwise an EA would have been available from CEAA.

In some cases there is also a possible discrepancy between approval date and actual operation date. A site may have been approved in July but actually put in the water earlier or later depending on the leniency or diligence of the regulatory bodies. Some early EAs were placed in the water prior to formal approval. However, with some EAs an estimated time of project operation was often given and thus if the project was approved, that date was used as the date it was sited. In cases where the EA did not provide this information, the approval date was used as the time the farm was sited. These assumptions meant that when the regional questions were being applied to each EA, it was not $100 \%$ known whether the number of farms in each CMR was representative of when that farm would have been sited.

A consideration of temporal cumulative environmental impacts at the time of siting could offset some of these potential sources of error. In other words, if temporal impacts had been considered at the time of siting, it would have been predicted that additional leases would have been granted as the industry was expanding and production had increased significantly every year since inception (Wildish et al., 2004). As such, N and $C$ values representing 2002 production levels and a lack of concrete siting dates within a CMR should not greatly affect the calculation predictions because 
overestimations of site numbers and production levels within a CMR reflects future estimations of industry expansion.

When responding to the questions, there were various opportunities for inconsistency. All responses to the questions were based on the information presented in the EA unless the question required further investigation due to lacking information. In some cases an EA presented information that conflicted with other research. In these cases, unless there was an adequate explanation in the EA, the information retained from scientific literature or experts in the field was used based on the potential for proponents to omit or avoid information that may be seen as questionable to the operation of the farm. This could, however, promote inconsistency between the evaluation of sites based on the range of proponents, assessors, and other contributing sources.

Two major examples of inconsistent information lie in determining the presence of endangered species and critical fish habitat. As discussed in the results, many EAs did not address the presence of endangered species, and the majority of EAs that did address the issue did not adequately present or justify mitigation measures used. Many EAs simply stated that endangered species were of concern or significance and it was unclear whether they were considered or deemed insignificant due to the frequency of occurrence in the area. Many EAs stated that endangered species were not found in the area or were of concern, while other literature and sources of information stated that the right whale, harbour porpoise, or various migratory and threatened bird species did and do frequent the area of the proposed site. For example, there is a right whale conservation area in the deep waters just east of Grand Manan (Chang et al., 2005a). These whales are known to periodically come in close to shore around Grand Manan island (Murison, 2006, pers. comm..) and this is an area of high finfish farm concentration. The harbour porpoise is known to frequent the southeastern coastal areas of N.B, and the harlequin duck and other migratory and at risk birds inhabit the rocky cliffs and shorelines in this region. These bird species also inhabit various other locations such as White Head island, areas around Grand Manan, and locations around Deer and Campobello islands.

It was also difficult to determine how the proponent of the EA drew a conclusion about the presence of endangered species or critical fish habitat. For example, did they rely on sitings, were sitings conducted at times of the year when species were not as 
prevalent to the area, was scientific literature consulted, were local fishermen consulted, or was the possibility of these species interacting with the farm simply not considered. In order to take a conservative approach, in cases where the explanation was not adequate, the rating of significance in the EA was disregarded and other sources were consulted for the pre-mitigation analysis. If the EA acknowledged the presence of endangered species or species at risk and did not adequately present mitigation measures, the post-mitigation analysis yielded the same pre-emptive score. However, in cases where an EA claimed that there were not species present and appeared to have adequately considered the issue, regardless of other sources of information, the presence of these species at the particular site was deemed insignificant and a score of $\mathrm{C}$ was not assigned.

There were also problems both obtaining information on areas of critical fish habitat and distinguishing between critical, important, or functional, and historical or current habitat. This made formulation, amendment and application of the regional questions difficult because not all subjectivity could be removed from the process. Information is scattered, inconclusive and often conflicting. Information could not be obtained for all species and information from various sources was relied upon. As discussed above, the assessment of critical fish habitat was inconsistent within the EAs. Thus, for question xii, the evaluation before consideration of mitigation largely reflected information found in other sources as opposed to the information presented in the EA. Although the author believes that the current state of the Bay of Fundy marine environment renders all fish habitat critical, if the EA indicated the impacts could be adequately mitigated, the site did not retain a score of $\mathrm{C}$.

The last potential source of error relates to the application of question ix to the EAs. Proper information could not be obtained regarding the location of sills within the study area. Some information suggested that the EAs did not fall within sill locations; however, it later became evident that this may not be the case. Furthermore, none of the 23 EAs had information indicating sills in the vicinity. Therefore, because it was not known whether the 23 proposed sites fell within an inlet or embayment that had a sill, it was assumed that they did not. This assumption could have minor effects on the outcomes of the Cumulative Ecosystem Indices for sites of conditional DSS acceptance, meaning those with a B+ or B-score, and the sites that had scored an A before and after 
consideration of mitigation. The sites with a score of $A$ in both Table 15 and 16 (282, $303,324)$ would all drop just below the A score level if question ix was given a score of 1.5 instead of 3 . If sills are present in the areas of the proposed sites, the new results lead to more sites not being accepted by the DSS and thus the bias of answering no to question ix for all sites is not in favour of the study.

Overall there was information missing from many of the EAs that left room for interpretation and 'filling in the gaps'. Much of this information pertained to regional information such as the presence of other industry, the population of the area, and the interaction of the project with its surroundings. The supporting information was also incomplete. This often gave way to assumptions of farm-ecosystem interactions and estimations of the extent of environmental damage both related to aquaculture and related to other factors. For example, the extent of damage to the sea floor is unknown. This study likely underestimates both the number of activities that contribute to habitat destruction and the amount of destruction that may or may not be reversible. Increased knowledge on these concerns is expected to fill in knowledge gaps.

\section{Omission of Cumulative Environmental Effects Variables from DSS}

The present study did not include various mariculture-related variables that have been suggested to cause potential regional, cumulative or far-field impacts on the marine environment. These variables were not addressed for a number of reasons such as an inability to address all concerns in a single DSS, lack of substantial evidence supporting inclusion, and/or inclusion of concerns through a variable already addressed. The omitted variables accompanied by a justification for exclusion from the DSS regional questions are presented below.

\section{Chemicals}

Many chemicals (medications, pesticides, antifoulant, etc.) have been used in salmon aquaculture in the Bay of Fundy. The ones with the most potential for widespread damage are soluble compounds, whereas compounds administered in feed or applied to cages are more likely to affect the immediate vicinity of the cage (DFO, 2003). Although the use of chemicals in salmon aquaculture has raised concern due to the possible 
implications on wild species, sediment and water quality, there exists no substantive evidence to date of widespread or cumulative impacts; impacts relate to the vicinity of the net-pen (Hellou et al., 2005). In SWNB, medications are generally administered as 7-day treatments, only if outbreaks or disease take place. They are not administered continuously throughout the growing season (Drost, 2005, pers. comm.). Two types of 7day treatment for lice are Excis and Slice; however, Slice is most commonly used in SWNB. A study conducted in Scotland on the long-term impacts of sea lice treatments showed that treatments of cypermethrin and emamectin benzoate (the active ingredients in Excis and Slice respectively), did not cause adverse effects or basin-wide effects on the zooplankton community, and the zooplankton community composition displayed natural seasonal cycles of abundance (Willis et al., 2005). A scaling exercise was conducted where a water-borne pesticide (Salmosan $®$, Azamethiphos) was coupled with lethality data from laboratory experiments with lobsters resulting in no evidence that single anti sea-louse (bath) treatments were likely to result in lobster deaths (DFO, 2003). Although sublethal impacts were not considered, there is not substantial evidence to determine whether these chemicals are in fact having long-term damage on indigenous wild species. Evidence does exist, however, demonstrating that lobsters exposed to sublethal concentrations of one of these chemicals, azamethipohos, had decreased reproductive success compared to control lobsters in a laboratory setting. More information is required to estimate the associated risk to wild populations of lobster and shrimp (Haya et al., 2001).

Overall, cumulative effects of these chemical pollutants have not been detected on an inlet-wide scale in SWNB (DFO, 2003). The use of chemicals should become part of the decision process as information and evidence on impacts becomes available. There is growing concern relating to the increase in antibiotic-resistant bacteria in sediment under fish farms, in farmed salmon, and in wild organisms caught near salmon farms (David Suzuki, 2006). These findings could lead to the use of more or stronger antibiotics on salmon farms which could potentially lead to increased environmental risks. Antibiotic use has decreased by $90 \%$ per unit weight (Beveridge et al. 1997 in Milewski, 2001); however, the concentrations of chemicals should be observed and necessary measures taken if levels become dangerous. 


\section{Metals}

The accumulation of trace metals in the sediment, water and species surrounding mariculture operations has become of increasing concern; however, current evidence suggests that the impacts are near-field (Burridge, 2003; Chou et al, 2002; Yeats, 2002). With improved understanding of the relationships between aquaculture and environmental contaminants, metals should be included as a potential impact of mariculture within the site-specific component of the DSS.

\section{Disease}

Transmission of disease from cultured to wild species has been a growing area of study and debate in the salmon aquaculture industry. Infectious Salmon Anaemia, the most significant disease affecting the salmon mariculture industry in SWNB, was first detected in three sites in the Bay of Fundy in fall of 1996 (Olivier, 2004). As previously discussed, studies on the potential transport zones of viruses in the marine environment have been conducted (Chang et al., 2005; Page et al., 2005). Buffer zones and tidal excursions were determined to remain within the boundaries of the CMRs. As such, it is assumed that management using the coastal management regions will aid in managing and preventing spread of disease. Disease is therefore assumed to be addressed in the questions relating to the CMRs. It is important to note, however, that infectious microorganisms have been found in fallowed sediments at abandoned farm sites (Husevag et al. 1991 in Hargarve, 2003) indicating that, irrespective of attempted disease control through antibiotic use, once a disease outbreak has occurred in an area, the probability of re-infection is increased (Hargrave, 2003). With this in mind, it is recommended that when use of a tracking model is available, such as the one presented by Page (2005) or Greenberg et al. (2005), it be used in siting decisions. This in combination with avoiding critical fish habitat will hopefully lessen the opportunity for sites already infected to interact with potential new sites, re-infection or mass infection of cultured species in densely populated areas, and disease transmission from cultured to wild populations. 


\section{Dispersion of feed dust}

During feeding at salmon farms in SWNB, feed pellets are often distributed by mechanical feeder or by hand (shovel) (Drost, 2005, pers. comm.). See Figure 12 below. These types of feeding techniques can cause a fine dust to be released into the air and transported by wind over a broad area or deposited in the water surface film enabling the potential for horizontal dispersion over substantial distances, especially in high-current regions (Hargrave, 2003). Although there is not substantial information on the extent, prevalence or severity of widespread dispersion relating to fine dust, recommendations have and should be made to the proponent to avoid mechanical feeders that produce fines, and use of other feeder types should be considered (EC, 2001).

Figure 12: Mechanical feeder, Chance Harbour, SWNB, 2005.

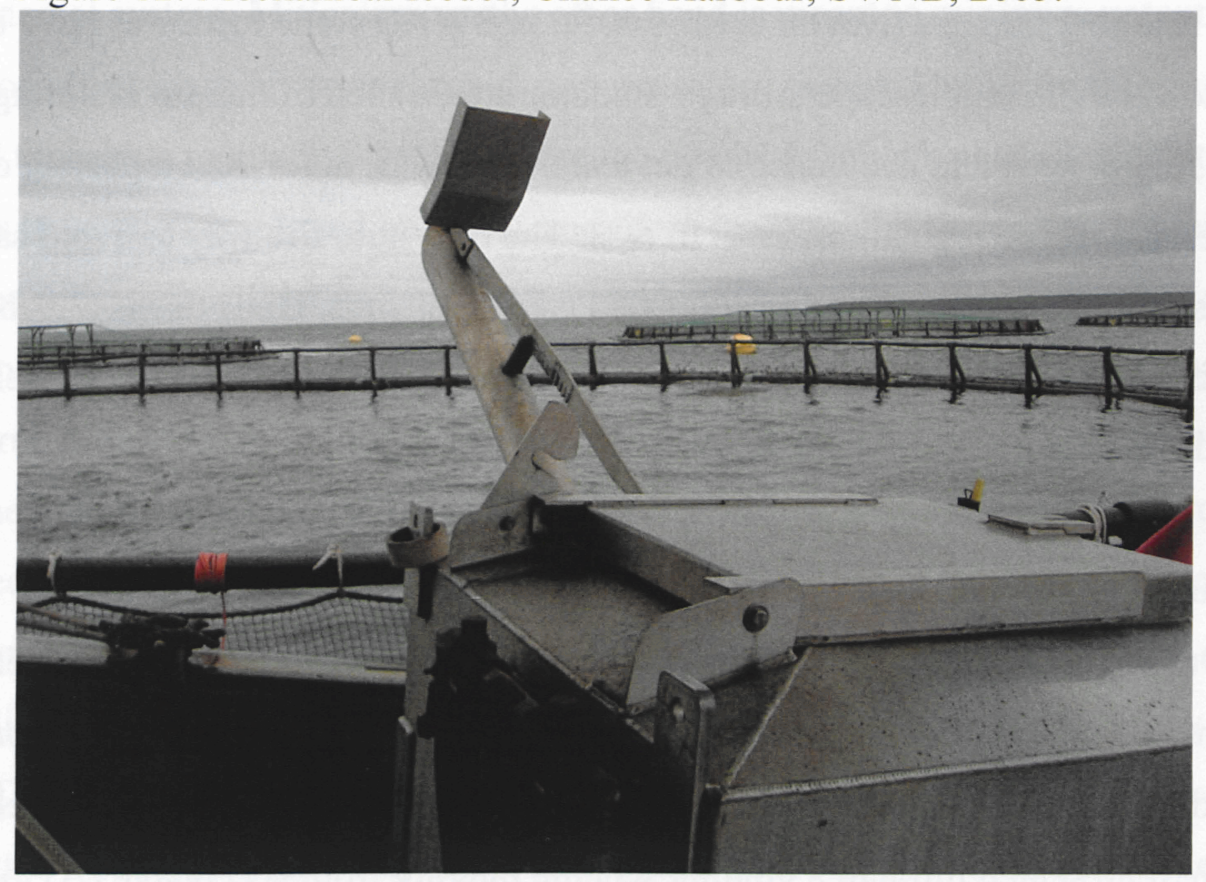

\section{Escapees}

Since the inception of the aquaculture industry, the prospect of escaped salmon has posed both economic and environmental threats. Their escape into the wild has the potential to result in harmful interactions with wild populations such as interbreeding, competition, the spread of pathogens, and a resultant pressure on already dwindling wild 
populations (Naylor et al., 2005; Milewski, 2001). Naylor et al. (2005) state that 'the risks that escaped farm fish pose are a function of the probability of escape, the magnitude of each escape event, and the impact of escaped fish on wild populations, ecosystems, and society'. The authors determined that 'risks of damage to wild salmon populations, ecosystems, and society are large when salmon are farmed in their native range, when large numbers of salmon are farmed relative to the size of wild populations, and when exotic pathogens are introduced' (Naylor et al., 2005). Various preventative and mitigation measures have been suggested. In 1999, DFO emphasized the need to manage watersheds and their bays as single management units (DFO, 1999a). Additionally, a variety of infrastructure, veterinary, and breeding approaches based on analyses of risks and critical control points are available to help reduce the number of escapes and the potential resulting impacts (Naylor et al., 2005). In SWNB some measures have been taken to lower the risk of escape through predator attack such as the use of stronger net materials, tauter nets, and avoidance of net tears. However, other than reporting of escape incidences, no escape regulations exist in N.B. The only sure fire way to avoid salmon escapes is to move culture inland to contained establishments. Until this is a viable and cost-effective option threats of escapes will be present and regulations and guidelines must be developed and employed in siting.

\section{Uncertainty}

Due to the potential uncertainty associated with determining exactly where environmental impacts fall on the scale of acceptability and significance, the scoring system adopted from Hargrave (2002) presents four levels of impact. These levels of impact are represented through a grading scheme ranging from acceptable (A) to unacceptable (C). Hargarve (2002) states that while it may be relatively easy to reach an agreement on acceptable versus unacceptable effects, there may still be uncertainty regarding potentially negative effects which is reflected through the two intermediate scores, B+ and B-. Questions requiring simply a YES or NO answer have only two scoring options; however, generally these questions address the presence or absence of something. Shades of grey exist when there is no clear YES or NO answer or when mitigation measures are considered. 


\section{Chapter 8: CONCLUSIONS}

\section{Mitigation's Double Edged Sword}

Despite the many benefits of using the Traffic Light DSS there remains one aspect that inhibits its full performance potential: mitigation. During development and testing of the original DSS, Hargrave (2002) stated that the DSS 'should be used to assist in the decision-making process recognizing that additional factors may be considered in making a final decision for acceptance or rejection'. The additional factors considered include monitoring and mitigation. Monitoring enables the proponent and regulatory agencies to track positive and negative changes in the affected environment. It is a logical accompaniment to any activity that alters the natural structure and function of an environmental system. Mitigation on the other hand is meant to minimize potential impacts or offset likely impacts through compensatory means. Unlike monitoring enforced through a regulating agency, there are no checks on whether all mitigation measures have been employed properly, and more importantly, there is no guarantee that mitigation measures will be or have been effective. Thus, although presented as an environmental aid, not only does mitigation not ensure protection but it can actually act against true protective measures, allow otherwise unsuitable projects to be approved and hinder the benefits of objective decision-making. Following analysis of the approved EAs it also became evident that there is inconsistency in allocation, provision and adequacy of mitigation measures between sites.

Site 402 was the only site in the sample of EAs that was not approved by the original DSS application by DFO. The site was found to be unacceptable because it was located at White Head island which is a habitat that supports $50 \%$ of the endangered Harlequin ducks (COSEWIC) known to winter in N.B. and 5\% of the Eastern population. The screening decision stated that the mitigation measures were not seen to be adequate to avoid significant threats of impact to the population. Although the majority of the duck population resides on the eastern side of the island, other sites on the southern and western side of this small island, and in many areas around Grand Manan and the Bay of Fundy were proposed close to, or in, endangered species habitat. These sites, however, were approved. This decision both shows the lack of consistency in the approval process 
and recognition by regulatory officials of an inability to mitigate against negative impacts when it comes to endangered species and habitats. The mitigation measures for almost all proposed sites against impacts to migratory birds and endangered species were the same. No site exceeded the mitigation measures as outlined in the EA for unapproved site 402; however, the other sites were approved and mitigation was deemed suitable. This demonstrates the inconsistency in the mitigation process.

Overall, the EA process uses mitigation as a band-aid solution and fails to recognize that some environmental effects cannot and should not be mitigated. Although mitigation may address or offset some environmental impacts, negative impacts to certain ecosystem components and inhabitants are simply too drastic to not only risk failed mitigation measures but allow band-aids to hide immitigable effects. For example, if a proposed farm is to be sited in an area frequented by endangered species, no mitigation measures can prevent a wild species in the marine environment from interacting with a mariculture site without either excluding it from its habitat, using harmful scare methods such as ADDs, or using other deterrent methods, all of which have an impact on the individual. No guarantee can be made that the species will not be negatively impacted in some way, and if the site does not use any deterrent methods, predator species will likely damage or destroy farming operations. The same theory can be applied to siting in critical fish habitat, close to ecologically significant areas, close to other protected areas, areas with other similarly polluting industry/activities, etc. What these things have in common are the prospect of additive or synergistic cumulative impacts either spatially, temporally or both in an environment that has been so heavily altered. It is therefore logical to conclude that in cases where mitigation is simply a means to avoid impacts and not remove all possibility of them, it should not be the answer and prevention or avoidance be enforced. Otherwise, there is no true means to protect endangered species, critical fish habitat and species, etc. and any farm has the potential to be placed in one of the Bay of Fundy's critical areas.

\section{Regulatory Illegitimacy}

Enforcing mitigation as opposed to protection and avoidance of endangered species and critical fish habitat not only undermines conservation efforts but places many 
mariculture sites in the Bay of Fundy in potential contravention of two major federal Acts: Species at Risk Act and the Fisheries Act. SARA prohibits the killing, harming, harassing, capturing or taking of species and makes it illegal to destroy their critical habitats. The Act became law in June 2003 and enforcement began in 2004 (DFO, 2006a). Prior to enforcement, DFO was meant to communicate to Canadian aquaculturists how to comply with the Act (DFO, 2006a). Unlike SARA, the Fisheries Act has been enforceable since the early years of the aquaculture industry in N.B. As previously stated, the two main sections of the Fisheries Act relevant to mariculture pertain to a harmful alteration, disruption or destruction of fish habitat (HADD) and the deposit of a deleterious substance in water frequented by fish.

Pursuant to $S A R A$ and the Fisheries Act, restrictions could be introduced regarding the establishment of farms in certain locations. In relation to SARA affecting aquaculture operations, DFO states that "areas of critical habitat may be designated "off limits," and access to brood stocks may, in some areas, be subject to special controls or prohibitions. The same could be true of pesticide use. There may also be changes required to methods of predator control and waste disposal" (DFO, 2006a). However, DFO also claims that 'in rare cases, the restriction against harming or killing species at risk may be modified through the issuance of a permit following a scientific assessment allowing for activities affecting a listed species, so long as the degree of impact does not jeopardize the survival or recovery of the species' (DFO, 2006a). Along the same thread, DFO acknowledges the economic struggle of the industry declaring that it is committed to making the industry grow in an environmentally sustainable manner and will always consider the potential impact on aquaculture when aquatic species are considered for SARA listing (DFO, 2006a). On the other hand, DFO states that 'as recovery strategies are completed and critical habitats identified over time for species at risk, additional restrictions may be put in place to protect other species potentially affected by aquaculture operations' (DFO, 2006a). These declarations represent the struggle to balance industry and conservation efforts; however, considering the purpose of SARA, it also represents a failure by DFO to enforce the Act. On the one hand DFO aims to protect the species against the ills of industry and on the other hand it wants to make sure industry is considered during assessments of species for $S A R A$ inclusion. As the Act is 
not termed the "Species at Risk and the Impact on Aquaculture Act", the focus should remain on the protection of the endangered individuals and let the industry work around them.

During siting, various stipulations are also given to minimize the impact on critical fish habitat. The Fisheries Act provisions are considered in the siting process, periodically lease areas are moved to less critical locations, but few, if any, HADD authorizations are required during the EA process. No known cases of Fisheries Act violations exist relating to deleterious substances, and few if any sites have been found to be in violation of a HADD after the site was in operation. The reason for this seems to be two-fold: someone must declare a site to be in violation of a HADD and an assessment must be done before DFO would become involved; and traditionally the prosperity of the industry has superseded the need to conserve fish habitat of either diminished or highly abundant stocks. Even sites that have reached hypoxic and anoxic conditions simply must take measures to return to an oxic state as soon as possible, and penalties are rarely, if ever, involved. Mariculture also discharges huge quantities of nutrients that have led to algal blooms, eutrophication and stress on the native species, in addition to various chemicals, trace metals, and debris, and yet no site seems to be in contravention of section 36(3).

Overall, DFO is failing to live up to duties under both SARA and the Fisheries Act. Important habitat is not adequately being protected and the species that depend on it are suffering in the name of a prosperous industry. Many mariculture sites have been in contravention of the Fisheries Act for decades and many sites put in the water since 2003 are in contravention of $S A R A$. Based on this truth, the integrity of the industry is approaching zero despite other environmentally conscience efforts. If these Acts are not upheld against industry that has the potential to cause widespread coastal, habitat and water quality alterations, what are their purposes? These Acts were not meant to protect species and species habitat against their natural predators; that is the ecosystem's responsibility. 


\section{Toward a More Sustainable Industry}

The long struggle to integrate human resource use with natural ecosystem processes has been tedious. Mariculture in the Bay of Fundy has been no exception. In a community dependent on the fruits of the marine environment, it is pertinent to allow economic sustainability without hindering environmental sustainability. If we continue to degrade our oceans we will exhaust all options for resource use. This has been known for a long time, especially in the Atlantic region with the numerous exhausted and diminishing wild stocks. Initially aquaculture offered a solution to the overfishing problem but with intensification of any industry it surpasses its ability to be sustainable. There exist few or no remaining inshore sheltered sites for further expansion of the industry (Chang et al., 2005a), and management of perceived localized and transitory impacts through fallowing periods does not solve environmental problems, especially pertaining to trace metals and food-wed dynamics. SWNB is at a point where production cannot be increased as the industry currently stands. Production should be significantly decreased in all areas and stopped in the Letang area as it has exceeded its carrying capacity. Fishermen should be subsidized or local economies should be transformed and expanded through introduction of new, sustainable employment opportunities.

There have been many suggestions to improve the industry such as better regional management, a move offshore and a move to inland artificial holdings. The problems with the former is the fact that mariculture requires a substantial footprint in the marine environment and unless methods can be developed to eliminate organic deposition, release of nutrients and the interaction with other wild species, mariculture may never be truly ideal or sustainable. Although a move offshore is attractive to enable future growth due to few (if any) remaining coastal or near-shore areas, it introduces new disturbances, encroaches on other important habitat and faces various feasibility issues (Chang et al., 2005a). The problem with the latter is the cost, energy and land required to house these operations. The increased pressure to compete in the global market means that despite efforts to improve industry standards, the demand for increased production will offset steps taken. It is thus crucial to ensure an environmental assessment process that is as rigorous as possible in an attempt to deter some of the devastating environmental costs. 
The following is a list of potential ways that the SWNB mariculture industry could become more sustainable through improved siting, production and management techniques.

- Remove the mitigation option within the DSS.

- Have DSS available for use by consultants- currently only employed by DFO.

- Move to an organic industry-no chemical inputs - some companies in Canada have begun to take an organic approach; N.B. does not seem to have attempted to do so.

- Decrease overall production in existing areas and prohibit siting in areas approaching the assimilative and environmental carrying capacity.

- Do not take widespread production offshore.

- Increase transparency in the siting process.

- Increase collaboration with other Bay of Fundy industry- available records for quantity and contents of effluents, and other characteristics affecting cumulative environmental impacts from industry.

- Conduct additional studies outlining areas frequented by endangered species and important critical fish habitat- much subjectivity still remains in these aspects of the DSS despite efforts to remove it. Isolated species sitings are not reliable measures for determining functionality of a habitat as the potential presence of species as these considerations are subject to change.

- Ensure SARA and Fisheries Act enforcement.

- Ban the use of acoustic deterrent devices.

- Ensure adequate buffer zones between finfish farms and all protected and ecologically significant areas.

- Manage the SWNB mariculture industry from a regional perspective. 


\section{REFERENCES}

Acadian Seaplants Limited. 2006. Seaweed Resource Science http://www.acadianseaplants.com/seaweedresource.html Dartmouth, N.S.

Agriculture, Fisheries and Aquaculture, Department of (AFA). 2000. Bay of Fundy Marine Aquaculture Site Allocation Policy. http://www.gnb.ca/afa-apa

Agriculture and Agri-food Canada. 2003. Fish and Seafood: Aquaculture Atlas of Canada. http://www.seafoodcanada.gc.ca/aquaculture-e.htm

Agriculture, Fisheries and Aquaculture. 2004. Sectors in review 2004. http://www.gnb.ca/0168/30/review2004.pdf

ANZECC \& ARMCANZ. 2000. Australian and New Zealand guidelines for fresh and marine water quality. National Water Quality Management Strategy Paper No 4, Australian and New Zealand Environment and Conservation Council \& Agriculture and Resource Management Council of Australia and New Zealand, Canberra, Australia.

Atlantic Salmon Federation (ASF). 2004. Status of North American Wild Atlantic Salmon:Government Leadership Needed.

Aure, J. and A. Stigebrandt. 1990. Quantitative estimates of eutrophication effects on fjords of fish farming. Aquaculture, 90: 135-156.

Australian Government. 2005. Total phosphorus fact sheet. http://npi.gov.au/database/substance-info/profiles/72.html

Baxter, W., Ross, W.A. and H. Spaling. 2001. Improving the practice of cumulative effects assessment in Canada. Impact Assessment and Project Appraisal, 19 (4): 253-262.

Blinn, Brenda M. 2005. Factors Affecting Habitat Selection by Common Eiders (Somateria mollissima) During Brood-Rearing in the Bay of Fundy, New Brunswick. Masters Thesis, University of New Brunswick.

Burridge, L.E. 2003. Chemical use in marine finfish aquaculture in Canada: A review of current practices and possible environmental effects. In DFO. A scientific review of the potential environmental effects of aquaculture in aquatic ecosystems. Vol. 1. Can. Tech. Rep. Fish. Aquat. Sci. 2450: ix + 131 p.

Canadian Council of Ministers of the Environment (CCME). 2003. Canadian water quality guidelines for the protection of aquatic life: Summary table. Updated December 2003. In. Canadian environmental water quality guidelines, 1999, Canadian Council of Ministers of the Environment, Winnipeg. 
Carroll, M. L., Cochrane, S., Fieler, R., Velvin, R., and P. White. 2003. Organic enrichment of sediments from salmon farming in Norway: environmental factors, management practices, and monitoring techniques. Aquaculture, 222: 165-180.

Carr, Mark H., Neigel, Joseph E., Estes, James A., Andelman, Sandy, Warner, Robert R. and John L. Largier. 2003. Comparing marine and terrestrial ecosystems: implications for the design of coastal marine reserves. Ecological Applications, 13(1) Supplement: S90-S107.

CCME, 2002. Canadian Sediment Quality Guidelines for the Protection of Aquatic Life.

CCNB. 2003. Environmental Quality Matrix for the Quoddy Region, Southwestern Bay of Fundy (Excluding St. Croix estuary and Cobscook Bay.

CCNB. 2004. A eutrophication survey of bays in the Quoddy Region. Final Report to the New Brunswick Environmental Trust Fund.

Chang, B.D., Page, F.H., Losier, R.J., Greenberg, D.A., Chaffrey, J.D. and E.P. McCurdy. 2005. Water circulation and management of infectious salmon anemia in the salmon aquauculture industry of Letete Passage, Back Bay, Bliss Harbour, and Lime Kiln Bay in SWNB. Can. Tech. Rep. Fish. Aquat. Sci. 2599: iii + 55p.

Chang, B.D., Page, F.H. and Hill, B.W.H. 2005a. Preliminary analysis of coastal marine resource use and the development of open ocean aquaculture in the Bay of Fundy. Can. Tech. Rep. Fish. Aquat. Sci. 2585: iv +36 p.

Chau, K.W. 2005. An unsteady three-dimensional eutrophication model in Tolo harbour, Hong Kong. Marine Pollution Bulletin, 51: 1078-1084.

Choi, K.W. and J.H.W. Lee. 2004. Numerical determination of flushing time for stratified water bodies. Journal of Marine Systems, 50: 263-281.

Chou, C.L., Haya, K., Paon, L.A., Burridge, L., and J.D. Moffatt. 2002. Aquaculturerelated trace metals in sediments and lobsters and relevance to environmental monitoring program ratings for near-field effects. Marine Pollution Bulletin, 44: 1259-1268.

Chou, C.L., Haya, K., Paon, L.A., and J.D. Moffatt. 2004. A regression model using sediment chemistry for the evaluation of marine environmental impacts associated with salmon aquaculture cage wastes. Marine Pollution Bulletin, 49:465-472.

Coombs, Karen. DAFA. Personal Communication. March-April 2006.

Cromey, C.J., Nickell, T.D. and Black, K.D. 2002. DEPOMOD - modelling the deposition and biological effects of waste solids from marine cage farms. Aquaculture, 214: 211-239. 
David Suzuki Foundation. Escaping farmed salmon pose risk. http://www.davidsuzuki.org/Oceans/Aquaculture/Salmon/Escapes.asp. Accessed April, 2006.

Debruyn, A.M.H., Trudel, M., Eyding, N., Harding, J., McNally, H., Mountain, R., Orr, C., Urban, D., Verenitch, S., and A. Mazumder. 2006. Ecosystemic effects of salmon farming increase mercury contamination in wild fish. Environmental Science \& Technology, 40 (11): 3489-3493.

Delhez, E. J. M. 2006. Transient residence and exposure times. Ocean Science, 2: 1-9.

Demers, Marc. (NCR). 2006. Personal Communication. February 2006.

DFO. 1999. The Impact of the Rockweed Harvest on the Habitat of Southwest New Brunswick. DFO Maritimes Regional Habitat Status Rep. 99/2E.

DFO. 1999a. Interaction Between Wild and Farmed Atlantic Salmon in the Maritime Provinces. DFO Maritimes Regional Habitat Status Report 99/1E.

DFO. 2001. Bay of Fundy Lobster (LFAs 35,36, and 38). DFO Science Stock Status Report C3-61 (2001).

DFO. 2002. Aquaculture Coordination Office. http://www.mar.dfompo.gc.ca/aqucrd/home.html

DFO, Science Branch, Maritimes Region. 2003. Salmon Holding Capacity in Southwestern New Brunswick. Can. Tech. Rep. Fish. Aquat. Sci. 2489: iv + $53 \mathrm{pp}$.

DFO. 2005. News Release: Federal Government Delivers on Aquaculture Investment July 12, 2005. http://www.mar.dfompo.gc.ca/communications/maritimes/news05e/NR-MAR-05-18E.html

DFO. 2006. American Shad. http://www.dfo-mpo.gc.ca/zone/underwater_sousmarin/shad/shad-alose e.htm

DFO. 2006a. The Aquaculture Industry and the Species at Risk Act. http://www.dfompo.gc.ca/species-especes/actMeans/actMeans_aquaculture_factsheet_e.asp

Doglioli, A.M., Magaldi, M.G., Vezzulli, L. And S. Tucci. 2004. Development of a numerical model to study the dispersion of wastes coming from a marine fish farm in Ligurian Sea (Western Mediterranean). Aquaculture, 231:215-235.

Drost, Terry. 2005. Corey Aquafeeds. Personal communication. June 2005 
Dudley, Robert W., Panchang, Vijay G., and Carter R. Newell. 2000. Application of a comprehensive modeling strategy for the management of net-pen aquaculture waste transport. Aquaculture, 187: 319-349.

Eggleston, David B., Ward, E. Elis, Etherington, Lisa L., Dahlgren, Craig P., and Martin H. Posey. 1999. Organism responses to habitat fragmentation and diversity: Habitat colonization by estuarine macrofauna. Journal of Experimental Marine Biology and Ecology, 236: 107-132.

EC (Environmental Assessment Section, Atlantic Region). 2001. Environmental Assessment of Marine finfish Aquaculture Projects: Guidelines for consideration of Environment Canada expertise. http://atlantic-web1.ns.ec.gc.ca/eaee/Default.asp?lang=En\&n=BE5579CF-0

Encarta, World Atlas. 2006. Map of Bay of Fundy, North America. http://encarta.msn.com/map 701510917/Fundy Bay of.html

Environment Canada (EC)-National Guidelines and Standards Office. 2005. Canadian Water Quality Guidelines: Nitrate. www.ec.gc.ca/ceqg-rcqe/

Environment Canada (EC)-National Guidelines and Standards Office. 2005a. Canadian Water Quality Guidelines: Phosphorus. www.ec.gc.ca/ceqg-rcqe/

Ervik, Arne, Hansen, Pia Kupka, Aure, Jan, Stigebrandt, Anders, Johannessen, Per and Terje Jahnsen. 1997. Regulating the local environmental impact of intensive marine fish farming I. The concept of the MOM system (Modelling-Ongrowing fish farms-Monitoring). Aquaculture, 158: 85-94.

Environmental Protection Agency (EPA). 2006. Management Measures for Marinas and Recreational Boating - IV. Glossary. http://www.epa.gov/owow/nps/MMGI/Chapter5/ch5-3.html

Fasham, M.J.R. 1993. Modelling marine biota. p.457-504.In: M. Heimann [ed.]. The global carbon cycle. Springer-Verlag, Berlin.

Ferreira, J.G. 2000. Development of an estuarine quality index based in key physical and biogeochemical features. Ocean and Coastal Management, 43:99-122.

Frankic, A., and C. Hershner. 2003. Sustainable aquaculture: developing the promise of aquaculture. Aquaculture International, 11: 517-530.

Frost, M.T., Rowden, A.A., and Attrill, M.J. 1999. Effect of habitat fragmentation on macroinvertebrate infaunal communities associated with the seagrass Zostera marina L. Aquatic Conserv: Mar. Freshw. Ecosyst. 9:255-263. 
Fundy Forum. 2001. Hot Topics in the Bay of Fundy http://www.fundyforum.com/issues.html

Gillibrand, P.A. and W.R. Turrell. 1997. The use of simple models in the regulation of the impact of fish farms on water quality in Scottish sea lochs. Aquaculture, 159: 33-46.

Goldburg, Rebecca and Tracy Triplett (The Environmental Defense Fund). 1997. Murky Waters: Environmental Effects of Aquaculture in the US. http://www.environmentaldefense.org/documents/490 AQUA.pdf

Graham, Jennifer, Engle, Stephen and Maria Recchia. 2002. Local Knowledge and Local Stocks: An Atlas of Groundfish Spawning in the Bay of Fundy. A report of the Centre for Community-Based Management, St. Francis Xavier University, Nova Scotia.

Gregory, D., Petrie, B., Jordan, F. and P. Langille. 1993. Oceanographic, geographic and hydrological parameters of Scotia-Fundy and southern Gulf of St. Lawrence inlets. Can. Tech. Rep. Hydrogr. Ocean Sci. No. 143: viii + 248 pp.

Greenberg, D., Chaffey, J., and M. Dowd. 2002. Model tidal diagnostics for aquaculture sites in the Quoddy region, p. 38-39. In B.T. Hargrave (Ed.), Environmental studies for sustainable aquaculture (ESSA): 2002 workshop report. Can. Tech. Rep. Fish. Aquat. Sci. 2411: v+117p.

Greenberg, David A., Shore, Jennifer A., Page, Fred H. and Michael Dowd. 2005. A finite element circulation model for embayments with drying intertidal areas and its application to the Quoddy region of the Bay of Fundy. Ocean Modelling, 10: 211-231.

Hargrave, B.T. 1994. A benthic enrichment index, p. 79-91. Modelling Benthic Impacts of Organic Enrichment from Marine Aquaculture. Can. Tech. Rep. Fish. Aquat. Sci. 1949: $\mathrm{xi}+125 \mathrm{p}$.

Hargrave, B.T. 2002. A traffic light decision system for marine finfish aquaculture siting. Ocean Coast. Manage, 45:215-235.

Hargrave, B.T. 2003. Far-field environmental effects of marine finfish aquaculture, p.149. In Fisheries and Oceans Canada. A scientific review of the potential environmental effects of aquaculture in aquatic ecosystems. Vol. 1. Can. Tech. Rep. Fish. Aquat. Sci. 2450: ix + 131 p.

Hargrave, B.T. 2003a. Appendix B: Evaluating the potential magnitude of eutrophication effects of salmon aquaculture in SWNB. Department of Fisheries and Oceans, Science Branch, Maritimes Region. 2003. Salmon Holding Capacity in 
Southwestern New Brunswick. Can. Tech. Rep. Fish. Aquat. Sci. 2489: iv + 53 pp.

Hargrave, B.T. 2006. Effects of free sulfides in marine sediments on macrobenthic infauna biodiversity. Department of Fisheries and Oceans, Maritimes Region, Expert Opinion 2006/01, Regional Advisory Office, Bedford Institute of Oceanography, Dartmouth, N.S. 17 p.

Hargrave, B.T. 2006a. Personal communication. March 2006.

Hargrave, B.T., Bugden, G., Keizer, P., Milligan, T., Silvert, W., Strain, P. and D. Wildish. No date. Environmental Interactions with Sea Cage Culture of Atlantic Salmon. http://www.mar.dfo-mpo.gc.ca/science/review/e/pdf/environmental.pdf

Harvey, J. (Conservation Council of New Brunswick Inc.). 2004. Response to the Report of the Commissioner for Aquaculture Development "Recommendations for Change", Fredericton, N.B.

Harvey, Janice. 2005. Personal communication. June 2005.

Harvey, Janice. 2006. Personal communication. March 2006.

Harvey, Janice. 2006a. Cage of Our Own Making Salmon Aquaculture: Not a Sustainable Venture. Elements Online Magazine, http://www.elements.nb.ca/theme/oceans06/janice/janice.htm

Haya, K., Burridge, L. E. and B. D. Chang. 2001. Environmental impact of chemical wastes produced by the salmon aquaculture industry. ICES Journal of Marine Science, 58(2): 492-496.

Hellou, J., Haya, K., Steller, S., and L. Burridge. 2005. Presence and distribution of PAHs, PCBs and DDE in feed and sediments under salmon aquaculture cages in the Bay of Fundy, New Brunswick, Canada. Aquatic Conservation-Marine and Freshwater Ecosystems, 15 (4): 349-365.

Henderson, A., Gamito, S., Karakassis, I., Pederson, P., and A. Smaal. 2001. Use of hydrodynamic and benthic models for managing environmental impacts of marine aquaculture. J. Appl. Ichthyol., 17: 163-172.

Hishamundai, N., Ridler, N.B. Macro policies to promote sustainable commercial aquaculture. Aquaculture International 10: 491-505, 2002.

Holmer, M., D. Wildish and B.T. Hargrave. 2005. Organic enrichment from marine finfish aquaculture and effects on sediment processes. In B.T. Hargrave (Ed.) Environmental Effects of Marine Finfish Aquaculture, Springer, Berlin, p. 181206. 
Hovel, Kevin A. 2003. Habitat fragmentation in marine landscapes: relative effects of habitat cover and configuration on juvenile crab survival in California and North Carolina seagrass beds. Biological Conservation, 110: 401-412.

Howlett, M., and J. Rayner. 2003. Studying Canadian Aquaculture Policy: Issues, Gaps, and Directions. Paper Destined for the Annual General Meeting of the Canadian Political Science Association, Dalhousie University. Halifax, Nova Scotia. May 30, 2003.

Howlett, M., and J. Rayner. 2004. (Not so) “'Smart regulation'? Canadian shellfish aquaculture policy and the evolution of instrument choice for industrial development. Marine Policy, 28: 171-184.

Irandi, E.A., Ambrose Jr., W.G. and B.A. Orlando. 1995. Landscape ecology and the marine environment: how spatial configuration of seagrass habitat influences growth and survival of the bay scallop. Oikos, 72(3): 307-313.

Irlandi, E.A., Orlando, B.A. and W.G. Ambrose Jr. 1999. Influence of seagrass habitat patch size on growth and survival of juvenile bay scallops, Argopecten irradians concentricus (Say). J. Exp. Mar. Biol. Eco., 235: 21-43.

Islam, Md. Shahidul. 2005. Nitrogen and phosphorus budget in coastal and marine cage aquaculture and impacts of effluent loading on ecosystem: review and analysis towards model development. Marine Pollution Bulletin, 50: 48-61.

Jacobs, S.R. and J.M. Terhune. 2002. The effectiveness of acoustic harassment devices in the Bay of Fundy, Canada: seal reactions and a noise exposure model. Aquatic Mammals, 28 (2): 147-158.

Johnston, D.W. and T.H. Woodley. 1998. A survey of acoustic harassment device (AHD) use in the Bay of Fundy, NB, Canada. Aquatic Mammals, 24 (1): 51-61.

Johnston, Dave W. 2002. The effect of acoustic harassment devices on harbour porpoises (Phocoena phocoena) in the Bay of Fundy, Canada. Biological Conservation, 108: 113-118.

Karim, Md. Rezaul, Sekine, Masahiko, and Masao Ukita. 2003. A model of fish preference and mortality under hypoxic water in the coastal environment. Marine Pollution Bulletin, 47: 25-29.

Kenchington, E. (DFO). 1999. Benthic faunal species associated with scallop grounds in the Bay of Fundy, Canada. 10-12 June, Kodiak, Alaska. http://www.cf.adfg.state.ak.us/geninfo/pubs/special/sp14/sp14 1f.pdf

Macleod, Catriona K., Crawford, Christine M. and Natalie A. Moltschaniwskyj. 2004. Assessment of long term change in sediment condition after organic enrichment: defining recovery. Marine Pollution Bulletin, 49: 79-88. 
Mendiguchia, C., Moreno, C., Manuel-Vez, M.P., and M. Garcia-Vargas. 2006.

Preliminary investigation on the enrichment of heavy metals in marine sediments originated from intensive aquaculture effluents. Aquaculture, 254 (1-4): 317-325.

Middleton, Joe. 2005. Salmon farmer. Personal communication. June, 2005.

Milewski, Inka (CCNB). 2001. Impacts of Salmon Aquaculture on the Coastal Environment: A Review. In: Tlusty, M.F., D.A. Bengston, H.O. Halvorson, S.D. Oktay, J.B. Pearce, and R.B. Rheault, Jr. (eds.) 2001. Marine Aquaculture and the Environment; A meeting for Stakeholders in the Northeast. 166 - 197 pp. Cape Cod Press, Falmouth, Massachusetts. 324 p.

Milligan, T.G. and B. Law. 2004. The effect of aquaculture on fine graned sediment dynamics in coastal embayments. In B.T. Hargrave [ed.]. Environmental Studies for Sustainable Aquaculture (ESSA): 2004 Symposium Report. Can. Tech. Rep. Fish. Aquat. Sci. 2542: vi +81 p.

Morris, Daniel S. 1996. Seal predation at Salmon farms in Maine, an overview of the problem and potential solutions. Marine Technology Society Journal, 30 (2): 3943.

Morton, A. B., and H. K. Symonds. 2002. Displacement of Orcinus orca (L.) by high amplitude sound in British Columbia, Canada. ICES Journal of Marine Science, 59: 71-80.

Murison, Laurie. Grand Manan Whale \& Seabird Research Station. Personal communication. May 2006.

Nath, Shree S., Bolte, John P. Ross, Lindsay G., and Jose Aguilar-Manjarrez. 2000. Applications of geographical information systems (GIS) for spatial decision support in aquaculture. Aquacultural Engineering, 23: 233-278.

Nature Trust of New Brunswick. 2006. Coastal Charlotte County. http://www.naturetrust.nb.ca/coastal-charlotte-county.php

Ecologically Significant Areas. http://www.naturetrust.nb.ca/ecologicallysignificant-areas.php

Naylor, Rosamond, Hindar, Kjetil, Fleming, Ian A., Goldburg, Rebecca, Williams, Susan, Volpe, John, Whoriskey, Fred, Eagle, Josh, Kelso, Dennis, and Marc Mangel. 2005. Fugitive Salmon: Assessing the Risks of Escaped Fish from Net-Pen Aquaculture. BioScience, 55(5).

New Brunswick Department of Environment and Local Government (NBDELG). 2001. Environmental Management Guidelines for the Marine Finfish Cage Aquaculture Industry in New Brunswick. 
New Brunswick Department of Environment and Local Government (NBDELG). 2005. Projects that must be registered under ELA: Schedule A-Undertakings. http://www.gnb.ca/0009/0377/0002/0006-e.asp Accessed: 04-18-2005.

New Brunswick Department of Training and Employment Development (Labour Market Analysis Branch). 2002. Profile of Enterprise Charlotte (Community Economic Development Agency) http://www.gnb.ca/0126/CEDAADEC/pdf/ECharlotteFinal.pdf

Nordvarg, Lennart and Lars Håkanson. 2002. Predicting the environmental response of fish farming in coastal areas of the Åland archipelago (Baltic Sea) using management models for coastal water planning. Aquaculture, 206: 217- 243.

Olivier, G. 2004. Changes in the environment due to the aquaculture industry, do they reflect an increased risk of disease incidences? In B.T. Hargrave [ed.]. Environmental Studies for Sustainable Aquaculture (ESSA): 2004 Symposium Report. Can. Tech. Rep. Fish. Aquat. Sci. 2542: vi +81 p.

Page, F.H. 2003. Appendix C. Fish-farm induced dissolved oxygen depletion. In Department of Fisheries and Oceans, Science Branch, Maritimes Region. 2003. Salmon Holding Capacity in Southwestern New Brunswick. Can. Tech. Rep. Fish. Aquat. Sci. 2489: $i v+53$ pp.

Page, F.H., Chang, B.D., and D.A. Greenberg. 2004. Fish health and oceanography project of the Aquaculture Collaborative Research and Development Program: final project report. Can. Tech. Rep. Fish. Aquat. Sci. 2543: vi $+47 p$.

Page, F.H., Chang, B.D., Losier, R.J., Greenberg, D.A., Chaffrey, J.D. and E.P. McCurdy. 2005. Water circulation and management if Infectious Salmon Anemia (ISA) in the salmon aquaculture industry of southern Grand Manan, Bay of Fundy. Can. Tech. Rep. Fish. Aquat. Sci. 2595: iii + 78p.

Pannacciulli, Federica G. Nd. Habitat fragmentation and genetic biodiversity and genetic biodiversity. Centro Ricerche Ambiente Marino. http://www.eumar.tmbl.gu.se/eumarint/documents/Meetings/Lerici/Fragm ENEA .pdf

Papatryphon, Elias, Petit, Jean, Van der Werf, Hayo M.G., Sadasivam, Kaushik J., and Kanyarushoki Claver. 2005. Nutrient-Balance Modeling as a Tool for Environmental Management in Aquaculture: The Case of Trout Farming in France. Environmental Management, Vol. 35, No. 2, pp. 161-174.

Parliament of Canada, Standing Committee on Fisheries and Oceans. 2001. Third report. http://www.parl.gc.ca/InfoComDoc/37/2/FOPO/Studies/Reports/foporp03/05hon-e.htm 
Percy, J.A., Wells, P.G. and A.J. Evans (eds). 1997. Bay of Fundy Issues: s scientific overview. Workshop proceedings, Wolfville, N.S., January 29 to February 1, 1996. Environment Canada- Atlantic Region Occasional Report no. 8, Environment Canada, Sackville, New Brunswick, 191 pp.

Perez, O.M., Telfer, T.C., Beveridge, M.C.M. and L.G. Ross. 2002. Geographical Information Systems (GIS) as a Simple Tool to Aid Modelling of Particulate Waste Distribution at Marine Fish Cage Sites. Estuarine, Coastal and Shelf Science, 54: 761-768.

Perez, O.M., Telfer, T.C. and L.G. Ross. 2003. On the calculation of wave climate for offshore cage culture site selection: a case study in Tenerife (Canary Islands). Aquacultural Engineering, 29: 1 -21.

Perez, O.M., Telfer, T.C., and L.G. Ross. 2003a. Use of GIS-Based Models for Integrating and Developing Marine Fish Cages within the Tourism Industry in Tenerife (Canary Islands). Coastal Management, 31:355-366.

Perez, O.M., Ross, L.G., Telfer, T.C., and L.M. del Campo Barquin. 2003b. Water quality requirements for marine fish cage site selection in Tenerife (Canary Islands): predictive modelling and analysis using GIS. Aquaculture, 224: 51-68.

Perez, Oscar M., Telfer, Trevor C., and Lindsay G. Ross. 2005. Geographical information systems-based models for offshore floating marine fish cage aquaculture site selection in Tenerife, Canary Islands. Aquaculture Research, 36: 946-961.

Peterson, R.H., Page, F., Steeves, G.D., Wildish, D.J., Harmon, P., and R. Losier. 2001. A survey of 20 Atlantic salmon farms in the Bay of Fundy: influence of environmental and husbandry variables on performance. Can. Tech. Rep. Fish. Aquat. Sci. 2337:v+117 p.

Pohle, G., Frost, B., and R. Findlay. 2001. Assessment of regional benthic impact of salmon mariculture within the Letang Inlet, Bay of Fundy. ICES Journal of Marine Science, 58: 417-426.

Rangeley R.W. and D.L. Kramer. 1998. Density-dependent antipredator tactics and habitat selection in juvenile pollock. Ecology 79(3): 943-952.

Roberts, David A. and Alistair G.B. Poore. 2005. Habitat configuration affects colonisation of epifauna in a marine algal bed. Biological Conservation, 12 7: 18 -26 .

Robinson, S.M.C., Bernier S. and A. MacIntyre. 2001. The impact of scallop drags on sea urchin populations and benthos in the Bay of Fundy, Canada. Hydrobiologia, 465 (1-3):103-114. 
Robinson, S.M.C., Auffrey, L.M., and M.A. Barbeau. 2004. Impacts of eutrophication on the intertidal zone in temperate areas with emphasis on the soft-shell clam, Mya arenaria. In B.T. Hargrave [ed.]. Environmental Studies for Sustainable Aquaculture (ESSA): 2004 Symposium Report. Can. Tech. Rep. Fish. Aquat. Sci. 2542: vi $+81 \mathrm{p}$.

Robinson, S.M.C., Auffrey, L.M. and M.A. Barbeau. 2005. Far-field impacts of eutrophication on the intertidal zone in the Bay of Fundy with emphasis on the softshell clam, Mya arenaria. Springer, Berlin, p. 253-274.

Rose, Tammy. (DFO, Habitat Management) Personal communication. February 8, 2006.

Salam, M. Abdus, Ross, Lindsay G., and C.M. Malcolm Beveridge. 2003. A comparison of development opportunities for crab and shrimp aquaculture in southwestern Bangladesh, using GIS modelling. Aquaculture, 220: 477-494.

Sharp, Glyn. Personal communication. May 2006.

Sheldon, Joan E. and Merryl Alber. 2001. Any way you slice it: a comparison of residence time calculations using simple compartment models of the Altamaha River Estuary. Presented at the Estuarine Research Federation meeting Nov. 4-8, 2001, St. Pete Beach, Florida. Manuscript submitted to Estuaries (special issue: "Freshwater Inflow: Science, Policy, Management")

Sheng, J., Wright, D.G., Greatbatch, R.J., and D.E. Dietrich. 1998. CANDIE: A new version of the DieCAST ocean circulation model. J. Atmosphere. Ocean. Technol, 15: 1414-1432.

Silvert, William. 1992. Assessing environmental impacts of finfish aquaculture in marine waters. Aquaculture, 107: 67-79.

Silvert, W. 1994. Modelling benthic deposition and impacts of organic matter loading. In: B.T. Hargrave (Editor), Modelling Benthic Impacts of Organic Enrichment from Marine Aquaculture. Can. Tech. Rep. Fish. Aquat. Sci., 1949: 1-18.

Silvert, William. 1994a. A decision support system for regulating finfish aquaculture. Ecological Modelling, 75/76: 609-615.

Silvert, W. and J. W. Sowles. 1996. Environmental impacts of marine finfish aquaculture. Journal of Applied Ichthyology, 12: 75-81.

Southwest New Brunswick Aquaculture Environment Coordinating Committee (AECC). 2004. DISCUSSION PAPER: Environmental Regulation and Management Related to the Application of Performance Based Standards For the Marine Salmon Aquaculture Industry in New Brunswick. 
Sowles, J.W., Churchill, L. and W. Silvert. 1994. The effect of benthic carbon loading on the degradation of bottom conditions under farm sites. In: B.T. Hargrave (Ed.), Modelling Benthic Impacts of Organic Enrichment from Marine Aquaculture. Can. Tech. Rep. Fish. Aquat. Sci., 1949: 31-46.

Special Committee on Sustainable Aquaculture. 2006. Minutes and Hansard Blues Report of Proceedings (Hansard Blues), 2006 Legislative Session: Second Session, 38th Parliament. Thursday, June 1, 2006.

Statistics Canada. 2002. Population and Dwelling Counts, for Canada, Provinces and Territories, and Census Divisions, 2001 and 1996 Censuses - 100\% Data http://www12.statcan.ca/english/census01/products/standard/popdwell/Table-CDP.cfm?PR=13

Statistics Canada. 2004. Median Family Income in Constant (2000) Dollars for All Census Families and Both Spouses or Partners With Earnings, for Canada and Census Divisions - 20\% Sample Data. http://www12.statcan.ca/english/census01/products/highlight/Income/Page.cfm?L ang $=\mathrm{E} \& G e 0=\mathrm{CD} \& \mathrm{Code}=0 \& V i e w=1 \mathrm{a} \&$ Table $=1 \mathrm{a} \&$ StartRec $=34 \&$ Sort $=2 \& \mathrm{~B} 1=\mathrm{Fa}$ mily1\&B2=Spouse 1

Stigebrandt, Anders, Aure, Jan, Ervik, Arne, and Pia Kupka Hansen. 2004. Regulating the local environmental impact of intensive marine fish farming III. A model for estimation of the holding capacity in the Modelling-Ongrowing fish farmMonitoring system. Aquaculture, 234: 239-261.

Stoetaert, K., Middelburg, J.J., Herman, P.M.J., and K. Buis. 2000. On the coupling of benthic and pelagic biogeochemical models. Earth Sci. Rev., 51: 173-201.

Strain, P.M., Wildish, D.J., and P.A. Yeats. 1995.The application of simple models of nutrient loading and oxygen demand to the management of a marine tidal inlet. Marine Pollution Bulletin, 30 (4): 253-261.

Strain, P. 2003. Appendix A: Oxygen demand and nutrient loads from finfish aquaculture in southwestern New Brunswick. In Department of Fisheries and Oceans, Science Branch, Maritimes Region. 2003. Salmon Holding Capacity in Southwestern New Brunswick. Can. Tech. Rep. Fish. Aquat. Sci. 2489: iv + 53 pp.

Strain, P.M. 2005. Eutrophication Impacts of Marine Finfish Aquaculture. DFO Can. Sci. Advis. Sec. Res. Doc. 2005/034: ii + 37 pp.

Strain, P.M. and B.T. Hargrave. 2005. Salmon Aquaculture, Nutrient Fluxes and Ecosystem Processes in Southwestern New Brunswick. Springer, Berlin. P. 29-58.

Stucchi, D., Sutherland, T., Levings, C., and J. Helfield. 2002. Wide area and near-field dissolved oxygen variations in the Broughton Archipelago.p.55-57. In B.T. 
Hargrave (Ed.), Environmental studies for sustainable aquaculture (ESSA): 2002 workshop report. Can. Tech.Rep. Fish. Aquat. Sci. 2411: v+117p.

Sturley, Darrell R.M. and Anthony J. Bowen. 1996. A model for contaminant transport in Lunenburg Bay, Nova Scotia. The Science of the Total Environment, 179:161172.

Sumagaysay-Chavoso, N. S., San Diego-McGlone, Ma. L., and L. T. David. 2004. Environmental capacity of receiving water as basis for regulating intensity of milkfish (Chanos chanos Forsskal) culture. J. Appl. Ichthyol., 20: 476- 487.

Tacon, A., and I. Forster. 2003. Aquafeeds and the environment: policy implications. Aquaculture, 226: 181-189.

Taylor, V.J., Johnston, D. W. and W. C. Verboom. 1997. Acoustic harassment device (AHD) use in the aquaculture industry and implications for marine mammals. In: Proceeding Symposium on Bio-Sonar and Bioacoustics, Loughborough University U.K.

Telfor, Trevor and Karen Robinson (Environmental Services, Institute of Aquaculture, University of Stirling). Environmental quality and carrying capacity for aquauculture in Mulroy Bay Co. Donegal. Marine Environment and Health Series, No.9, 2003., Marine Institute: Marine Environment and Food Safety Services, Parkmore, Galway.

The Standing Senate Committee on Fisheries. 2001. Aquaculture in Canada's Atlantic and Pacific Regions: Interim Report. Chair: The Honourable Gerald J. Comeau Deputy Chair: The Honourable Joan Cook. June 2001.

Tovar, A. 2000. Environmental Implications of Intensive Marine Aquaculture in Earthen Ponds. Marine Pollution Bulletin, 40 (11): 981-988.

Ugarte, Raúl A. and Glyn Sharp. 2001. A new approach to seaweed management in Eastern Canada: the case of Ascophyllum nodosum. Cahiers de Biologie Marin, 42:63-70.

van Rijn, L.C., Davies, A.G., Ribberink, J.S., and J. van de Graff [eds]. 2001. Sediment transport modelling in marine coastal environments. Aqua. Publications. 450p.

Wells, Peter G. 2003. Assessing health of the Bay of Fundy-concepts and framework. Marine Pollution Bulletin, 46: 1059-1077.

Westmacott, S. 2001. Developing decision support systems for integrated coastal management in the tropics: Is the ICM decision-making environment too complex for the development of a useable and useful DSS? Journal of Environmental Management, 62: 55-74. 
Wildish, D.J., Keizer, P.D., Wilson, A.J. and J.L. Martin. 1993. Seasonal changes of dissolved oxygen and plant nutrients in seawater near salmonid net pens in the macrotidal Bay of Fundy. Canadian Journal of Fisheries and Aquatic Sciences. Vol. 50, no. 2, pp. 303-311.

Wildish, D.J., Akagi, H.M., and E. Garnier. 2001.Geochemical monitoring of the Bay of Fundy salmon mariculture industry from 1998-2000. Can. Tech. Rep. Fish. Aquat. Sci.2361: iii + 19p.

Wildish, D.J., Dowd, M., Sutherland, T.F. and C.D. Levings. 2004. Near-field Organic Enrichment from Marine Finfish Aquaculture. In. DFO. 2004. A Scientific Review of the Potential Environmental Effects of Aquaculture in Aquatic Systems. Volume III. Can. Tech. Rep. Fish. Aquat. Sci. 2450: ix+117p.

Wildish, D.J., Akagi, H.M., and N. Hamilton. 2005. Interfacial geochemistry and macrofauna at a new salmon farm in Passamaquoddy Bay, Bay of Fundy. Can. Tech. Rep. Fish. Aquat. Sci. 2574: iii + 40p.

Wildish, D.J. and G.W. Pohle. 2005. Benthic macrofaunal changes resulting from finfish mariculture. In B.T. Hargrave (Ed.) Environmental Effects of Marine Finfish Aquaculture, Springer, Berlin, p. 275-304.

Willis, K.J., Gillibrand, P.A., Cromey, C.J. and K.D. Black. 2005. Sea lice treatments on salmon farms have no adverse effects on zooplankton communities: a case study. Marine Pollution Bulletin, 50: 806-816.

Worm, B. and H.K. Lotze.2000. Nutrient pollution, low-trophic level harvesting and cumulative human impact on coastal ecosystems. In: R.W. Rangeley and J. Davies (eds.) Gulf of Maine rockweed: Management in the face of scientific uncertainty. Proceedings of the GPAC workshop. Huntsman Marine Science Centre Occasional Report 00/1, St. Andrews, New Brunswick, pp 40-41.

Worm, B., H.K Lotze, H. Hillebrand and U. Sommer. 2002. Consumer versus resource control of species diversity and ecosystem functioning. Nature 417: 848-851.

Wu, R.S.S., Shin, P.K.S., MacKay, D.W., Mollowney, M., and D. Johnson.1999. Management of marine fish farming in the sub-tropical environment: a modelling approach. Aquaculture, 174: 279-298.

Wursig, Bernd and Glenn A. Gailey. 2002. Marine Mammals and Aquaculture: Conflicts and Potential Resolutions. In: Responsible Marine Aquaculture, Eds R.R. Stickney and J.P. McVey, CAB International. 
Xue, X., Hong, H., and A.T. Charles. 2004. Cumulative environmental impacts and integrated coastal management: the case of Xiamen, China. Journal of Environmental Management, 71:271-283.

Yeats, P.A. 2002. Trace metal tracers of fish farm wastes. 2002, p. 80-83. In B.T. Hargrave [ed.]. Environmental Studies for Sustainable Aquaculture (ESSA): 2002 workshop report. Can. Tech. Rep. Fish. Aquat. Sci. 2411:v + 117 p.

\section{Legislation}

Aquaculture Act, S.N.B. 1988, c. A-9

Clean Environment Act, S.N.B. 1973, c.C-6.

Clean Water Act, S.N.B. 1989, c. C-6.1.

Environmental Impact Assessment Regulation - Clean Environment Act, N.B. Reg. 87-

83.

Fisheries Act. R.S., 1985, c. F-14.

Migratory Birds Convention Act, 1994 ( 1994, c. 22 ).

Pesticides Control Act, RSNB 1973, c. P-8. 


\section{APPENDICES}

Appendix A

1. Notes to CCNB Environmental Quality Matrix

2. Definition for deleterious substance

3. Estimated Site Potential 1993 Formula 


\section{Notes to the Matrix}

\section{Colour Interpretation}

Colours are allocated to the matrix boxes on a comparative basis rather than an absolute basis. That is, high to low impact designations are made relative to other subregions within the Quoddy Region. While this may also translate into absolute measures relative to the entire Gulf of Maine (e.g. marine mammal habitat), it may not mean that a "red" designation for water quality in the Quoddy Region is comparable to a "red" designation for Boston Harbour. Similarly, development of coastal areas in the Quoddy Region is qualitatively and quantitatively different than in the southern Gulf of Maine, but within the Quoddy Region can be rated a high, moderate and low impact. as follows:

Within each category on the matrix, the colour designations have particular meaning. These are described

\section{Category: Water Quality}

Red - serious water quality problems

Yellow - moderate water quality problems

Green - generally good water quality

Category: Presence and quality of critical habitats

Red - critical habitats seriously impaired or significant losses

Yellow - critical habitats moderately impaired, moderate losses, or significant threats

Green - critical habitats largely undiminished and in relatively good shape

Category: Changes in Species

Red - dramatic declines in populations, loss of diversity, dramatic shifts in dominance within trophic levels, and high incursions of invaders over past 50 years

Yellow - moderate declines in populations and diversity, shifts in dominance and moderate incursions of invaders Green - overall population stability or increase, maintenance of diversity, maintenance of historic trophic

relationships, and low impacts by invaders.

Category: Changes in use and integrity of riparian and water zones

Red - dramatic changes in use of land or water zones and / or impairment of ecological integrity over past 50 years

Yellow - moderate changes and/or impairment

Green - general maintenance of traditional uses and low impacts on ecological integrity

Category: Changes in resource use

Red - dramatic changes in resource use over past 50 years (no judgement as to the desirability of those changes intended)

Yellow - moderate changes in resource use

Green - general maintenance of traditional resource use

Source: CCNB, 2003. 


\section{Explanations of Indicators in the Quoddy Region}

\begin{tabular}{|c|c|}
\hline & Category: Water Quality \\
\hline Bacteria & $\begin{array}{l}\text { We interpreted this as the extent and frequency of shellfish bed dosures as well } \\
\text { as the presence of raw sewage or wastewater flowing into waterways and onto } \\
\text { beaches (Lotze and Milewski, 2002; Environment Canada). }\end{array}$ \\
\hline Nutrients. & $\begin{array}{l}\text { Designations are based on the presence of large sources of nutrients, especially } \\
\text { finfish aquaculture and fish plants, as well as the probable dilution factors of the } \\
\text { subregions (Loze and Milewski 2002; observations; Chopin pers. com). }\end{array}$ \\
\hline Sediments. & $\begin{array}{l}\text { Designations are based on the presence of sediment loads, particularly finfish } \\
\text { aquaculture, and land-based activities contributing to erosion and nun-off. } \\
\text { Sediments still present from historic sources are also considered, ie. pulp and } \\
\text { saw mills (Lotze and Milewski 2002). }\end{array}$ \\
\hline $\begin{array}{l}\text { Toxic contaminants and } \\
\text { radionuclides. }\end{array}$ & $\begin{array}{l}\text { Designations are based on current and past monitoring of persistent organic } \\
\text { pollutants and heavy metals, the influence of the Saint John River plume carrying } \\
\text { contaminants from industry, and the presence of local sources such as the Point } \\
\text { Lepreau Nuclear Cenerating Station, the Domtar pulp mill in Woodland, the } \\
\text { Inving mill in Lake Utopia, the aquaculture industry, the shipping industry. } \\
\text { (Lotze and Milewski 2002, Sunderland, pers. com; Harvey 1994, Harvey et al } \\
\text { 1998). }\end{array}$ \\
\hline \multirow[t]{2}{*}{ Dissolved oxygen. } & $\begin{array}{l}\text { This is generally based on monitoring of the finfish aquaculture industry (Lotze } \\
\text { and Milewski 2002). }\end{array}$ \\
\hline & Category: Presence and Quality of Critical Habitats \\
\hline Benthic habitat. & $\begin{array}{l}\text { We considered current and past fish and scallop dragging in the area, the ability } \\
\text { of the bottom to recover from this, and the presence of aquaculture operations } \\
\text { (Lotze and Milewsk 2002; observations). }\end{array}$ \\
\hline Wetlands. & $\begin{array}{l}\text { There are no large wetlands in the area. Allocations were based on threats to the } \\
\text { several small wetlands from infilling and adjacent development (observations). }\end{array}$ \\
\hline Seagrass beds. & $\begin{array}{l}\text { Designations based on the presence and intensity of commercial-scale rockweed } \\
\text { harvesting, degree of colonization by annual algae, and possible disruption from } \\
\text { fish or scallop dragging (Harvey et al 1998; Lotze and Milewski 2002), } \\
\text { observations.) }\end{array}$ \\
\hline Nesting and foraging areas. & $\begin{array}{l}\text { We considered the extent of intact habitat as well as disturbances due to noise } \\
\text { and light from adjacent development, particularly aquaculture (Lotze and } \\
\text { Milewski 2002; observations). }\end{array}$ \\
\hline Spawning and nursery areas. & $\begin{array}{l}\text { This is based on a recent report on the loss of spawning grounds in the Bay of } \\
\text { Fundy, the presence of aquaculture operations in embayments, other habitat } \\
\text { disturbance such as rodweed harvesting and coastal development (Coon 1999; } \\
\text { Lotze and Milewski 2002; Graham et al 2002). }\end{array}$ \\
\hline $\begin{array}{l}\text { Legally protected areas, } \\
\text { private and public }\end{array}$ & $\begin{array}{l}\text { Designations based on the extent of coastline and/or number of areas protected } \\
\text { in each subregion (Harvey, 1994; observations). }\end{array}$ \\
\hline
\end{tabular}




\begin{tabular}{|c|c|}
\hline Marine mammal habitat & $\begin{array}{l}\text { Designations based on the quality of habitat relative to disturbances such as boat } \\
\text { traffic, noise and food supply (Lotze and Milewski 2002). }\end{array}$ \\
\hline & Category: Changes in species \\
\hline Populations & $\begin{array}{l}\text { Designations based on the relative abundance of populations of fish, marine } \\
\text { mammal and bird species over } 100 \text { years. Note the numbers of seabirds have } \\
\text { increased overall from historic lows but shorebirds are generally declining. All } \\
\text { commercial and anadromous fish populations have dramatically declined (Lotze } \\
\text { and Milewski 2002). }\end{array}$ \\
\hline Diversity & $\begin{array}{l}\text { Loss of biodiversity throughout the food web is associated with loss of fish } \\
\text { populations (ie. Atlantic salmon, large groundfish, spawning populations of fish) } \\
\text { due to overfishing and with aquaculture operations affecting the benthos (Lotze } \\
\text { and Milewski 2002; aquaculture monitoring by Pohle (L'Etang) and Milewski } \\
\text { (Crow Harbour). }\end{array}$ \\
\hline Dominance & $\begin{array}{l}\text { This is indicated by shifts in dominant species in all trophic levels (Lotze and } \\
\text { Milewski 2002). }\end{array}$ \\
\hline \multirow[t]{2}{*}{ Invaders } & $\begin{array}{l}\text { Considered were green crab (populations appear lower and thus less imact - } \\
\text { anecdotal) and the presence of aquaculture escapees, particularly Atlantic } \\
\text { Salmon, in estuaries and rivers. This may or may not be considered in invader } \\
\text { by others but we wanted to include it for information purposes. We did not } \\
\text { consider plants (Lotze and Milewsli 2002; observations). }\end{array}$ \\
\hline & Category: Changes in use and integrity of niparian and water zones \\
\hline $\begin{array}{l}\text { Clearing and development of } \\
\text { natural areas }\end{array}$ & $\begin{array}{l}\text { We considered natural areas to be those areas of coastline which are dark and } \\
\text { quiet at night and with no significant disturbance either on land or water. We } \\
\text { consider aquaculture operations on water to be development of an area, } \\
\text { regardless of whether the adjacent land is cleared or developed, due to the } \\
\text { intensity of noise, activity, movement and light (even underwater lights are used) } \\
\text { (Lotze and Milewski 2002; Harvey et al 1998; present threats). }\end{array}$ \\
\hline $\begin{array}{l}\text { Replacement of traditional } \\
\text { uses. }\end{array}$ & $\begin{array}{l}\text { This is the extent to which activity on land or water has changed over the past } \\
50-100 \text { years (observation). }\end{array}$ \\
\hline $\begin{array}{l}\text { Erosion and depositional } \\
\text { changes }\end{array}$ & $\begin{array}{l}\text { We considered the presence or absence of human activity that generate } \\
\text { deposition of sediments or exacerbate erosion, such as wood and fish processing } \\
\text { facilities, aquaculture, and shoreline development (Lotze and Milewski 2002). }\end{array}$ \\
\hline \multirow[t]{2}{*}{$\begin{array}{l}\text { Tidal barriers on streams, } \\
\text { marshes or estuaries }\end{array}$} & $\begin{array}{l}\text { We considered the number of tidal crossings in each area and the percentage of } \\
\text { these that restrict tidal flow to some degree (Thomas } 2003 \text { unpublished). }\end{array}$ \\
\hline & Category: Changes in resource use \\
\hline Shift in targeted species & $\begin{array}{l}\text { We considered the degree to which new species harvesting (ie. sea urchins, } \\
\text { rockweed, sea cucumbers, crab, dogfish) is replacing traditional harvesting (ie. } \\
\text { groundfish, inshore herring, Atlantic salmon, clams), and the change in intensity } \\
\text { of harvest of lobster and scallops (increasing) (Lotze and Milewski 2002). }\end{array}$ \\
\hline
\end{tabular}




\begin{tabular}{|l|l|}
\hline Species introductions & $\begin{array}{l}\text { We did not consider freshwater introductions in the region because any such } \\
\text { introductions are longstanding and appear to be relatively benign (note that the } \\
\text { St. Croix watershed is not induded in this matrix) (anecdotal). We did not } \\
\text { consider plants. Green indicates the absence of introductions (as opposed to } \\
\text { invaders) in the coastal waters (obsenation). }\end{array}$ \\
\hline $\begin{array}{l}\text { Shift from harvesting to } \\
\text { recreation/tourism }\end{array}$ & $\begin{array}{l}\text { Colours indicate the degree to which resource harvesting activity is declining } \\
\text { while tourism is increasing, ie, fewer fishing boats and more sightseeing. It does } \\
\text { not consider just growth in tourism while harvesting activity remains the same } \\
\text { (observation). }\end{array}$ \\
\hline $\begin{array}{l}\text { Shift from harvesting to } \\
\text { aquaculture }\end{array}$ & $\begin{array}{l}\text { Colours indicate the degee to which harvesting is declining in an area while } \\
\text { aquaculture is increasing, including the displacement of fishing, spawning and } \\
\text { nursery gounds (Lotze and Milewski 2002; fishermen pers. com., observation). }\end{array}$ \\
\hline
\end{tabular}

Source: CCNB, 2003

\section{Definition for deleterious substance}

Deleterious substance:

(a) any substance that, if added to any water, would degrade or alter or form part of a process of degradation or alteration of the quality of that water so that it is rendered or is likely to be rendered deleterious to fish or fish habitat or to the use by man of fish that frequent that water, or

(b) any water that contains a substance in such quantity or concentration, or that has been so treated, processed or changed, by heat or other means, from a natural state that it would, if added to any other water, degrade or alter or form part of a process of degradation or alteration of the quality of that water so that it is rendered or is likely to be rendered deleterious to fish or fish habitat or to the use by man of fish that frequent that water (Fisheries Act, s. 34.1)

\section{Estimated Site Potential 1993 Formula}

$\mathrm{ESP}=[($ Area $\times \mathrm{D} \%) \times 6.0] \times 18 \mathrm{~kg} / \mathrm{m}^{3} / 4 \mathrm{~kg}$

Where,

- ESP= "Estimated Site Potential" or maximum number of fish permitted on site at any one time;

- Area $=$ the total approved area $\left(\mathrm{km}^{2}\right)$ of the site below mean low tide; 
- $\mathrm{D} \%=$ the percentage of the surface area which may be used for the cages, excluding the walkways. This percentage is determined using the following equation: $\mathrm{D} \%=10.225-[.1125 \times(\mathrm{D}-8.0)])$

Where,

- $10.225=$ the percentage of usable surface area of a site with a depth at the center of a site of $8.0 \mathrm{~m}$ at mean low tide allowing for sagging and crossover of mooring lines while also considering a variety of cage types;

- $0.1125=$ is the percentage of usable surface area lost proportionally per meter of depth due to increased distance requirements for proper mooring;

- $\mathrm{D}=$ the depth in meters at the center of the site at mean low tide;

- $8.0=$ the minimum site depth in meters at mean low tide established under the N.B. Aquaculture Regulation 91-158;

- $6.0=$ the average depth in meters for the nets in a marine cage culture operation;

- $8=$ the maximum stocking density allowed on a marine finfish aquaculture site expressed in $\mathrm{kg} / \mathrm{m} 3$;

- $4.5=$ the average market weight in $\mathrm{kg}$ of cultured Atlantic salmon in the Bay of Fundy (Sweeney International, 2004). 


\section{Appendix B}

1. Table 1: Licensed farms and Approved Production Limits (APL) for ODD and EVEN year classes for salmon aquaculture sites grouped into CMRs (oceanographic regions and sub-regions) in SWNB (2002)

2. Table 2: Hydrographical Components of Coastal Management Regions, Bay of Fundy.

3. Table 3: Total Estimated Site Potential (ESP) and Combined Total Approved Production Limits (APL) (2002) per CMR.

4. Table 4: Salmon dissolved oxygen consumption rate and time required to use a DO buffer of $1 \mathrm{mg} / \mathrm{l}$.

5. Bay of Fundy: Marine Aquaculture Sites, Bay Management Areas, Controlled Areas, Exclusion Areas (DAFA, 2002) 
Table 1: Licensed farms and Approved Production Limits (APL) for ODD and EVEN year classes for salmon aquaculture sites grouped into CMRs (oceanographic regions and sub-regions) in SWNB (2002).

\begin{tabular}{|c|c|c|c|c|c|}
\hline \multicolumn{2}{|c|}{$\begin{array}{l}\text { Region (sub-region) } \\
\text { CMR }\end{array}$} & \multirow[t]{2}{*}{$\begin{array}{l}\text { Number of } \\
\text { Sites (2002) }\end{array}$} & \multicolumn{2}{|c|}{$\begin{array}{c}\text { APL (xl09) } \\
\text { odd even }\end{array}$} & $\begin{array}{l}\text { Percent } \\
\text { of Total }\end{array}$ \\
\hline \multicolumn{5}{|c|}{ Grand Manan } & \\
\hline & $\begin{array}{l}\text { (south) } \\
\text { (north) }\end{array}$ & 11 & 3.19 & $\begin{array}{l}0.22 \\
2.55\end{array}$ & $\begin{array}{l}17.2 \\
12.9\end{array}$ \\
\hline \multicolumn{6}{|c|}{ Campobello-Deer Island } \\
\hline & $\begin{array}{l}\text { Campobello Island) } \\
\text { Deer Islamd north) } \\
\text { Deer Island south) }\end{array}$ & $\begin{array}{r}9 \\
10 \\
11\end{array}$ & $\begin{array}{l}0.23 \\
- \\
0.64\end{array}$ & $\begin{array}{l}1.33 \\
2.80^{2} \\
1.34\end{array}$ & $\begin{array}{r}7.8 \\
14.2 \\
10.0\end{array}$ \\
\hline \multicolumn{6}{|c|}{ N. Passamaquoddy Bay } \\
\hline 6 & & 8 & 1.08 & 0.27 & 6.8 \\
\hline \multicolumn{6}{|c|}{ Letang/Letete } \\
\hline 7 & $\begin{array}{l}\text { (Lime Kiln Bay/Letang } \\
\text { (Bliss Harbour) } \\
\text { (Back Bay) } \\
\text { (Letete Passage) }\end{array}$ & $\begin{array}{l}8 \\
7 \\
8 \\
4\end{array}$ & $\begin{array}{l}1.08 \\
1.42 \\
1.32 \\
0.30\end{array}$ & $\begin{array}{c}- \\
\vdots \\
0.34\end{array}$ & $\begin{array}{l}5.4 \\
7.2 \\
6.7 \\
3.2\end{array}$ \\
\hline $\begin{array}{r}\text { Other A } \\
8\end{array}$ & $\begin{array}{l}\text { las } \\
\text { (Beaver Harbour, Mace } \\
\text { Foleys Cove) }\end{array}$ & es Bay, 6 & 0.30 & 1.39 & 8.5 \\
\hline Cobscoo & Bay (Maine) ${ }^{4}$ & 26 & 1.50 & 1.50 & NA \\
\hline TOTAL & New Brunswick) & $\underline{93}$ & $\underline{9.54}$ & 10.23 & \\
\hline
\end{tabular}

'Total APL for 22 BMAs designated in SWNB in 2002 by NBDAFA (19.7 $\times 10$ ); Does not include one haddock/cod site on Deer Island; 'Includes areas within Letete Passage and Letang Habour not excompassed by Lime Kin Bay, Bliss Hxbour and Back Bxy; "Cobscook Bay figures reflect total leases issued. Thirteen are contained in each of two BMAs. Not all leases are active in any one yexr. In 2002, 4 leases were actively farmed and 7 were stocked in 2003. The APL is based on anticipated values for 2004 forward.

Source: DFO, 2003, p. 11. 
Table 2: Hydrographical Components of Coastal Management Regions, Bay of Fundy.

\begin{tabular}{|c|c|c|c|c|c|c|}
\hline AREA & $\begin{array}{c}\text { Total Area } \\
\left(\mathrm{km}^{2}\right)\end{array}$ & $\begin{array}{c}\text { Volume (mean } \\
\text { Tide) } \\
\left(\times 10^{6} \mathrm{~m}^{3}\right)\end{array}$ & $\begin{array}{l}\text { Volume } \\
\text { (I) }\end{array}$ & $\begin{array}{l}\text { Residence } \\
\text { Time (d)* }\end{array}$ & $\begin{array}{c}\text { Flushing } \\
\text { rates }\end{array}$ & $\begin{array}{c}\text { Intertidal Area } \\
\left(\mathbf{k m}^{2}\right)\end{array}$ \\
\hline Grand Manan & 172 & 3721 & $3.72 \times 10^{12}$ & 3 & 15 & 558.2 \\
\hline Campobello/Deer Islands & 172 & 3721 & $3.72 \times 10^{12}$ & 3 & 15 & 558.2 \\
\hline N. Passamaquoddy Bay & 172.3 & 3721 & $3.72 \times 10^{12}$ & 15 & 75 & 558.2 \\
\hline Letang/Letete Passage & 37.2 & 405 & $4.05 \times 10^{11}$ & 9 & 45 & 121.5 \\
\hline Lime Kiln Bay & 1.96 & 11.04 & & & & 3.8 \\
\hline Bliss Harbour & 4.06 & 35.57 & & & & 6.1 \\
\hline Back Bay & 4.7 & 21.23 & & & & 8.4 \\
\hline Letete Passage & 6.78 & 50 & & & & 12.5 \\
\hline Other Areas & $50.5^{2}$ & 405 & $4.05 \times 10^{11}$ & 3 & 15 & 101.3 \\
\hline
\end{tabular}

* time to exchange $63 \%$ of water

Source: Hargrave, 2006, pers.comm: originally found in Gregory et al., 1993.

2 'Other' CMR area derived from data in Gregory et al., 1993 and an estimation of the additional 'Other' areas where farms have been sited.

Table 3: Total Estimated Site Potential (ESP) and Combined Total Approved Production Limits (APL) (2002) per CMR

\begin{tabular}{|l|l|l|l|c|}
\hline CMR & \multirow{2}{*}{$\begin{array}{c}\text { Approx.Total } \\
\text { ESP/CMR }\end{array}$} & \multicolumn{2}{|c|}{$\begin{array}{c}\text { Total APL }(\mathbf{x} \\
\mathbf{1 0}^{\mathbf{6}} \mathbf{)}\end{array}$} & $\begin{array}{c}\text { Combined Total APL } \\
(\mathbf{x ~ 1 0})\end{array}$ \\
\cline { 3 - 4 } & & Even & Odd & \\
\hline GM & $11,489,380$ & 2.71 & 3.19 & 5.9 \\
\hline CDI & $10,077,501$ & 5.47 & 0.87 & 6.34 \\
\hline NPB & $2,851,949$ & 0.27 & 1.08 & 1.35 \\
\hline LL & $8,071,833$ & 0.34 & 4.12 & 4.46 \\
\hline OTHER & $9,040,572$ & 1.89 & 1.53 & 3.43 \\
\hline
\end{tabular}

*ESP and APL data taken from spreadsheet provided by DELG, EAs and DFO, 2003.

*Other CMR TAPL data has been updated from 2002 data. APL data added to the TAPL taken from EAs was based on the highest proposed APL found in the EA or estimated from the ESP. 
Table 4: Salmon dissolved oxygen consumption rate and time required to use a DO buffer of $1 \mathrm{mg} / \mathrm{l}$.

\begin{tabular}{|l|l|l|l|l|}
\hline CMR & $\begin{array}{l}\text { Consumption rate } \\
\text { TESP }(\mathrm{mg} \mathrm{DO} / \mathrm{hr})\end{array}$ & $\begin{array}{l}\text { Consumption rate } \\
\text { TAPL }(\mathrm{mg} \text { DO/hr) }\end{array}$ & \multicolumn{2}{|l|}{ DO buffer utilization/2 (d) } \\
\cline { 4 - 5 } & TESP & TAPL \\
\hline GM & $5.17 \times 10^{9}$ & $2.66 \times 10^{9}$ & 120.0 & 233 \\
\hline CDI & $4.53 \times 10^{9}$ & $2.85 \times 10^{9}$ & 136.9 & 217.5 \\
\hline NPB & $1.28 \times 10^{9}$ & $6.08 \times 10^{8}$ & 484.3 & 1019.5 \\
\hline LL & $3.63 \times 10^{9}$ & $2.01 \times 10^{9}$ & 18.5 & 33.5 \\
\hline OTHER & $4.07 \times 10^{9}$ & $1.54 \times 10^{9}$ & 16.6 & 43.8 \\
\hline
\end{tabular}

Values based on procedure found in Page (2003) and outlined in Chapter 5. 


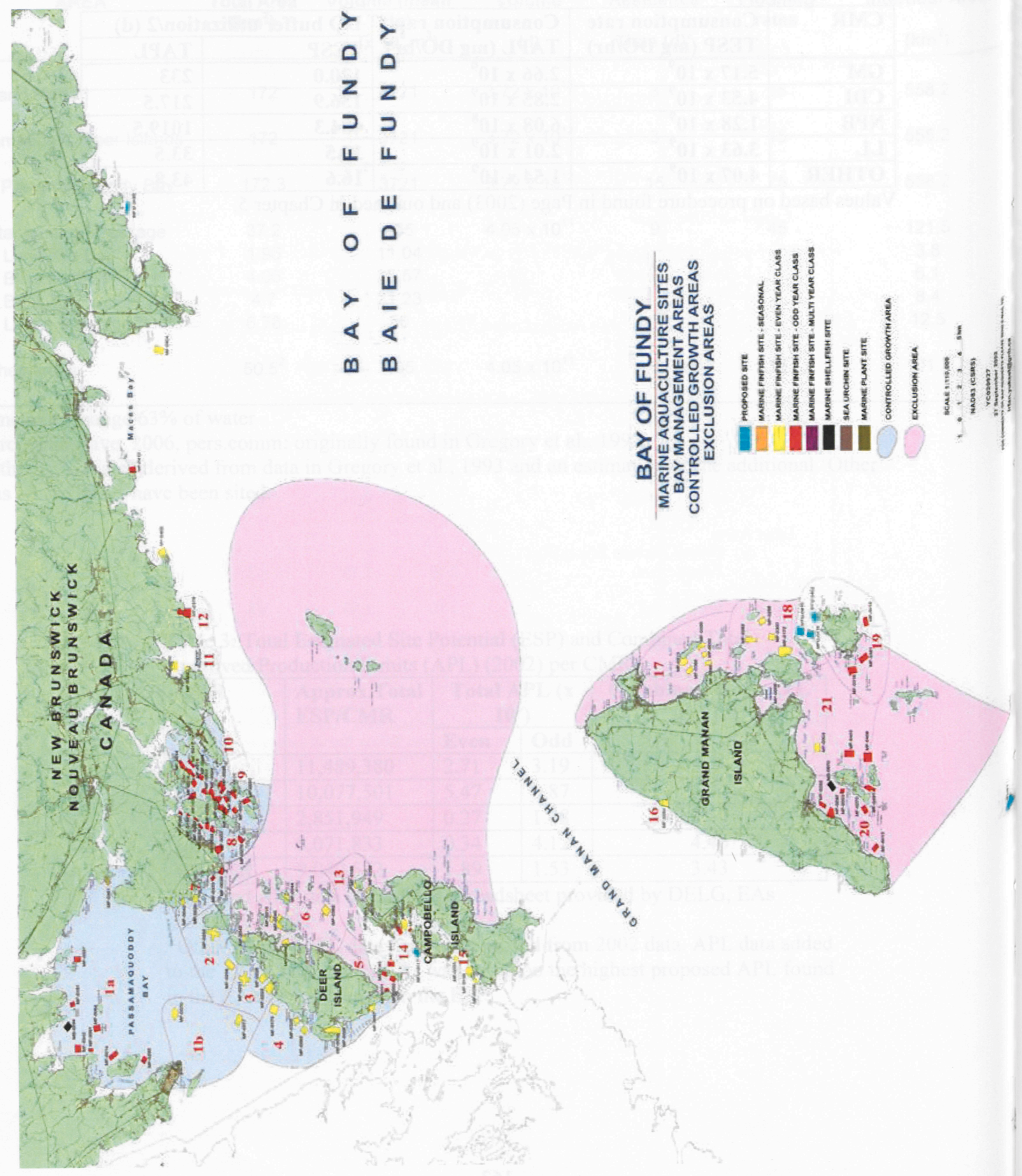




\section{Appendix C}

1. Environmental Monitoring Results for 2002, 2003, 2004, and 2005.

2. Example calculation of total affected area and percent habitat loss. 


\begin{tabular}{|c|c|c|c|c|c|c|c|c|c|c|}
\hline \multirow{2}{*}{\multicolumn{5}{|c|}{ Environmental Monitoring Results }} & \multicolumn{2}{|c|}{2002} & 2003 & 2004 & & \multirow[t]{2}{*}{2005} \\
\hline & & & & & $10 \mathrm{~cm}$ & \multicolumn{2}{|c|}{$2 \mathrm{~cm}$} & \multicolumn{2}{|c|}{$2 \mathrm{~cm}$} & \\
\hline $\begin{array}{c}\text { Site } \\
\# \\
\end{array}$ & $\begin{array}{l}\text { Year } \\
\text { class }\end{array}$ & BMA & CMR & $\begin{array}{l}\text { Calc. } \\
\text { ESP }\end{array}$ & $\begin{array}{l}\text { Sediment } \\
\text { condition }\end{array}$ & $\begin{array}{l}\text { Sediment } \\
\text { condition }\end{array}$ & $\begin{array}{l}\text { Sediment } \\
\text { condition }\end{array}$ & $\begin{array}{l}\text { Sediment } \\
\text { condition }\end{array}$ & $\begin{array}{c}\text { Site } \\
\#\end{array}$ & $\begin{array}{l}\text { Sediment } \\
\text { condition }\end{array}$ \\
\hline 61 & Odd & 1 & NPB & 491,760 & Hypoxic & Hypoxic & Hypoxic & Hypoxic & 61 & Hypoxic \\
\hline 84 & Odd & 1 & NPB & 312,312 & Hypoxic & Hypoxic & Hypoxic & Hypoxic & 84 & \\
\hline 181 & Odd & 1 & NPB & 327,711 & Anoxic & Anoxic & Hypoxic & Oxic 2 & 181 & \\
\hline 214 & Odd & 1 & NPB & 426,000 & Oxic 1 & Oxic & Hypoxic & Oxic 2 & 214 & \\
\hline 290 & Odd & 1 & NPB & 293,771 & Hypoxic & Hypoxic & Hypoxic & Oxic 2 & 290 & Oxic 1 \\
\hline 337 & Odd & 1 & NPB & 351,075 & Hypoxic & Hypoxic & Hypoxic & Hypoxic & 337 & \\
\hline 342 & Odd & 1 & NPB & 199,320 & Hypoxic & Hypoxic & Oxic 2 & Oxic 1 & 342 & \\
\hline 370 & Even & 1B & NPB & 450,000 & Oxic 2 & Oxic & Oxic 2 & Oxic 2 & 370 & Hypoxic \\
\hline 377 & Even & 1B & CDI & & Oxic 2 & Oxic & Oxic 2 & Oxic 2 & 377 & Hypoxic \\
\hline 255 & Even & 2 & CDI & 651,533 & Oxic 2 & Oxic & Oxic 1 & Oxic 1 & 255 & \\
\hline 256 & Even & 2 & CDI & 480,330 & Oxic 2 & Oxic & Oxic 1 & Oxic 1 & 256 & Oxic 1 \\
\hline 42 & Even & 3 & $\mathrm{CDI}$ & 226,750 & Hypoxic & Hypoxic & Hypoxic & Oxic 2 & 42 & Oxic 1 \\
\hline 222 & Even & 3 & $\mathrm{CDI}$ & 467,429 & Oxic 1 & Oxic & Oxic 2 & Oxic 2 & 222 & Oxic 2 \\
\hline 228 & Even & 3 & CDI & 458,252 & Oxic 2 & Oxic & Oxic 2 & Oxic 1 & 228 & Hypoxic \\
\hline 251 & Even & 3 & CDI & 632,400 & Oxic 2 & Oxic & Oxic 2 & Hypoxic & 251 & Hypoxic \\
\hline 58 & Even & 4 & $\mathrm{CDI}$ & & Oxic 2 & Oxic & Oxic 1 & Hypoxic & 58 & Oxic 1 \\
\hline 59 & Even & 4 & CDI & 344,798 & Oxic 2 & Oxic & Oxic 2 & Oxic 2 & 59 & Hypoxic \\
\hline 60 & Even & 4 & CDI & 284,640 & Oxic 1 & Oxic & Oxic 1 & Oxic 1 & 60 & \\
\hline 179 & Even & 4 & $\mathrm{CDI}$ & 451,170 & Oxic 1 & Oxic & Oxic 1 & Oxic 1 & 179 & Oxic 1 \\
\hline 320 & Even & 4 & CDI & & Oxic 1 & Oxic & Oxic 2 & Oxic 2 & 320 & Oxic 2 \\
\hline 49 & Odd & 5 & CDI & 228,480 & Oxic 1 & Oxic & Oxic 1 & Oxic 2 & 49 & \\
\hline 50 & Odd & 5 & CDI & 264,120 & Oxic 1 & Oxic & Oxic 1 & Oxic 1 & 50 & \\
\hline 51 & Odd & 5 & CDI & 241,994 & Oxic 1 & Oxic & Oxic 1 & Oxic 1 & 51 & \\
\hline 57 & Even & 5 & CDI & 319,056 & Oxic 1 & Oxic & Oxic 1 & Oxic 2 & 57 & Oxic 2 \\
\hline 411 & Odd & 5 & CDI & & Oxic 1 & Oxic & Oxic 1 & Oxic 2 & 411 & Oxic 1 \\
\hline 44 & Even & 6 & CDI & 225,780 & Oxic 2 & Oxic & Hypoxic & Oxic 2 & 44 & Oxic 2 \\
\hline 45 & Even & 6 & CDI & 406,794 & Oxic 2 & Oxic & Hypoxic & Oxic 2 & 45 & Hypoxic \\
\hline 46 & Even & 6 & CDI & 305,280 & Hypoxic & Hypoxic & Hypoxic & Oxic 2 & 46 & Hypoxic \\
\hline 215 & Even & 6 & CDI & 199,547 & Oxic 2 & Oxic & Oxic 2 & Oxic 2 & 215 & Hypoxic \\
\hline 362 & Even & 6 & CDI & 195,300 & & & & & 362 & \\
\hline 64 & Odd & 13 & CDI & 56,069 & Hypoxic & Hypoxic & Anoxic & & 64 & \\
\hline 186 & Even & 13 & CDI & & Oxic 2 & Oxic & Anoxic & Hypoxic & 186 & Oxic 2 \\
\hline 206 & Even & 13 & $\mathrm{CDI}$ & & Oxic 2 & Oxic & Oxic 2 & Oxic 2 & 206 & Hypoxic \\
\hline 52 & Even & 14 & $\mathrm{CDI}$ & 326,840 & Oxic 1 & Oxic & Oxic 2 & Oxic 1 & 52 & Oxic 1 \\
\hline 53 & Even & 14 & $\mathrm{CDI}$ & 746,997 & Hypoxic & Oxic & Hypoxic & Oxic 1 & 53 & Oxic 2 \\
\hline 54 & Odd & 14 & CDI & 99,434 & Oxic 2 & Oxic & Hypoxic & Oxic 2 & 54 & Oxic 1 \\
\hline 55 & Even & 15 & CDI & 229,200 & Oxic 2 & Oxic & Oxic 1 & Oxic 1 & 55 & Oxic 1 \\
\hline 56 & Even & 15 & CDI & 206,136 & Oxic 2 & Oxic & Oxic 1 & Oxic 1 & 56 & \\
\hline 168 & Even & 15 & CDI & & Oxic 2 & Oxic & Oxic 1 & Oxic 1 & 168 & Oxic 1 \\
\hline 38 & Odd & 7 & $\mathrm{LL}$ & 223,800 & Oxic 1 & Oxic & Oxic 1 & Oxic 2 & 38 & Hypoxic \\
\hline 39 & Even & 7 & $\mathrm{LL}$ & 442,802 & Oxic 1 & Oxic & Oxic 1 & & 39 & \\
\hline 40 & Even & 7 & $\mathrm{LL}$ & 200,679 & Oxic 2 & Oxic & Oxic 2 & Oxic 2 & 40 & Oxic 2 \\
\hline 333 & Odd & 7 & $\mathrm{LL}$ & 173,498 & & & & & 333 & \\
\hline 33 & Odd & 8 & $\mathrm{LL}$ & 122,522 & Oxic 2 & Oxic & Oxic 2 & Oxic 2 & 33 & \\
\hline 34 & Odd & 8 & LL & 145,542 & Hypoxic & Hypoxic & Oxic 2 & Oxic 1 & 34 & Oxic 1 \\
\hline
\end{tabular}




\begin{tabular}{|c|c|c|c|c|c|c|c|c|c|c|}
\hline 35 & Odd & 8 & $\overline{\mathrm{LL}}$ & 338,400 & Hypoxic & Hypoxic & Hypoxic & Oxic 2 & 35 & Oxic 2 \\
\hline 36 & Odd & 8 & $\mathrm{LL}$ & 258,480 & Hypoxic & Oxic & & & 36 & \\
\hline 37 & Odd & 8 & $\mathrm{LL}$ & 542,724 & Hypoxic & Oxic & Oxic 2 & Hypoxic & 37 & Oxic 1 \\
\hline 95 & Odd & 8 & $\mathrm{LL}$ & 115,254 & Hypoxic & Hypoxic & Hypoxic & & 95 & \\
\hline 159 & Odd & 8 & $\mathrm{LL}$ & 84,412 & Oxic 1 & Oxic & Oxic 1 & Oxic 1 & 159 & Oxic 1 \\
\hline 276 & Odd & 8 & $\overline{\mathrm{LL}}$ & 313,320 & Hypoxic & Oxic & Hypoxic & Oxic 2 & 276 & Oxic 2 \\
\hline 25 & Odd & 9 & $\mathrm{LL}$ & 284,585 & Hypoxic & Hypoxic & Hypoxic & Hypoxic & 25 & Oxic 2 \\
\hline 26 & Odd & 9 & $\mathrm{LL}$ & 504,597 & Oxic 2 & Oxic & Hypoxic & Oxic 2 & 26 & Oxic 1 \\
\hline 27 & Odd & 9 & $\overline{L L}$ & 244,655 & Hypoxic & Hypoxic & Hypoxic & Hypoxic & 27 & Hypoxic \\
\hline 28 & Odd & 9 & $\overline{\mathrm{LL}}$ & 671,559 & Hypoxic & Hypoxic & Hypoxic & Hypoxic & 28 & Oxic 2 \\
\hline 29 & Odd & 9 & $\overline{\mathrm{LL}}$ & 352,709 & Hypoxic & Hypoxic & Hypoxic & Hypoxic & 29 & Hypoxic \\
\hline 30 & Odd & 9 & $\mathrm{LL}$ & 364,547 & Hypoxic & Hypoxic & Hypoxic & Hypoxic & 30 & Oxic 2 \\
\hline 32 & Odd & 9 & $\mathrm{LL}$ & 239,199 & Oxic 2 & Oxic & Hypoxic & Hypoxic & 32 & Oxic 2 \\
\hline$\overline{14}$ & Odd & 10 & $\mathrm{LL}$ & 323,202 & Hypoxic & Oxic & Hypoxic & Hypoxic & 14 & Oxic 2 \\
\hline 16 & Odd & 10 & $\mathrm{LL}$ & 397,891 & Hypoxic & Hypoxic & Hypoxic & Oxic 2 & 16 & Oxic 2 \\
\hline 17 & Odd & 10 & $\mathrm{LL}$ & 289,440 & Hypoxic & Hypoxic & Oxic 2 & Hypoxic & 17 & Hypoxic \\
\hline 18 & Odd & 10 & $\mathrm{LL}$ & 284,226 & Hypoxic & Oxic & Hypoxic & Oxic 1 & 18 & Oxic 2 \\
\hline 20 & Odd & 10 & $\mathrm{LL}$ & 416,462 & Hypoxic & Hypoxic & Hypoxic & Hypoxic & 20 & \\
\hline 22 & Odd & 10 & $\mathrm{LL}$ & 257,280 & Hypoxic & Hypoxic & Hypoxic & Oxic 2 & 22 & \\
\hline 23 & Odd & 10 & $\mathrm{LL}$ & 271,917 & Hypoxic & Oxic & Hypoxic & Hypoxic & 23 & Oxic 2 \\
\hline 24 & Odd & 10 & $\mathrm{LL}$ & 232,378 & Oxic 2 & Oxic & Oxic 1 & Oxic 2 & 24 & \\
\hline 4 & Even & 16 & $\overline{G M}$ & 481,497 & Oxic 1 & Oxic & Hypoxic & Hypoxic & 4 & Oxic 2 \\
\hline 2 & Even & 17 & $\mathrm{GM}$ & 237,361 & Oxic 1 & Oxic & Oxic 2 & Oxic 2 & 2 & Hypoxic \\
\hline 213 & Even & 17 & $\mathrm{GM}$ & 276,000 & Oxic 2 & Oxic & Hypoxic & Oxic 1 & 213 & Oxic 2 \\
\hline 349 & Even & 17 & GM & 443,158 & Oxic 1 & Oxic & Oxic 2 & Oxic 2 & 349 & Oxic 2 \\
\hline 350 & Even & 17 & $\overline{G M}$ & 443,158 & Oxic 1 & Oxic & Oxic 2 & Oxic 2 & 350 & Oxic 2 \\
\hline 368 & Even & 17 & $\overline{\mathrm{GM}}$ & 443,158 & Oxic 2 & Oxic & Oxic 2 & Oxic 2 & 368 & Hypoxic \\
\hline 172 & Even & 18 & $\mathrm{GM}$ & 652,764 & Oxic 1 & Oxic & Oxic 2 & Oxic 1 & 172 & Oxic 2 \\
\hline 282 & Even & 18 & GM & 378,407 & Oxic 1 & Oxic & Oxic 1 & Oxic 1 & 282 & Oxic 1 \\
\hline $282 b$ & Even & 18 & GM & 378,407 & & Oxic & Oxic 1 & Oxic 1 & $282 b$ & Oxic 1 \\
\hline 298 & Even & 18 & $\mathrm{GM}$ & 368,100 & Oxic 1 & Oxic & Oxic 1 & Oxic 1 & 298 & Oxic 2 \\
\hline 300 & Even & 18 & GM & 443,158 & Oxic 1 & Oxic & Oxic 2 & Oxic 2 & 300 & hypoxic \\
\hline 324 & & 18 & GM & 280,000 & & & & & & \\
\hline 316 & Odd & 19 & GM & 589,353 & Oxic 1 & Oxic & Oxic 1 & Oxic 2 & 316 & Oxic 1 \\
\hline 381 & Odd & 19 & $\mathrm{GM}$ & 443,158 & Oxic 1 & Oxic & Oxic 1 & Oxic 1 & 381 & Oxic 1 \\
\hline 416 & Odd & 19 & $\overline{G M}$ & $1,200,000$ & Oxic 1 & Oxic & Oxic 1 & Oxic 1 & 416 & \\
\hline 3 & Odd & 20 & GM & 197,558 & Oxic 1 & Oxic & Oxic 1 & Oxic 1 & 3 & Oxic 2 \\
\hline 202 & Odd & 20 & $\overline{G M}$ & 443,158 & Oxic 2 & Oxic & Oxic 1 & Hypoxic & 202 & Oxic 1 \\
\hline 270 & Odd & 20 & GM & 400,000 & Oxic 2 & Oxic & Oxic 1 & Oxic 2 & 270 & Oxic 1 \\
\hline 292 & Odd & 20 & GM & 797,512 & Oxic 2 & Oxic & Oxic 1 & Oxic 2 & 292 & Oxic 2 \\
\hline 413 & Odd & 20 & $\overline{\mathrm{GM}}$ & 344,000 & Oxic 1 & Oxic & Oxic 1 & Oxic 1 & 413 & Oxic 1 \\
\hline 303 & Even & 21 & GM & 440,000 & Oxic 1 & Oxic & Oxic 1 & Oxic 1 & 303 & Oxic 1 \\
\hline 403 & Odd & 21 & $\mathrm{GM}$ & 480,000 & Oxic 1 & Oxic & Oxic 1 & Oxic 1 & 403 & Oxic 1 \\
\hline $403 b$ & Odd & 21 & GM & 443,158 & & Oxic & Oxic 1 & Oxic 1 & $403 b$ & Oxic 1 \\
\hline 408 & Odd & 21 & $\overline{G M}$ & 443,158 & Oxic 1 & Oxic & Oxic 1 & Oxic 1 & 408 & Oxic 1 \\
\hline 491 & Odd & 21 & GM & 443,158 & Oxic 1 & Oxic & Oxic 1 & Oxic 1 & 491 & Oxic 1 \\
\hline
\end{tabular}




\begin{tabular}{|c|c|c|c|c|c|c|c|c|c|c|}
\hline 6 & $\overline{N A}$ & $\overline{\mathrm{NA}}$ & other & \multirow{3}{*}{$\begin{array}{c}573,815 \\
356,136 \\
573,815\end{array}$} & \multirow{7}{*}{$\begin{array}{l}\text { Oxic } 1 \\
\text { Oxic } 1 \\
\text { Oxic } 1\end{array}$} & \multirow{2}{*}{\multicolumn{2}{|c|}{ Oxic 1}} & \multirow[b]{3}{*}{ Oxic 2} & \multirow{2}{*}{$\begin{array}{c}6 \\
396\end{array}$} & \multirow[b]{3}{*}{ Oxic 2} \\
\hline 396 & & NA & other & & & & & & & \\
\hline 400 & Even & NA & other & & & Oxic & Oxic 2 & & 400 & \\
\hline 404 & Even & NA & other & 640,000 & & Oxic & Hypoxic & Oxic 1 & 404 & Oxic 2 \\
\hline 412 & Odd & NA & other & 573,815 & & Oxic & Oxic 2 & Oxic 2 & 412 & Oxic 2 \\
\hline 495 & Odd & NA & other & 413,864 & & & Oxic 2 & Oxic 2 & 495 & Oxic 2 \\
\hline 501 & Even & NA & other & 744,791 & & & & Oxic 1 & 501 & Oxic 1 \\
\hline $\begin{array}{l}496 \\
408\end{array}$ & & & $\begin{array}{l}\text { other } \\
\text { other }\end{array}$ & $\begin{array}{l}714,285 \\
573,815\end{array}$ & & & & & & $\begin{array}{l}\text { Oxic } 1 \\
\text { Oxic } 1\end{array}$ \\
\hline 10 & Even & 11 & other & 489,573 & Oxic 2 & $\overline{\text { Oxic }}$ & Hypoxic & Oxic 2 & 10 & Hypoxic \\
\hline 12 & Even & 11 & other & 186,504 & Hypoxic & Hypoxic & Hypoxic & Hypoxic & 12 & Oxic 2 \\
\hline $\begin{array}{l}378 \\
494\end{array}$ & Even & 12 & $\begin{array}{l}\text { other } \\
\text { other }\end{array}$ & $\begin{array}{r}573,815 \\
914,228\end{array}$ & Oxic 2 & Oxic & Oxic 2 & Oxic 2 & 378 & Oxic2 \\
\hline
\end{tabular}

**ESP values in red are mean estimates, where data was not available, derived from ESPs of the other sites within the respective CMR.

** ESP values in green were obtained from EAs

**Sites highlighted in grey indicate sites that have not been in operation since or before 2002 or were only in operation for 1 of the 4 monitoring periods presented in the table (2002-2005).

Source: Denise Joy (DELG), 2005-2006, pers.comm.)

\section{Example calculation of total affected area and percent habitat loss}

The Letete/Letang CMR is used for sample calculations. Suppose a proponent wishes to increase production or site a new farm in this CMR. Referring to the EMP results, it appears that 19 out of 26 farms were hypoxic or anoxic in the past 3 years (2003-2005). Thus, using the question as outlined in Chapter 5 , the following total affected area was determined.

$19\left(0.48+0.90 \mathrm{~km}^{2}\right)+0.75 \mathrm{~km}^{2}=22.22 \mathrm{~km}^{2}$

This area $\left(22.22 \mathrm{~km}^{2}\right)$ divided by the total area of the $\operatorname{LLCMR}\left(37.2 \mathrm{~km}^{2}\right)$ is equal to 0.73 or $73 \%$ habitat loss. As such, proposed siting in this CMR with respect to benthic habitat would warrant a score of $\mathrm{C}$. 
Appendix D

1. List of 23 obtained finfish environmental assessments 


\section{List of 23 obtained finfish environmental assessments}

Project Title

Site \#

494

256

168

4. Development of a Salmon Aquaculture Site

5. Establishment of a New Salmon Aquaculture Site

6. Re-location of a Salmon Aquaculture Site

7. Establishment of an Aquaculture Site at Head Harbour Island

8. Establishment of an Aquaculture Site

9. Proposed Finfish Aquaculture Site \#PE-0404 Welch Cove, Maces Bay, Charlotte County, NB

10. Finfish Aquaculture, Proposed Site \# PE-0411, Indian Island, NB

11. Finfish Aquaculture, Proposed Site \#0416, Sand Cove, White Head Island, Grand Manan, NB

12. Finfish Aquaculture, Proposed Site \#0413, Buck Rock, Grand Manan, NB

13. Round Meadow Cove, Chance Harbour, Bay of FundyAtlantic Salmon Aquaculture Facility

14. Proposed Finfish Aquaculture, Site \#PE-402-White Head Island, New Brunswick

15. Finfish Aquaculture, White Head Island

16. Expansion of an Aquaculture Facility

$282 b$

17. Finfish Aquaculture, Proposed Site \#0403, East of Wood Island, Grand Manan, N.B.
6

2000

Approval year

2003

2005

1998

1998

1998

1998

1998

1999

2001

2001

2001

2001

403 
18. Establishment of a New Salmon Aquaculture Site

19. Expansion of an Atlantic Salmon Aquaculture Site

20. Orange Cove-Finfish Aquaculture Site (Atlantic salmon) 496

21. Duck Cove-Aquaculture Site for Rearing-Finfish (Atlantic salmon)

22. Finfish Aquaculture

23. Development of a Salmon Aquaculture Site
2000

324

1998 